\title{
RECOVERED CARBON BLACK FROM WASTE TIRE PYROLYSIS
}

CHARACTERISTICS, PERFORMANCE, AND VALORISATION

Arqam Anjum 


\section{RECOVERED CARBON BLACK FROM WASTE TIRE PYROLYSIS}

CHARACTERISTICS, PERFORMANCE, AND VALORISATION

Arqam Anjum 


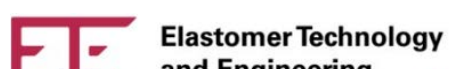

\section{@entinental}

The Future in Motion

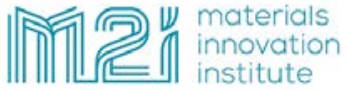

This research is conducted at University of Twente in collaboration with Continental Tires AG and M2i Materials Innovation Institute.

\section{Graduation Committee:}

Chairman: Prof. Dr. Ir. H.F.J.M. Koopman University of Twente, ET

Supervisors: Associate Prof. Dr. W.K. Dierkes University of Twente, ET/ ETE Prof. Dr. A. Blume University of Twente, ET/ ETE

Internal: $\quad$ Prof. Dr. Ir. G. Brem University of Twente, ET/ TE

Prof. Dr. S.R.A. Kersten University of Twente, TNW/ SPT

External: $\quad$ Prof. Dr. M. Beiner Martin Luther University

Prof. Dr. D. Katrakova-Krüger Cologne University of Applied Sciences

Expert: Prof. Dr. Ir. J.W.M. Noordermeer University of Twente, ET/ ETE
Referees:
Dr. C. Norris
Artis

Dr. M. Warskulat

Orion Engineered Carbons 


\title{
RECOVERED CARBON BLACK FROM WASTE TIRE PYROLYSIS
}

\author{
CHARACTERISTICS, PERFORMANCE, AND VALORISATION
}

\section{DISSERTATION}

\author{
to obtain \\ the degree of doctor at the University of Twente, \\ on the authority of the rector magnificus, \\ prof. dr. ir. A. Veldkamp, \\ on account of the decision of the Doctorate Board \\ to be publicly defended \\ on Wednesday, $8^{\text {th }}$ of December, 2021 at 14.45 hours
}

by

\section{Arqam Anjum}

born on the 1st of April, 1991

in Karachi, Pakistan 
This dissertation has been approved by:

Supervisor

Associate Prof. Dr. W.K. Dierkes

Prof. Dr. A. Blume

Cover design: Arqam Anjum

Printed by: IPSKAMP printing, Enschede, the Netherlands

Lay-out: Arqam Anjum

ISBN: 978-90-365-5289-9

DOI: $10.3990 / 1.9789036552899$

(c) 2021 Arqam Anjum, The Netherlands. All rights reserved. No parts of this thesis may be reproduced, stored in a retrieval system or transmitted in any form or by any means without permission of the author. Alle rechten voorbehouden. Niets uit deze uitgave mag worden vermenigvuldigd, in enige vorm of op enige wijze, zonder voorafgaande schriftelijke toestemming van de auteur. 


\section{Table of Contents}

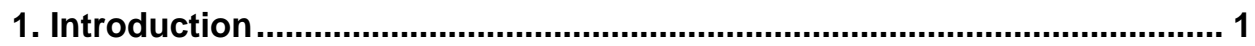

2. Recovered carbon black from waste tire pyrolysis, a review 7

3. Recovered carbon black characteristics and in-rubber performance, a comparative study 53

4. Influence of pyrolysis parameters on the properties of recovered carbon black.

4.1 Influence of pyrolysis temperature and residence time on the yield and quality of recovered carbon black 79

4.2 Influence of pyrolysis temperature on the characteristics of recovered carbon black 101

5. Influence of pyrolysis parameters on the in-rubber performance of recovered carbon black

5.1 Influence of pyrolysis temperature on the in-rubber performance of recovered carbon black 141

5.2 Influence of pyrolysis residence time on the in-rubber performance of recovered carbon black 
7. Material characteristics vs. in-rubber performance of recovered carbon black, a correlation study

8. Upgrading the quality of recovered carbon black, Argon-plasma treatment

9. Recovered carbon black as a substitute for fossil resources based carbon black.

10. Concluding remarks and summary 261

Samenvatting 267

Appendix I 273

Bibliography 279

Acknowledgements 281 
CHAPTER 1

\section{INTRODUCTION}

This chapter gives a brief historical background of rubber recycling. The aim of this research and the structure of the thesis are stated. 


\subsection{History of rubber and its recycling}

The known history of rubber dates back to late $15^{\text {th }}$ century when mankind was utilizing it in its rather raw form. Christopher Columbus, during his second voyage, observed the natives of Haiti playing a game with balls made of gum of a tree ${ }^{1}$. Those mysterious balls were light in weight and bounced high in the air.

This interesting material found its first commercial use in the $18^{\text {th }}$ century when it was sold as pencil erasers in the United Kingdom ${ }^{2}$. Other notable uses of rubber in those times include rain coats, boots and gloves ${ }^{3}$. However, it was until the midst of the $19^{\text {th }}$ century that rubber was yet to be used as a performance material with reasonable life expectation. In 1839, with the accidental discovery of vulcanization by Charles Goodyear ${ }^{4}$, the rubber industry was revolutionized and the demand for this material started to grow. By the end of the $19^{\text {th }}$ century, rubber found its place in the automotive industry with the discovery of pneumatic tires by J. B Dunlop ${ }^{5}$. The use of rubber in this dynamic application required further improvement in material strength and lifespan.

The rise in the demand for quality of tires paved the way for carbon black as reinforcing filler in the early $20^{\text {th }}$ century. Its unique ability to enhance physical properties of rubber made it one of the most important components in rubber products, with a consumption second only to rubber itself 6 . However, the efforts of making rubber more durable and of high performance also created the problem of generating waste which was difficult to recycle.

Soon after the development of the vulcanization process, the use of that time waste natural rubber was initiated by reclaiming it at high temperatures. The resultant product was a black material with reduced crosslink density and shortened polymer back bone chain length, which was re-used in rubber compounds as a processing aid. The boost in rubber recycling came during World War II, when raw materials were scarce and therefore the production of reclaimed rubber was increased to fill the gap. Post war, the demand soon decreased as new technological developments such as radial tires lead to a reduction of the use of reclaim due to technical limitations?.

The situation began to change again in the last quarter of the $20^{\text {th }}$ century when the interest in safeguarding the environment was growing and the potential hazards of rubber and tire waste were recognized. By the end of the last century, several recycling methods were developed and waste rubber found various outlets such as civil engineering applications, landscaping, artificial turf, additive to asphalt etc. Most of these uses are outside the conventional rubber industry, and the creation of a circular economy in the tire industry especially still remains a challenge as only $8 \%$ $-10 \%$ recycled material goes into certain parts of a tire ${ }^{8}$. 
Scrap tire pyrolysis, a process which recovers valuable raw materials from tire rubber by decomposing it in a reductive environment, has the potential of paving the path to circularity in tire manufacturing. The three pyrolytic products are: energy rich gas, highly aromatic oil and recovered carbon black $(\mathrm{rCB})^{9}$. Gas can be reused for heating the reactor or in other energy applications, and oil exhibiting high benzene, toluene and xylene (BTX) contents has already found its application in the chemical industry as a building block. $\mathrm{rCB}$ contains carbon black originally added as reinforcing filler next to pyrolytic remains of the organic elastomer, and inorganics added during tire manufacturing ${ }^{9,10}$. The fact that it contains $70 \%-80 \%$ of carbon suggests its re-use in rubber as a potential substitute of fossil-based carbon black. Making carbon circular not only reduces the demand of fossil carbon black, but also helps in converting rubber waste into high value products.

\subsection{Aim of the research}

This research is a collaborative project of the University of Twente, Continental Tires AG, and M2i Materials Innovation Institute. The objective of the present research is to re-use the carbon black in rubber compounds, which is recovered by pyrolysis of post-consumer passenger car tires. The thesis is focused on understanding the influence of pyrolysis parameters on $\mathrm{rCB}$ characteristics and their consequent effect on its in-rubber performance. A part of the key characteristics of the rCB are characterized at the Continental Tires AG research and development facility in Hannover, Germany. Besides material characterization and in-rubber testing, a suitable after-treatment will be developed to further enhance its performance. Finally, the aim is to substitute highly-reinforcing carbon black by recovered carbon black in high proportions without compromising key performances of the rubber.

\subsection{Structure of the thesis}

The thesis encompasses 10 chapters as given below:

Chapter 2 gives a brief overview of the tire recycling methods. Scrap-tire pyrolysis is extensively reviewed with emphasis on its solid fraction: rCB. Material characteristics, rubber reinforcement potential and after-treatments are discussed. Carbon black production, characteristics and its use in rubber as reinforcing filler is also covered. 
Chapter 3 compares commercially available rCBs with various amounts of organic and inorganic impurities. The influence of these impurities on their characteristics and in-rubber properties is elaborated.

Chapter 4 covers the influence of pyrolysis process parameters on product yield and recovered carbon black characteristics. Section 4.1 covers the influence of both, temperature and resistance time, on the yield and volatiles content of $\mathrm{rCB}$. Section 4.2 covers the in-depth characterization of rCB: morphology, surface area, structure, surface chemistry and surface activity.

Chapter $\mathbf{5}$ focuses on the influence of pyrolysis temperature and residence time on the in-rubber performance of the recovered carbon blacks. The rCB performance is compared with the one of semi-reinforcing carbon black N660.

Chapter 6 discusses the possibility of the presence of active sulfur compounds in recovered carbon blacks. Their presence was indicated in Chapter 5 , and this is further investigated in this chapter.

Chapter 7 explores the correlations between the key material characteristics of rCB and its in-rubber performance.

Chapter $\mathbf{8}$ is based on the after-treatment of rCB using low-pressure argon plasma etching. The etching process is optimized and the treated rCBs are characterized in terms of their volatiles content and surface activity. In-rubber properties are also evaluated.

Chapter 9 describes the possibility of utilizing $\mathrm{rCB}$ to partially substitute highreinforcing carbon black N330. A blending ratio of $\mathrm{rCB} / \mathrm{N} 330$ is proposed without affecting the cure properties, mechanical properties and with improved dynamic properties.

Chapter 10 concludes the findings of the thesis. 


\section{References}

[1] J. Kennedy, Science, 213, 757 (1981).

[2] J. A. Brydson, "Rubbery Materials and their Compounds", Elsevier Science Publishers Ltd., Essex (1988).

[3] Hancock. T, "Personal Narrative of the Origin and Progress of the Cautchouc or India-Rubber Manufacture in England", Longmans, London (2019).

[4] C. Goodyear, Improvement in India-Rubber Fabrics, US. Pat. US3462A (March $9,1844)$.

[5] J. B. Dunlop, "The History of the Pneumatic Tire", A. Thom \& Co., Dublin (1924).

[6] J. B. Donnet, R. C. Bansal, and M. J. Wang, Carbon Black: Science and Technology, 2nd ed., Marcel Dekker, New York (1993).

[7] M. Forrest, "Recycling and Re-use of Waste Rubber", Smithers Rapra Technology Ltd., Shawbury (2014).

[8] M. Myhre, S. Saiwari, W.K. Dierkes and J.W.M. Noordermeer, Rubber Chem. Technol., 85, 408 (2012).

[9] P. T. Williams, Waste Management, 33, 1714 (2013).

[10] J. D. Martínez, N. Puy, R. Murillo, T. García, M. V. Navarro, A. M. Mastral, Renewable and Sustainable Energy Reviews, 23, 179 (2013). 
Chapter 1 


\section{RECOVERED CARBON BLACK FROM WASTE TIRE PYROLYSIS, A REVIEW}

This chapter provides an overview of recycling routes with emphasis on scrap tires. Re-purposing of partly worn-out tires is briefly discussed. Pyrolysis of scrap tire rubber in particular is extensively reviewed. Various types of pyrolysis reactors and their influence on the pyrolytic products are described. Special emphasis is laid on the solid fraction of pyrolysis: recovered carbon black ( $(\mathrm{CB})$, its characteristics and potential reuse in tires. Upgrading processes of $\mathrm{rCB}$ by various after-treatments are reviewed. As a reference, fossil based carbon black manufacturing, its use as rubber reinforcing filler, and its key material characteristics are discussed. The differences between virgin and recovered carbon blacks in terms of material characteristics and performance are described. Current challenges in standardization of recovered carbon black against virgin carbon black standards are highlighted. 


\subsection{Recycling of Tires}

Used tires can be classified into two types

(i) Partly worn-out tires, and

(ii) scrap tires.

Partly worn-out tires are those which can be re-used as second hand purchase or can be repaired to make them reusable. The re-use of partly worn-out tires is generally characterized by the residual tread depth. With a certain tread depth (depending on the country regulations), tires can be reused as such or otherwise repaired by retreading, through which the life of a tire can be extended. However, in case of scrap tires, re-using is not an option and therefore, recycling is the next level on the sustainability scale to follow. Before rather strict regulations within the EU were introduced in $2003^{1}$, almost half of the scrap tires were disposed of in landfills. These landfills lead to major environmental problems such as:

- Tire stockpiles to provide breeding grounds for mosquitos and vermin. These are disease carrying insects and affect human health.

- Tires stockpiles can self-ignite and cause uncontrollable burning and earth as well as air pollution.

- Tires take up landfill space and make these unstable. 


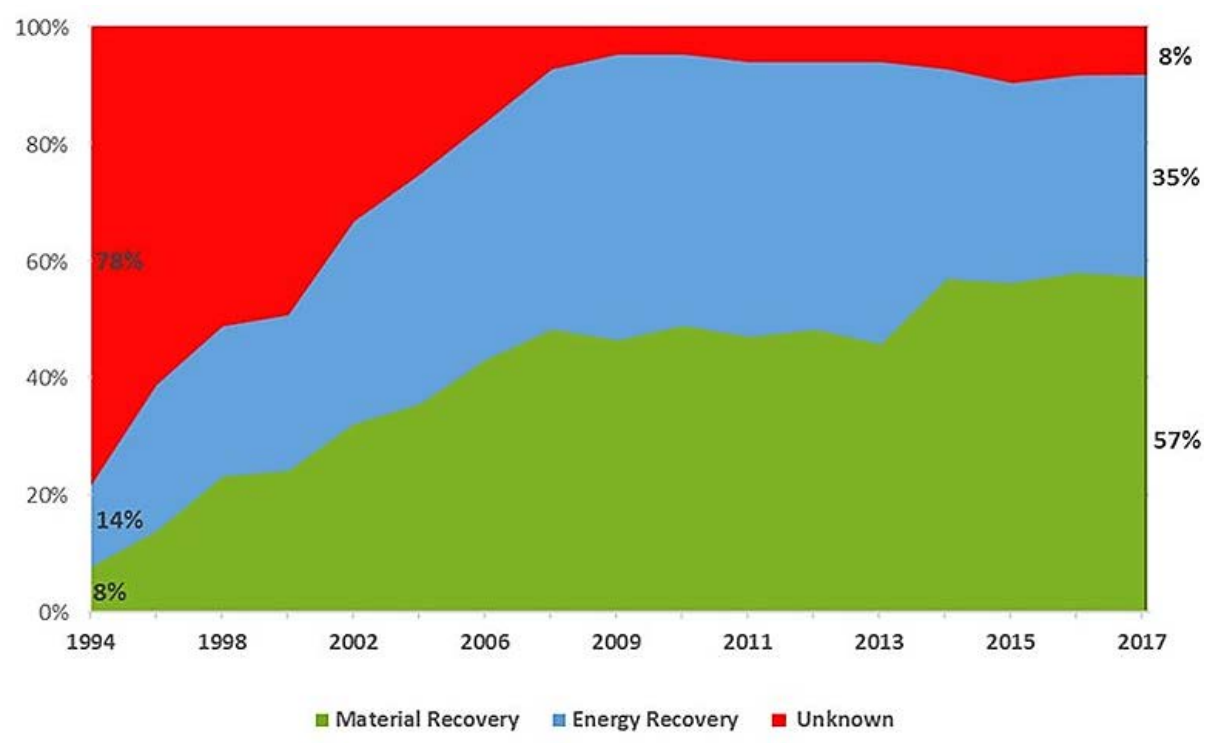

Figure 2.1 Tire recycling trends in Europe ${ }^{2}$.

Around 3.45 million tons of tires met their end of life alone in Europe in $2019^{3}$, and approximately 29 million tons of tires were scrapped worldwide in the same year ${ }^{4}$. Different routes of recycling have been taken based on their impact on environmental protection, energy conversion and material recovery. Since landfill is not an environmentally friendly option and is strictly regulated in the European Union, other outlets for scrap tires emerged in the past decade as potential solutions: Figure 2.1. Figure 2.2 shows the journey of tires starting from raw materials through manufacturing, reuse after maintenance, use as energy source, material recovery, either for use in other applications, or ultimately for recovery of raw materials which possibly could go back into tires. In the following part, different techniques of tire recycling are briefly covered. The major focus of this review is on raw material recovery from pyrolysis processes. Furthermore, pyrolysis products and their upgrading to useful materials is also discussed. 


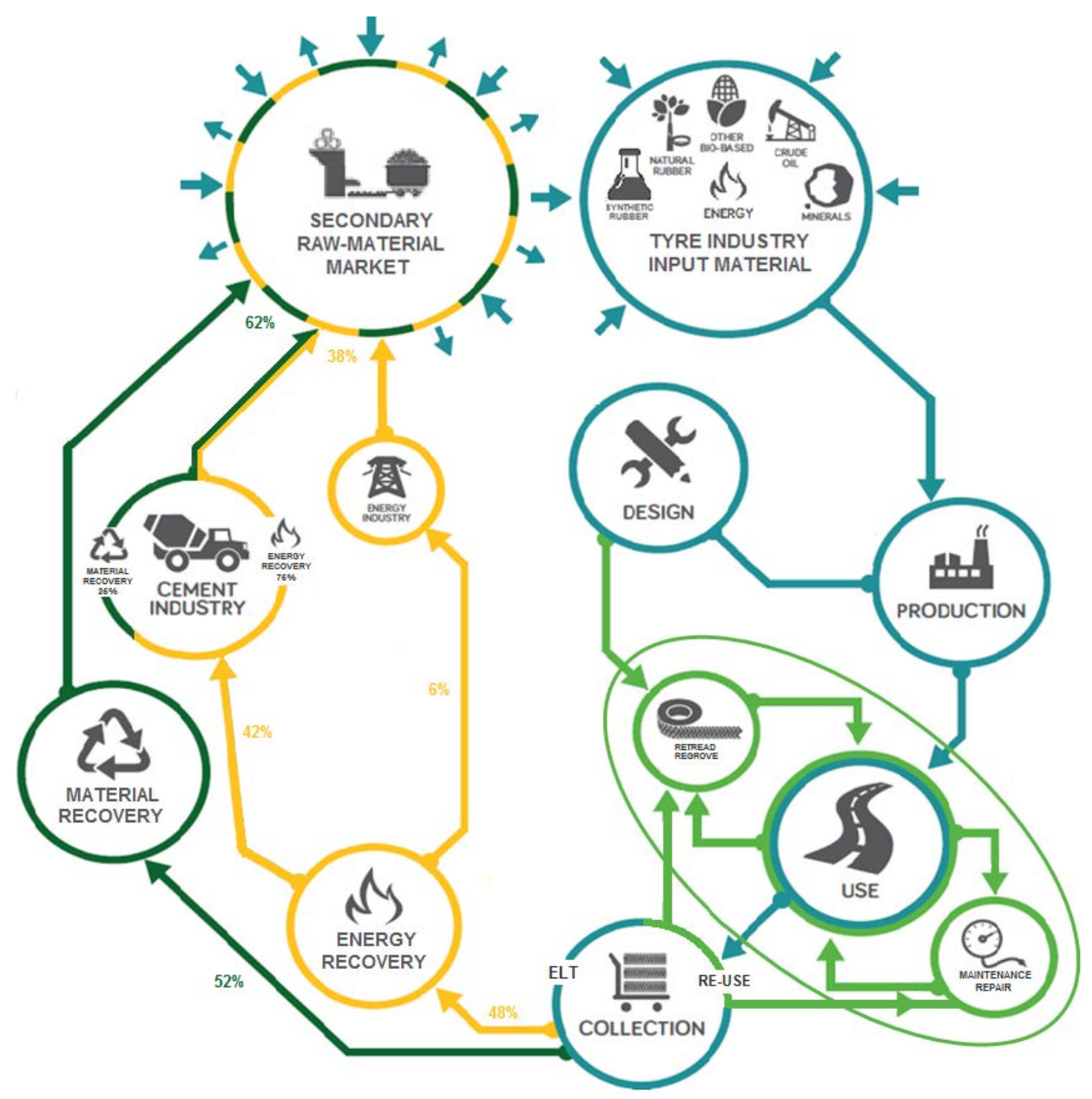

Figure 2.2 Tire life cycle with various recycling loops 5 .

\subsubsection{Reuse and retreading}

Retreading is a process used for extending the lifespan of partially worn-out tires in a very resource-efficient way, so that both energy and material can be saved. This makes it the most environmentally friendly way to deal with used tires.

This method allows to reuse old tire casings to save up to $75 \%$ of material and $70 \%$ of energy along with reduction of the quantity of waste ${ }^{6}$. The main principle is that 
the used tire carcasses pass through a recapping system where the remaining part of the old tread is stripped off and is replaced by a new one. Retreading can be done by either a cold or hot process at a temperature of $100^{\circ} \mathrm{C}$ or $150^{\circ} \mathrm{C}$ respectively ${ }^{7}$. In spite of its economic and environmental benefits, the process is rarely used for passenger car tires anymore due to the availability of imported new tires from China at low cost ${ }^{8}$. In case of truck and airplane tires, it is a common practice and, for truck tires it is continuously growing. Truck tires maybe retreaded for as many as five times before finally being discarded ${ }^{9}$.

Reuse of whole tires other than retreading includes marine docks, erosion control, agricultural purposes, highway crash barriers and artificial reefs ${ }^{10}$. Millions of tires in the USA, Australia and New Zealand are used for artificial reefs, but lately it is recognized as a threat for sea life. Tires can also be reused in ground form in civil engineering applications and as insulating materials.

\subsubsection{Material recovery}

When it comes to used tire rubber recycling, the most common and efficient method practiced is grinding of scrap tires. Ground rubber is proven to be a good thermal and acoustic insulator with additional resistance to dynamic loading and cracking. It widely serves as civil engineering material in road pavements, seawalls and insulation for building constructions ${ }^{11-12}$. Tire rubber granulates are used as fillers and modifiers in different polymer composites ${ }^{13}$. A low percentage (i.e. 2 to $5 \%$ ) of fine ground rubber can be incorporated into new tires with a still acceptable reduction in performance ${ }^{14}$. The ground rubber is not only limited to manufacturing of various products; it is also a prerequisite for other recycling methods including pyrolysis.

Two grinding methods, mechanical and cryogenic grinding, are mainly applied. Mechanical grinding is performed at ambient temperatures, while cryogenic grinding refers to low temperatures: below the glass transition temperature of rubber. Ambient temperature grinding produces ground rubber particles having a rough surface which features good physical bonding when blended with a polymer. However, due to high shear forces and heat build-up, the ground rubber is partly degraded ${ }^{15}$. Grinding of rubber in its glassy state is done in order to reach a high degree of comminuting with particle sizes below 80 mesh $(<180 \mu \mathrm{m})^{16-17}$. The resultant ground rubber offers better flow characteristics compared to the mechanically ground rubber due to its smoother surface which offers almost no occlusion to the elastomers. Besides the high costs of cryogenic operation, the smooth surface of cryogenically ground particles makes them less active for particle-polymer matrix interaction ${ }^{18-19}$. The 
differences in surface roughness of ambiently and cryogenically ground particles is shown in Figure 2.3.
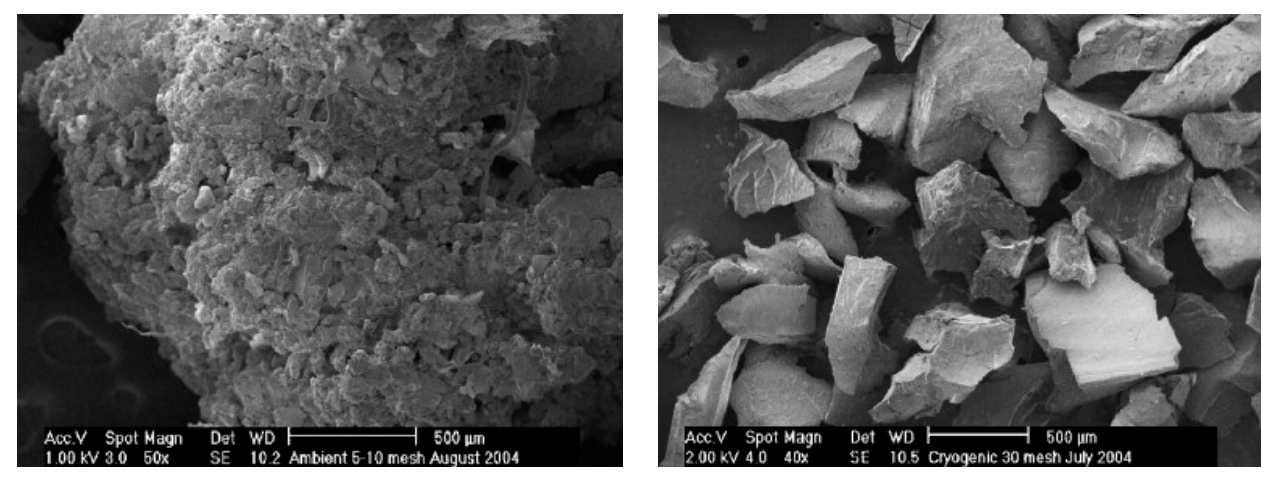

Figure 2.3 Ambient (left) and cryogenically ground rubber particles (right) ${ }^{20}$.

\subsubsection{Reclaimed and de-vulcanized rubber}

The history of rubber recycling by reclaiming began soon after the development of the vulcanization process, and received commercial interest in Europe during World War II, when the raw materials for rubber, especially for making tires, could not be shipped because of trade blockages ${ }^{21}$. Post-war in the 1950's, the price of natural and synthetic rubber decreased affecting the demand and use of reclaimed rubber. Two decades later, reclaimed rubber again started gaining importance due to the oil crises which lead to an increase in commodity prices ${ }^{22}$. In recent years, a considerable part of the research activities were dedicated to the reuse of rubber with special emphasis on de-vulcanization and reclaiming of rubber due to increasing awareness regarding environmental protection and legislations from national authorities ${ }^{23}$.

The main principle of the reclaiming or reclamation process is to destroy the threedimensional cross-linked rubber network formed by chemical sulfur bridges/crosslinks built during vulcanization. In this process, high shear forces are applied without addition of chemicals. The processes can be further categorized as batch and continuous processes. The former involves a two roll mill or an internal mixer, while the continuous process equipment relies on an extruder ${ }^{24}$. Due to the absence of chemicals, mechanically reclaimed rubber is cost efficient and can be 
used for non-sulfur cured rubbers as well. The limitation of these processes lies in the fact that during the cleavage of crosslinks, main chain carbon-carbon bonds are also broken by the high shear forces, reducing the polymer chain length. This gives the rubber a lower viscosity, but also a lower quality ${ }^{23}$ as to the properties which may be obtained upon re-vulcanization.

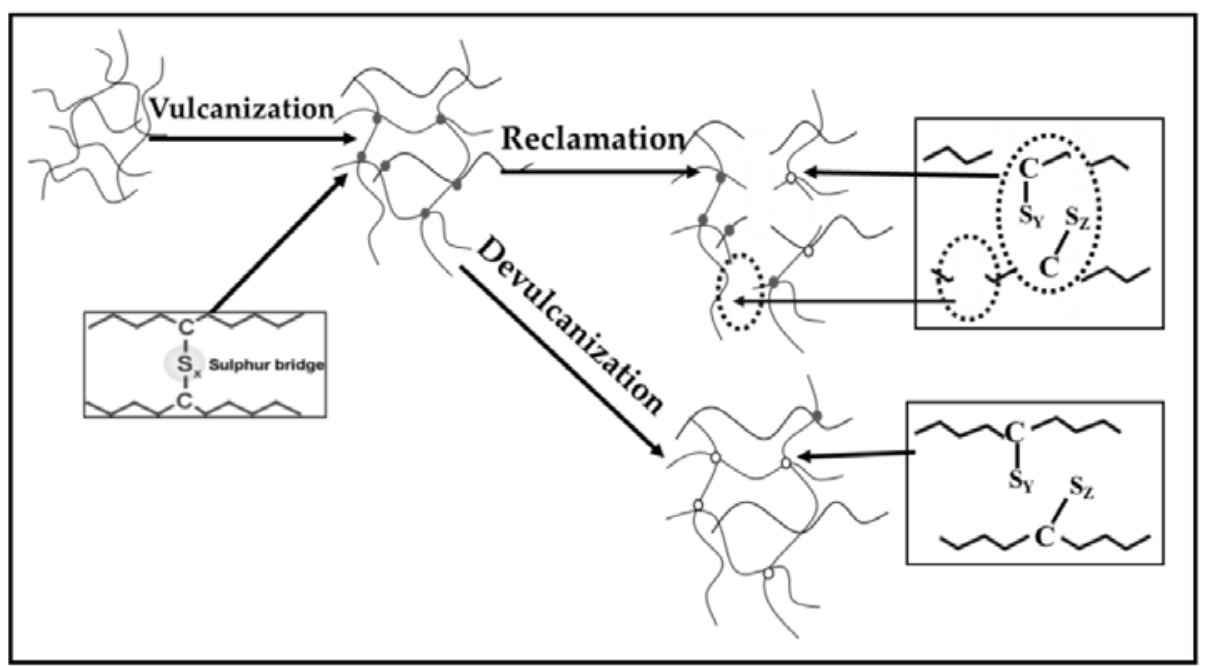

Figure 2.4 Two reactions during rubber recycling; reclamation (main chain and crosslink scission) and de-vulcanization (crosslink scission) ${ }^{25}$

De-vulcanization is the ideal case of reclaiming rubber, where primarily crosslinks are broken with little damage to polymer main chains. As the name suggests, it is the reverse process to vulcanization, cleaving the mono-sulfidic, di-sulfidic and polysulfidic crosslinks of sulfur vulcanized rubber. The difference between devulcanization and reclaiming is elaborated in Figure 2.4. Chemical de-vulcanization processes, in which de-vulcanization agents are incorporated, are more selective in cleaving crosslinks. Several de-vulcanization processes were developed in the last five decades using different types of de-vulcanization agents such as diphenyl sulfide, diallyl sulfide and amine/thiol mixtures. De-vulcanization agents can be divided into two categories with respect to their mechanisms ${ }^{26}$. 


\section{Chapter 2}

- Those which react with free radicals to prevent reformation of crosslinks, e.g. disulfides, thiols and phenolics.

- Those which follow a nucleophilic mechanism and break sulfur crosslinks, e.g. amines.

However, in practice, factors such as thermal inhomogeneity, an uncontrolled temperature, mechanical forces and the type of agents affect the overall control of the breakdown process, leading to degradation of polymer chains as well.

\subsubsection{Energy recovery}

The major share of components in tire compounding are the elastomers, i.e. hydrocarbons exhibiting a high calorific value. The calorific value of tire combustion is around $32 \mathrm{MJ} / \mathrm{kg}$ to $36 \mathrm{MJ} / \mathrm{kg}$, which is even higher than the one of coal $(23 \mathrm{MJ} / \mathrm{kg}$ to $25 \mathrm{MJ} / \mathrm{kg})^{27-28}$. Therefore, another possible way of scrap tire use is as energy source. The use of tires for energy purposes can be classified on the basis of the type of industrial plants ${ }^{17}$. There are six commonly known types:

- Combustion in cement kilns: Complete combustion of tires at high temperatures in an oxidizing atmosphere. Main advantages are lowering of the cement manufacturing costs and the absence of solid waste, as all tire components stay in the cement and even improve the properties. However, emission of organic volatiles is a major issue.

- Co-combustion plants: The plant feed consists of $25 \mathrm{wt} . \%$ of tires, paper and biomass. The amount of tires is limited by emission restrictions.

- Thermal combustion plants: The plant feed consists of $45 \%$ tires blended with paper and pulp.

- Combustion in paper pulp plants: Many pulp plants in the US using wood waste as fuel are transformed into co-combustion plants by additionally incorporating tires as fuel. However, they face many drawbacks such as high costs, emissions and irregular supply of energy.

- Incineration plants: Incineration of waste material converting it into ash, gas and heat. However, the major solid waste incinerators stay away from the incineration of tires, as their high calorific value causes difficulties in 
temperature control. In addition, the flue gas residues can contaminate the environment.

Despite the high calorific value of tire combustion, a study ${ }^{10}$ shows that only $37 \%$ of the energy embedded in a tire is recoverable as energy, and therefore, should not be a preferred scrap tire outlet.

\subsubsection{Raw material recovery}

\subsubsection{Gasification}

Gasification is a thermal process used to convert tire rubber directly into a useful mixture of gases. The mixture is composed of hydrogen and carbon monoxide, commonly known as syngas. Tire rubber is in first instance converted to methane gas, which further reacts with steam to produce syngas. After the removal of contaminants, syngas can be used as fuel for power gas turbines and fuel cells. This gasification also yields a small amount of char, dioxins, $\mathrm{NO}_{x}$ and $\mathrm{SO}_{2}$. Dioxins, nitrogen, and sulfur oxides are hazardous to human health and can cause serious respiratory problems. Sulfur and nitrogen oxides are also a precursors of acid rain and pose danger to many plants and aquatic life ${ }^{29}$. A gasification plant typically consists of a gasifier, a gas cleaning system and an energy recovery system. The quality of the gas mixture is generally determined in terms of lower heating value (LHV) which is the amount of heat released during the combustion of a specified amount of gas. The composition and quality of a gas mixture depends on the operating conditions and the oxidizing agents. For instance, gasification with air and $\mathrm{CO}_{2}$ results in a higher LHV compared to gasification with air and steam ${ }^{30}$. Similarly, an increase in temperature leads to an increase in LHV of syngas ${ }^{31}$.

\subsubsection{Pyrolysis}

Pyrolysis is a thermal treatment used to decompose organic material under nonoxidative conditions. This method has been used for thousands of years for the production of charcoal from biomass. Pyrolysis processes in terms of polymer recycling are considered as processes dealing with reverse polymerization, depolymerization or polymer cracking ${ }^{32}$. It receives a lot of attention due to its ability to yield high value products from the recycled material. 


\section{Chapter 2}

Pyrolysis is an environmentally sound process for recycling of scrap tires, as it produces a minimal amount of nitrogen oxide and sulfur oxide when compared to other processes such as incineration. The process is endothermic in nature and operated in a temperature range of $300^{\circ} \mathrm{C}-700^{\circ} \mathrm{C}$. Pyrolysis of scrap tires yields two fractions: a solid and a volatile one ${ }^{33}$. The volatile fraction is further processed to get a condensable and non-condensable fraction as tire derived oil (TDO) and pyrolytic tire gas, respectively ${ }^{34}$. The derived products can be easily handled, stored and transported.

Pyrolysis processes based on the operating parameters can generally be classified as fast and slow pyrolysis. The main operating parameters are heating rate, temperature and residence time. These parameters also dominate the yield fraction of the final products; for example the gas fraction increases with increasing pyrolysis temperature ${ }^{35}$. The process can be further categorized on the basis of the reactor environment such as steam, vacuum, hydro, catalytic, and mildly oxidative pyrolysis. The type of pyrolysis reactor is selected on the basis of the focused product yield. For instance, plasma pyrolysis is often used when gas and char are required as main pyrolytic products.

Pyrolysis is mainly classified on the basis of rate of conversion: slow and fast. These types are further characterized based on the type of reactors. Within these classifications, various types of reactors are used. The geometries of commonly used reactors are shown in Figure 2.5 . 
Stirred tank

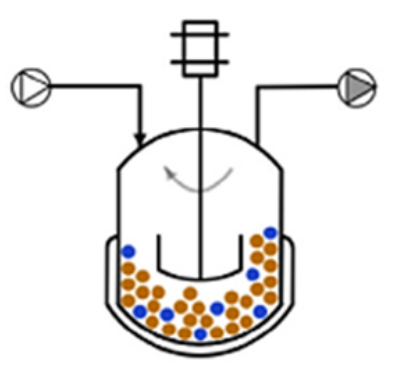

Fixed bed

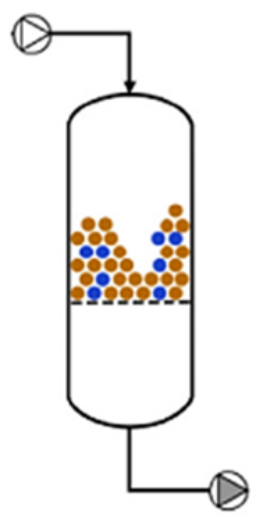

Fluidized bed

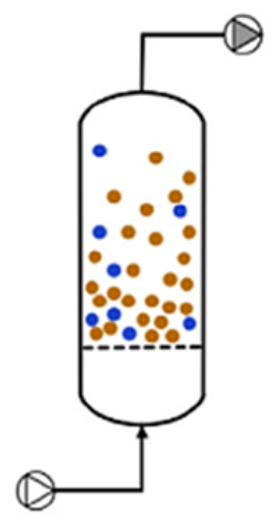

\section{Conical spouted bed}
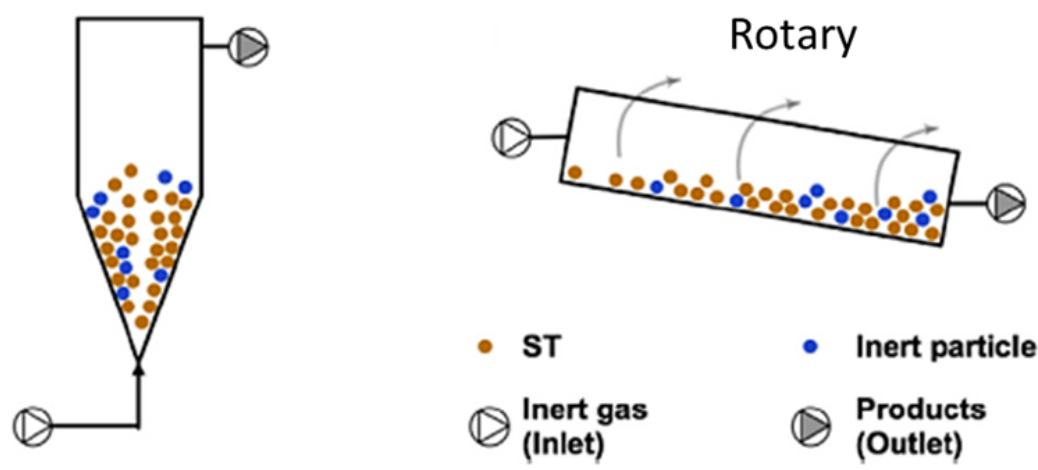

Figure 2.5 Types of pyrolysis reactors used for scrap tires (ST) ${ }^{17}$.

Slow pyrolysis deals with lower heating rates and longer residence times. The process is based on slow thermal decomposition of rubber at low temperatures. The solid and vapor residence time is in the range of hours. A longer residence time causes secondary conversion of primary products. These conversions lead to a higher yield of the solid fraction due to the carbonization and formation of coke ${ }^{36}$, while other products such as gas and oil are also produced along with it, but in reduced quantities ${ }^{32}$. A higher char fraction does not necessarily mean a higher quality product as carbonization and coke formation have a negative impact on the surface activity of the char; this will be further discussed in Section 2.2.3. Slow pyrolysis is commonly performed in a batch or semi-batch fixed bed reactor. 
However, with adjusting the heating rate and residence time for volatiles, it can be transformed into fast pyrolysis ${ }^{32}$.

- Fixed Bed Reactor: Fixed bed reactors are easy to construct and operate. For this reason, they are mostly used for small scale experiments, especially by scientists in laboratories. Considering the corrosive nature of the resultant pyrolytic liquids, most of the reactors are made of stainless steel or quartz glass. The limitation of this reactor is the inability of efficient heat transfer into larger rubber parts (e.g. whole tires). It requires small particles as feedstock ${ }^{37}$.

- Rotary Kiln: This type is generally used for large scale operations. The slow rotation of the inclined kilns enables good mixing of the feedstock, resulting in uniform pyrolytic products. Rotary kiln plants are set up when higher liquid yields together with low gas yields are required. Li et al. pyrolyzed scrap tires using a continuous rotary kiln reactor. They found that the char yield remains unaffected ${ }^{38}$. Kawakami used a similar technology and reported a high oil yield of $50 \%{ }^{39}$.

Fast pyrolysis is generally characterized by short residence times, high temperatures and fast heating rates. In contrast to slow pyrolysis, a rapid thermal decomposition is occurring as a consequence of high heating rates. Fast pyrolysis processes require small particle size feedstock and a short residence time of the vapors in the hot zone. Specially designed devices are used, which quickly remove the vapors. The process favors the production of liquid fuels, as rapid quenching of the volatiles restricts further breakdown of high molecular weight species into gaseous products. This route of tire recycling is considered as an efficient route for the production of liquid fuels, chemicals and derived products with a higher yield. The liquid fuel obtained from fast pyrolysis is of a high calorific value.

The commonly practiced reactors are fluidized bed, ablative, entrained and free-fall reactors $^{32}$.

- Fluidized bed reactor: These reactors are installed and used on laboratory scale, pilot scale, as well as industrial scale. Kaminsky ${ }^{40}$ and co-workers studied this technology extensively and developed it for scrap tire pyrolysis. The technology is favorable when the product yield is focused on the liquid fuel fraction.

- Conical spouted bed reactor: A fast pyrolysis of tires can be carried out in this type with higher yields as well as higher quality of char and oil. The low 
and uniform residence time of the volatiles leads to less organic impurities and more consistent products.

- $\quad$ Flash pyrolysis: Flash pyrolysis is characterized by high heating rates and very short residence times. The residence time is a fraction of a second for this pyrolysis process, which prevents cracking of gases into a noncondensable fraction. This maximizes the liquid yield.

- Catalytic pyrolysis: This is a well-known pyrolysis method for the generation of a high yield of pyrolyzed gas. Catalysts are used for a high degree of cracking of hydrocarbons, which decreases the oil yield. Commonly used catalysts are zeolite, aluminosilicate zeolite (ZSM-5) and aluminum oxide. A further benefit of this process is an oil containing large amounts of benzene, toluene and xylene (BTX), which are valuable components for the chemical industry ${ }^{41}$.

\subsection{Pyrolysis products}

\subsubsection{Pyrolytic gas}

The gaseous fraction obtained from the pyrolysis of scrap tires mainly consists of hydrogen, carbon monoxide, carbon dioxide and $\mathrm{C}_{1}$ to $\mathrm{C}_{4}$ hydrocarbons (paraffins and olefins). Traces of $\mathrm{H}_{2} \mathrm{~S}, \mathrm{SO}_{2}$ and $\mathrm{NH}_{3}$ are also present. Sulfur based gases are produced due to the reaction of sulfur used during vulcanization into volatile compounds. The composition and the calorific value of the pyrolytic gas is predominantly dependent on the composition of the tire, mainly the type of elastomers used. For instance, the hydrogen yield can range from $13.8 \%$ to $27.6 \%$, and the methane concentration from $14.1 \%$ to $27.9 \%$, depending on the tire type ${ }^{42}$. Furthermore, both composition and calorific values will be affected by the pyrolysis reactor conditions as well. The major influencing parameters are temperature, heating rate and type of reactor. The calorific value of the gas is reported to be in the range of $20 \mathrm{MJ} \cdot \mathrm{m}^{-3}$ to $65 \mathrm{MJ}^{-3} \mathrm{~m}^{-3}$, which is determined by the above mentioned parameters and the composition of the gas ${ }^{43}$. The overall gas yield is known to increase with higher temperature, as further thermal cracking of oil occurs. This reduces the oil and increases the gas fraction. Higher residence times also favor higher yields of pyrolytic gas. Pyrolytic gas can be used by the pyrolysis plant for power generation, or it could be further used as a fuel source. 


\subsubsection{Pyrolytic oil}

The liquid fraction from tire pyrolysis is known as scrap tire pyrolytic oil (STPO) or tire derived oil (TDO). The physical appearance is a brownish liquid with sulfuric odor, which looks quite similar to crude oil. TDO got a lot of attention due to its high calorific value of around $44 \mathrm{MJ} \mathrm{kg}^{-1}$, comparable to valued fuels such as diesel $(45 \mathrm{MJ} / \mathrm{kg})^{44}$. The derived oil contains a large variety of chemicals and constituents. The complex mixture is mainly consisting of aromatics, non-aromatics, oxygenated aromatics, oxygenated non-aromatics, nitrogenated aromatics or nitrosulfurated aromatics. The high abundance of aromatics is due to the presence of SBR rubber and the cyclisation of olefin structures followed by dehydration reactions ${ }^{45}$. Again, the ratio of aromatics, paraffins and olefins depends upon the type of tire and process conditions as shown in Table 2.1. 
Table 2.1 Chemical analysis of tire-derived oil ${ }^{41}$.

\begin{tabular}{|c|c|c|c|c|}
\hline Type of Oil & $\operatorname{Temp}\left({ }^{\circ} \mathrm{C}\right)$ & Aromatics & Paraffins & Olefins \\
\hline \multirow{10}{*}{ 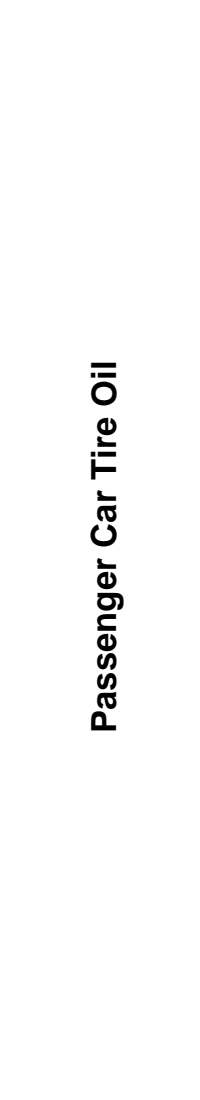 } & 550 & 41.54 & 54.55 & 3.91 \\
\hline & 650 & 41.21 & 54.85 & 3.94 \\
\hline & 800 & 41.15 & 54.88 & 3.97 \\
\hline & 300 & 53.4 & & \\
\hline & 400 & 66.6 & & \\
\hline & 500 & 70.9 & & \\
\hline & 600 & 74 & & \\
\hline & 700 & 74.8 & & \\
\hline & - & 36.14 & 42.68 & 21.18 \\
\hline & $<440$ & $<5$ & 29.96 & 65.04 \\
\hline
\end{tabular}

The considerable amounts of aromatics and olefins limit the direct use of TDO as fuel. These compounds cause a lower flash point and cetane number of TDO than diesel fuels, leading to a long ignition delay and thus more fuel consumption before ignition. The major consequence of this delay is an irregular by running engine, a poor thermal efficiency and a high level of emissions ${ }^{32}$. Furthermore, the presence of sulfur also appears to be an obstacle for using it as an alternative fuel. This is due to the strict environmental legislation which limits its amount in gasoline and diese ${ }^{17}$. 
Therefore further processing is always required, so that TDO can be considered as a substitute to fossil fuel.

\subsubsection{Char or recovered carbon black (rCB)}

Char, which is often called recovered carbon black ( $\mathrm{rCB}$ ), is the solid fraction of scrap tire rubber pyrolysis. The process of $\mathrm{rCB}$ recovery via pyrolysis is very different from producing virgin carbon black. Carbon black is produced under oxidative conditions by incomplete combustion, while the process is essentially in absence of oxygen for rCB from tires. Furthermore, the morphology is well controlled during manufacturing of virgin carbon black. Recovered carbon black is a mixture of several types of carbon used in various components of a tire with predefined morphologies along with impurities. Figure 2.6 is the TEM image of $\mathrm{rCB}$ in which the presence of a wide variety of carbon blacks with a broad range of particle sizes is evident. However, in this image carbon black particles and impurities are indistinguishable.

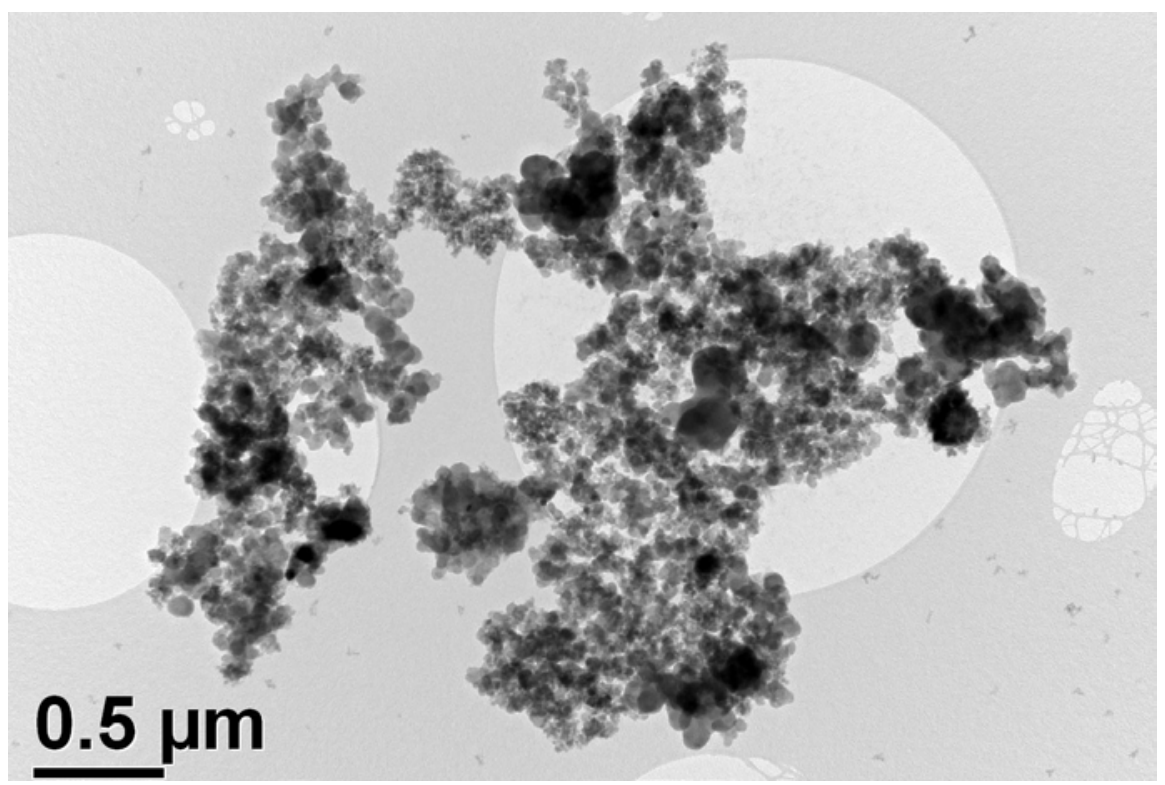

Figure 2.6 TEM image of recovered carbon black showing the morphology ${ }^{46}$. 
The composition of $\mathrm{rCB}$ is mainly dominated by the tire feed material and pyrolysis conditions. The major organic portion of $\mathrm{rCB}$ consists of carbon black, originally incorporated as reinforcing filler during tire manufacturing, while other carbonaceous products are also present as a consequence of re-polymerization reactions of polymer derivatives. Carbonaceous deposits are formed by the release of organic vapors which originate from the thermal degradation of elastomers during pyrolysis. Some of these vapors are converted into coke by dealkylation and dehydrogenation, and adsorbed onto the $\mathrm{rCB}$ surface ${ }^{32,47}$ as depicted in Figure 2.7. The surface of carbon black contains moieties which can act as nuclei on which carbon structures grow by cyclisation resulting in much coarser particles of $\mathrm{rCB}^{48}$. Other contaminants within rCB are TDO and inorganic ash. The ash content is mainly composed of silica, zinc compounds, sulfur compounds and traces of other elements to include calcium, aluminum, sodium, magnesium and potassium ${ }^{49}$.

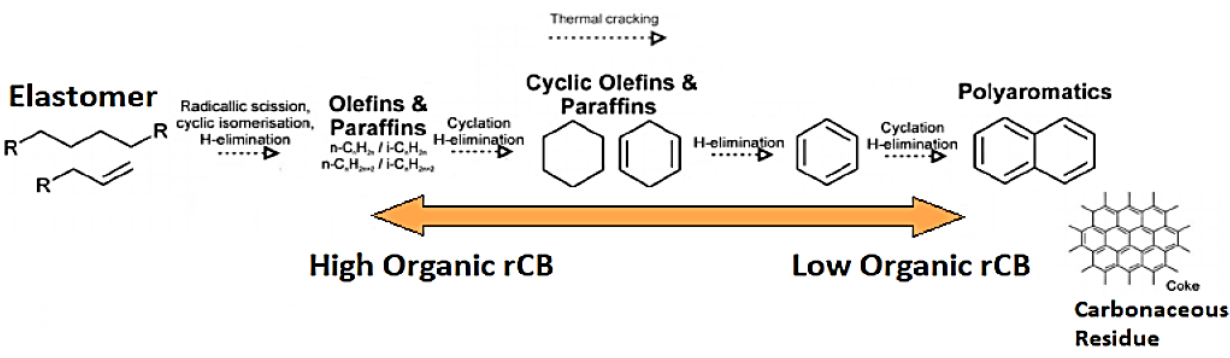

Figure 2.7 Formation of organics and polyaromatics during pyrolysis ${ }^{46}$.

The composition of rCB varies with respect to the tires used as feedstock. For instance, truck tires as feedstock result in rCB with an ash content of approximately $14 \%$, while passenger car tires contain a higher amount of silica resulting in an increased ash content as high as $40 \%{ }^{32}$. Furthermore, feedstock particle size along with other process parameters such as temperature, residence time, and heating rate also define the quality and the quantity of $\mathrm{rCB}$. The caloric value of $\mathrm{rCB}$ usually lies in the range of $14 \mathrm{MJ} / \mathrm{kg}$ to $30 \mathrm{MJ} / \mathrm{kg}^{50-52}$ and is similar to that of solid fuels. 


\subsection{Recovered carbon black reuse as filler in rubber compounds}

The colloidal properties of recovered carbon black (rCB) such as particle size and surface area are found to be comparable to the ones of commercial rubber reinforcing grades of carbon black. The specific BET surface area of $\mathrm{rCB}$ ranges from $30 \mathrm{~m}^{2} / \mathrm{g}$ to $120 \mathrm{~m}^{2} / \mathrm{g}^{34,38,53}$, similar to the carbon blacks series N300, N500 and $\mathrm{N} 600$ which are commonly used in the tire industry. The ideal use of this $\mathrm{rCB}$ would be in tires again. However, despite similar colloidal properties like medium (N550) and high reinforcing (N330) carbon blacks, the reinforcing strength of the rCBs shows a great disparity to the commercial grades of carbon black. The presence of a high amount of different organic and inorganic contaminants on the rCB surface limits its use as reinforcing fillers in the rubber industry ${ }^{54-55}$. Furthermore, in tire compounding surface activity is of great importance for filler-polymer interactions. For higher reinforcement strengths in rubber compounds, higher degrees of fillerpolymer interactions are required. In case of $\mathrm{rCB}$, these interactions are hampered by the structure and mineral/ash content ${ }^{32}$. It has been reported that the surface chemistry of $\mathrm{rCB}$ is similar to low grade commercial carbon blacks, and so is their performance ${ }^{56}$.

A study was conducted by Norris ${ }^{55}$ and coworkers on the surface area and structure of rCBs collected from different providers. The data were used for the evaluation of the in-rubber performance of $\mathrm{rCB}$. In addition, colloidal properties and in-rubber performance of rCBs were compared to commercial carbon black grades. In this study it was found that the colloidal properties of the $\mathrm{rCBs}$ fall in the range of commercial CB N300 and N500 series. However, the in-rubber performance of rCBs characterized by dynamic mechanical analysis falls in the category of semireinforcing fillers like N600 and N700. Figure 2.8 shows optical microscopy results which reveal the poor dispersion of $\mathrm{rCBs}$ when compared to the virgin carbon blacks. This disparity in $\mathrm{rCB}$ properties and in-rubber performance was stated to be a result of carbonaceous residue on the $\mathrm{rCB}$ surface. The carbonaceous residue was held responsible for the reduced surface activity and poor dispersion of $\mathrm{rCb}$. Moreover, no correlation was found among $\mathrm{rCB}$ in-rubber properties and their colloidal characteristics.

rCB was recently utilized in natural latex. In latex formulation, a dispersion of all ingredients including carbon black was made in its aqueous medium. The dispersion of rCB in latex was improved by using a novel method: atomization dispersion and high temperature sputtering drying. In this process, the $\mathrm{rCB} /$ latex dispersion was sprayed by a high pressure gas The sprayed out droplets were immediately dried and an improved dispersion was achieved. This consequently lead to reduced fillerfiller interactions and improved mechanical properties ${ }^{57}$. 

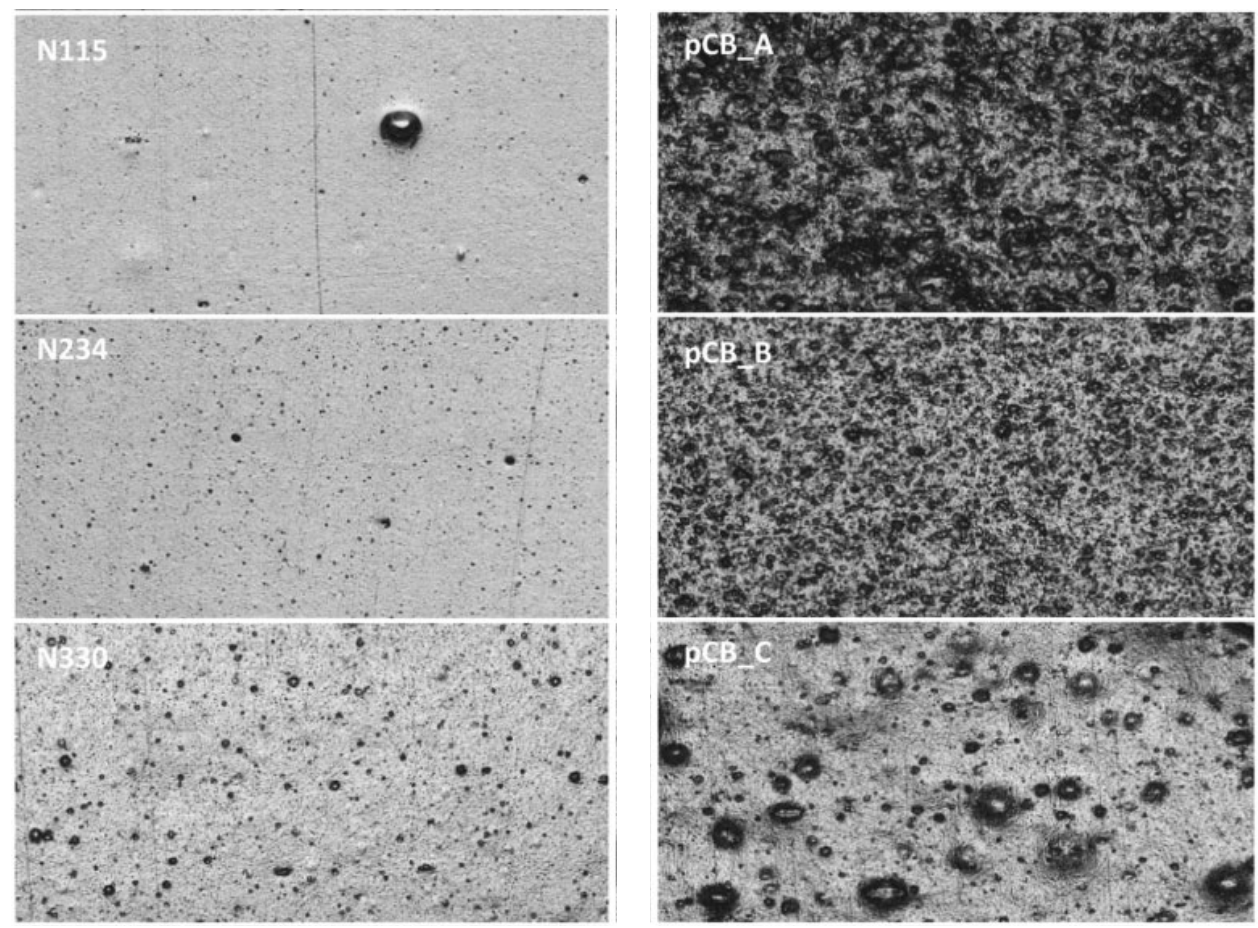

Figure 2.8 Dispersion of carbon blacks (N115, N234, N330) vs. various recovered carbon blacks in natural rubber ${ }^{55}$. STSA of pCBs: $p C B \_A=59 \mathrm{~m}^{2} / \mathrm{g}, p C B \_B=$ $52 \mathrm{~m}^{2} / \mathrm{g}$, and pCB_C $=68 \mathrm{~m}^{2} / \mathrm{g}$

Regardless of the presence of contaminants in $\mathrm{rCB}$, which reduces its commercial viability, it can potentially be used as fuel, adsorbent and additive. A high calorific value makes it suitable as solid fuel. However, this use is restricted due to the presence of sulfur, which when oxidized with fuel, is toxic to the environment. Therefore, removal or reduction of sulfur is necessary for fuel applications. Similarly, rCB can be used as activated carbon after appropriate upgrading. This application is widely accepted as the most promising use of rCB till date. The important characteristics of activated carbon are surface area, pore size, pore size distribution and pore volume, for which upgrading is done. This results in higher adsorption capacities due to the existence of micro and meso pores. Besides, the higher ash content (20 to $25 \mathrm{wt} . \%$ ) of $\mathrm{rCB}$ can be reduced by different acid/base demineralization processes prior to further activation processes ${ }^{58-59}$. 


\subsection{Upgrading of recovered carbon black}

Upgrading is important due to the fact that the rCB obtained from pyrolysis contains contaminants such as ash and carbonaceous deposits, which restrict its use as a high quality product. Additionally, an inappropriate degree of aggregation and reduced surface activity limits its use as reinforcing filler in tire manufacturing. Therefore, the use of $\mathrm{rCB}$ as a replacement of commercial $\mathrm{CB}$ requires upgrading processes. Through this, the following economic benefits can be expected:

- Recovering of components in the ash could lead to savings of minerals becoming scarce (e.g. zinc)

- The upgraded rCB could be used as commercial CB replacement. This leads to a reduced $\mathrm{CO}_{2}$ emission as virgin $\mathrm{CB}$ production demand will be decreased.

- Re-use of $\mathrm{rCB}$ in different applications will help in global tire waste management.

- High value $\mathrm{rCB}$, with the ability to be re-used in tires, will help in manufacturing more sustainable tires.

Different methods of upgrading are reported in literature. In order to remove contaminants, three methods are used: consecutive pyrolysis, physical separation and demineralization. All three methods target specific contaminants. Moreover, physical activation methods are commonly used to produce activated carbon.

Consecutive pyrolysis: A repetition of the pyrolysis process is conducted in order to remove the volatiles. These volatiles including moisture are condensed within the porous structure of the carbon during cooling within the first cycle of operation. The second pyrolysis operation is also done in order to remove a part of the elastomers which are not decomposed in the first run. This additional run will assure a relatively volatile free $\mathrm{rCB}$; a second run at $500^{\circ} \mathrm{C}$ is reported to remove the volatiles ${ }^{32}$. However, the ash content having a higher thermal stability and sulfur attached to the inorganic compounds remain in the rCB.

Physical separation: Steel wires are removed by magnetic separation after a tire is shredded into small pieces. Magnetic separation is again used to separate the remaining parts of steel wire from the $\mathrm{rCB}^{34}$. Fine grinding is a physical method to decrease the rCB agglomerate size. Pilusa et al. ${ }^{60}$ used this method for surface area 
increment and achieved a size of $38 \mu \mathrm{m}$. The NEA ${ }^{61}$ process uses an impact classifier mill ICM and reported rCB d97 particle size in the range of $6.2 \mu \mathrm{m}$ to $20 \mu \mathrm{m}$. $\mathrm{NETZSCH}{ }^{62}$ developed a fluidized bed jet mill process for milling $\mathrm{rCB}$ and achieved a d99 of $7 \mu \mathrm{m}$.

Demineralization: rCB contains sulfur and ash usually in the order of 2 to $3 \mathrm{wt} . \%$ and 7 to $16 \mathrm{wt} . \%$ respectively ${ }^{45,52,63}$. Acid/base demineralization treatments are often used in order to remove sulfur compounds. Numerous leaching agents have been used successfully for extraction of heavy metals in e.g. ash. Inorganic mineral acids, especially sulfuric and hydrochloric acid, are the most commonly used leaching agents ${ }^{59,64-65}$. Their high leaching efficiency and cost effectiveness makes them suitable for this purpose. Organic acids including acetic and citric acid are also reported for removal of heavy metals ${ }^{66}$. Furthermore, alkaline solutions such as sodium and ammonium hydroxide are used ${ }^{67}$. As ammonium hydroxide only allows the removal of amphoteric metals (zinc), other impurities remain in the solid residue ${ }^{68}$. Oxidizing agents like nitric acid and hydrogen peroxide were used for sulfur removal by Bunthid et al. ${ }^{69}$

The limitation of these techniques is their industrial viability. Most authors used extreme conditions to incorporate leaching agents in high concentrations or used long extraction times. Extreme conditions are used in order to meet the limits defined by environmental agencies (e.g. sulfur < 1 wt.\%). These extreme conditions are not applicable on an industrial scale for $\mathrm{rCB}$ upgrading as it is economically infeasible. Additionally, use of such strong acids and bases would causes additional waste and creates another environmental issue.

Physical activation: The specific BET surface area of the $\mathrm{rCB}$ is reported to be in the range of $20 \mathrm{~m}^{2} \mathrm{~g}^{-1}$ to $80 \mathrm{~m}^{2} \mathrm{~g}^{-1}$ 70-71. Several studies have attempted to improve the surface area of $\mathrm{rCB}$ by means of physical activation. The production of activated carbon from $\mathrm{rCB}$ requires an activating agent which reacts with the $\mathrm{rCB}$ to produce hydrogen, carbon monoxide, carbon dioxide and methane. The most commonly used activating agents are steam and carbon dioxide. The reaction with carbon at elevated temperatures and extended reaction times results in a loss of carbon by burn-off. As a consequence, pores of $\mathrm{rCB}$ open up resulting in a higher specific surface area i.e. $400 \mathrm{~m}^{2} \mathrm{~g}^{-1}$ to $1500 \mathrm{~m}^{2} \mathrm{~g}^{-1}$, similar to the commercial counterparts ${ }^{72}$. The pore size characteristics showed that the activated carbon mainly has a mesoporous arrangement. However, the pore size distribution is fairly dependent on the amount of burn-off. The burn-off sequence involves micro-pore formation, pore widening and, at longer burn-off times, pore wall destruction and loss of surface area $^{34}$. Merchant et al. ${ }^{70}$ observed that micro-pores are developed till $40 \%$ burn-off; above that, meso- and macro-pores are developed. The meso-pore volume 


\section{Chapter 2}

achieved in rCB is quite similar to the pore volume of commercial active carbon; however, the micro-pore volume is somewhat less than the one of the commercial carbons. Different activating agents affect the pore size and the surface area of activated carbons. For instance, steam activated carbon has a $20 \%$ larger surface area and also a higher pore volume compared to carbon dioxide activated carbons ${ }^{52}$. Similarly, process conditions and type of reactor also alter the characteristics of activated carbons. Higher surface areas are reported when using higher temperatures and longer activation times due to a higher degree of burn-off ${ }^{73}$.

Plasma surface treatment: Carbon black has been treated by different plasma techniques with various precursurs to create active surface. Donnet et al. ${ }^{74}$ utilized various gases in a plasma environment as precursors to modify carbon black surfaces. Carbon black treated with argon, ammonia and air showed an increased number of defects on graphitic structures which are crucial for better filler-polymer interactions. Mathew ${ }^{75}$ modified fullerenic carbon black by utilizing low pressure plasma and acetylene gas as precursor. The modified product was then incorporated in dissimilar rubber blends which showed a better dispersion compared to untreated carbon. Recently Probst ${ }^{76}$ emphasized the importance of this technique for the upgrading of recovered carbon black. The review concluded that both low temperature plasma and thermal plasma might be economical solutions to achieve better rCB surface activity and consequently to enhance its reapplication in rubbers.

In this section, different recycling methods for the partly-worn and scrap tires were discussed. The recycled material properties from processes such as devulcanization and pyrolysis are predominantly dependent on the tire composition. To understand this correlation, understanding of the complexity of the tire is required including the various types and compositions. For instance, the composition of recovered carbon black obtained from pyrolysis is determined by the different grades of carbon black used in the various parts of the tires ${ }^{23}$. These different grades of carbon black have different colloidal properties, surface chemistry and activity. Similarly, the contaminants present in $\mathrm{CCB}$ will also be dominated by the types of tires. Taking the example of $\mathrm{rCB}$ obtained from passenger car tires: It contains a higher amount of ash as compared to truck tire based rCB. Hence, for consistent properties, scrap tires must be sorted according to their composition. 


\subsection{Carbon black}

Carbon black is prepared by incomplete combustion or thermal cracking of hydrocarbons. Mineral oil as feedstock is pumped into a reactor along with a limited supply of air for incomplete combustion at about $2000^{\circ} \mathrm{C}$. The thermo-oxidative reaction is quenched by water and the product further cooled down by heat exchangers and direct water spray. Carbon black is then separated from the gas stream by filtering ${ }^{77}$.

In the reaction zone, the gasified oil feedstock is heated up to the temperature of $2000^{\circ} \mathrm{C}$, at which the molecules decompose into fragments. After losing hydrogen, these fragments combine, precipitate from the gas phase and act as nuclei for further precipitation until all feedstock is consumed. The rate of formation of nuclei is higher at increased temperatures due to the rate of pyrolysis. The higher the nuclei formation rate, the earlier the particles will stop to grow, thus limiting their size. Highly reinforcing carbon black types with a small particle size are produced at higher temperatures and shorter residence times than the less reinforcing types, and vice versa $^{78}$. Figure 2.9 shows the different stages involved in carbon black formation: atomization of feedstock, formation of primary particles, and subsequent development of particle aggregates. 


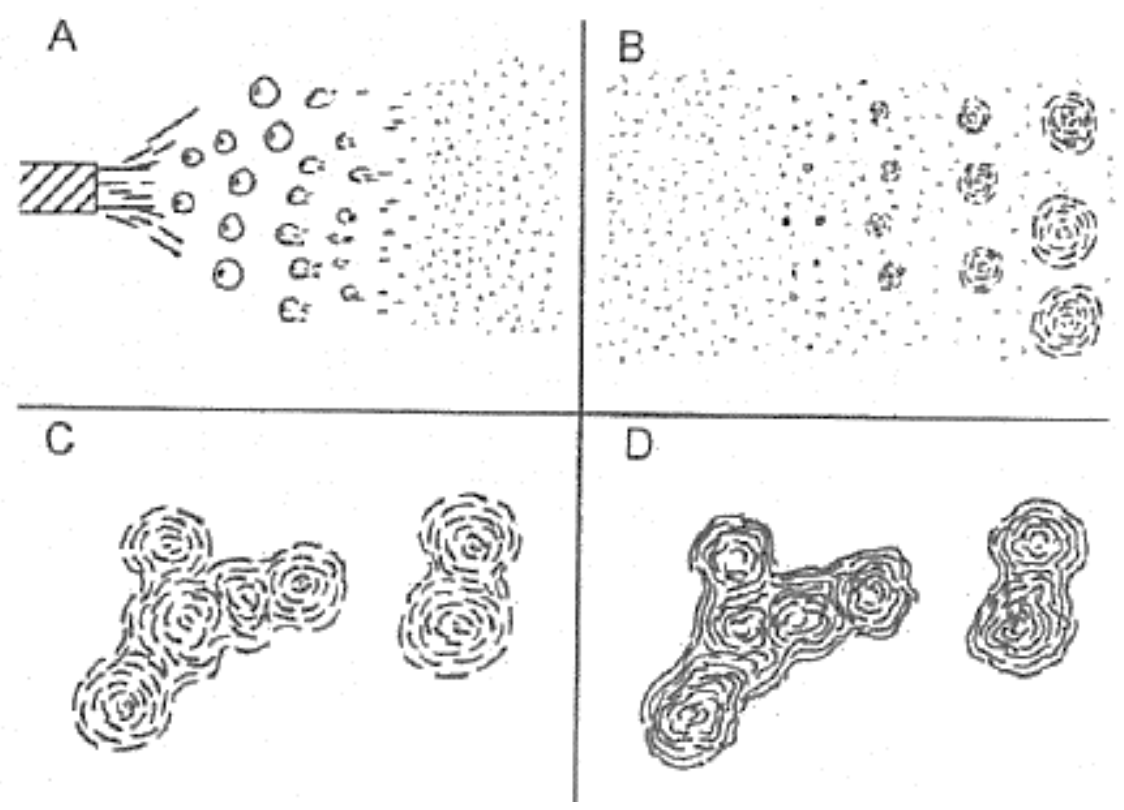

Figure 2.9 Carbon black formation stages ${ }^{79}$.

Carbon black primary particles, also known as nodules, consist of concentric graphitic layers as shown in Figure 2.10. These nodules form aggregates by collision in the high temperature furnace environment. The main properties of carbon black including particle size and aggregate structure are determined in the reactor and can be altered on later only to a minor extent. However, post-treatments can be used for altering the surface chemistry of carbon black ${ }^{80}$. 


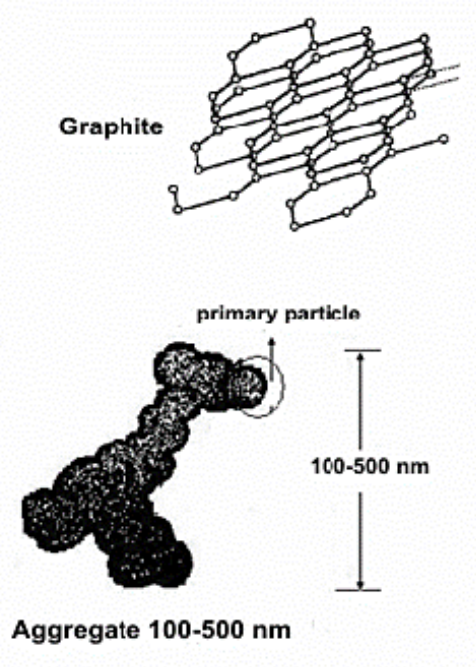

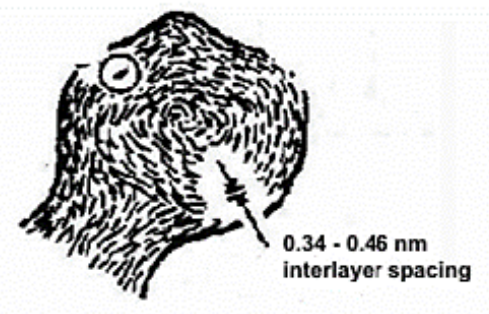

Particle or Nodule $\mathbf{1 0 - 1 0 0 ~ n m ~}$

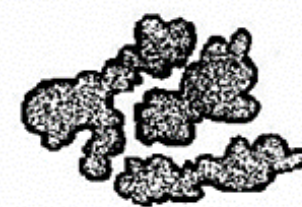

Agglomerate - clusters of aggregates 1 micron $-0.1 \mathrm{~mm}$

Figure 2.10 Aggregate, structure, and agglomerate formation of carbon black ${ }^{79}$.

\subsubsection{Carbon black reinforcement of rubber}

After the discovery that carbon black is an active reinforcing filler, it became the most widely used filler in the rubber industry. Almost $60 \%$ of the overall carbon black production is consumed by the tire industry. Carbon black has the ability to enhance a number of physical properties of elastomers such as stiffness, modulus, tear and tensile strength, rupture energy, resistance to abrasion, fatigue and cracking, collectively known as reinforcement ${ }^{81}$. From the 1950's onwards, a lot of research has been done on elastomer reinforcement by carbon black. The main parameters of carbon black which govern its reinforcing ability in rubber compounds are as follows ${ }^{82}$ :

- Size and size distribution of the primary particles. These primary particles are further fused together to form aggregates. Particle size and its distribution determine the surface area of carbon blacks.

- Structure of the carbon black. Structure includes the size, shape and distribution of aggregates. This parameter defines the degree of 
irregularity/branching of the carbon black aggregates due to the clustering of primary particles.

- Surface activity. It is related to the presence of different functional groups on the surface of carbon black. It also determines the adsorption capacity and determines the surface energy.

\subsubsection{Primary particles and structure}

The primary particle size is the most fundamental and important feature of reinforcement of rubbers. The primary particles are spherical in shape with a size of $20 \mathrm{~nm}$ to $300 \mathrm{~nm}$. The smaller the particle size, the higher the specific surface area. The reinforcement capability of carbon black in rubber compounds is enhanced by an increased specific surface area.

The primary nanoparticles coalesce and form aggregates having a size range of $100 \mathrm{~nm}$ to $500 \mathrm{~nm}^{83}$. These aggregates are present in different shapes and can further be classified as spheroidal, ellipsoidal, linear or branched as shown in Figure 2.11 . 


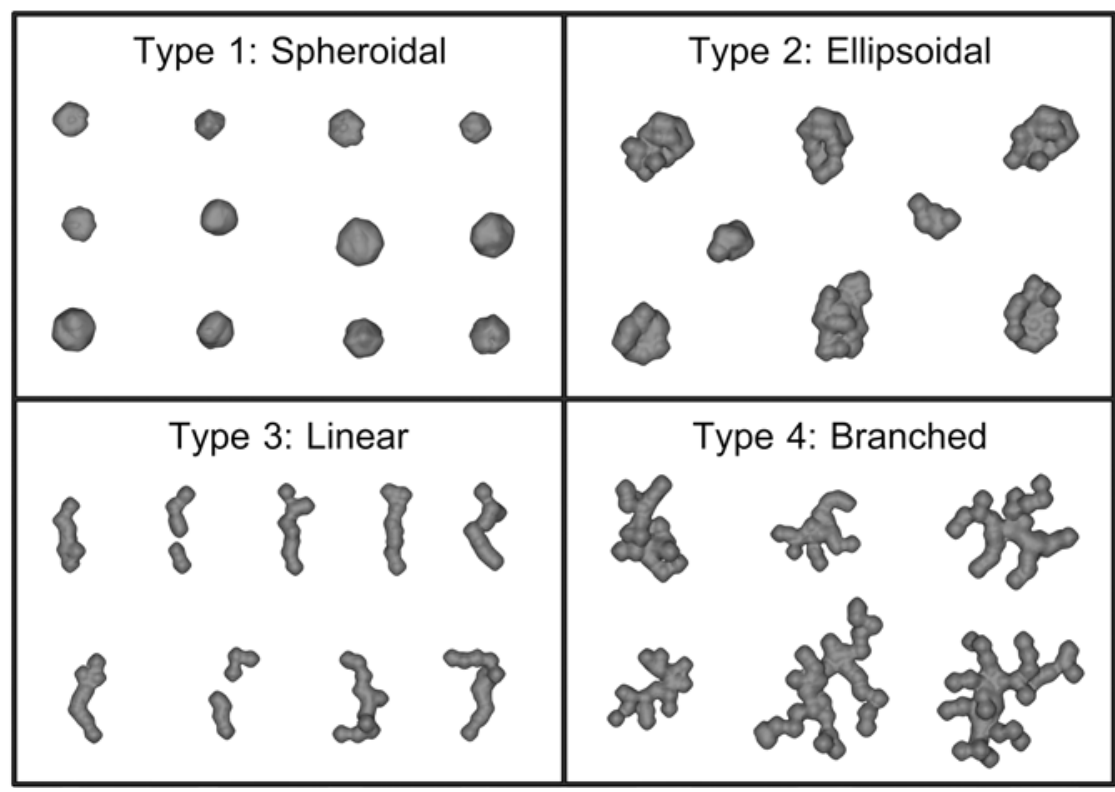

Figure 2.11 Classification of carbon black aggregate morphologies ${ }^{84}$.

The specific surface area is measured in different ways, including nitrogen adsorption (Brunauer Emmett Teller, BET), cetyl trimethyl ammonium bromide (CTAB) adsorption and iodine adsorption number (IAN) according to the ASTM standards D6556-21, D3765-04 and D1510-21, respectively. Standards are also defined for structure evaluation. It is measured as oil adsorption number (OAN), compressed oil adsorption number (COAN) and void volume according to the ASTM standards D2414-21, D3493-21 and D7854-21, respectively. ASTM D1765-21 defines the nomenclature of carbon black with respect to the particle size and the structure. This standard describes the filler by a combination of a letter and 3 digits i.e Nxyz: $\mathrm{N}$ stands for normal curing or $\mathrm{S}$ for slow curing, while $\mathrm{x}$ defines the mean particle size. The other two digits yz are used to indicate the structure of aggregates.

At lower strains, filler reinforced rubber properties such as wear resistance or hysteresis are mainly governed by the specific surface area of carbon black. The structure effect is mainly noticeable when the material is subjected to higher strains $(>10 \%)$. Properties such as the tensile modulus at higher strains are greatly influenced by the structure as shown in Figure $2.12^{85}$. 


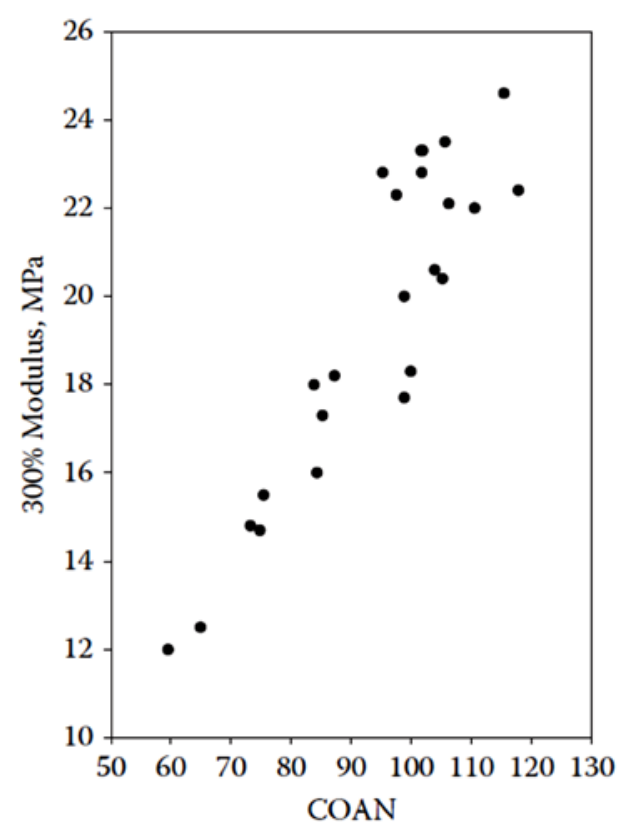

Figure 2.12 Influence of carbon black structure (COAN) on modulus at $300 \%$ strain.

\subsubsection{Surface chemistry}

The surface activity dictates the polymer-filler interactions, filler-filler interactions and filler-ingredient interaction. Surface activity can be physical or chemical in nature. In chemical sense, it is related to the presence of chemical groups on the carbon black surface. Carbon blacks are produced from hydrocarbons and therefore the dangling bonds at the edges of graphite layers are mostly hydrogen based. Other than hydrogen, oxygen, sulfur and nitrogen atoms are present. Sulfur and nitrogen originate from the precursor oil used as feedstock, while oxygen is chemisorbed when heated carbon is exposed to air. The surface oxides are formed on the edges of graphitic basal planes by molecular oxygen attacking the peripheric or defect sites. Several oxygen containing surface functional groups have been detected and their presence has a profound effect on carbon black surface properties ${ }^{86-88}$. 


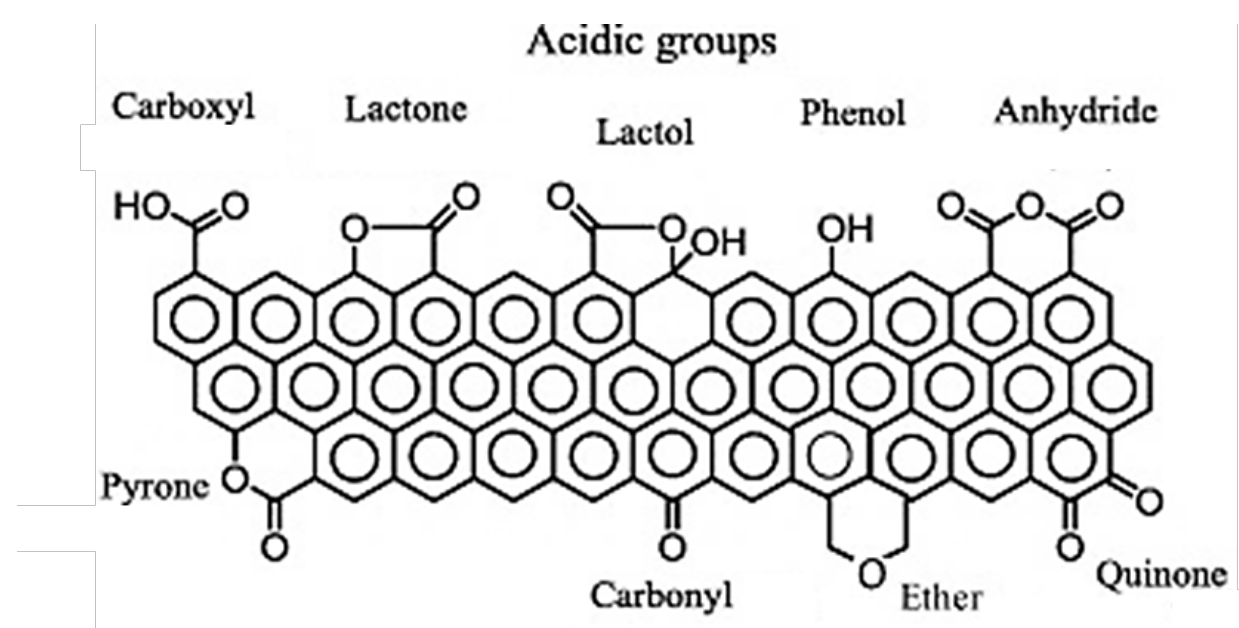

Neutral or basic groups

Figure 2.13 Carbon black surface functional groups ${ }^{89}$

Carbon blacks can have either acidic or basic character depending on the amount and type of the surface functional groups. Figure 2.13 shows acidic groups including carboxyl, anhydride, lactone, lactol and phenol. The other groups such as pyrone, carbonyl, ether and quinone are of weak basic or neutral nature. The acidic character is directly related to the oxygen content ${ }^{90}$. However, the basic properties are less dependent on the basic oxide groups and mainly dictated by the m-electron system of graphitic basal planes. These are sufficiently basic to bind protons from aqueous solutions of acids ${ }^{91}$. The surface chemistry of carbon black mainly influences the vulcanization process of the rubber compound. Acidic groups delay the onset of vulcanization by absorbing the curing aids and releasing them at a later stage. Just a few carbon blacks designated with the code $\mathrm{S}$ (slow curing) are acidic by nature, while great majority designated with $\mathrm{N}$ (normal curing) are predominantly basic.

\subsubsection{Surface energy}

In a physical sense, surface activity is defined as the variations in surface energy determining the adsorptive capacity of the filler and its energy of adsorption. The total surface energy of a filler is defined by Equation 2.1: 


$$
\gamma_{s}=\gamma_{s}{ }^{d}+\gamma_{s}{ }^{s p}
$$

where $\gamma_{s}{ }^{\text {sp }}$ defines the specific part of the surface energy which is due to polar interactions, while $\gamma_{s}{ }^{d}$ describes the dispersive component and is based on van der Waals forces. Carbon black has a higher dispersive than specific/polar component, making it more compatible with non-polar hydrocarbon based rubbers. The surface energy of carbon black has a greater effect on the mechanical properties of filled elastomers than its chemical nature ${ }^{92}$.

The carbon black surface contains heterogeneities due to the disordered graphitic planes. The carbon black surface morphology shown in Figure $2.14^{93}$ consists of graphitic planes (I), amorphous carbon (II), crystallite edges (III) and slit shaped cavities (IV). It is recognized that polymer chemisorption and physisorption happens preferably at these highly energetic sites. Additionally, chemical functional groups (mainly oxygen based) are also attached to these defect sites. Recent studies using gas adsorption have demonstrated the contribution of different energetic sites to the surface activity: graphitic planes are the lowest energy sites $(16 \mathrm{~kJ} / \mathrm{mol})$, while crystallite edges and slit shape cavities are the highest energetic sites of $(25 \mathrm{~kJ} / \mathrm{mol}$ and $30 \mathrm{~kJ} / \mathrm{mol}$, respectively). 


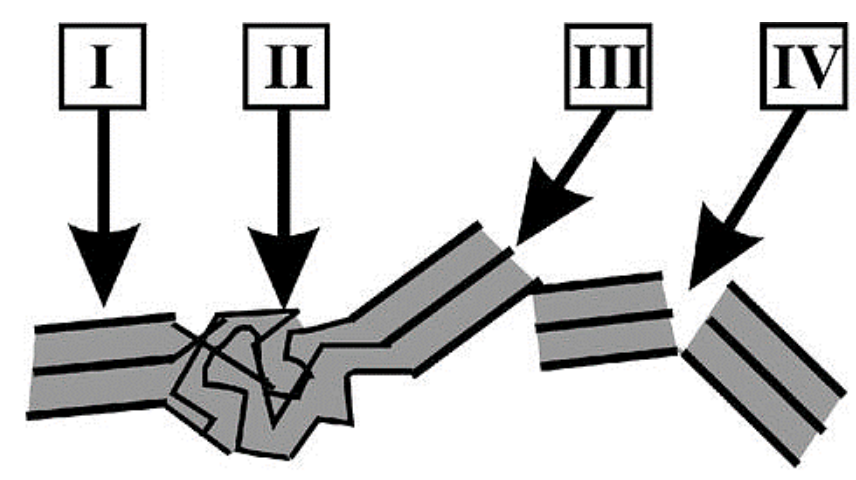

I $\begin{aligned} & \text { Graphitic } \\ & \text { Planes }\end{aligned}$ II Amorphous

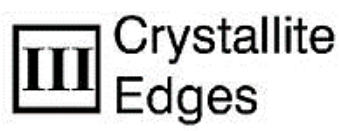

IV Slit Shaped

Figure 2.14 Energetic sites on the carbon black surface ${ }^{93}$.

Wang, Wolff, and Donnet ${ }^{94}$ studied carbon black surface activities as a function of its crystallite microstructure. They reported a decrease in surface activity with increasing crystallite dimensions indicating the presence of less crystal edges in large crystallites. These energetic sites have a profound influence on rubber reinforcement. Loss of these energetic centers by graphitization leads to lower fillerpolymer interactions, resulting in lower bound rubber, reduced modulus and tensile strength, and lower abrasion resistance ${ }^{95-96}$.

Based on these filler properties, the reinforcement strength of carbon black fillers in rubbers depends on filler-filler and filler-polymer interactions. These interactions are both physical and chemical in nature. Filler-polymer interactions are defined as the adsorption of polymer chain segments onto the carbon black surface. This can be of physical and/or chemical nature. It leads to the formation of bound rubber and a glassy immobilized layer around the filler particle. Both phenomena are related to hindered segmental chain mobility of elastomers. The strength of filler-polymer interactions defines the degree of effective immobilization of elastomer segments ${ }^{97}$. 
In different parts of tires, various grades of carbon black are used as shown in Table 2.2. These grades are chosen according to the performance and properties required by the specific parts of the tire. For instance, highly reinforcing carbon blacks are used in tread compounds, while other parts such as sidewalls contain medium reinforcing carbon blacks.

Table 2.2 Different carbon black grades in tire components ${ }^{98}$.

\begin{tabular}{|c|c|}
\hline Tire components & Carbon black grades \\
\hline Tread & N134, N115, N220, N234, N339, N375 \\
\hline Belt & N326, N330, N375 \\
\hline Sidewall & N330, N550, N660 \\
\hline Carcass & N550, N326, N330 \\
\hline Apex & N550, N660, N774 \\
\hline Innerliner & N660, N772, N550 \\
\hline
\end{tabular}

\subsection{Rubber reinforcement mechanisms}

In Figure 2.15, various contributions to rubber reinforcement are shown. Out of the four contributions, three are related to filler addition: the hydrodynamic effect, fillerpolymer interactions and filler-filler interactions. The polymer network contribution is related to the crosslinking of rubber chains by the curing agent. Except for filler-filler interactions, all other contributions are more or less strain independent. 


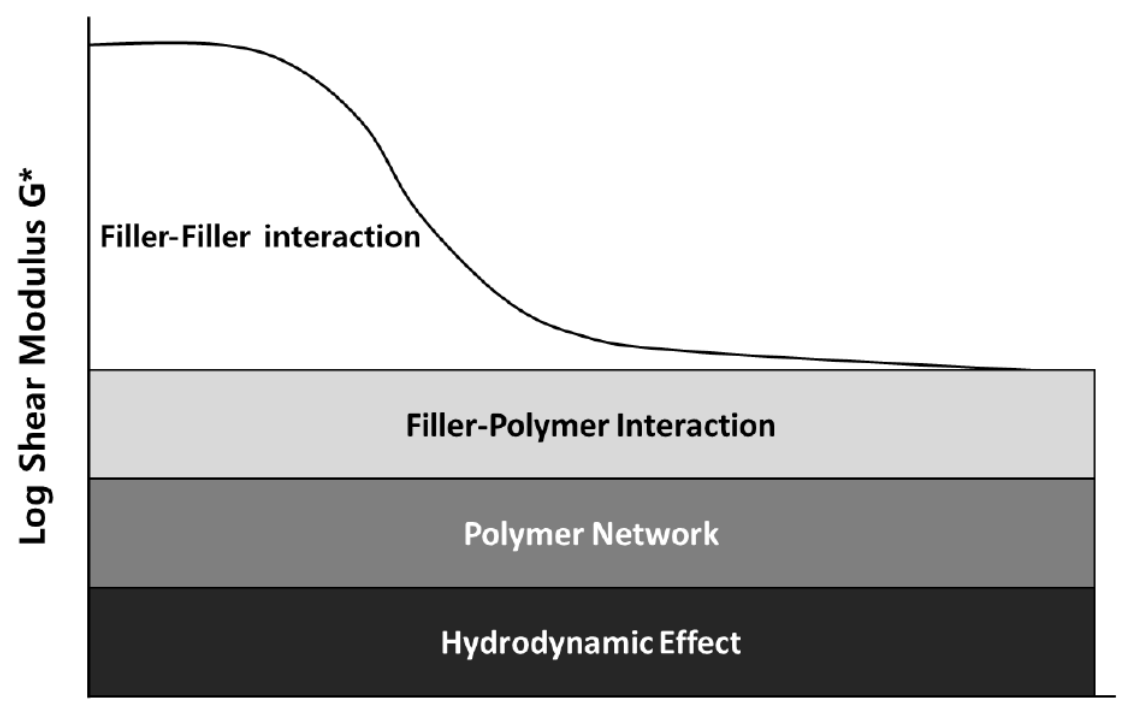

\section{Log Shear Deformation}

Figure 2.15 Various contributions to the shear modulus of a filled compound ${ }^{99}$.

\subsubsection{Hydrodynamic effect}

The simplest model to describe the rubber reinforcement is the hydrodynamic model based on Einstein's viscosity equation ${ }^{100}$. It is based on the concept of viscosity increase of a liquid by the addition of a small fraction of solid spherical particles due to the hydrodynamic obstruction. Einstein's equation (Eq. 2.2) reads:

$$
\eta=\eta_{0}(1+2.5 \phi)
$$

With $\eta$ the viscosity of the dispersion, $\eta_{0}$ the viscosity of fluid without fillers and $\phi$ is the filler volume fraction. This equation was later used by Smallwood ${ }^{101}$ for filled elastomers by replacing the liquid viscosity by the elastomer modulus and, the filler being assumed as perfectly spherical, wetted and well dispersed in the elastomer 
matrix without mutual interaction of the filler particles. The modified equation is called the Einstein-Smallwood equation (Eq. 2.3):

$$
G=G_{0}(1+2.5 \phi)
$$

Where $G$ is the shear modulus. An equivalent equation with $E$ for the tensile modulus may be used. Equation 3 is only valid for very small filler fractions. Guth and Gold ${ }^{102}$ further introduced a higher order term as power series $\left(\phi^{2}\right)$ to account for the fillerfiller interactions at higher filler loadings, see Eq. 2.4:

$$
G=G_{0}\left(1+2.5 \phi+14.1 \phi^{2}\right)
$$

The above equation fitted the data for fine thermal black fillers up to a volume fraction of 0.3. Above this filler volume fraction, it seriously deviates from this relationship. Guth suggested this deviation due to the asymmetric nature of carbon black aggregates. He further modified the equation and introduced a shape dependence, reads Eq. 2.5:

$$
G=G_{0}\left(1+0.67 f \phi+1.62 f^{2} \phi^{2}\right)
$$

With $f$ being the aspect ratio, i.e., the ratio of the length to the width of the aggregates. Several models have been on later by altering the Guth-Gold equation in order to explain the hydrodynamic behavior of fillers in elastomers. However, all these models are limited for certain specific cases and failed to predict the increase in modulus of composites with higher filler fractions. A recent review of such hydrodynamic approaches is given by Heinrich and Klüppel ${ }^{103}$, that explaining the 
reinforcement effect for higher filler fractions through hydrodynamic models is fundamentally impossible as soon as a filler network is formed resulting in a percolating solid phase and strong contributions to reinforcement.

\subsubsection{Polymer network}

The polymer network contribution is related to the crosslink density of the elastomer matrix. It is defined as the number of elastically active chains between crosslinks per unit volume $\left(\mathrm{cm}^{3}\right)$ between the elastomer chains, and based on the statistical theory of rubber elasticity which derives the relationship between stress and strain. The shear modulus $\mathrm{G}$ for uniaxial deformation is derived in its simplest form and for small deformations as given in Eq. 2.6:

$$
G=v k T=\rho R T / M_{c}
$$

Where $v$ is the crosslink density, $\mathrm{k}$ is the Boltzman's constant and $\mathrm{T}$ the absolute temperature. In the right expression, $\rho$ is the density, $M_{c}$ is the number average molar mass of network chains between crosslinks, and R is the gas constant.

\subsubsection{Filler-polymer interactions}

In a filled rubber compound, bound rubber is explained as the part of still unvulcanized rubber which cannot be extracted by a solvent, due to the adsorption of the rubber molecules onto the filler surface. The bound rubber layer formation around the filler particles is based on a complex physicochemical adsorption process and mechanical interlocking. The bound rubber content is not only dependent on the nature of the filler, but also affected by the filler morphology. Kaufman ${ }^{104}$ explained the presence of bound rubber by describing three distinct regions based on the degree of rubber molecule mobility:

a) a region of mobile rubber i.e. rubber matrix; 
b) an outer shell surrounding the carbon black which is less mobile and called bound rubber;

c) a hard inner shell where the mobility of rubber chain segments is extremely hindered generally termed as immobilized or glassy layer. The volume of the shell is dependent on the strength of the filler-polymer interactions and the specific surface area of the filler ${ }^{99}$.

Dannenberg ${ }^{105}$ measured the bound rubber layer for SBR rubber filled with carbon black. At a constant filler loading, the bound rubber content increased with larger surface area. This observation was explained as the difference in interfacial area in the compound between different grades of carbon black. Polymer properties such as chemical structure (polar/nonpolar, saturated/unsaturated) and microstructure (configuration, molecular weight) also affect the amount of bound rubber. Moreover, processing conditions, especially mixing time, have a great impact on bound rubber formation. During mixing, the mechanical breakage of the carbon black aggregate structure creates free radical functionalities on the surface of the carbon black particles. These free radicals lead to a chemisorptive mechanism through which bound rubber increases ${ }^{106}$. Regardless of the nature of the interaction between filler surface and polymer, bound rubber is widely considered as a measure of surface activity of fillers.

\subsubsection{Filler-filler interactions - Payne effect}

Payne $^{107}$ studied carbon black filled natural rubber and found a significant strain amplitude dependence of the modulus above 20 phr (parts per hundred rubber) of carbon black. He observed a sigmoidal decrease in the Young's modulus of filled rubber with increasing strain amplitude. This dependence vanished when the carbon black content in natural rubber was reduced to below 20 phr. He found similar behavior in terms of storage modulus from shear measurements and termed it 'strain softening'. This phenomenon was later intensively investigated by the others like Medalia ${ }^{108}$ and Voet and Cook $^{109}$.

Payne interpreted the sigmoidal decrease as breakage of van der Waals bonds between carbon black aggregates/agglomerates, which are continuously broken and reformed. At low strain amplitudes below 1\% these bonds stay basically intact, and a rigid filler network is the dominant elastic contribution: The shear modulus is approximately $200 \%$ higher compared to the modulus at high strains, where the number of bonds is effectively reduced. At high strain amplitudes of approx. $10 \%$ strain, at which the filler network is broken, the modulus is significantly lowered and 
becomes strain independent. Wang ${ }^{110}$ later formulated the hypothesis that the breakdown of the filler network also leads to the release of occluded rubber trapped in the voids of agglomerates, which also causes decrease in the effective volume of fillers, hence resulting in decrease of modulus. Kraus ${ }^{111}$ presented first quantitative model to describe the Payne effect. The model is based on de-agglomeration and re-agglomeration of carbon black by the breakage and reformation of van der Waals bonds. The rates of van der Waal's bonds breakage $\left(R_{b}\right)$ and reformation $\left(R_{m}\right)$ of these bonds are considered as function of strain amplitude $\left(\gamma_{0}\right)$. The breakage rate of filler contacts are assumed proportional to the remaining number of contacts $(\mathrm{N})$ :

$$
R_{b}=K_{b} \gamma_{0}^{m} N
$$

$\mathrm{K}_{\mathrm{b}}$ is the rate constant. The rate of re-agglomeration $\left(\mathrm{R}_{\mathrm{m}}\right)$ or making of contacts is proportional to the number of broken contacts. Which is the difference between the number of elastically active contacts at zero deformation $\mathrm{N}_{0}$ and the remaining contacts $\mathrm{N}$ at a given strain amplitude and is assumed to vary with $\gamma_{0}{ }^{-\mathrm{m}}$ :

$$
R_{m}=K_{a} \gamma_{0}^{-m}\left(N_{0}-N\right)
$$

Further, at equilibrium the two rates $\mathrm{R}_{\mathrm{b}}$ and $\mathrm{R}_{\mathrm{m}}$ should be equal, which gives $\mathrm{N}$ as:

$$
N=N_{0} /\left(1+\left(\gamma_{0} / \gamma_{c}\right)^{2 m}\right)
$$

Kraus derived equation for storage modulus G' from the two rates equations. G'o and $G_{\infty}^{\prime}$ represent storage modulus at zero strain and high strain amplitudes, respectively. $\gamma_{c}$ is a characteristic strain given by $\left(\mathrm{K}_{\mathrm{m}} / \mathrm{K}_{\mathrm{b}}\right)^{1 / 2 \mathrm{~m}}$ at which $\mathrm{G}^{\prime}-\mathrm{G}_{\infty}$, has decreased to half to its zero strain value. The excess modulus of the agglomeration network at any amplitude as proportional to $\mathrm{N}$.

$$
G^{\prime}-G_{\infty}^{\prime} / G_{0}^{\prime}-G_{\infty}^{\prime}=1 /\left(1+\left(\gamma_{0} / \gamma_{c}\right)^{2 m}\right)
$$

Eq. 2.10 shows that the van der Waal's interactions between carbon black contacts give a ready mechanism of energy storage of the system, however, it is semiquantitative as it does not furnish mechanism for mechanical loses. Each act of breaking and remaking of a contact is deemed to dissipate additional strain energy 
over and above that dissipated by the vulcanizate in the absence of contacts. Kraus referred mechanical loses due to excess frictional forces within the carbon black particles and between particles and polymer system. Hence, an additional equation for the loss modulus G" is proposed:

$$
G^{\prime \prime}-G_{\infty}^{\prime \prime} / G_{m}^{\prime \prime}-G_{\infty}^{\prime \prime}=2\left(\gamma_{0} / \gamma_{c}\right)^{m} /\left(1+\left(\gamma_{0} / \gamma_{c}\right)^{2 m}\right)
$$

G" 0 and G" ${ }_{\infty}$ are loss moduli at zero and high strain amplitudes. Kraus reproduced Payne data and used above equation to evaluate it quantitatively and found a correlation. Moreover, it was reported that the $\mathrm{m}$ and $\gamma_{\mathrm{c}}$ are nearly independent on type of polymer and filler. Vieweg et al. ${ }^{112}$ calculated the value of $\mathrm{m}$ and $\gamma_{\mathrm{c}}$ for different rubbers such as NR, SBR and BR filled with carbon black and found a universal value of $0.5-0.6$ indicating that this parameter is fairly dependent on the geometry of the aggregates/agglomerates and is independent of type of rubber or filler. The idea of filler network formation within the rubber matrix is widely excepted and studied by several authors. The Payne effect and the filler network concept has also been observed in vulcanizates containing silica or polymeric fillers such as micro-gels ${ }^{113}$. The filler network of carbon black is further described by Klüppel ${ }^{114}$ by proposing a kinetic cluster-cluster aggregation model. In this model, fractal characteristic of filler-network is considered, a schematic view is given Figure 2.16. In this model, the elastic modulus of the material is defined as a function of the fractal unit cells, number of primary particles in the backbone of the unit cells and the elastic modulus of filler particles. In summary, it is concluded that the reinforcement in rubber composites with application relevant filler contents is at small strain amplitudes to large extent caused by contributions of a percolating filler network. 


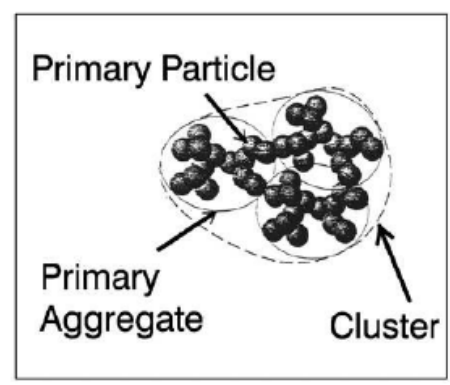

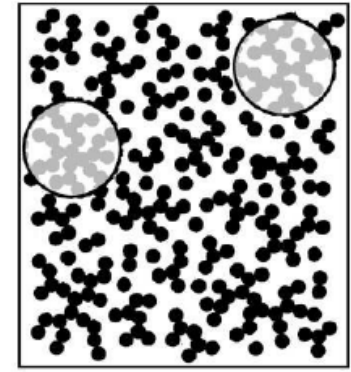

$\Phi<\Phi^{*}$

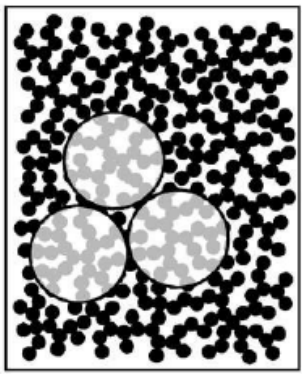

$\Phi>\Phi^{*}$

Figure 2.16. Filler aggregated clusters below and above the percolation threshold $\phi^{* 115}$.

The focus of the present thesis is to provide a better understanding of recovered carbon black characteristics and in-rubber properties. The influence of pyrolysis parameters on these properties will be investigated. Based on the material characteristics, a suitable after-treatment will be explored. Finally, the best performing $\mathrm{rCB}$ will be used to replace virgin carbon black in new rubber compounds.

\section{References}

[1] Council Directive on the Landfill of Waste (99/31/EC) (OJ 182, 16.7.99), as Amended by Regulation (EC) No. 1882/2003. Union, E., (2003).

[2] European Tyre and Rubber Manufacturers Association, Eur. Rubber J. (2019).

[3] European Tyre and Rubber Manufacturers Association, Press release, Brussels, (2021).

[4] Global ELT Management, Report, A Global State of Knowledge on Regulation, Management Systems, Impacts of Recovery and Technologies (2019).

[5] European Tyre and Rubber Manufacturers Association, Circular Economy, www.etrma.org

[6] G. Ferrer, Resour., Conserv. Recycl., 19, 221 (1997).

[7] B. Lebreton and A. Tuma, Int. J. Prod. Econ., 104,639 (2006). 
[8] O. Page and H. Kotze, Presented at South African Transport Conference (SATC), Pretoria, July (2009).

[9] T. Amari, N.J. Themelis, and I.K. Wernick, Resour. Policy, 25, 179 (1999).

[10] J. Jang, T.S. Yoo, J.H. Oh, and I. Iwasaki, Resource, Conserv, Recycle, 22, 1 (1998).

[11] H. J. Lee and H.S. Roh, Constr. Build. Mater., 21, 1016 (2007).

[12] S. Amirkhanian, R.K. Dhir, M.D. Newlands, and J.L. Halliday, Recycling and Reuse of Waste Materials, Thomas Telford, Dundee (2003).

[13] M. Sienkiewicz, J. Kucinska-Lipka, H. Janik and A. Balas, Waste Manage., 32, 1742 (2012).

[14] M. Phillips, Recycl. Today, 35, 42 (1997).

[15] W.K. Dierkes, Untreated and Treated Rubber Powder, In Rubber Recycling, CRC Press, Boca Raton (2005).

[16] M. Myhre and D.A. MacKillop, Rubber Chem. Technol., 75, 429 (2002).

[17] I. Hita, M. Arabiourrutia, M. Olazar, J Bilbao, M. Arandes and P. Castano, Renew. Sust. Energ. Rev., 56, 745 (2016).

[18] J. J. Leyden, Rubber World, 206(6) 28 (1991).

[19] J. Adhikari, A. Das, T. Sinha, P. Saha, and J. Kim, Grinding of Waste Rubber, In Rubber Recycling: Challenges and Developments, Royal Society of Chemistry, Cambridge, (2019).

[20] A. Pehlken and D.H. Mueller, Resour., Conserv. Recycl., 54, 140 (2009).

[21] R. N. Hader, D. Le Beau, Ind. Eng. Chem., 43, 250 (1951).

[22] E.R. Grilli, Finance Dev., 18, 25, (1981).

[23] M. Forrest, Recycling and Re-use of Waste Rubber, Smithers Rapra Technology Ltd., Shawbury (2014).

[24] W.G. Glasser, S.S. Kelley, H.F. Mark, N.M. Bikales, C.G. Overberger and G. Menges, Encyclopedia of Polymer Science, John Wiley \& Sons, New York (1987).

[25] S. Saiwari, Ph.D. thesis, University of Twente, Enschede (2013).

[26] M. Myhre, S. Saiwari, W.K. Dierkes and J.W.M. Noordermeer, Rubber Chem. Technol., 85, 408 (2012). 
[27] I.M. Rodriguez, M. Laresgoiti, M. Cabrero, A. Torres, M. Chomon and B. Caballero, Fuel Process. Technol., 72, 9 (2001).

[28] R. Giere, K. Smith and M. Blackford, Fuel, 85, 2278 (2006).

[29] www.teck.com.

[30] H. Karatas, H. Olgun and F. Akgun, Fuel Process. Technol., 102, 166 (2012).

[31] G. Xiao, M.J. Ni, Y. Chi and K.F Cen, Energ. Convers. Manag., 49, 2078 (2008).

[32] J.D. Martínez, N. Puy, R. Murillo, T. García, M.V. Navarro, and A.M. Mastral, Renew. Sust. Energ. Rev., 23, 179 (2013).

[33] M. Ryms, K. Januszewicz, W.M. Lewandoski, and E.K. Radziemska, Ecol Chem. Eng., 20, 93 (2013).

[34] P.T. Williams, Waste Manage., 33, 1714 (2013).

[35] N. Antoniou, G. Stavropoulos and A. Zabaniotou, Renew. Sust. Energ. Rev., 39, 1053 (2014).

[36] J. Scheirs and W. Kaminsky, Feedstock Recycling and Pyrolysis of Waste Plastics, John Wiley and Sons, Chichester (2006).

[37] R. K. Altayeb, MS.c. Thesis, American University of Sharjah, Sharjah (2015).

[38] S.Q. Li, Q. Yao, Y. Chi, J.H. Yan and K.F. Cen, Ind. Eng. Chem. Res., 43, 5133 (2004).

[39] S. Kawakami, K. Inoue, H. Tanka and T. Sakai, Pyrolysis Process for Scrap Tires, In Thermal Conversion of Solid Wastes and Biomass, 557-572, Washington (1980).

[40] W. Kaminsky and C. Mennerich, J. Anal. Appl. Pyrolysis, 58, 803 (2001).

[41] N. Antoniou and A. Zabaniotou, Renew. Sust. Energ. Rev., 20, 539 (2013).

[42] M. Kyari, A. Cunliffe and P.T. Williams, Energ. Fuel., 19, 1165 (2005).

[43] P.T. Williams, S. Besler and D.T. Taylor, Fuel, 69, 1474 (1990).

[44] C. Roy, A. Chaala and H. Darmstadt, J. Anal. Appl. Pyrolysis, 51, 201 (1999).

[45] A. Cunliffe and P.T. Williams, J. Anal. Appl. Pyrolysis, 44, 131 (1998).

[46] C. Norris and S. Renegar, Presented at International Rubber Conference (IRC), London, (2019). 
[47] R. Murillo, E. Aylon, M. Navarro, M. Callen, A. Aranda and A. Mastral, Fuel Process. Technol., 87, 143 (2006).

[48] O, Senneca, P. Salatino and R. Chirone, Fuel, 78, 1575 (1999).

[49] N.U. Cardona M. Betancur, and J.D. Martínez, Sust. Material. Technol., 28, 287 (2021).

[50] J. Conesa, I.M. Gullon, R. Font and J. Jauhiainen, Environ. Sci. Technol., 38, 3189 (2004).

[51] S. Ucar, S. Karagoz, A.R. Ozkan and J. Yanik, Fuel, 84, 1884 (2005).

[52] A. Cunliffe and P.T. Williams, Environ. Technol., 19, 1177 (1998).

[53] G. Lopez, M, Olazar, R. Aguado and J. Bilbao, Fuel, 89, 1946 (2010).

[54] S. Bhadra, P.P De, N. Mondal, R. Mukhapadhyaya and S.D. Gupta, J. Appl. Polym. Sci., 89, 465 (2003).

[55] C. Norris, M. Hale and M. Bennett, Plast. Rubber Compos., 43, 245 (2014).

[56] H. Darmstadt, C. Roy and S. Kaliaguine, Carbon, 33, 1449 (1995).

[57] X. Tian, Q. Zhuang, S. Han, S. Li, H. Liu, L. Li, J. Zhang, C. Wang, and H. Bian, J. Clean. Prod., 280, 124460 (2021).

[58] K.L. Henry, MEng. Thesis, Stellenbosch Univeristy Stellenbosch (2015).

[59] L. Laman, E. Kay, US 3,823,224 (1974).

[60] J. Pilusa and E. Muzenda, Int. J. Chem. Nucl. Mater. Metall. Eng, 7, 392 (2013).

[61] D.C. Karhoff, Presented at Recovered Carbon Black Conference, Berlin, (2019).

[62] C. Hoefels, Presented at Recovered Carbon Black Conference, Berlin, (2019).

[63] R. Cypres and B. Bettens, Pyrolysis and Gasification, Elsevier Applied Science, London, (1989).

[64] O. Chan, W. Cheung and G. McKay, Carbon, 49, 4674 (2011).

[65] G.G. Choi, S.H. Jung, S.J. Oh and J.S. Kim, Fuel Process. Technol., 123, 57 (2014).

[66] M. Marafi, A. Stanislaus, Ind. Eng. Chem. Res., 50, 9495 (2011).

[67] P. Dong, T. Maneerung, W.C. Ng, X. Zhen, Y. Dai, Y.W. Tong, Y.P Ting, S.N. Koh, C.H. Wang and K.G. Neoh, J. Hazard. Mater., 321, 62 (2017). 
[68] S.L. Tsai and M.S. Tsai, Resour., Conserv. Recycl., 22, 163 (1998).

[69] D. Bunthid, P. Prasassarakich and N. Hinchiranan, Fuel, 89, 2617 (2010).

[70] A.A Merchant and M.A. Petrich, AlChE Symp. Ser., 39, 1370 (1993).

[71] C. Giavarini, Fuel, 64, 1331 (1985).

[72] A.M. Cunliffe and P.T. Williams, Energ. Fuel., 13, 166 (1999).

[73] A. Zabaniotou and G. Stavropoulos, J. Anal. Appl. Pyrolysis, 70, 711 (2003).

[74] J.B. Donnet, W.D Wang, A. Vidal, and M.J. Wang, Carbon, 32, 199 (1994).

[75] T. Mathew, Ph.D. Thesis, University of Twente, Enschede, (2008).

[76] N. Probst, Kautsch. Gummi Kunstst., 74, 35 (2021).

[77] J. B. Donnet, R. C. Bansal, and M. J. Wang, Carbon Black: Science and Technology, 2nd ed., Marcel Dekker, New York (1993).

[78] G. Ulrich, Chem. Eng. News, 6, 22, (1984).

[79] K.C. Baranwal and H.L. Stephens, "Elastomer Technology: Special Topics, 1st ed., Rubber Division, American Chemical Society, Ohio (2003).

[80] N. Nakajima, Rubber Chem. Technol., 54, 266 (1981).

[81] E. Dannenberg, Rubber Chem. Technol., 48, 410 (1975).

[82] S. Wolff and M.J. Wang, Carbon Black Reinforcement of Elastomers, In Carbon Black: Science and Technology, 2nd ed., Marcel Dekker, New York (1993).

[83] G. Kraus, Reinforcement of Elastomers, Wiley Interscience, New York, (1965).

[84] C.R. Herd, G.C. McDonald and W.M. Hess, Rubber Chem. Technol., 65, 107 (1992).

[85] B. Rodgers, W.H. Waddell and W. Klingensmith, Rubber Compounding, In Science and Technology of Rubber, Academic Press, 401-454, Cambridge, (2005).

[86] H. Boehm, Carbon, 32, 759 (1994).

[87] H. Boehm, Carbon, 40, 145 (2002).

[88] M. Dubinin, Chemistry and Physics of Carbon, Marcel Dekker, New York, (1966).

[89] N. Li, X. Ma, Q. Zha, K. Kim, Y. Chen and C. Song, Carbon, 49, 5002 (2011). 
[90] M.L. Studebaker, Rubber Chem. Technol., 30, 1400 (1957).

[91] CAL.Y. Leon, J.M. Solar, V. Calemma and L.R. Radovic, Carbon, 30, 797 (1992).

[92] S. Wolff and M.J. Wang, Rubber Chem. Technol., 65, 329 (1992).

[93] A. Schröder, M. Klüppel, R.H. Schuster and J. Heidberg, Carbon, 40, 207 (2002).

[94] M.J. Wang, S. Wolff and J.B. Donnet, Rubber Chem. Technol., 64, 714, (1991).

[95] J. Brennan, T. Jermyn and B. Boonstra, J. Appl. Polym. Sci., 8, 2687 (1964).

[96] .A.I. Medalia, Rubber Chem. Technol., 46, 877 (1973).

[97] M. Klüppel and G. Heinrich, Kautsch. Gummi Kunstst., 58, 217 (2005).

[98] www.continentalcarbon.com

[99] M.J. Wang, Rubber Chem. Technol., 71, 520, (1998).

[100] A. Einstein, Ann. der Physik 19, 289 (1906).

[101] H.M. Smallwood, J. Appl. Phys. 15, 758 (1944).

[102] E. Guth, J. Appl. Phys. 16, 20 (1945).

[103] G. Heinrich and M. Klüppel, Adv. Polym. Sci., 160, 1, 2002.

[104] S. Kaufman, W. Slichter and D. Davis, J. Polym. Sci., Part B: Polym. Phy., 9, 829 (1971).

[105] E. M. Dannenberg, Rubber Chem. Technol. 59, 512 (1986).

[106] A. Gessler, Rubber Age, 101, 54 (1969).

[107] A.R. Payne, J. Appl. Polym. Sci. 6, 57 (1962).

[108] A.I. Medalia, Rubber Chem. Technol. 47, 411 (1974).

[109] A. Voet, F.R. Cook, Rubber Chem. Technol. 40, 1364 (1967).

[110] M.J. Wang, Rubber Chem. Technol. 72, 430 (1999).

[111] G. Krauss, J. Appl. Polym. Sci., 39, 75 (1997).

[112] S. Vieweg, R. Unger, E. Hempel, and E. Donth, J. Non-Crust. Solids, 235, 470 (1998). 
Chapter 2

[113] A. Bischoff, M. Klüppel, and R.H. Schuster, Polym Bullet., 40, 283 (1998)

[114] M. Klüppel, Kautsch. Gummi Kunstst., 50, 282 (1997).

[115] M. Klüppel, R.H. Schuster, and G. Heinrich, Rubber Chem. Technol., 70, 243 (1997). 
Chapter 2 


\section{RECOVERED CARBON BLACK CHARACTERISTICS AND IN-RUBBER PERFORMANCE, A COMPARATIVE STUDY}

This study aims to characterize the state-of-the-art recovered carbon black (rCB), the material properties and their influence on in-rubber performance. Commercially available rCBs, pyrolyzed from waste truck tire or passenger car tire rubber and mixtures of both materials, are tested. Material characterization is performed to determine organic impurities, ash, elemental composition, and BET specific surface area of the rCBs. Furthermore, the in-rubber properties of these rCB's are evaluated. A semi-reinforcing carbon black N660 is taken along as reference.

This study affirms earlier findings ${ }^{1-2}$ : The specific surface area of rCBs, does not translate into its in-rubber performance potential. All rCBs, used in this study exhibit a high specific surface area similar to the one of reinforcing carbon black from the N300 series, while tensile properties of rubber compounds produced therewith are similar to the reference semi-reinforcing $N 660$ in all cases. As a consequence of different feedstocks used for pyrolysis, the rCB ash content is increased which mainly influences the compounds cure behavior: higher initial torque, lower curing rate and higher marching modulus intensity mainly due to the increase in silica content. Moreover, indications of the presence of active sulfur in the ash content of rCB are also observed. 


\subsection{Introduction}

Pyrolysis of waste tires yields a solid fraction of $30 \%$ to $40 \%$ and a volatile fraction of $60 \%$ to $70 \%{ }^{3-5}$. The volatile fraction is further separated into a condensable fraction of $40 \%$ to $60 \%$ tire derived oil (TDO), and a non-condensable fraction of 10 to $25 \%$ tire derived gas (TDG) ${ }^{6}$. TDO is abundant in BTX (Benzene, Toluene, Xylene) and can be used as a substitute for fuel purposes ${ }^{7}$. TDG is an energy-rich gas with a calorific value in the range of $20 \mathrm{~mJ} / \mathrm{m}^{3}$ to $65 \mathrm{~mJ} / \mathrm{m}^{3}$ and can be used to generate heat for the pyrolysis process, thereby making the pyrolysis process energy independent ${ }^{8}$.

The solid fraction of the pyrolysis is often called char, pyrolytic carbon black (pCB) or recovered carbon black ( $\mathrm{rCB}$ ). The major part of rCB consists of carbon black, which was originally added during tire manufacturing. Carbonaceous deposits are also formed and adsorbed on the rCB surface; these are organic species generated during the pyrolysis process ${ }^{9-10}$. The amount of carbonaceous residues depends on the process conditions: for instance, in vacuum pyrolysis the low pressure and shorter residence time limit the formation of carbonaceous residues on the $\mathrm{rCB}$ surface $^{11}$. Another component of $\mathrm{rCB}$ is ash. It is composed of inorganic species, mainly silica, zinc, sulfur and traces of other elements to include calcium, aluminium, sodium, magnesium and potassium added during tire manufacturing, and dirt material which comes with the waste tires. Since varied amounts of inorganic additives are used in different types of tires, the ash content in $\mathrm{rCB}$ varies with respect to the feedstock ${ }^{12}$.

Studies have been conducted to evaluate the potential use of recovered carbon black as a substitute of conventional carbon black in tires. The colloidal properties of various rCBs from different pyrolysis processes were characterized and found to be in a range similar to the values of both, semi-reinforcing and highly reinforcing carbon blacks ${ }^{13-14}$. Norris et al. ${ }^{1}$ conducted a study on the in-rubber performance of rCBs exhibiting colloidal properties similar to reinforcing carbon blacks of the N300 series. However, despite the good colloidal properties, the in-rubber reinforcing potential of rCBs was similar to low- or semi-reinforcing carbon blacks. This disparity in the property-performance relationship was ascribed to carbonaceous residues reducing the surface activity of $\mathrm{rCB}$; hence, leading to poor polymer-filler interactions. Roy and coworkers ${ }^{7}$ characterized the surface activity of $\mathrm{rCB}$ exhibiting a specific surface area comparable to the high reinforcing grades of carbon black. They found that the surface activity of these rCB types was in the range of semi-reinforcing carbon black.

Several studies were conducted to demineralize rCB. Removal of ash from rCB was reported by performing different acid-base treatments ${ }^{15-18}$. Recently, Martinez et al. ${ }^{19}$ used acid demineralization to reduce the $\mathrm{rCB}$ ash content and studied its effect on 
in-rubber performance. They concluded that reducing the ash content lead to a reduction in Mooney viscosity and slight improvements in tensile strength, elongation and tear strength.

Since the ash consists of several inorganic compounds, it is not clear what the role of these different ash components on the $\mathrm{rCB}$ in-rubber performance is. In the present study, rCBs with different ash contents obtained from feedstocks of passenger car tires, truck tires and a mixture of both are evaluated for their material properties and in-rubber performance. Since process type and conditions are partially different for these rCBs, only rCBs are taken with similar levels of organic impurities.

\subsection{Experimental}

\subsubsection{Materials}

Reference carbon black: A semi-reinforcing commercial grade N660 was used as reference (Corax N660, Orion Engineered Carbons, Frankfurt, Germany). This carbon black grade exhibits a BET specific surface area in the range of $35 \mathrm{~m}^{2} / \mathrm{g}$ to $45 \mathrm{~m}^{2} / \mathrm{g}$, and the surface area measured as iodine adsorption number (IAN) is $36 \mathrm{mg} / \mathrm{g}$. The aggregate structure value characterized by the oil absorption number (OAN) is $91 \mathrm{ml} / 100 \mathrm{~g}$.

Recovered carbon blacks: Recovered carbon blacks ( $\mathrm{rCBs}$ ) characterized in this study were obtained from 2 different suppliers using dissimilar pyrolysis processes and feedstocks: passenger car tires, truck tires and a mixture of both. The ash contents of these recovered carbon blacks from different feedstocks is given in Table 3.1. Further details of the suppliers as well as the processes are not publicly available. 
Table 3.1 Notations of recovered carbon blacks, their respective feedstocks and ash contents.

\begin{tabular}{|c|c|c|}
\hline Recovered carbon blacks & Feedstock & Ash content (\%) \\
\hline PCT & Passenger car tire & 25 \\
\hline TT & Truck tire & 15 \\
\hline Mix-1 & Mixture of PCT and TT & 21 \\
\hline Mix-2 & Mixture of PCT and TT & 21 \\
\hline
\end{tabular}

Rubber: The polymer used for in-rubber evaluation was an oil-extended solutionstyrene butadiene rubber (S-SBR); trade name Buna VSL 2538-2 and manufactured by ARLANXEO, Cologne, Germany. This S-SBR type contains $25 \%$ of vinyl groups and $38 \%$ styrene. It is oil extended with 37.5 parts per hundred rubber (phr) of treated distillate aromatic extracted (TDAE) oil.

Protective agents: Compounding ingredients including N-(1,3-dimethylbutyl)-N'phenyl-p-phenylenediamine (6PPD) and 2,2,4-trimethyl-1,2-dihydroquinoline (TMQ) as antioxidants were provided by Flexsys, Belgium. Wax for ozone protection was delivered by Sasol Wax GmbH, Germany.

Cure package: This includes elemental sulfur from J.T. Baker, zinc oxide (ZnO), stearic acid and N-tert-butyl-benzothiazole sulfonamide (TBBS) from Merck.

\subsubsection{Methods}

\subsubsection{Thermo-Gravimetrical Analysis}

Thermo-gravimetrical analysis (TGA) was performed using TA Instrument Discovery TGA 550. For each sample, at least three measurements were performed and the mean value is taken. The measurements were performed under a gas flow rate of $40 \mathrm{ml} / \mathrm{min}$ in a temperature range of $25^{\circ} \mathrm{C}$ to $1000^{\circ} \mathrm{C}$. The heating rate was set to $20^{\circ} \mathrm{C} / \mathrm{min}$. From $25^{\circ} \mathrm{C}$ till $650^{\circ} \mathrm{C}$, a nitrogen environment was used to measure the moisture content and the amount of volatiles removed from rCB. The weight loss around $100^{\circ} \mathrm{C}$ represents the moisture content, while the volatiles content is measured in the temperature range from $250^{\circ} \mathrm{C}$ till $500^{\circ} \mathrm{C}$. From $650^{\circ} \mathrm{C}$ onwards, air was introduced for carbon burn-off, and this weight loss was measured as fixed 
carbon. The remaining weight after fixed carbon burn-off was the mineral ash content.

\subsubsection{Elemental Analysis}

Elemental analysis was performed using the JSM 6400 from Jeol, a scanning electron microscope connected with an energy dispersive x-ray analyzer (SEMEDX). Samples were prepared by glueing carbon black onto a metal sample holder. After the glue was dry, pressurized air was used to remove non-glued parts of the sample. The samples were then placed in an oven at $100^{\circ} \mathrm{C}$ for 24 hours for degassing.

\subsubsection{BET surface area}

The Brunauer Emmet Teller (BET) specific surface area was measured by the nitrogen $\left(\mathrm{N}_{2}\right)$ adsorption isotherm in a Gemini VII 2390 Micrometrics apparatus. Samples were initially degassed at $300^{\circ} \mathrm{C}$ for 24 hours. The BET surface area and STSA (statistical thickness surface area) were then determined at $-196^{\circ} \mathrm{C}$. The data were analyzed using the software TriStar 3000V6.04.

\subsubsection{Toluene extract transmittance}

The degree of toluene discoloration by carbon black extractables was measured according to the ASTM standard D1618-99. These measurements were performed using a Cary 300 UV-Vis spectrophotometer from Agilent.

\subsubsection{Compounding}

The compound formulation used in this study is shown in Table 3.2. Since the recovered carbon blacks ( $\mathrm{rCB}$ ) contain different ash contents, the amount of pyrolytic carbon black was adjusted according to their ash content as mentioned in Table 3.1, in order to have a similar amount of carbon black in both, the reference and the rCB compounds. No further adjustments for e.g. the presence of silica and $\mathrm{ZnO} / \mathrm{ZnS}$ were done. 
Chapter 3

Table 3.2 Compound formulation for reference N660 and rCB compounds.

\begin{tabular}{|c|c|c|}
\hline Mixing stage & Materials & Formulation (phr) \\
\hline \multirow{3}{*}{ Master } & S-SBR oil extended & 137.5 \\
\hline & $\begin{array}{c}\text { Carbon black/ Recovered } \\
\text { carbon black }\end{array}$ & 60 \\
\hline & 6PPD & 1.5 \\
\hline \multirow{4}{*}{ Batch } & TMQ & 1 \\
\hline & Wax & 2.5 \\
\hline & Zinc oxide & 3 \\
\hline & Stearic acid & 2 \\
\hline \multirow{2}{*}{$\begin{array}{l}\text { Final curing } \\
\text { package }\end{array}$} & Sulfur & 1.65 \\
\hline & TBBS & 0.7 \\
\hline
\end{tabular}

*adjusted according to the ash content of rCBs, as given in Table 3.3

Table 3.3 Adjusted amount of carbon blacks in phr according to their ash contents.

\begin{tabular}{|c|c|c|}
\hline Recovered carbon blacks & Ash content (\%) & $\begin{array}{c}\text { Adjusted amount } \\
\text { (phr) }\end{array}$ \\
\hline N660 & 0 & 60 \\
\hline PCT & 25 & 75 \\
\hline TT & 15 & 72.6 \\
\hline Mix-1 & 21 & 72.6 \\
\hline Mix-2 & 21 & \\
\hline
\end{tabular}

Mixing was carried out in a Brabender Plasticorder 350S internal batch mixer. A two stage mixing procedure was followed as shown in Table 3.4. 
Table 3.4 Mixing sequence.

\begin{tabular}{|c|c|c|c|}
\hline \multicolumn{2}{|c|}{ First stage } & \multicolumn{2}{|c|}{ Second stage } \\
\hline \multicolumn{2}{|c|}{ Internal mixer } & \multicolumn{2}{|c|}{ Internal mixer } \\
\hline Steps & Time & Steps & Time \\
\hline Polymer addition & $00: 00-00: 20$ & \multirow{2}{*}{$\begin{array}{l}\text { Add } 1^{\text {st }} \text { stage } \\
\text { compound }\end{array}$} & \multirow[t]{2}{*}{$00: 00-00: 30$} \\
\hline Mastication & $00: 20-00: 50$ & & \\
\hline $1 / 2$ Carbon & $00: 50-01: 00$ & \multirow[t]{2}{*}{ Mastication } & \multirow[t]{2}{*}{$00: 30-00: 50$} \\
\hline Mixing & $01: 00-01: 30$ & & \\
\hline $\begin{array}{c}1 / 2 \text { Carbon + remaining } \\
\text { additives }\end{array}$ & $01: 30-01: 40$ & \multirow[t]{2}{*}{ Curatives } & \multirow[t]{2}{*}{$00: 50-01: 10$} \\
\hline Mixing & $01: 40-02: 10$ & & \\
\hline Hopper cleaning & $02: 10-02: 20$ & \multirow[t]{2}{*}{ Mixing } & \multirow[t]{2}{*}{$01: 10-03: 10$} \\
\hline Mixing & $02: 20-04: 20$ & & \\
\hline $\begin{array}{l}\text { Discharge and } \\
\text { sheeting }\end{array}$ & - & $\begin{array}{l}\text { Discharge and } \\
\text { sheeting }\end{array}$ & - \\
\hline
\end{tabular}

In the first stage, all ingredients were mixed except for the curatives. The internal batch mixer for the first stage mixing was operated at a rotor speed of $100 \mathrm{rpm}$, a fill factor of $75 \%$ and a set temperature of $90^{\circ} \mathrm{C}$. The dump temperature of the batches after the first stage mixing was $\sim 160^{\circ} \mathrm{C}$. Curatives were added in the second stage of mixing. The same mixer was operated at a rotor speed of $80 \mathrm{rpm}$, a fill factor of $75 \%$ and a set temperature of $50^{\circ} \mathrm{C}$; the dump temperature was $\sim 110^{\circ} \mathrm{C}$. The compounds were sheeted off on a two roll mill. Each compound containing a certain type of carbon black was prepared three times to control the reproducibility of the results. The compounds are marked according to the notations used for the carbon blacks in Table 3.1, which refers to their respective feedstocks. 


\subsubsection{In-rubber evaluation}

\subsubsection{Payne effect before vulcanization}

A Rubber Process Analyzer (RPA) Elite from TA Instruments was used to measure the shear storage modulus ( $\left.G^{\prime}\right)$ as a function of strain amplitude. A strain sweep was carried out at $100^{\circ} \mathrm{C}$ in the range of $0.56 \%-100 \%$ strain amplitude at a frequency of $0.5 \mathrm{~Hz}$. The Payne effect $\left(\Delta \mathrm{G}^{\prime}\right)$ was calculated acc. to Equation (3.1):

$$
\Delta G^{\prime}=G^{\prime}(0.56 \%)-G^{\prime}(100 \%)
$$

Where $\mathrm{G}^{\prime}(0.56 \%)$ and $\mathrm{G}^{\prime}(100 \%)$ are the shear storage moduli at strain amplitudes of $0.56 \%$ and $100 \%$, respectively.

\subsubsection{Cure characteristics}

The Rubber Process Analyzer RPA Elite from TA Instruments was also utilized for curing measurements according to ISO 3417 . The increase in torque was measured for 60 minutes at $160^{\circ} \mathrm{C}$.

\subsubsection{Cure rate index}

The cure rate index (CRI) was calculated by Equation (3.2):

$$
C R I\left(\mathrm{~min}^{-1}\right)=\frac{100}{T_{90}-T_{S 2}}
$$

Where $T_{90}$ is the time required for $90 \%$ curing and $T_{s 2}$ is the scorch time in minutes.

\subsubsection{Marching modulus intensity}

The marching modulus intensity (MMI) of all cure curves was calculated by Equation (3.3): 


$$
\operatorname{MMI}\left(\frac{d N m}{\min }\right)=\frac{T_{60}-T_{40}}{60 \min -40 \min }
$$

Where $T_{60}$ and $T_{40}$ are the torque values after 60 and 40 minutes of curing in the RPA, respectively. This time range was selected as it was beyond the time required for $90 \%$ curing of compounds and represents only the marching modulus behavior.

\subsubsection{Vulcanization}

Samples were vulcanized in a Wickert press WLP 1600 with a pressure of 100 bar at $160^{\circ} \mathrm{C}$ to sheets with a thickness of $2 \mathrm{~mm}$. All compounded rCB samples showed strong marching modulus; therefore, all samples were vulcanized according to their respective $T_{90}$ calculated from the derivatives of their cure curves using the tangent method as shown in Figure $3.1^{20}$.

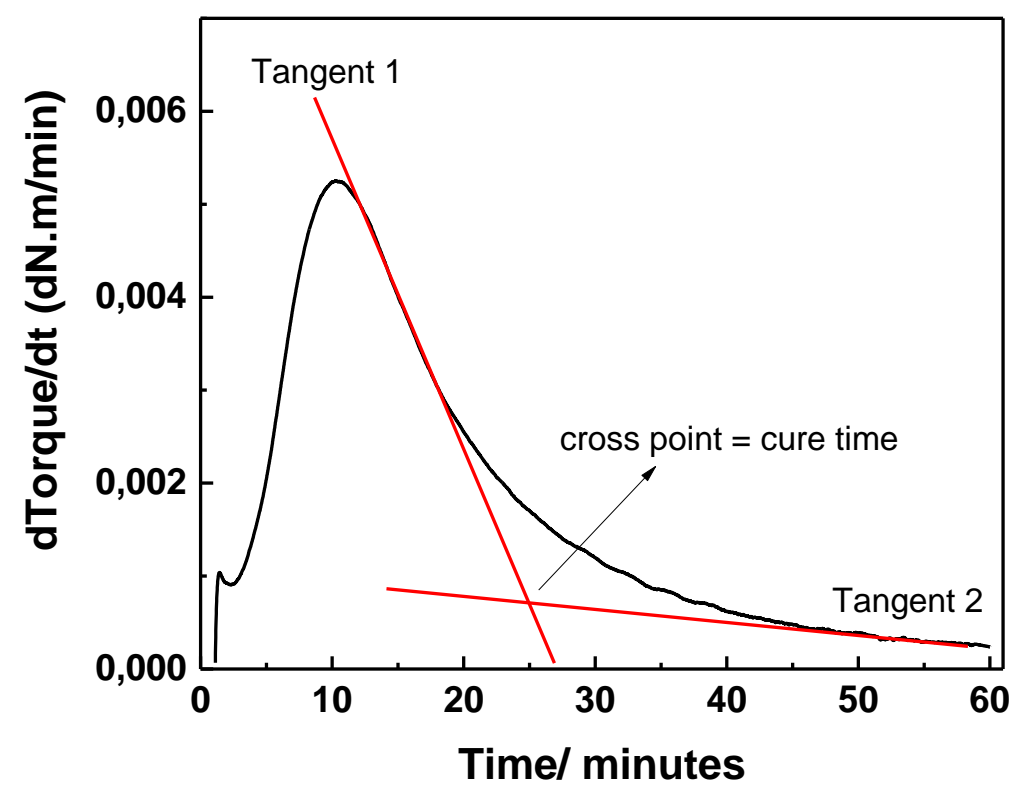

Figure 3.1 Cure time calculation from the derivative of the cure curve ${ }^{20}$. 
Chapter 3

\subsubsection{Hardness}

For hardness measurements, round discs with a thickness of $6 \mathrm{~mm}$ and a diameter of $60 \mathrm{~mm}$ were vulcanized at $\mathrm{T}_{90}+5$ minutes at $160^{\circ} \mathrm{C}$.

\subsubsection{Tensile properties}

Type 2 dumbbell test specimens were prepared according to ISO 37 . Tensile properties including modulus at different strains, tensile strength, and elongation at break were tested with a Zwick tensile tester model Z1.0/TH1S ( Zwick Roell Group, Germany) at a cross-head speed of $500 \mathrm{~mm} / \mathrm{min}$. For tensile properties, an average of five dumbbell samples was taken, while for the stress-strain graph, the median was chosen.

\subsubsection{Filler dispersion}

The macro dispersion of fillers was visualized using the DisperGRADER Alpha View (Alpha Technologies). 


\subsection{Results and Discussion}

\subsubsection{Material characteristics}

\subsubsection{Thermo-gravimetrical analysis}

The TGA analysis was performed from $25^{\circ} \mathrm{C}$ to $650^{\circ} \mathrm{C}$ in nitrogen environment and from $650^{\circ} \mathrm{C}$ to $1000^{\circ} \mathrm{C}$ in air. In Figure 3.2 , up to $100^{\circ} \mathrm{C}$, a moisture removal of $>0.5 \%$ is seen in all cases. From $100^{\circ} \mathrm{C}$ to $450^{\circ} \mathrm{C}, \sim 1 \%$ of weight loss in rCBs show the exit of lighter volatiles such as oil fractions. At temperatures higher than $450^{\circ} \mathrm{C}, 2 \%$ to $3 \%$ volatiles are removed from all recovered carbon blacks ( $\mathrm{rCB}$ ). The weight loss of N660 in this temperature range is around 1\%, indicating a low amount of volatiles fraction. At temperatures higher than $650^{\circ} \mathrm{C}$ and after change from $\mathrm{N}_{2}$ to air, a rapid weight loss is observed in all rCBs and carbon black N660 due to the carbon burnoff. The recovered carbon blacks reach a plateau after carbon burn-off, representing the amount of non-volatiles, mineral ash present in the rCBs. Depending of the feedstock, rCBs contain a different amount of non-volatiles: $r C B$ from truck tires contains the lowest ash content of 15\%, while rCB from passenger car tires has the highest ash content of $25 \%$, and the mixture of both contains $21 \%$. The ash content present in rCBs is mainly due to the use of inorganic fillers and minerals in tire manufacturing. Since in truck tire manufacturing, only small amounts of inorganic fillers are used compared to passenger car tire rubber, a lower amount of ash is present. During passenger car tire manufacturing, a higher amount of inorganic silica filler is incorporated for lower rolling resistance and better fuel consumption which leads to higher ash content in rCB. 


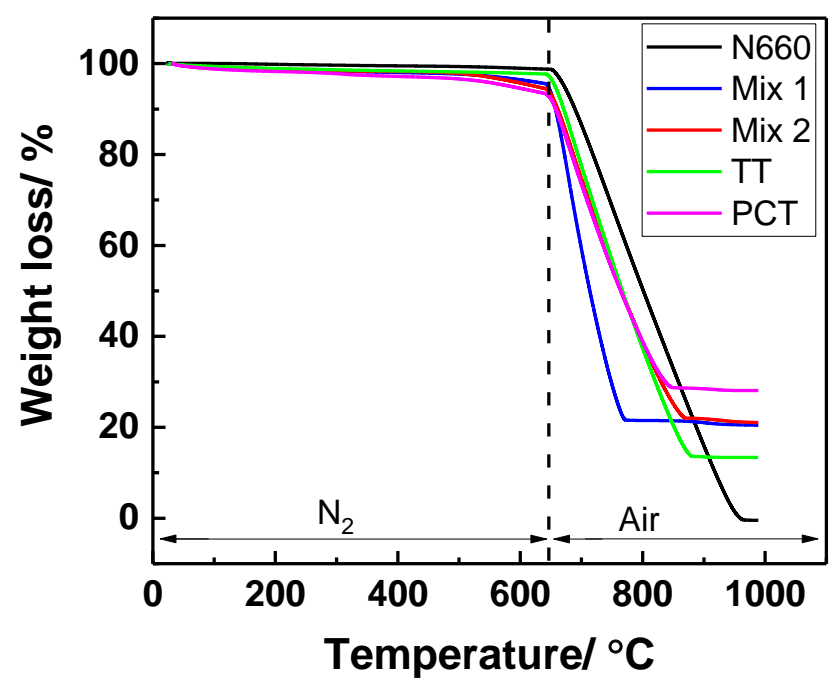

Figure 3.2 Weight loss with increasing temperature of recovered carbon blacks and carbon black N660 as a function of temperature.

\subsubsection{Elemental analysis}

The results of elemental analysis are presented in Table 3.5. N660 carbon black contains traces of sulfur from the petroleum feedstock. A small amount of oxygen in carbon black N660 is detected, which is generally attributed to carbon black surface functionalities. Among the recovered carbon blacks, the highest amount of carbon is detected in truck tire based $\mathrm{rCB}(\mathrm{TT})$, while the lowest amount is found in passenger car tire based $\mathrm{rCB}$ (Mix-1,-2<PCT). The reduction of the carbon content from TT to PCT can also be seen in the increasing inorganic ash content $(T T<M i x-1,-2<P C T)$. Zinc is found in the range of $2.5 \%$ to $4 \%$, and sulfur in the range of approximately $2 \%$ in all rCBs. The major ash component difference for the different feedstocks is seen for the silicon and oxygen content $(\mathrm{TT}<\mathrm{Mix}-1,-2<\mathrm{PCT})$. The increase in silicon and oxygen is due to the use of silica in tire manufacturing. Generally, a higher amount of silica is used in passenger car tire rubber compared to truck tire manufacturing, where carbon black is still mainly used. 
Table 3.5 Elemental analysis of carbon black N660 and recovered carbon blacks.

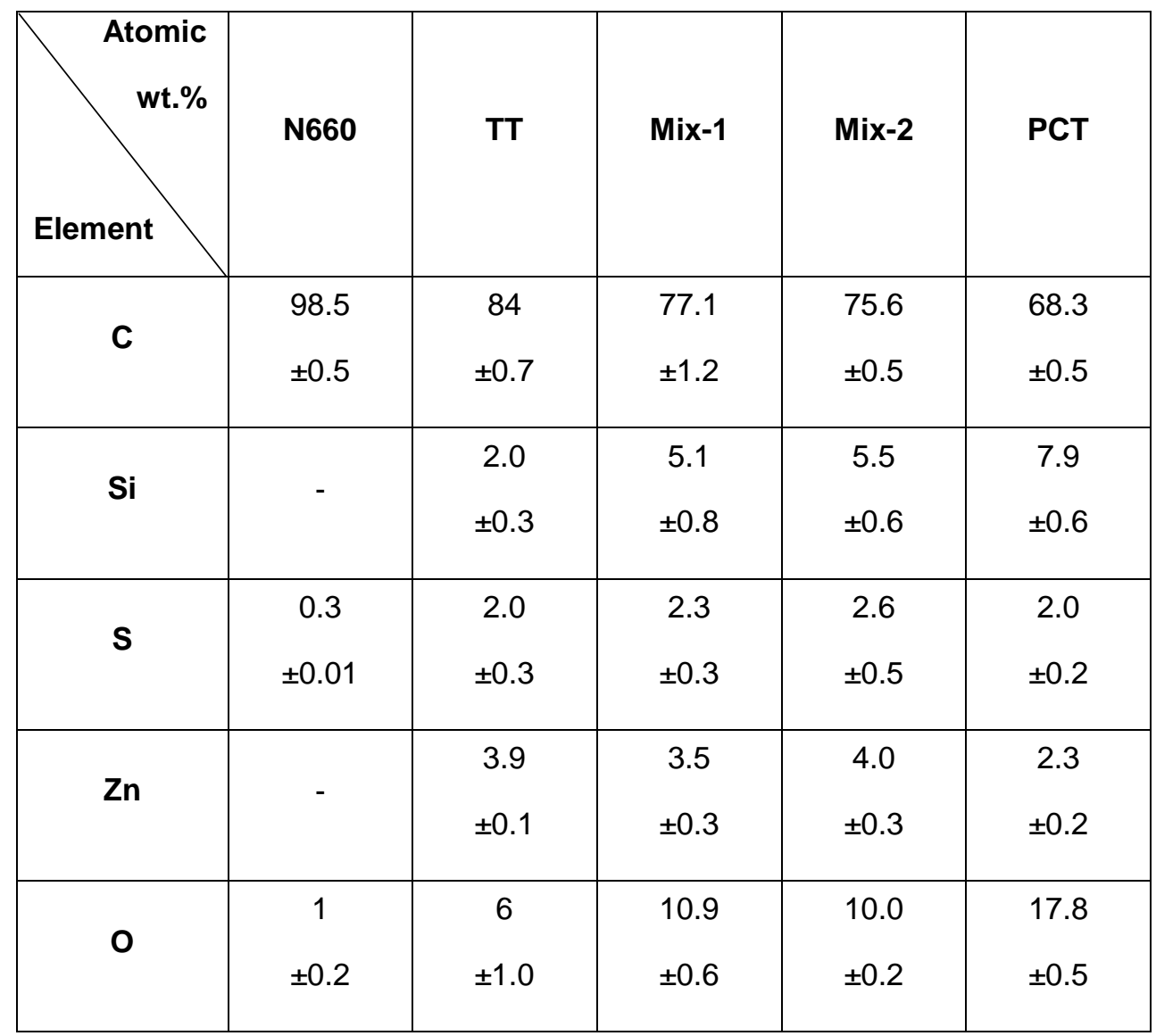

\subsubsection{Specific surface area}

The measured BET specific surface area and statistical thickness surface area (STSA) are shown in Figure 3.3. The BET surface area of carbon black N660 is the lowest, while rCB surface areas are in the range of $74 \mathrm{~m}^{2} / \mathrm{g}$ to $87 \mathrm{~m}^{2} / \mathrm{g}$, similar to reinforcing carbon blacks of the N300 series. STSA is also higher for rCBs compared to carbon black N660. No trend is found among the rCBs specific surface areas with respect to their ash contents due to different process conditions employed for the pyrolysis. 


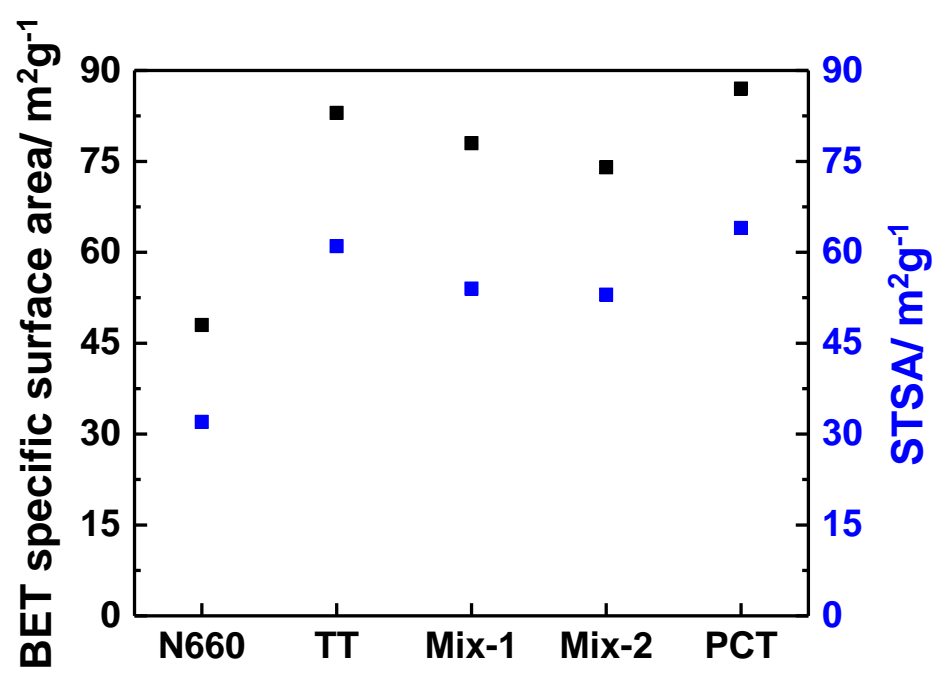

Figure 3.3 BET specific surface area (left y-axis) and STSA (right y-axis) of N660 and $\mathrm{rCBs}$.

\subsubsection{Toluene transmittance}

Transmittance of the toluene extract is measured for all samples to characterize the organic impurity content. In Figure 3.4, N660, rCBs based on TT and based on PCT show similar transmittance. Mix-2 has the highest transmittance indicating the lowest amount of organic impurities. In contrast, Mix-1 has the lowest amount of transmittance, indicating the highest organic impurity concentration. The amount of organic impurities depends mainly on pyrolysis process conditions, after-treatments, as well as feedstock composition. Since these rCBs were collected from different suppliers, the contributions of these factors were not further detailed. 


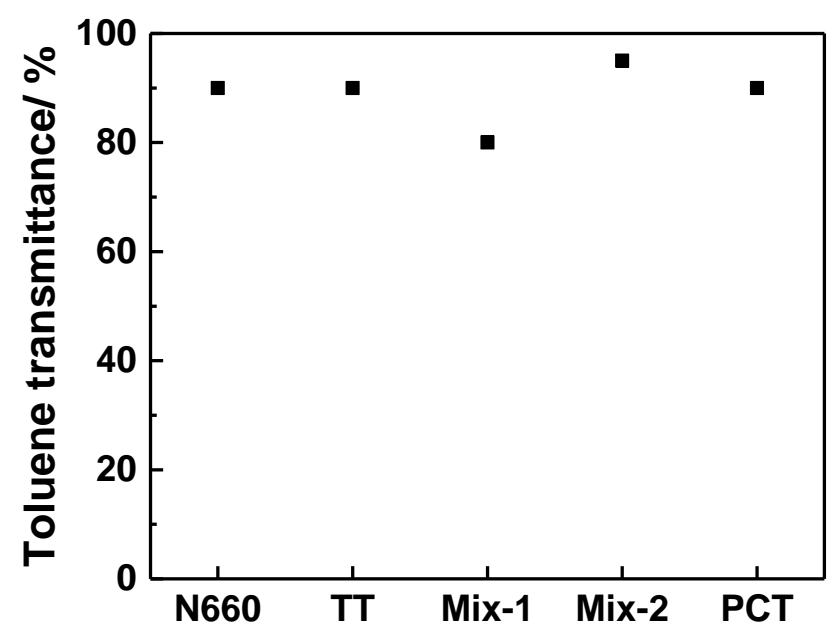

Figure 3.4 Transmittance of toluene extracts for N660 and rCBs.

\subsubsection{In-rubber performance}

\subsubsection{Mixing behaviour}

In Figure 3.5, mixing dump torques are presented. The N660 compound has lowest dump torque indicating the lowest viscosity. In rCB compounds, the torque increases with increasing ash content. This was expected since the $\mathrm{rCB}$ quantities were adjusted according to their respective ash contents (Table 3.3), meaning that 15 $25 \%$ additional rCB is added relative to N660. An increasing ash content leads to an increase of the solids fraction in the compound, resulting in higher viscosities. 


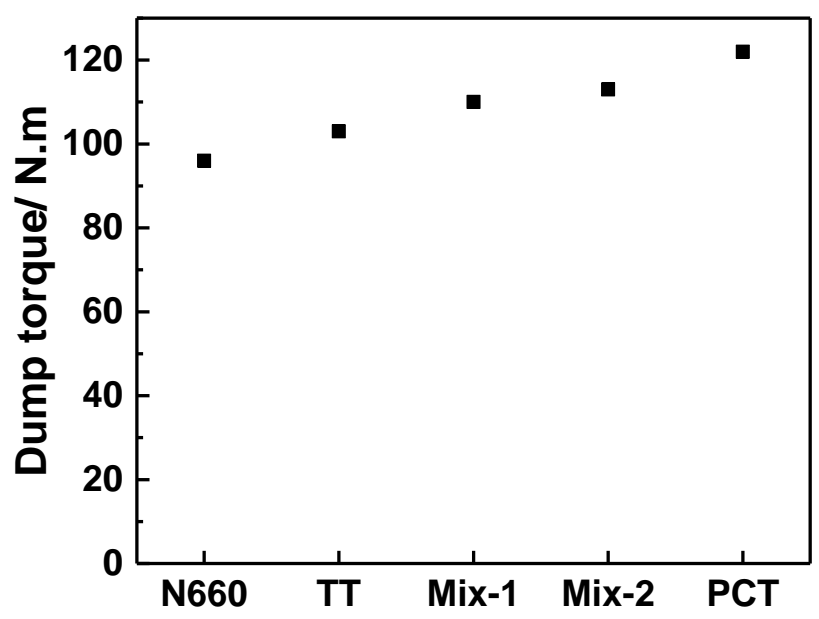

Figure 3.5 Dump torque of compounds containing N660 and rCBs from different feedstocks.

\subsubsection{Cure characteristics}

Figure 3.6 shows the curing behavior over time of the compounds filled with the different $\mathrm{rCBs}$ and the reference N660. The differences in minimum torque $\left(\mathrm{ML}_{\mathrm{L}}\right)$, maximum torque $\left(\mathrm{M}_{H}\right)$, torque difference $(\Delta S)$, optimum cure (tgo), and scorch retardation $\left(T_{\text {scorch }}\right)$ are summarized in Table 3.6. The $\mathrm{N} 660$ based compound shows the lowest $\mathrm{ML}$, while $\mathrm{rCB}$ compounds show a systematic increase with increasing ash content $(\mathrm{TT}<\mathrm{Mix}-1,-2<\mathrm{PCT})$. This finding is in-line with the mixing dump torque, since both quantities represent the compound viscosity, which increases with the solid fraction added as filler. Additionally, rCBs contain sulfur in the ash, which might cause pre-scorch of the compounds during mixing leading to higher initial torques. Moreover, the N660 compound has the longest scorch time followed by a sharp torque increase which then reaches a plateau, suggesting optimum cure state. However, rCB compounds have shorter scorch times and the torque never reaches a plateau caused by the marching behavior. 


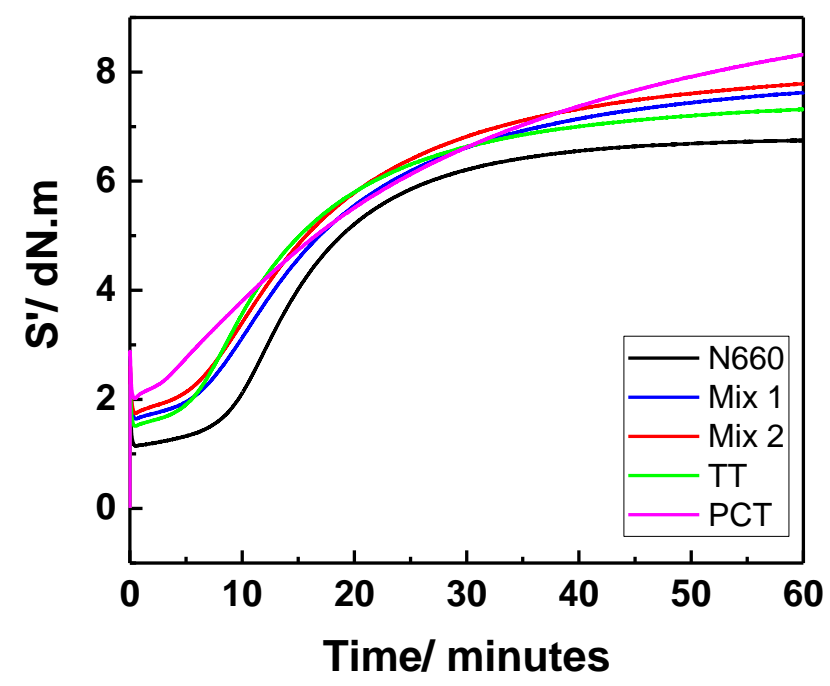

Figure 3.6 Cure characteristics of compounds containing carbon black N660 and rCBs from different feedstocks.

Table 3.6 Initial torque and scorch time of the compounds containing N660 and different rCBs.

\begin{tabular}{|c|c|c|c|c|c|}
\hline Compounds & $\begin{array}{c}\mathbf{M}_{\mathbf{L}} \\
(\mathbf{d N . m})\end{array}$ & $\begin{array}{c}\mathbf{M}_{\mathbf{H}} \\
(\mathbf{d N} . \mathbf{m})\end{array}$ & $\begin{array}{c}\mathbf{\Delta} \mathbf{S} \\
(\mathbf{d N} . \mathbf{m})\end{array}$ & $\begin{array}{c}\mathbf{t}_{90} \\
(\mathbf{m i n})\end{array}$ & $\begin{array}{c}\mathbf{T}_{\text {scorch }} \\
(\mathbf{m i n})\end{array}$ \\
\hline $\mathbf{N 6 6 0}$ & 1.1 & 6.8 & 5.6 & 21 & 9.9 \\
\hline TT & 1.5 & 7.4 & 5.9 & 21 & 6.7 \\
\hline Mix-1 & 1.6 & 7.6 & 6 & 26 & 7.9 \\
\hline Mix-2 & 1.7 & 7.8 & 6.1 & 27 & 7.3 \\
\hline PCT & 2.0 & 8.4 & 6.3 & 32 & 5.8 \\
\hline
\end{tabular}

The cure rate index and marching modulus intensity are plotted as a function of ash content in Figure 3.7. The N660 compound ( $0 \%$ ash) shows the highest cure rate index with lowest marching modulus intensity. In the rCB compounds, the increasing 
ash content clearly influences both properties in an opposite way: the cure rate index decreases while the marching modulus intensity increases. From the elemental analysis, it is already known that the major ash component in the different rCBs is silica ( $T T>M i x>P C T$ ), and this is varying most. The increasing quantity of silica in the different rCBs may lead to a higher tendency of adsorption of curatives, hence slowing down the curing process from the beginning and releasing these curatives after a certain time causing delayed crosslinking and thus marching modulus. The influence of slower curing due to rise in ash content of $\mathrm{rCB}$ is also evident with t9o increase in Table 3.6.

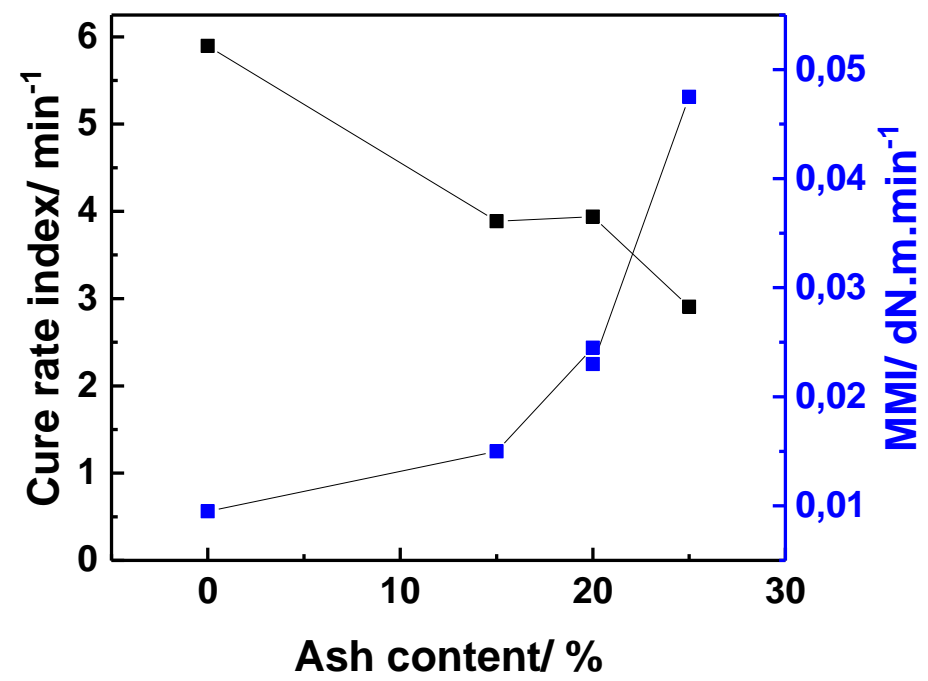

Figure 3.7 Cure rate index and marching modulus intensity of N660 and rCB compounds with respect to their ash contents.

\subsubsection{Filler-filler and filler-polymer interactions}

The Payne effect measurements were performed on uncured mixed compounds to understand the filler-filler and polymer-filler interactions. In Figure 3.8(a), the N660containing compound has the lowest magnitude of $G^{\prime}$ at small strains $\left(G^{\prime}(0.56 \%)\right)$, indicating lower filler-filler interactions. In case of $\mathrm{rCB}$ compounds, a clear trend of increasing G' with increasing ash content is seen. In Figure 3.8(b), the Payne effect $\left(\Delta G^{\prime}\right)$ of all samples is plotted as a function of ash content to illustrate the influence 
of ash on the filler-filler interactions. The $\mathrm{N} 660$ compound ( $0 \%$ ash) exhibits the lowest Payne effect which consequently represents good dispersion, while the rCB compounds have an increasing Payne effect with higher ash content. Considering G' at higher strain amplitudes ( $G^{\prime}(100 \%)$ ), the N660 compound has the lowest G' magnitude compared to rCBs. In silica compounds, $G^{\prime}(100 \%)$ ) is commonly used as a representative of filler-polymer interactions as strong chemical coupling of silica and polymer with silane clearly affect the magnitude of high strain modulus. However, in carbon black compounds these interactions are mainly of physical nature and thus the differences are rather insignificant. The slightly higher $\left.G^{\prime}(100 \%)\right)$ of rCB than N660 may also be a result of pre-scorch. Since the mixing dump temperature is $160^{\circ} \mathrm{C}$, and rCBs also contain sulfur in the ash, it may lead to prescorch and a higher storage modulus at higher deformations. In Figure 3.9, the macro dispersion analysis of the compounds visualizes the poor dispersion of rCBs compared to N660.
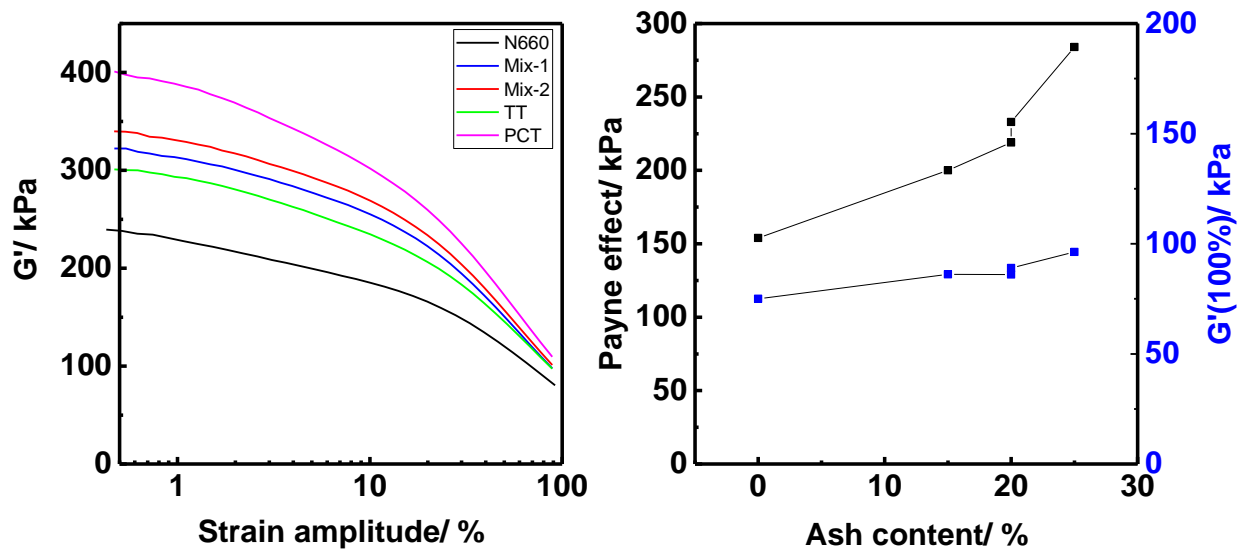

Figure 3.8(a) Strain dependent measurements of uncured compounds containing recovered carbon blacks and carbon black N660. (b) Payne effect as a function of ash content. 

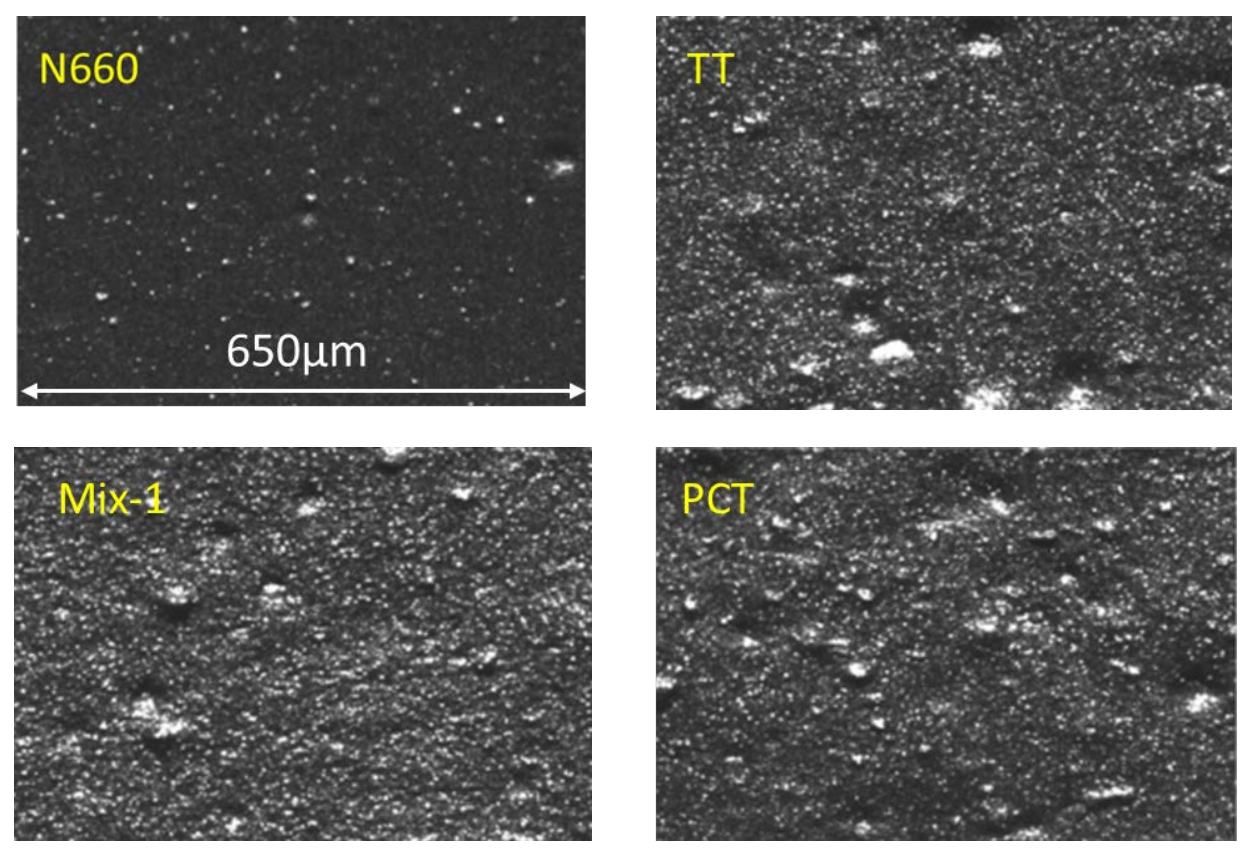

Figure 3.9 Macro dispersion of compounds containing N660 and different rCBs.

\subsubsection{Stress-strain properties}

Stress-strain properties of cured compounds with different recovered carbon blacks and carbon black N660 are plotted in Figure 3.10. Despite the higher specific surface areas, the stress strain behavior of the samples containing the rCBs is similar or even lower than of the ones with N660. Higher specific surface areas of carbon black are generally related to higher reinforcement. However, in the case of recovered carbon black, even though the specific surface area is in the range from $74 \mathrm{~m}^{2} / \mathrm{g}$ to $87 \mathrm{~m}^{2} / \mathrm{g}$, the stress strain curves are more or less similar in most of the regions. The Elongation at break and ultimate tensile strength are low in rCB compared to N660. Several possibilities can be underlined to explain such disparity between the specific surface area and the performance. Firstly, the higher surface area of rCB does not represent its surface activity: The formation of carbonaceous residues on $\mathrm{rCB}$ surface during pyrolysis may lead to lower surface activity and consequently poor performance. The poor dispersion of $\mathrm{rCB}$ in rubber, as evident from dispersion analysis (Figure 3.9) and from Payne effect (Figure 3.8), can also cause a detrimental effect on its rubber reinforcement.

Stress-strain curves of rCB filled rubber are similar to N660 containing rubber, in spite of the fact that higher polymer-filler interactions for rCBs are seen in the strain 
sweep measurements. This contrast can be attributed to pre-scorch of rCBs due to the presence of active sulfur leading to higher $G^{\prime}(100 \%)$ in these measurements.

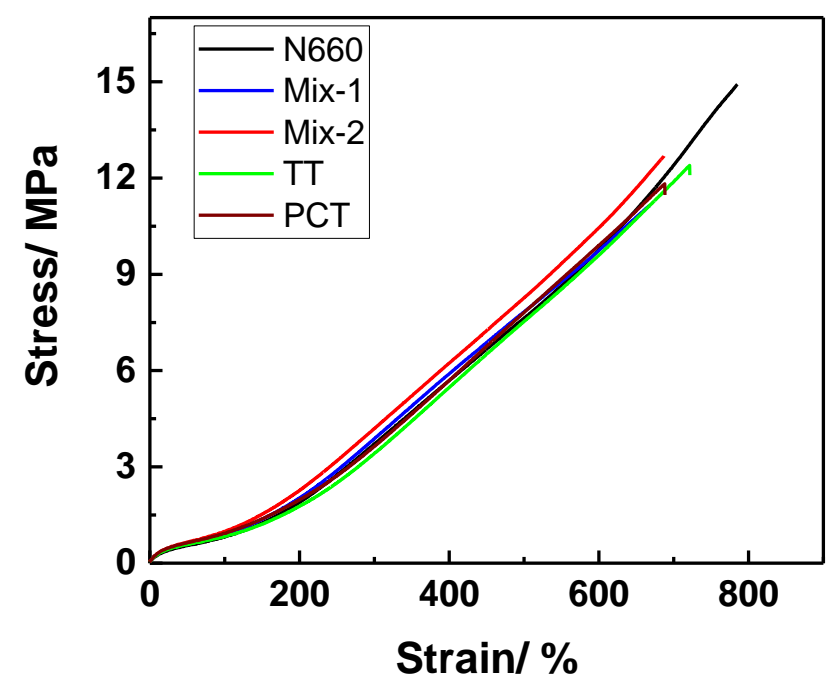

Figure 3.10 Stress-strain curves for compounds filled with carbon black N660 and recovered carbon blacks from different feedstocks.

In Table 3.7, the mechanical properties are summarized. Modulus at $100 \%$ and $300 \%$ strain of the TT sample with the lowest ash content among the rCB materials is the lowest, while the samples with higher ash contents result in higher moduli. Elongation at break is the highest for rubber with N660, while for recovered carbon black samples the elongation decreases systematically with the rise in ash load in rubber. The reduction of elongation is also contributed by the fact that the filler loading was increased according to the ash content. Considering the trends of modulus and elongation with ash content, it is in line with the previously mentioned possibility of the effect of active sulfur: A higher amount of active sulfur leads to a higher degree of crosslinking, resulting in both, increase of modulus and reduction of elongation. The reactivity of sulfur will be further determined and discussed in Chapter 6. N660 and rCBs based on TT result in similar Shore A hardness, while the other samples have a slightly higher hardness due to higher solids fraction. 
Commenting on the overall differences in Mix-1 and Mix-2, it is worth mentioning that even while Mix-2 is cleaner than for Mix-1 (15\% higher toluene transmittance for Mix2 than Mix-1, Figure 3.4), the differences in in-rubber properties are negligible. Generally, a higher amount of organic impurities in rCB leads to lower in-rubber performance due to the coverage of the active sites of carbon black. However, since both, Mix-1 and Mix-2, are in a higher range of transmittance of $80 \%$ and $95 \%$ respectively, it is expected that most of the carbon black surface is clean and that the influence of organic impurities is not significant. Additionally, the elemental analysis (Table 3.5) shows that such a difference in transmittance translates into a small amount of volatiles content, as the Mix-1 carbon content is only slightly higher $(\sim 1.5$ wt.\%) than Mix-2.

Table 3.7 Physical properties of recovered carbon blacks and carbon black N660.

\begin{tabular}{|c|c|c|c|c|c|}
\hline & $\begin{array}{c}\text { Modulus } \\
\text { at 100\% } \\
\text { (MPa) }\end{array}$ & $\begin{array}{c}\text { Modulus } \\
\text { at 300\% } \\
\text { (MPa) }\end{array}$ & $\begin{array}{c}\text { Tensile } \\
\text { strength/ } \\
\text { (MPa) }\end{array}$ & $\begin{array}{c}\text { Elongatio } \\
\mathbf{n} \text { (\%) }\end{array}$ & $\begin{array}{c}\text { Hardness } \\
\text { (shore A) }\end{array}$ \\
\hline N660 & 0.8 & 3.7 & 14 & 770 & 39 \\
\pm 0.01 & \pm 0.16 & \pm 1.5 & \pm 60 & \pm 1 \\
\hline TT & 0.8 & 3.3 & 12 & 713 & 39 \\
& \pm 0.01 & \pm 0.08 & \pm 0.4 & \pm 20 & \pm 1 \\
\hline Mix-1 & 0.9 & 3.9 & 11 & 670 & 41 \\
& \pm 0.01 & \pm 0.05 & \pm 0.6 & \pm 20 & \pm 1 \\
\hline Mix-2 & 0.9 & 4 & 11.5 & 675 & 41 \\
& \pm 0.01 & \pm 0.08 & \pm 0.6 & \pm 20 & \pm 1 \\
\hline PCT & 0.95 & 3.8 & 11.5 & 668 & 41 \\
& \pm 0.01 & \pm 0.08 & \pm 0.4 & \pm 20 & \pm 1 \\
\hline
\end{tabular}

\subsection{Conclusions}

This study determines the material properties and in-rubber performance of recovered carbon blacks produced from different feedstocks and in various pyrolysis processes. The recovered carbon blacks were produced from truck tire and 
passenger car tire rubber, and a mixture of both. The ash content of these rCBs is in the range of 15 to $25 \%$, mainly due to the differences in silica content. All investigated rCBs have a transmittance value close to the reference N660 indicating similar levels of volatiles content. The specific surface areas of these rCBs are in the range of carbon blacks from the N300 series, while in-rubber performance is similar to a semi-reinforcing carbon black N660. The ash content increase with feedstock in rCBs ( $\mathrm{TT}<\mathrm{Mix}<\mathrm{PCT}$ ) strongly influences cure behavior. The cure rate reduces, while the marching modulus is more pronounced with higher ash content. This is typical silica behavior in rubber compounds, as silica tends to adsorb the curatives leading to a slow curing process, and releases them at a later stage causing marching modulus. Moreover, the presence of active sulfur in the rCB ash is also indicated by the strain sweep measurements, which show higher polymer-filler interactions suggesting pre-scorch.

\section{References}

[1] C. Norris, M. Hale and M. Bennett, Plast. Rubber Compos., 43, 245 (2014).

[2] L. Moulin, S. Da Silva, A. Bounaceur, M. Herblot, and Y. Soudais, Waste Biomass Valorization, 8, 2757 (2017).

[3] P.T. Williams, Waste Manage., 33, 1714 (2013).

[4] M. Ryms, K. Januszewicz, W.M. Lewandoski, and E.K. Radziemska, Ecol Chem. Eng., 20, 93 (2013).

[5] N. Antoniou, G. Stavropoulos and A. Zabaniotou, Renew. Sust. Energ. Rev., 39, 1053 (2014).

[6] P.T. Williams, S. Besler and D.T. Taylor, Fuel, 69, 1474 (1990).

[7] C. Roy, A. Chaala and H. Darmstadt, J. Anal. Appl. Pyrolysis, 51, 201 (1999).

[8] N. Antoniou and A. Zabaniotou, Renew. Sust. Energ. Rev., 20, 539 (2013).

[9] R. Murillo, E. Aylon, M. Navarro, M. Callen, A. Aranda and A. Mastral, Fuel Process. Technol., 87, 143 (2006).

[10] O, Senneca, P. Salatino and R. Chirone, Fuel, 78, 1575 (1999).

[11] C. Roy, A. Rastegar, S. Kaliaguine, H. Darmstadt, and V. Tochev, Plast. Rubber Compos. 23, 21 (1995). 
[12] J.D. Martínez, N. Puy, R. Murillo, T. García, M.V. Navarro, and A.M. Mastral, Renew. Sust. Energ. Rev., 23, 179 (2013).

[13] S.Q. Li, Q. Yao, Y. Chi, J.H. Yan and K.F. Cen, Ind. Eng. Chem. Res., 43, 5133 (2004).

[14] G. Lopez, M, Olazar, R. Aguado and J. Bilbao, Fuel, 89, 1946 (2010).

[15] O. Chan, W. Cheung and G. McKay, Carbon, 49, 4674 (2011).

[16] G.G. Choi, S.H. Jung, S.J. Oh and J.S. Kim, Fuel Process. Technol., 123, 57 (2014).

[17] M. Marafi, A. Stanislaus, Ind. Eng. Chem. Res., 50, 9495 (2011).

[18] P. Dong, T. Maneerung, W.C. Ng, X. Zhen, Y. Dai, Y.W. Tong, Y.P Ting, S.N. Koh, C.H. Wang and K.G. Neoh, J. Hazard. Mater., 321, 62 (2017).

[19] J.D. Martínez, N. Cardona-Ulribe, R. Murillo, T. García, and J.M. Lopez, Waste. Manage., 85,574 (2019).

[20] S. Mihara, Ph.D. thesis, University of Twente, Enschede (2009). 


\section{INFLUENCE OF PYROLYSIS PARAMETERS ON THE PROPERTIES OF RECOVERED CARBON BLACK}

A new ultra-fast pyrolysis process with a residence time of 6 seconds is introduced for the recovery of carbon black from passenger car tires. The present work investigates the influence of pyrolysis process parameters on the physico-chemical characteristics of the recovered carbon black ( $r C B)$. Its differences with commercial virgin carbon black are also covered.

Chapter 4.1 mainly focuses on the influence of the pyrolysis temperature and residence time on

(i) product yield and

(ii) recovered carbon black $(r C B)$ quality in terms of volatiles.

The ash content composition is also characterized and reported here; a detailed discussion of the chemical composition and its influence on other $\mathrm{CB}$ characteristics is given in Chapter 4.2. Chapter 4.2 focuses on a better understanding of the physico-chemical nature of $\mathrm{CCB}$, and how it is influenced by process temperature. It covers the characterization of $\mathrm{rCB}$ and its key properties crucial for rubber reinforcement to include morphology, surface area, structure, physical and chemical surface activity. The in-rubber properties are the scope of Chapter 5.

By the influence of pyrolysis temperature and time, the yield of pyrolytic oil and $r C B$ as well as the volatile content of the latter can be reduced by increasing both process parameters. At higher temperatures with longer residence times, a similar level of organic impurities in rCBs is achieved as in commercial carbon black N660. The quantity of ash in $\mathrm{rCB}$ remains unaffected by these parameters. Removal of volatiles from $\mathrm{rCB}$ at higher temperatures shows a positive effect on surface chemistry and nano-roughness by revealing a cleaner carbon black surface. However, even at the highest pyrolysis temperature, the nano-roughness of rCB is lower than for N660. Besides, volatiles removal exposes more of the polar surface of silica, which is also 
present in the rCB ash, leading to higher specific interactions compared to N660. Moreover, a higher pyrolysis temperature improves the $\mathrm{rCB}$ surface area, aggregate structure and tint strength. At the highest pyrolysis temperature of $700^{\circ} \mathrm{C}, \mathrm{rCB}$ exhibits a higher surface area, similar tint strength, but lower structure than N660. Spectral analysis reveals the nature of the ash components: zinc and sulfur are present in the form zinc sulfide and sulfur complexes which are formed during vulcanization of the rubber and during the pyrolysis process itself. 
CHAPTER 4.1

\section{INFLUENCE OF PYROLYSIS TEMPERATURE AND RESIDENCE TIME ON THE YIELD AND QUALITY OF RECOVERED CARBON BLACK}

\subsubsection{Introduction}

Carbon black is the most widely used reinforcing filler in the rubber industry, produced by high temperature cracking of certain petroleum fractions ${ }^{1}$. Almost two thirds of the global carbon black production ends-up in tires, and every year, 4.5 million tons of carbon black is discarded as component of scrap tires ${ }^{2}$. Recovery of carbon black ( $\mathrm{rCB}$ ) from tire pyrolysis is a response on environmental concerns concerning scrap tires, and may help to reduce $\mathrm{CO}_{2}$ generation from carbon black manufacture using fossil fuels.

Carbon black is an essential component of tires, and its reinforcing capability depends mainly on particle size, specific surface area, aggregate structure and surface activity. These properties affect filler-filler and filler-polymer interactions, factors which define the reinforcement of the rubber by the filler ${ }^{3}$ : A higher specific surface area and branched aggregate structure ensures more intensive polymerfiller interactions leading to enhanced mechanical properties ${ }^{4-5}$. The physical surface activity of carbon black is based on the crystallographic defects present on the graphitic layer edges. These defects are energetic sites and play a key role in the improvement of mechanical properties by physically absorbing polymer chains ${ }^{6-8}$. The surface chemistry of carbon black is also of importance as it determines its acidity or basicity which mainly affects the vulcanization process, but to some extent also the chemical interaction between the filler and the polymer ${ }^{9-10}$.

Recovered carbon black ( $\mathrm{rCB}$ ) from scrap tire pyrolysis recently gained a lot of attention as a potential reinforcing filler containing $70 \%$ to $80 \%$ of carbon black originally added during tire manufacturing. In addition, it contains $20 \%$ to $30 \%$ of organic and inorganic remains of the pyrolysis ${ }^{11}$. The level of organics in rCBs depends on both, the feedstock and the pyrolysis process conditions, while the 
amount of carbon black recovered and the inorganics are mainly dependent on the type of feedstock ${ }^{12}$. For instance, rCBs from passenger car tires from the European market have a high inorganic (ash) content in comparison to truck tires as feedstock: passenger car tires contain a significant amount of silica, an alternative reinforcing filler used for low rolling resistance of tires and so higher fuel efficiency.

rCBs have been studied concerning their key reinforcing parameters, to include surface area and structure using previously defined carbon black ASTM standards. In these studies, the surface area of rCBs was determined to be in the range of $60 \mathrm{~m}^{2} / \mathrm{g}$ to $95 \mathrm{~m}^{2} / \mathrm{g}$ with a structure value of around $80 \mathrm{~mL} / 100 \mathrm{~g}$, suggesting that rCBs show similar characteristics as highly reinforcing carbon blacks of the N300 series $^{13-15}$. However, the utilization of standards which are defined for virgin carbon blacks for measuring the $\mathrm{rCB}$ reinforcing potential can be misleading, as rCB contains a considerable portion of organics and inorganics.

Understanding the chemical and physical nature of the $\mathrm{rCB}$ surface reveals the application potential as a filler in rubber. The physico-chemical nature of the $\mathrm{rCB}$ surface was studied, and the results suggest that both, inorganic and organic impurities cover the active sites of carbon black, thereby reducing the surface activity $^{16}$. During pyrolysis, the formation of carbonaceous residue on the rCB surface by condensation of decomposed polymer fragments is also reported ${ }^{17}$. Although several studies explain the origin of organic and inorganic fractions in $\mathrm{rCB}$, the influence of the different components on the reinforcing ability of $\mathrm{rCB}$ is not well understood. Moreover, several types of processes are available for tire pyrolysis, in which the influence of the process parameters on the rCB reinforcing characteristics are different and hence needs to be studied whenever new processes are developed.

This present chapter focuses on the influence of the pyrolysis parameters on product yield, recovered carbon black quality and composition. The quality of recovered carbon black is quantified in terms of the amount of volatiles using standard quality indicators. The physico-chemical nature of the rCBs in terms of morphology, surface area, structure, physical and chemical surface activity will be covered in Chapter 4.2.

\subsubsection{Experimental}

\subsubsection{Pyrolysis process description}

An entrained-flow reactor is used to study the effects of the process parameters of the flash recovery process on the quality of the produced solid: recovered carbon 
black. Figure 4.1.1 shows a schematic view of the reactor setup; its working principle is as follows:

A twin-screw feeding system feeds the rubber particles at a controlled rate of $1 \mathrm{~kg} / \mathrm{hr}$ into the reactor. The reactor is a stainless steel grade 316 cylindrical tube with a length of $4200 \mathrm{~mm}$ and an internal diameter of $50 \mathrm{~mm}$. The reactor tube is divided into three heating zones, which are electrically heated by high temperature heating coils. The top zone is equipped with a $9 \mathrm{~m}$ heating coil having a power output of $2300 \mathrm{~W}$. The central and bottom zones are each equipped with a $12 \mathrm{~m}$ heating coil with a power output of $2870 \mathrm{~W}$. The temperature of each heating zone can be separately controlled by a K-type thermocouple mounted in the middle of the heating zone at the center point of the tube. The temperature can thus be accurately controlled, thereby reducing temperature fluctuations along the tube length in time. Several other K-type thermocouples are installed along the length of the reactor to monitor the temperature profile inside the reactor. The feed particles are entrained by the nitrogen carrier gas flowing at a rate of 26 liters per minute through the reactor during which the tire particles are pyrolyzed to form recovered carbon black (rCB), volatiles and gaseous components.

At the bottom of the reactor, the solid rCB product gets collected in the char pot. Fine rCB particles can escape the char pot being carried by the gas along with the volatiles. These fine particles are separated from the gas flow using two cyclonic separators and trapped in the char pots placed at their bottom. The cyclonic separation system is placed inside an oven maintained at a temperature of $400^{\circ} \mathrm{C}$ to prevent condensation of the pyrolytic volatiles.

The volatiles leaving the cyclonic separation system together with the carrier gas enter the quenching system where they are rapidly cooled. Condensation of the volatiles takes place in two stages. First the hot gases pass through a cyclonic cooler, entering tangentially to create a swirling motion along the cold wall, in which the heavy oil/tar is condensed and collected at the bottom. The gases leaving the cyclonic cooler pass through a $1 \mathrm{~m}$ long jacketed cooling tube, in which the remaining condensable gases are collected as oil and enter a rotational particle separator (RPS), where oil and any aerosol particles present in the gas are separated.

The non-condensable gases pass through a flowmeter to measure the flowrate. Then the concentrations of different components in the gas are measured using gas analyzers before the gases leave to the exhaust. 


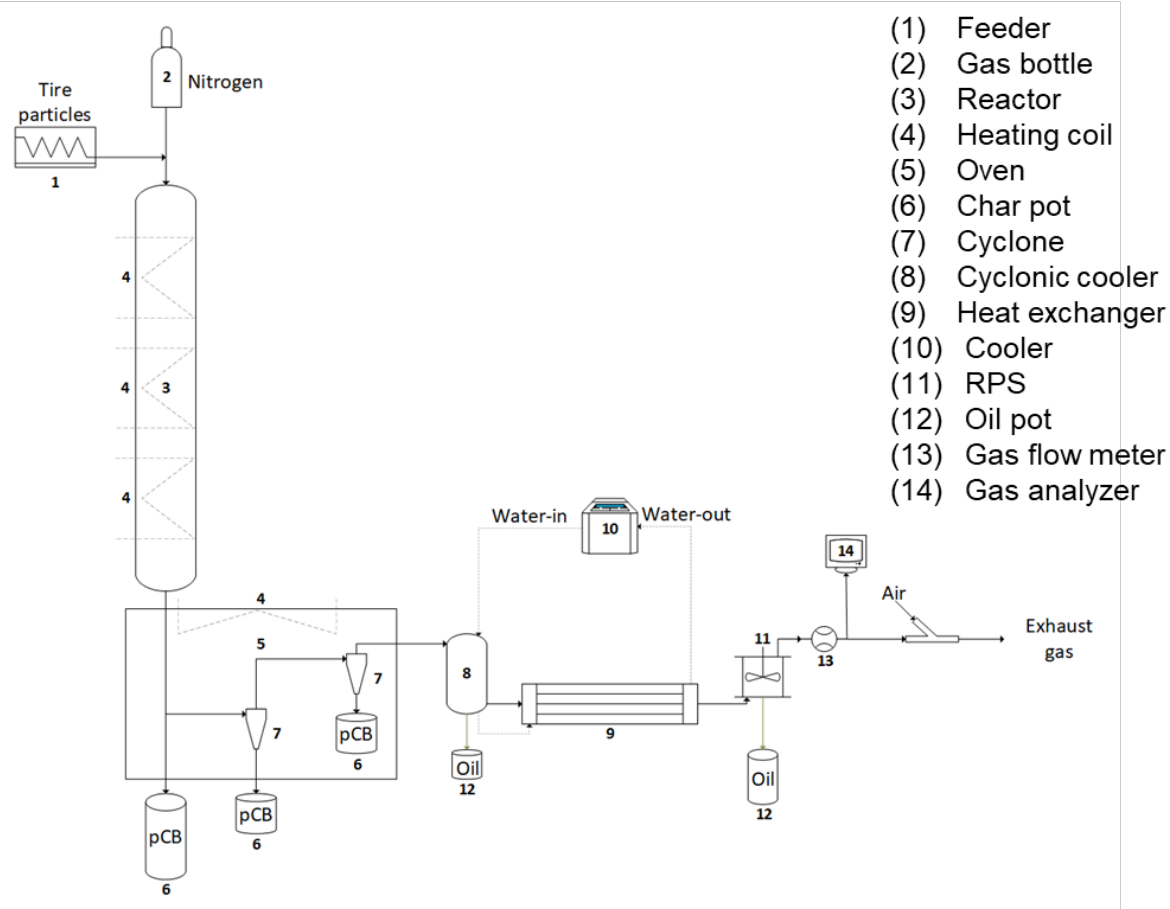

Figure 4.1.1 Entrained flow reactor experimental setup. (Courtesy: B. Ramani)

\subsubsection{Materials and methods}

Feed material: Granulated passenger car tires supplied by Granuband Recycling B.V, Amsterdam, the Netherlands, were utilized as feedstock. The material was received in granulated form, which was pre-separated from other tire components such as steel and fibers. The particle size distribution ranged from $100 \mu \mathrm{m}$ to $800 \mu \mathrm{m}$ with 90 wt.\% of the particles smaller than $500 \mu \mathrm{m}$ as shown in Figure 4.1.2. 


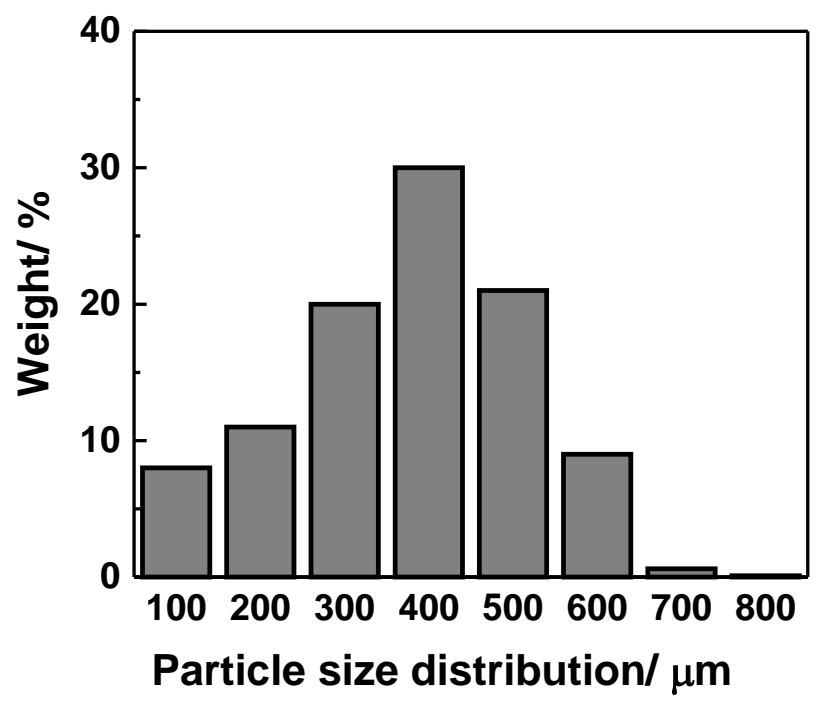

Figure 4.1.2 Particle size distribution of the feedstock.

The feed material was pyrolyzed in the entrained flow reactor, and the pyrolytic products including gas, oil and recovered carbon black were collected. The recovered carbon black was analyzed and compared to the reference virgin carbon black, grade N660.

Reference carbon black: A semi-reinforcing commercial grade of N660 was used as reference (Corax, Orion Engineered Carbons, Frankfurt, Germany). This carbon black grade has a BET surface area in the range of $35 \mathrm{~m}^{2} / \mathrm{g}$ to $45 \mathrm{~m}^{2} / \mathrm{g}$. The surface area measured in terms of iodine adsorption number (IAN) is $36 \mathrm{mg} / \mathrm{g}$, while the aggregate structure value determined by the oil absorption number (OAN) is $91 \mathrm{ml} / 100 \mathrm{~g}$.

\subsection{Thermo-Gravimetrical Analysis}

Thermo-Gravimetrical Analysis (TGA) was performed using a TA Instrument Discovery TGA 550. For each sample, at least three measurements were performed and the mean values taken. The measurements were performed under a gas flow rate of $40 \mathrm{ml} / \mathrm{min}$ in a temperature range of $25^{\circ} \mathrm{C}$ to $1000^{\circ} \mathrm{C}$. The heating rate was set to $20^{\circ} \mathrm{C} / \mathrm{min}$. From $25^{\circ} \mathrm{C}$ till $650^{\circ} \mathrm{C}$, a nitrogen environment was used to measure the moisture content and the amount of volatiles removed from rCB. In Figure 4.1.3, 
different temperature ranges are highlighted for the various fractions. The weight loss around $100^{\circ} \mathrm{C}$ represents the moisture content, while the volatiles content is measured in the temperature range from $250^{\circ} \mathrm{C}$ till $500^{\circ} \mathrm{C}$. From $650^{\circ} \mathrm{C}$ onwards, air was introduced for carbon burn-off, and this weight loss was measured as fixed carbon. The remaining weight after fixed carbon burn-off was measured as ash content as shown in Figure 4.1.3.

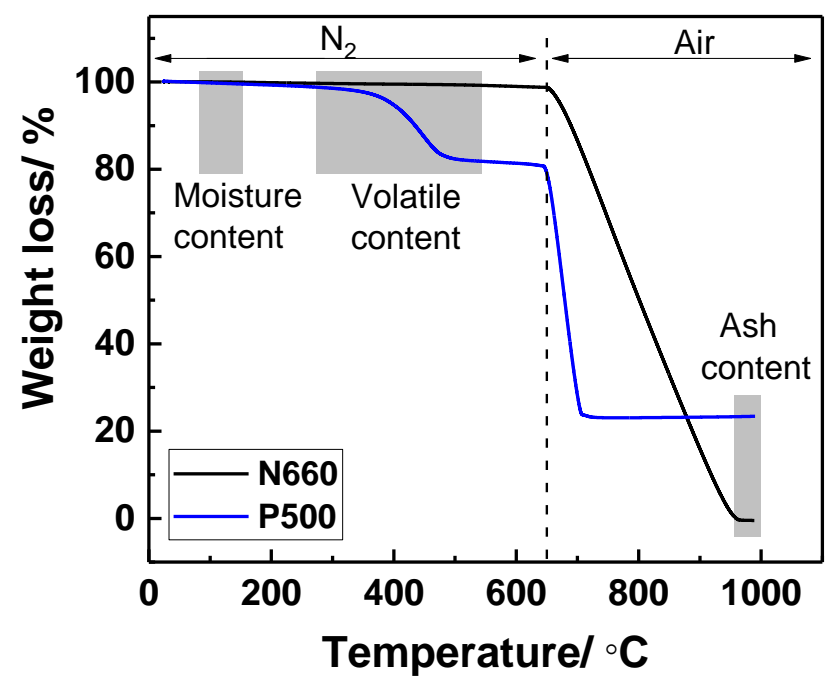

Figure 4.1.3 Volatile content and ash content of N660 and rCB P500 (pyrolyzed at $500^{\circ} \mathrm{C}$ ) measured from TGA analysis.

\subsection{Elemental analysis}

Elemental analysis was performed for measuring the carbon, hydrogen and nitrogen content in rCBs and N660 using a Thermo Scientific Flash 2000. For each sample, at least three measurements were performed and the mean values taken. The $\mathrm{rCB}$ ash content composition was analyzed using X-ray Fluorescence (XRF) using a Bruker S8 TIGER series 2. 
Chapter 4.1

\subsection{Toluene transmittance}

The degree of toluene discoloration by carbon black extractables was measured according to the ASTM standard D1618-99. Transmittance measurements were performed using a Cary 300 UV -Vis spectrophotometer from Agilent. 


\subsubsection{Results and discussion}

\subsubsection{Feed material}

The results of the thermo-gravimetric and elemental analysis from the TGA and elemental analyzer are summarized in Table 4.1.1. In the TGA analysis of the feed material, the volatile content represents all kinds of hydrocarbons including rubber, while fixed carbon is the carbon black added during tire manufacturing. The remaining ash content comprises inorganic components present in the tire rubber such as silica, sulfur and zinc species.

Table 4.1.1 TGA and elemental analysis of tire feed material and carbon black N660.

\begin{tabular}{|l|l|l|}
\hline Material properties & Tire (feedstock) & Carbon black N660 \\
\hline TGA analysis & $\mathbf{w t} . \%$ & wt.\% \\
Volasture & $<0.5$ & $<0.5$ \\
Fixed carbon & $65\left(72^{\star}\right)$ & $1\left(1^{\star}\right)$ \\
Ash & $26\left(28^{\star}\right)$ & $98\left(98^{\star}\right)$ \\
\hline Elemental analysis & 9 & $<1$ \\
C & wt.\% & wt.\% \\
H & 80 & 98.5 \\
N & 7 & 0.3 \\
Rest & 0.5 & 0.3 \\
\hline
\end{tabular}

*on ash free basis

The reference carbon black N660 is also analyzed to understand the amount of volatiles generally present in commercial carbon. Since tire feedstock contains rubber and other hydrocarbons, therefore the volatiles content is $72 \%$ (on ash-free basis), and in order to recover $\mathrm{rCB}$ with organic impurities similar to N660, volatiles should be reduced to $1 \%$ as seen in N660. Similarly, in the elemental analysis the 
hydrogen content is related to the volatiles present in the material and must be reduced from $7.3 \mathrm{wt} . \%$ to $0.3 \mathrm{wt} \%$.

\subsubsection{Influence of the pyrolysis temperature}

\subsection{Product yield}

The influence of the pyrolysis temperature on the yield of the pyrolytic products was studied in the temperature range from $500^{\circ} \mathrm{C}$ to $700^{\circ} \mathrm{C}$. In Figure 4.1.4, Both the rCB and the oil fractions decrease until $600^{\circ} \mathrm{C}$ with a corresponding increase in the gas fraction. The reduction of the solids fraction indicates a higher degree of conversion of volatiles into oil, which further cracks into lighter volatile matter, thereby increasing the corresponding gas yield. The latter is caused by thermal cracking of the pyrolysis oil vapors into lighter gases such as $C_{1}$ to $C_{4}$ hydrocarbons. Above $600^{\circ} \mathrm{C}$, the $\mathrm{rCB}$ fraction does not change significantly, while the oil fraction keeps reducing until $700^{\circ} \mathrm{C}$ with a corresponding increase in gas fraction.

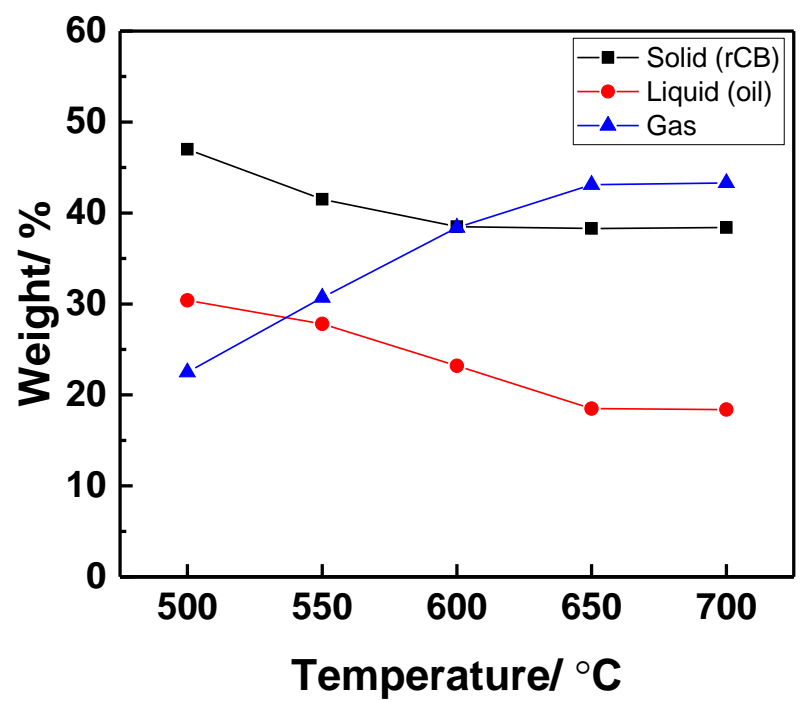

Figure 4.1.4 Product distribution at different pyrolysis temperatures. 


\subsection{Recovered carbon black composition}

The influence of the pyrolysis temperature on the volatiles and ash content of the recovered carbon black $(\mathrm{rCB})$ samples was determined using thermo-gravimetric analysis (TGA) as explained in Section 4.1.2.2.1. The volatile content of rCBs was measured in terms of \% weight loss and plotted as a function of pyrolysis temperature in Figure 4.1.5. Since rCBs also contain non-volatile matter (ash), the volatiles content is calculated on the ash-free basis for better comparison with virgin carbon black. A decreasing trend with increasing pyrolysis process temperature is noticed, which indicates a positive impact of higher process temperatures on reducing the volatile content. However, in case of the reference carbon black N660, the presence of volatiles is significantly lower: around $1 \%$.

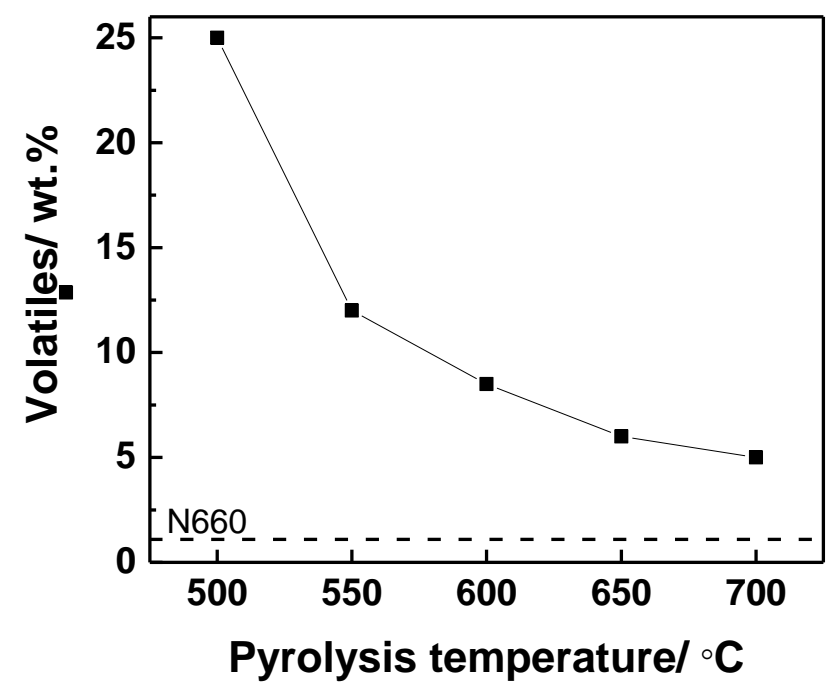

Figure 4.1.5 Volatiles in rCBs (ash free basis) and N660 (dashed line) from TGA analysis.

The amounts of volatiles and ash are summarized in Table 4.1.2. A major decrease in rCBs volatiles is achieved when the pyrolysis temperature is increased from $500^{\circ} \mathrm{C}$ to $600^{\circ} \mathrm{C}$; after that, the volatiles content still slightly decreases up to $700^{\circ} \mathrm{C}$, indicating that most of the volatiles removal is achieved at approximately $600^{\circ} \mathrm{C}$. 
Table 4.1.2 Amount of moisture, volatiles and ash content of rCBs from TGA analysis.

\begin{tabular}{|c|c|c|c|}
\hline $\begin{array}{c}\text { rCB pyrolysis } \\
\left.\text { temperature ( }{ }^{\circ} \mathbf{C}\right)\end{array}$ & Moisture (wt.\%) & Volatiles (wt.\%) & Ash (wt.\%) \\
\hline Ref - N660 & $<0,5$ & $\mathbf{1}$ & - \\
\hline 500 & $<0,5$ & 25 & 18 \\
\hline 550 & $<0,5$ & 13 & 21 \\
\hline 600 & $<0,5$ & 9 & 23 \\
\hline 650 & $<0,5$ & 8 & 23 \\
\hline 700 & $<0,5$ & 5 & 23 \\
\hline
\end{tabular}

Toluene transmittance is commonly used in the carbon black industry as a measure of organic impurities which are extractable by toluene. In Figure 4.1.6, the transmittance of toluene is mainly improved up to $600^{\circ} \mathrm{C}$, with only a slight further improvement till $700^{\circ} \mathrm{C}$. Such a trend of transmittance improvement is in-line with the TGA analysis, in which volatiles are also significantly reduced up to $600^{\circ} \mathrm{C}$. However, even at $700^{\circ} \mathrm{C}$, the transmittance of $\mathrm{rCB}$ is $50 \%$ less than for the reference N660: After pyrolysis, a higher amount of residual volatiles in $\mathrm{rCB}$ dissolves in toluene, resulting in poor transmittance compared to N660. 


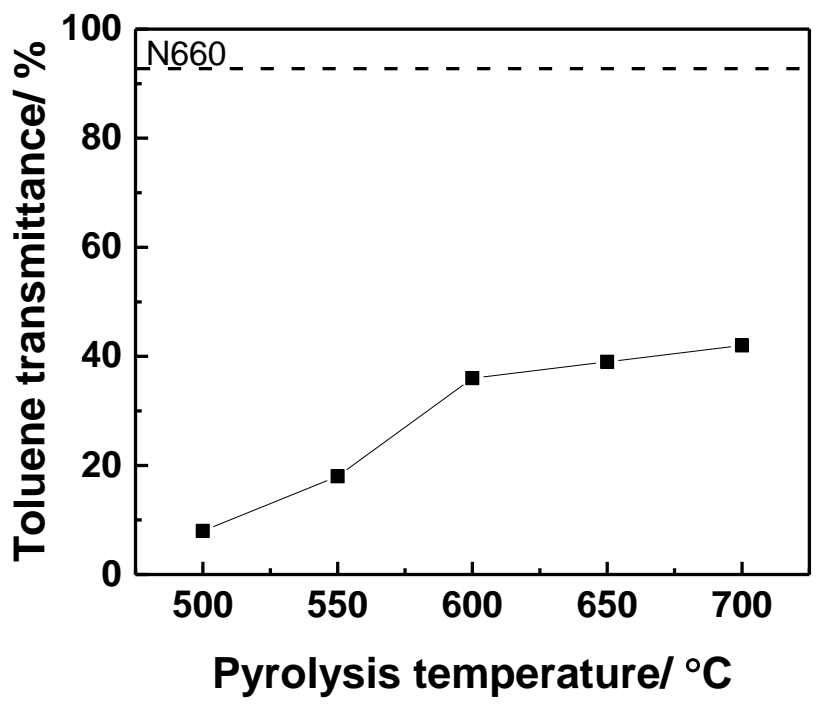

Figure 4.1.6 Toluene transmittance of reference N660 (dashed line) and of rCBs produced at different temperature.

The elemental analysis of rCBs is summarized in Table 4.1.3. Carbon and hydrogen contents mainly decrease with increasing pyrolysis temperature from $500^{\circ} \mathrm{C}$ to $600^{\circ} \mathrm{C}$. This trend is similar to the one seen previously in the weight loss and transmittance results. Since the volatiles in rCBs are hydrocarbon based, the decrease in hydrogen content is the key indicator of reduction of volatiles. The decrease in carbon and hydrogen resulted in corresponding increase of the remaining components: the ash content. 
Table 4.1.3 CHN Elemental analysis of rCBs and reference N660.

\begin{tabular}{|l|l|l|l|l|}
\hline $\begin{array}{l}\text { rCB pyrolysis } \\
\text { temperature } \\
\left({ }^{\circ} \mathbf{C}\right)\end{array}$ & $\mathbf{C ~ ( w t . \% )}$ & $\mathbf{H}(\mathbf{w t} . \%)$ & $\mathbf{N}(\mathbf{w t .} \%)$ & Rest (wt.\%) \\
\hline 500 & $\begin{array}{l}74,6 \\
\pm 1 \%\end{array}$ & $\begin{array}{l}2,5 \\
\pm 0.09 \%\end{array}$ & $\begin{array}{l}0,3 \\
\pm 0.03 \%\end{array}$ & 22,6 \\
\hline 550 & 73,8 & 1,3 & 0,3 & 24,5 \\
$\pm 1 \%$ & $\pm 0.09 \%$ & $\pm 0.03 \%$ & 0,3 \\
\hline 600 & 73,5 & 0,8 & $\pm 0.03 \%$ & 25,4 \\
\hline 650 & $\pm 1 \%$ & $\pm 0.1 \%$ & 0,2 & 26,4 \\
\hline 700 & 72,7 & 0,7 & $\pm 0.03 \%$ & \\
\hline N660 & $\pm 1 \%$ & $\pm 0.05 \%$ & 0,3 & 26,4 \\
\hline
\end{tabular}

The rCB ash content ('rest' in Table 4.1.3 / non-volatile content) was analyzed using $\mathrm{X}$-ray fluorescence (XRF) and is shown in Table 4.1.4. The ash mainly consists of silicon, oxygen, zinc, sulfur and calcium with traces of other metals and minerals. High quantities of silicon and oxygen are due to the presence of silica $\left(\mathrm{SiO}_{2}\right)$ used as reinforcing filler in passenger car tires. The presence of sulfur and zinc is due to their use as vulcanizing agent (sulfur) and activator ( $\mathrm{ZnO}$ ) during tire manufacturing, respectively. The ash quantity does not depending on the pyrolysis temperature, and the ratio of all ash constituents remains the same: The components of the ash are stable in this temperature range. The chemical nature of the carbon and ash components will be discussed in Chapter 4.2 along with further material characterization. 
Table 4.1.4 Elemental composition of ash content of $r$ CBs with respect to pyrolysis temperature.

\begin{tabular}{|c|c|c|c|c|c|c|c|c|c|c|}
\hline $\begin{array}{l}\text { Atomic wt. \% } \\
\text { pyrolysis } \\
\left.\text { temperature ( }{ }^{\circ} \mathbf{C}\right)\end{array}$ & $\mathrm{O}$ & $\mathrm{Si}$ & $\mathrm{Zn}$ & $\mathrm{S}$ & $\mathbf{C a}$ & $\mathrm{Na}$ & $\mathrm{Fe}$ & $\mathrm{K}$ & $\mathrm{Al}$ & $\mathrm{Mg}$ \\
\hline $\mathbf{5 0 0}$ & 43 & 18 & 18 & 9 & 4 & 3 & 2 & 1 & 1 & 1 \\
\hline $\mathbf{5 5 0}$ & 43 & 19 & 18 & 9 & 4 & 2 & 2 & 1 & 1 & 1 \\
\hline $\mathbf{6 0 0}$ & 44 & 19 & 17 & 8 & 5 & 2 & 2 & 1 & 1 & 1 \\
\hline $\mathbf{6 5 0}$ & 43 & 19 & 17 & 8 & 4 & 3 & 3 & 1 & 1 & 1 \\
\hline $\mathbf{7 0 0}$ & 43 & 19 & 17 & 8 & 5 & 2 & 3 & 1 & 1 & 1 \\
\hline
\end{tabular}

\subsubsection{Influence of residence time}

Since in the temperature study the amount of volatiles in rCB could not be reduced to the level of the reference carbon black, the effect of residence time was studied at three different temperatures: $500^{\circ} \mathrm{C}, 600^{\circ} \mathrm{C}$ and $700^{\circ} \mathrm{C}$. At each temperature, rCBs were produced applying four residence times. The residence time was varied by putting the material 1, 2, 3 and 4 times through the reactor. Pyrolysis at aforementioned temperatures with $1 \times$ residence time are similar process conditions previously discussed in temperature study. Sample notation of e.g. 5004x means pyrolysis at $500^{\circ} \mathrm{C}$ and 4 passes through the reactor. The residence time for each pass is around 6 seconds. 


\subsection{Products yields}
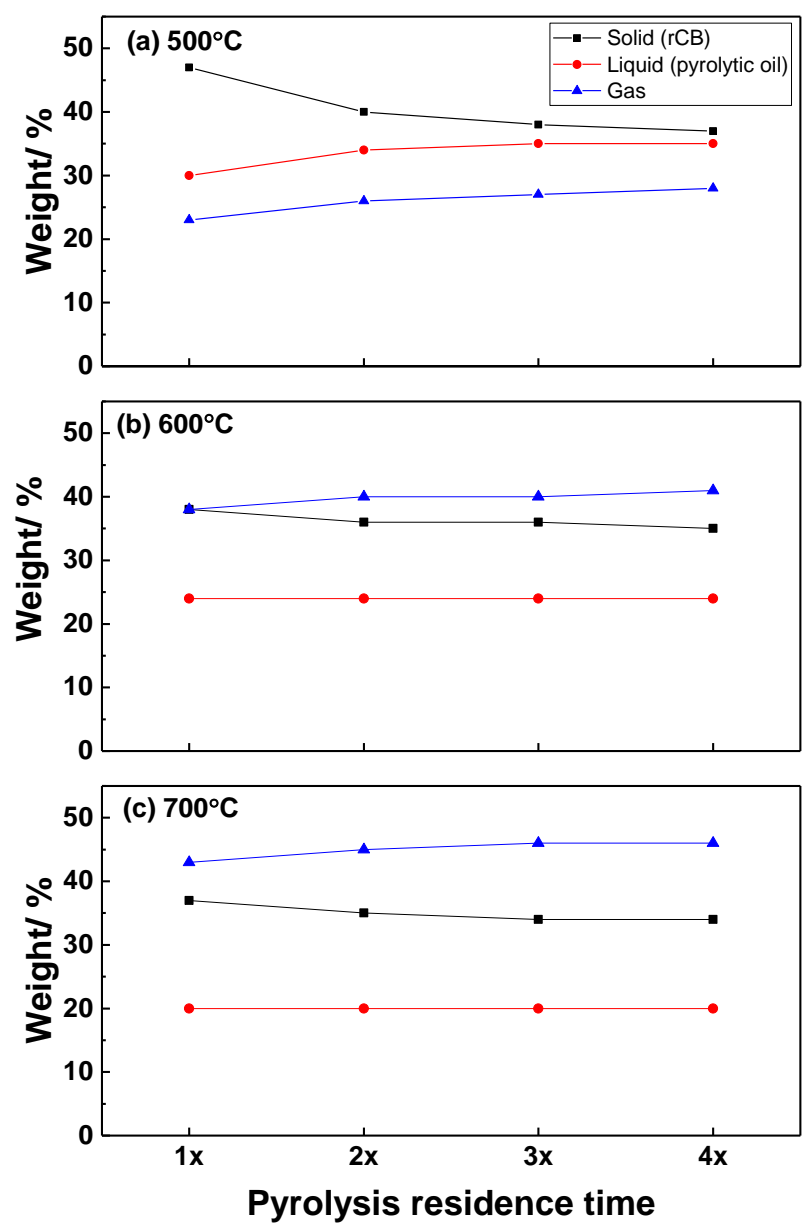

Figure 4.1.7 Product distributions at a pyrolysis temperature of (a) $500^{\circ} \mathrm{C}$ (b) $600^{\circ} \mathrm{C}$ and (c) $700^{\circ} \mathrm{C}$ with four residence times $(\ldots \mathrm{x}=$ no. of passes through the reactor).

The product yield was measured by weighing solid and liquid fractions, while the remaining was the gas fraction. In Figure 4.1.7(a) at $500^{\circ} \mathrm{C}$, the $\mathrm{rCB}$ yield is strongly reduced by doubling the residence time with a corresponding increase in oil and gas, 
suggesting a higher conversion of volatiles. However, a further increase in residence time results in only a slight reduction of the $\mathrm{rCB}$ content. In Figure 4.1.7(b) and (c), at temperatures of $600^{\circ} \mathrm{C}$ and $700^{\circ} \mathrm{C}$, the rCB yields at $1 \times$ residence time are already similar to that of $5004 x$, and is only slightly affected beyond doubled residence time indicating nearly complete conversion of feedstock into volatiles for two passes through the reactor. In addition, at higher temperatures and longer residence times, the corresponding increase is only seen in the gas content, while the oil content remains constant suggesting that the volatiles further removed from the rCB at longer residence times are mostly cracked into lighter fractions as gas.

\subsection{Recovered carbon black composition}

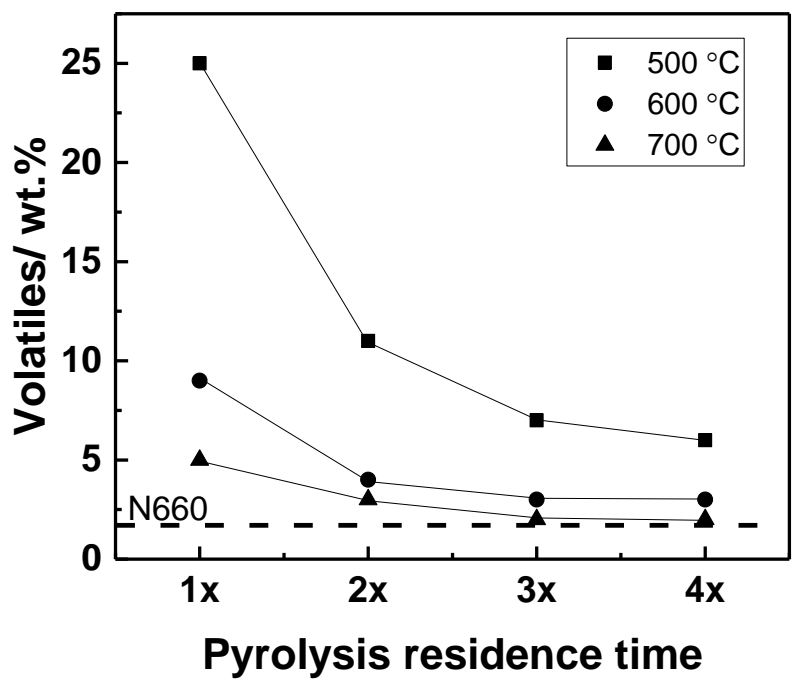

Figure 4.1.8 Amount of volatiles (ash-free basis) in N660 and rCBs produced at different temperatures and residence times.

In Figure 4.1.8, the volatiles content of $\mathrm{N660}$ and rCB from the TGA analysis is shown. At $500^{\circ} \mathrm{C}$, the amount of volatiles keeps decreasing with increasing residence time. But even at $4 x$, the remaining volatiles content is still higher than the one of the reference carbon black N660. At $600^{\circ} \mathrm{C}$, the conversion is further enhanced up to $3 x$ residence time, but no significant further decrease in volatiles 
content is achieved by increase of temperature. Only at $700^{\circ} \mathrm{C}$, the volatiles amount reaches the same level as the one of the virgin $\mathrm{N} 660$ at tripled residence time. In all three temperature series, little or no further reduction in volatiles is observed after tripling the residence time.

Toluene transmittance, the organic impurity indicator, also shows a trend in-line with the TGA volatiles analysis. In Figure 4.1 .9 , the $500^{\circ} \mathrm{C}$ series has the lowest transmittance, and at the longest residence time it reaches a similar level to the samples of the $600^{\circ} \mathrm{C}$ or $700^{\circ} \mathrm{C}$ series with minimum residence time. This is an expected finding, since a lower pyrolysis temperature has a slower feedstock-tovolatiles conversion rate. Besides, $\mathrm{rCBs}$ at $600^{\circ} \mathrm{C}$ and $700^{\circ} \mathrm{C}$ show a significant improvement in transmittance with doubled residence time, slightly further improved at tripled residence time reaching the value of N660.

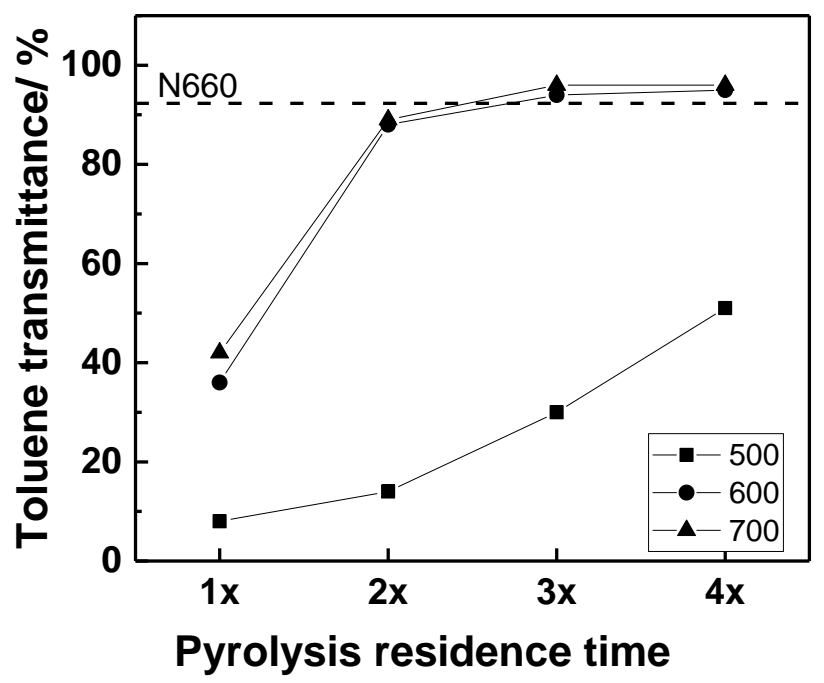

Figure 4.1.9 Toluene transmittance of $\mathrm{N660}$ (dashed line) and rCBs produced at different temperatures and residence times.

The elemental analysis is summarized in Table 4.1.5. Similar to previous findings, the hydrogen content decreases with increasing residence time, indicating removal of organics from rCBs. 
Table 4.1.5 CHN elemental composition of rCBs produced at different temperatures and residence times.

\begin{tabular}{|c|c|c|c|c|c|}
\hline $\begin{array}{c}\text { Temperaturel } \\
{ }^{\circ} \mathrm{C}\end{array}$ & $\begin{array}{c}\text { No. of } \\
\text { feedings }\end{array}$ & $\begin{array}{c}\text { C } \\
\text { (wt. \%) }\end{array}$ & $\begin{array}{c}\mathrm{H} \\
\text { (wt. \%) }\end{array}$ & $\begin{array}{c}\mathrm{N} \\
\text { (wt. \%) }\end{array}$ & $\begin{array}{l}\text { Rest } \\
\text { (wt. \%) }\end{array}$ \\
\hline \multirow{4}{*}{500} & $1 x$ & $75 \pm 1 \%$ & $2.5 \pm 0.1 \%$ & $0.3 \pm 0.05 \%$ & 23 \\
\hline & $2 x$ & $74 \pm 1 \%$ & $1.0 \pm 0.1 \%$ & $0.2 \pm 0.05 \%$ & 24 \\
\hline & $3 x$ & $74 \pm 1 \%$ & $0.7 \pm 0.1 \%$ & $0.2 \pm 0.05 \%$ & 25 \\
\hline & $4 x$ & $74 \pm 1 \%$ & $0.6 \pm 0.1 \%$ & $0.2 \pm 0.05 \%$ & 25 \\
\hline \multirow{4}{*}{600} & $1 x$ & $74 \pm 1 \%$ & $0.8 \pm 0.1 \%$ & $0.3 \pm 0.05 \%$ & 25 \\
\hline & $2 x$ & $74 \pm 1 \%$ & $0.4 \pm 0.1 \%$ & $0.2 \pm 0.05 \%$ & 26 \\
\hline & $3 x$ & $74 \pm 1 \%$ & $0.4 \pm 0.1 \%$ & $0.2 \pm 0.05 \%$ & 26 \\
\hline & $4 x$ & $74 \pm 1 \%$ & $0.4 \pm 0.1 \%$ & $0.3 \pm 0.05 \%$ & 26 \\
\hline \multirow{4}{*}{700} & $1 x$ & $73 \pm 1 \%$ & $0.6 \pm 0.1 \%$ & $0.3 \pm 0.05 \%$ & 26 \\
\hline & $2 x$ & $73 \pm 1 \%$ & $0.4 \pm 0.1 \%$ & $0.2 \pm 0.05 \%$ & 26 \\
\hline & $3 x$ & $73 \pm 1 \%$ & $0.3 \pm 0.1 \%$ & $0.2 \pm 0.05 \%$ & 27 \\
\hline & $4 x$ & $73 \pm 1 \%$ & $0.3 \pm 0.1 \%$ & $0.2 \pm 0.05 \%$ & 27 \\
\hline
\end{tabular}

Although toluene transmittance (Figure 4.1.9) and TGA analysis (Figure 4.1.8) indicate that $\mathrm{rCB}$ at $700^{\circ} \mathrm{C}$ with $3 \mathrm{x}$ residence time exhibits a slightly lower amount of volatiles than the reference N660, the hydrogen content in the elemental analysis is similar to the one of N660. In addition, the elemental concentrations in Table 4.1.5 are measured including ash content; if calculated on an ash free basis, the hydrogen fraction of the rCBs would increase by $0.1 \%$. The higher hydrogen content of rCBs compared to N660 can be explained by carbonaceous residue formation during 
pyrolysis: At higher temperatures and longer residence times, not only thermal cracking of the elastomer occurs, but at the same time dehydrogenation and cyclization of cracked elastomer segments. In Figure 4.1.20, the different steps of formation of organics (volatiles) and polyaromatics (non-volatiles) are depicted. Norris and Renegar reported that in the first step of a radical scission of elastomer chains, hydrocarbons such as olefins and paraffins are formed ${ }^{18}$. These hydrocarbons are organics or volatiles, as they can be removed at lower temperatures ranging from $250^{\circ} \mathrm{C}$ to $450^{\circ} \mathrm{C}$. At higher temperatures, a higher rate of thermal cracking can be expected leading to a higher rate of dehydrogenation and cyclization.

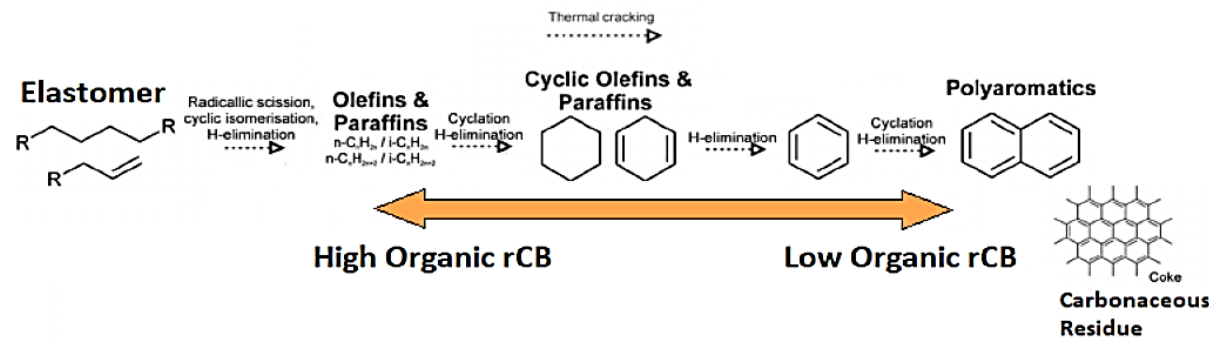

Figure 4.1.20 Formation of organics and polyaromatics during pyrolysis ${ }^{18}$.

At longer residence times, the dehydrogenation and cyclization rate will further increase, which will eventually lead to the formation of polyaromatics. These polyaromatics grow with time covering the $\mathrm{rCB}$ surface forming stable non-volatile graphite-like depositions called carbonaceous residue or coke. These compounds are not extractable by organic solvents.

\subsubsection{Conclusions}

Passenger car tires were pyrolyzed in an entrained flow reactor at different temperatures and residence times. These process parameters significantly influence the yield of the pyrolytic products and the quality of the recovered carbon black in terms of volatiles. Increasing process temperature lead to higher conversion rates and faster rubber conversion into heavy volatiles, which further disintegrate into lighter ones. This is evident from the reduction of solid and liquid yields with a corresponding increase in gas yields. The higher conversion rate showed a positive influence on the rCB quality by a lower amount of volatiles. However, only an 
increasing process temperature was not enough to reduce the volatiles present in $\mathrm{rCB}$ to the level of the reference carbon black. Longer residence times further decreased the solids yield by reducing the volatile content from rCB. At higher temperatures with longer residence times, toluene transmittance showed that the volatiles are almost completely removed from the $\mathrm{rCB}$, and that a product even cleaner than the commercial carbon black was achieved. However, after complete removal of volatiles, the $\mathrm{rCB}$ hydrogen content was still higher than for the commercial carbon black, indicating the formation of non-volatile carbonaceous residue on the rCB surface at higher temperatures and longer residence times.

\section{References}

[1] J. B. Donnet, R. C. Bansal, and M. J. Wang, Carbon Black: Science and Technology, 2nd ed., Marcel Dekker, New York (1993).

[2] S. Verheul, Recycl. Prod. News, 25, 4 (2017).

[3] M.J. Wang, Rubber Chem. Technol., 71, 520, (1998).

[4] S. Wolff and M.J. Wang, Carbon Black Reinforcement of Elastomers, In Carbon Black: Science and Technology, 2nd ed., Marcel Dekker, New York (1993).

[5] W.H. Hess, F. Lyon, and K.A. Burges, Kautsch. Gummi Kunstst., 20, 135 (1967).

[6] M.J. Wang, S. Wolff and J.B. Donnet, Rubber Chem. Technol., 64, 714, (1991).

[7] H. Balard, and E. Brendle, Kautsch. Gummi Kunstst., 55, 464 (2002).

[8] A. Schröder, M. Klüppel, R.H. Schuster and J. Heidberg, Carbon, 40, 207 (2002).

[9] M.L. Studebaker, Rubber Chem. Technol., 30, 1400 (1957).

[10] H. Boehm, Carbon, 32, 759 (1994).

[11] N. Probst, M. Löffler, and A. Lloyd, Kautsch. Gummi Kunstst., 65, 20 (2012).

[12] P.T. Williams, Waste Manage., 33, 1714 (2013).

[13] C. Roy, A. Chaala and H. Darmstadt, J. Anal. Appl. Pyrolysis, 51, 201 (1999).

[14] J.D. Martínez, N. Puy, R. Murillo, T. García, M.V. Navarro, and A.M. Mastral, Renew. Sust. Energ. Rev., 23, 179 (2013).

[15] C. Norris, M. Hale and M. Bennett, Plast. Rubber Compos., 43, 245 (2014). 
[16] J. Zhou, T. Yu, S. Wu, Z. Xie, and Y. Yang, Ind. Eng. Chem. Res., 49, 245 (2010).

[17] H. Darmstadt, C. Roy and S. Kaliaguine, Carbon, 33, 1449 (1995).

[18] C. Norris and S. Renegar, Presented at International Rubber Conference (IRC), London, (2019). 
Chapter 4.1 
CHAPTER 4.2

\section{INFLUENCE OF PYROLYSIS TEMPERATURE ON THE CHARACTERISTICS OF RECOVERED CARBON BLACK}

\subsubsection{Introduction}

The aim of this part of the study is to understand the influence of the pyrolysis temperature on the characteristics of the recovered carbon black, and the differences to virgin carbon black. It was expected that the pyrolysis temperature would have the largest effect on the $\mathrm{rCB}$ characteristics; therefore this part was mainly focused on rCBs from the temperature study using minimum residence time. In this investigation, the recovered carbon blacks produced at varying pyrolysis temperatures as described in Chapter 4.1 are extensively characterized in terms of morphology, surface area, structure, physical and chemical surface activity. The inorganic components and their contribution to the properties are also discussed. The surface activity is quantitatively determined by measuring the polar and dispersive surface energies. Further, surface heterogeneities are examined by analyzing the size exclusion effect using the morphological index ${ }^{1}$.

\subsubsection{Experimental}

\subsubsection{Materials and methods}

Reference carbon black: A semi-reinforcing commercial grade of N660 was used as reference (Corax, Orion Engineered Carbons, Frankfurt, Germany). This carbon black grade exhibits a BET surface area in the range of $35 \mathrm{~m}^{2} / \mathrm{g}$ to $45 \mathrm{~m}^{2} / \mathrm{g}$, and the surface area measured as iodine adsorption number (IAN) is $36 \mathrm{mg} / \mathrm{g}$. The aggregate structure value determined by the oil absorption number (OAN) is $91 \mathrm{ml} / 100 \mathrm{~g}$.

Recovered carbon blacks: The recovered carbon blacks (rCB) used in this study were produced by ultra-fast pyrolysis. The feedstock was whole passenger car tires 
delivered by Granuband, Amsterdam, the Netherlands. Feedstock specifications and pCB specifications including volatile and ash contents were defined in Chapter 4.1.

Process conditions: Passenger car tires were pyrolyzed in an entrained flow reactor as explained in Chapter 4.1. In the current chapter, the influence of the process temperature on the characteristics of the recovered carbon black are discussed. The notations of the different rCBs from passenger car tires produced at different process temperatures are listed in Table 4.2.1.

Table 4.2.1 Notations for the recovered carbon blacks produced at different pyrolysis temperatures.

\begin{tabular}{|c|c|}
\hline $\begin{array}{c}\text { Recovered carbon } \\
\text { black }\end{array}$ & $\begin{array}{c}\text { Pyrolysis process } \\
\text { temperature }\left({ }^{\circ} \mathbf{C}\right)\end{array}$ \\
\hline P500 & 500 \\
\hline P550 & 550 \\
\hline P600 & 600 \\
\hline P650 & 650 \\
\hline P700 & 700 \\
\hline
\end{tabular}

\subsubsection{Morphology and elemental mapping by Transmission Electron Microscopy (TEM)}

Transmission Electron Microscopy (TEM) was used to visualize the morphology of the reference carbon black N660 and the recovered carbon blacks including particle size and structure. A Philips CM300ST-FEG Transmission Electron Microscope $300 \mathrm{kV}$ was utilized for both, TEM and energy-filtered TEM (EFTEM).

For the analysis, $\sim 1 \mathrm{mg}$ of a sample was dispersed in $10 \mathrm{ml}$ ethanol using an ultrasonic bath. One droplet of the dispersion was placed on a Holey carbon film and dried. These carbon films are used to avoid displacement of the sample while the electron beam is focused. TEM images were obtained by focusing the electron gun on each sample for about 1 hour during which no apparent changes in sample morphology or microstructure were observed. 


\subsubsection{Surface area by lodine Adsorption Number (IAN)}

Surface area was measured by Continental AG (Hannover, Germany) using the lodine Adsorption Number test according to ASTM D1510.

\subsubsection{Structure by Oil Absorption Number (OAN) and Void Volume (VV) measurements}

The structure was characterized by the Oil Absorption Number (OAN) according to ASTM standard D2414. The Void Volume (VV) was measured according to ASTM D7854-18c. A Void Volume profile is obtained by compressing the filler sample with increasing pressure, and the values for each sample taken at $50 \mathrm{MPa}, 75 \mathrm{MPa}$ and $100 \mathrm{MPa}$. Since the trends observed at different pressures were similar, only the measurements at $75 \mathrm{MPa}$ were chosen as representative values and discussed in the results section. Both measurements were performed by Continental AG (Hannover, Germany).

\subsubsection{Tint strength}

Tint strength was performed by Continental AG (Hannover, Germany) according to ASTM standard D 3265.

\subsubsection{Aggregate size distribution}

Aggregate size distribution was measured as well by Continental AG (Hannover, Germany) using a Disc Centrifuge Photosedimentometer according to ISO 15825. The measured aggregate sizes of all rCBs were in the range of $97 \mathrm{~nm}$ to $170 \mathrm{~nm}$. The mean aggregate size was used to analyze the differences among the different rCBs.

\subsubsection{Surface functionality by X-ray Photoelectron Spectroscopy (XPS)}

Photoelectron spectra were obtained using a Quantera SXM (Scanning XPS Microprobe) from Physical Electronics.

The spectrophotometer was operated under a vacuum of $3^{\star} 10^{-8}$ Torr. A monochromatic Al Ka $(50 \mathrm{~W}, 1486 \mathrm{eV})$ anode was used as primary excitation source at an angle of $45^{\circ}$ relative to the sample surface. Survey scans were recorded in the 
range from $0 \mathrm{eV}$ to $1200 \mathrm{eV}$ to see the gross overall atomic content of the surface layer. The measured intensities were in the range of 600 counts/s to 12000 counts/s.

$$
C x=\frac{I x}{S x} / \sum_{i}^{n} \frac{I i}{S i}
$$

The atomic concentrations were calculated according to Equation 4.2.1, in which li is the peak area of a photoelectron peak of an element present in the compound, $\mathrm{Si}$ is the relative sensitivity factor of the peak and $\Sigma$ is the sum over all elements. Cx is the atomic fraction of element $x, I x$ is the peak area of element $x$, while $S x$ is the atomic sensitivity parameter and $\Sigma$ is the sum of all elements.

In all cases, Gauss-Lorentz functions were used to fit the XPS spectra. C1s spectra of graphitic material show an asymmetric tailing at higher binding energies. These spectra were fitted with one graphitic peak, and the asymmetric tail of the signal was fitted with the oxygen containing group peaks.

For N660, O1s spectra were fitted with 2 peaks, while rCB O1s was sufficiently fitted with one peak. The spectra of other rCBs components including zinc, silicon and sulfur were also analyzed. Zn2p3 spectra were fitted with one peak, while Si2p and S2p spectra were fitted with 2 peaks.

Elemental spectra of the recovered carbon black sample P650 with peak fittings of all non-carbon components are shown as representative graphs in Figure 4.2.1. These spectra as well as the carbon spectra along with their fittings will be discussed in the results section. 

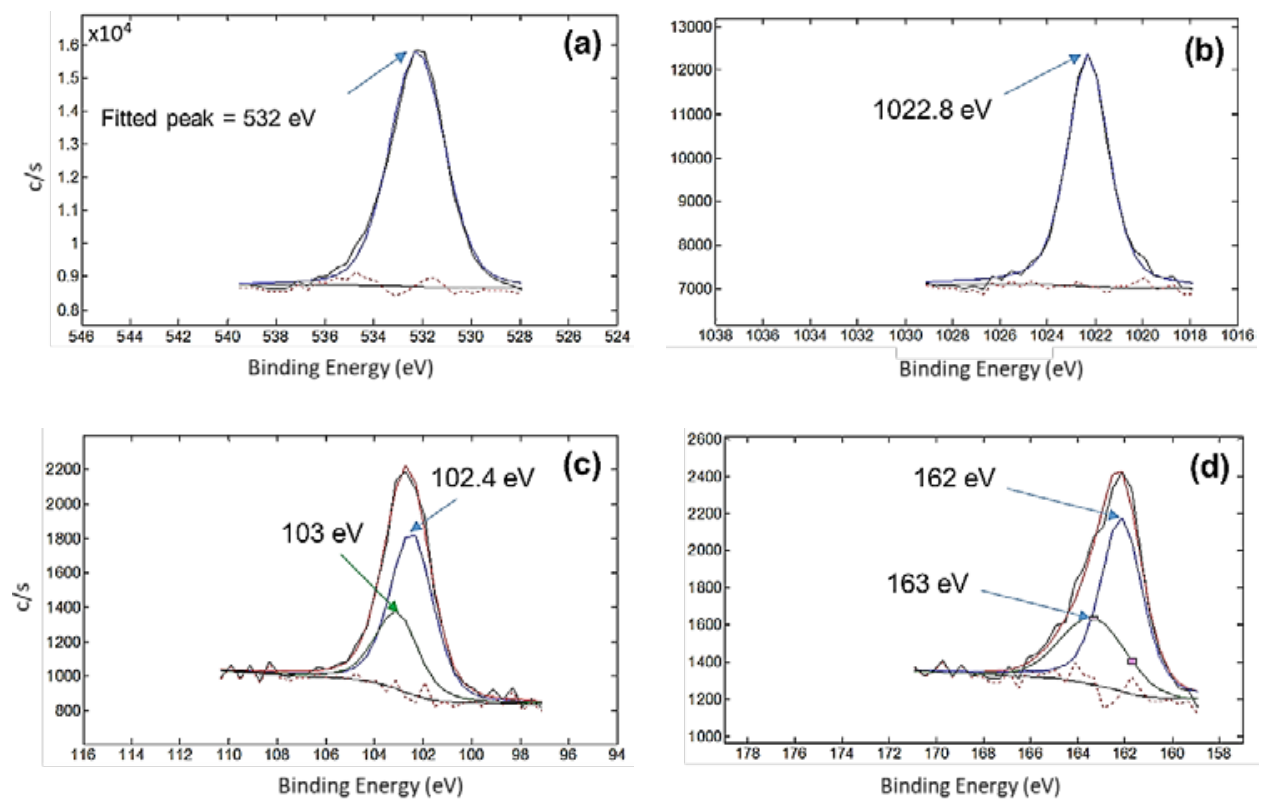

Figure 4.2.1 Fitted spectra of rCB P650 for (a) oxygen, (b) zinc, (c) silicon and (d) sulfur.

\subsubsection{Surface activity by Inverse Gas Chromatography (IGC)}

Reference $\mathrm{N} 660$ and $\mathrm{rCB}$ samples were ground in a ball mill for 10 minutes at $250 \mathrm{rpm}$. The ground samples were sieved and the particles between $100 \mu \mathrm{m}$ and $400 \mu \mathrm{m}$ size were used. A stainless steel column with a length of $100 \mathrm{~mm}$, an external diameter of $3.175 \mathrm{~mm}$ and an internal diameter of $2 \mathrm{~mm}$ were filled with the ground samples under mechanical vibration. The amounts of the samples filled into the columns are given in Table 4.2.2. The higher quantity of P500 in the IGC column is due to its higher density, since it still contains a high amount of volatiles or unconverted rubber. After filling, the columns were placed in the chromatograph for conditioning at $170^{\circ} \mathrm{C}$ for 16 hours with a helium flow of $5 \mathrm{~mL} / \mathrm{min}$ for stabilization of the surface. 

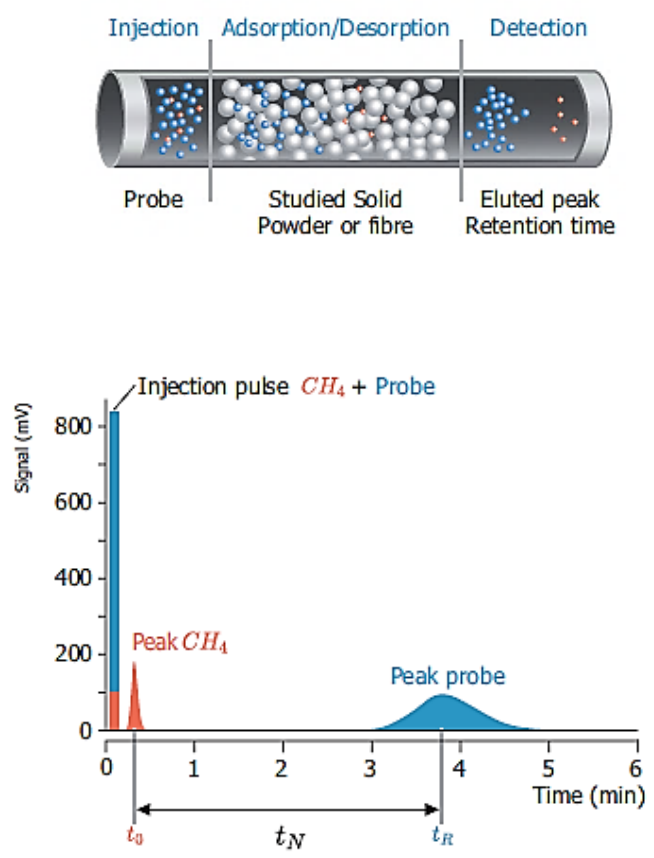

Figure 4.2.2 Measurement of retention time $\left(\mathrm{t}_{\mathrm{N}}\right)$ for a molecular probe in IGC 2 .

Table 4.2.2 Weight of the analyzed samples in the chromatography column

\begin{tabular}{|c|c|}
\hline Samples & Weight (g) \\
\hline N660 & 0.1630 \\
\hline P500 & 0.2176 \\
\hline P600 & 0.1691 \\
\hline P700 & 0.1720 \\
\hline
\end{tabular}

IGC measurements were performed at infinite dilutions using a PerkinElmer Clarus 580 with double flame ionization detector. Measurements were performed at $150^{\circ} \mathrm{C}$ with helium as carrier gas at a flowrate of $5 \mathrm{~mL} / \mathrm{min}$. The software used for analysis was Solid 3.2.1 by Adscientis. At least three injections were made for each probe 
and the retention times $\left(\mathrm{t}_{\mathrm{N}}\right)$ were computed from the GC peaks as shown in Figure 4.2.2. Using $t_{N}$ and carrier gas (helium) flow rate $\left(D_{c}\right)$, the net retention volume $\left(V_{N}\right)$ was calculated using Equation 4.2.2:

$$
V_{N}=D_{c} \cdot t_{N}
$$

The free energy of adsorption $\left(\Delta G_{a}\right)$ was then calculated using De Boer's Equation?

$$
\Delta G_{a}=-R T \cdot \ln \left(V_{N}\right)
$$

Where $\mathrm{R}$ is the gas constant $\left(8.3145 \mathrm{~J} \cdot \mathrm{mol}^{-1} \cdot \mathrm{K}^{-1}\right)$ and $\mathrm{T}$ is the column temperature.

From the IGC measurements, the dispersive component of the surface energy $\left(\gamma_{s}{ }^{d}\right)$ was determined using the Dorris and Gray approach ${ }^{4}$. A set of linear alkanes was injected into the sample column, and the resultant $\Delta G_{a}$ values were plotted against the topological index $X_{t}$, which in case of linear alkanes is the number of carbon atoms. There from linear "alkane line" is obtained, of which the slope corresponds to the increment of free energy per methylene group $\left(\Delta \mathrm{G}_{\mathrm{a}}{ }^{\mathrm{CH}}{ }^{2}\right)$ as shown in Figure $4.2 .3^{5}$.

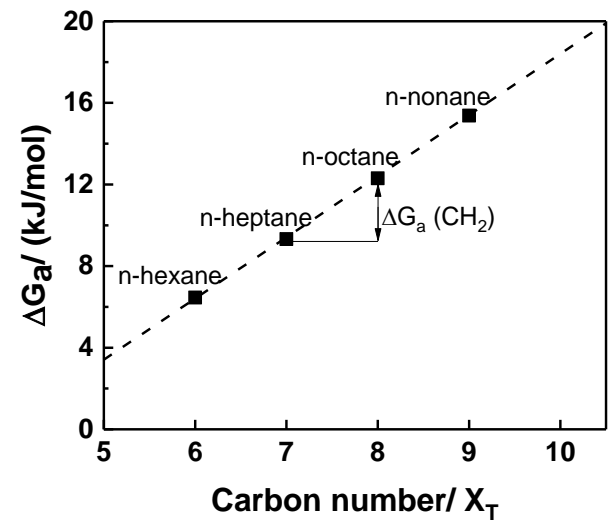

Figure 4.2.3 Determination method of $\Delta \mathrm{G}_{\mathrm{a}}{ }^{\mathrm{CH}}$ for $\mathrm{n}$-alkane adsorption. 
The dispersive component $\left(\mathrm{Y}_{\mathrm{s}}^{\mathrm{d}}\right)$ of the total surface energy is then calculated using Equation 4.2.4:

$$
\gamma_{s}^{d}=\frac{\left(\Delta G_{a}^{C H_{2}}\right)^{2}}{4 N^{2} a_{C H_{2}}^{2} \gamma_{C_{2}}}
$$

Where $\mathrm{N}$ is Avogadro's number $\left(6.02214^{*} 10^{23} \mathrm{~mol}^{-1}\right)$, acH2 is the area covered by one methylene group $\left(0.06 \mathrm{~nm}^{2}\right)$, and $\mathrm{YCH}_{2}$ is the surface energy of the pure methylene group surface ${ }^{4}$.

Several polar probes responsible for different types of specific interactions were injected and the free energy of adsorption $\left(\Delta G_{a}\right)$ for each probe was determined. The topology index $\left(\mathrm{X}_{\mathrm{t}}\right)$ of polar probes is based on the Wiener index, which is related to the molecular shape and polarizability of the probes ${ }^{6} . \Delta G_{a}$ as a function of $X_{t}$ is then plotted together with the previously obtained alkane line into the same graph, and the distance between $\Delta G_{a}$ of the polar probe and the corresponding point on the alkane line is taken as specific interaction parameter (IsP) as shown in Figure 4.2.4: ISP is defined by the difference of the free energy of adsorption of a polar probe $\left(\Delta G_{a}\right)$ and the $\mathrm{n}$-alkane reference line as given in Equation 4.2.57:

$$
I_{S P}=\Delta G_{a}^{S P}-\Delta G_{a}^{d}
$$

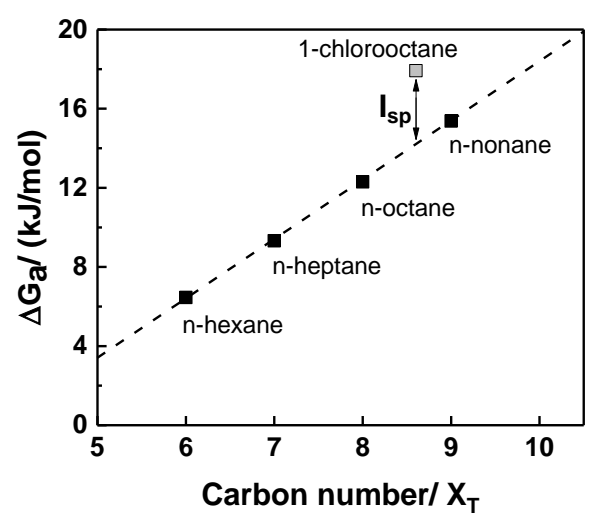

Figure 4.2.4 Determination of the specific interaction parameter Isp. 
To determine the global surface polarity, the summation of specific interaction parameters of all probes $\left(\Sigma I_{S P}\right)$ is used. The nano roughness of the carbon blacks was measured by utilizing the $\mathrm{E}$. Brindlé and $\mathrm{E}$. Papirer ${ }^{1}$ approach using branched isooctane and cyclooctane probes. The topological index $X_{t}$ of branched and cyclic alkanes was also based on the Wiener index as for the polar probes. The use of branched and cyclic alkanes enables the analysis of the size exclusion effect or nano roughness. The $\Delta G_{a}$ of these alkanes will be plotted in a similar way as for the polar probes to determine the size exclusion effect.

If the measured retention time or corresponding $\Delta G_{a}$ is similar to the calculated value from the alkane line, it can be concluded that the surface is planar and the accessibility for linear as well as branched or cyclic alkanes is the same. If the measured value is lower or higher than the calculated one, it indicates a size exclusion or dissolution effect, respectively. The former effect originates from the surface nano roughness, which limits the access of branched and/or cyclic alkanes compared the linear alkanes. The dissolution effect originates from the IGC probes dissolved on the surface. This effect is noticed when the surfaces are polluted with organics or coated with polymers which interact with cyclic probes, thereby resulting in higher retention times ${ }^{8}$.

For an easier calculation of the surface nano roughness, an Index of Morphology (IM) was defined. This index is a description of the significance of the size exclusion effects or of the dissolution effects. The morphology index IM is given by the ratio of the retention time of the branched/cyclic alkane molecule $\left(t_{N}\right)$ and the retention time of the same linear $n$-alkane equivalent $\left(t_{N}\right.$ ref), see Eq. 4.2.6. $V_{N}$ and $V_{N}{ }^{\text {ref }}$ are the corresponding retention volumes calculated using Equation 4.2.2 from their respective retention times.

$$
I M=\frac{t_{N}}{t_{N}^{r e f}} * 100=\frac{V_{N}}{V_{N}^{r e f}} * 100 *
$$

An IM value of 100 for branched or cyclic alkanes corresponds to zero size exclusion effect i.e. absence of nano roughness. If the IM is below 100 , a lower value indicates a stronger size exclusion effect. For cyclic probes, IM values can have values above 100 , which indicates dissolution effects. This is due to the ability of cyclic probes to penetrate in the organic soft domains of the material, which also indicates that the surface is polluted with amorphous organic substances. 


\subsubsection{Results and discussion}

\subsubsection{Microstructure and morphology of recovered carbon black}

TEM images are taken to visualize the differences between the virgin carbon black (N660) and the rCB. The differences within the rCBs produced at different temperatures are shown in Figure 4.2.5. Three recovered carbon blacks produced at $500^{\circ} \mathrm{C}, 600^{\circ} \mathrm{C}$ and $700^{\circ} \mathrm{C}$ were selected for TEM characterization. P500, P600, and $\mathrm{P} 700$ was selected as an indicator for the $\mathrm{CCB}$ quality produced at the lowest medium and highest process temperatures, respectively
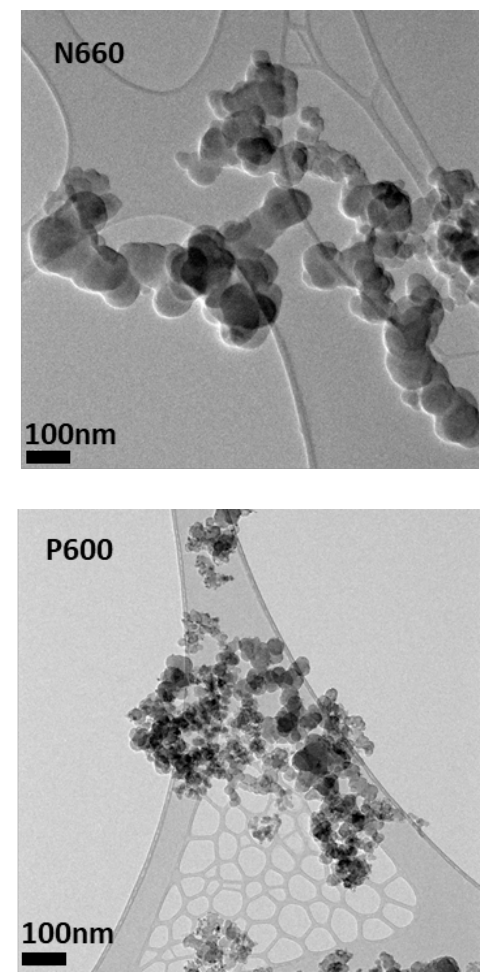
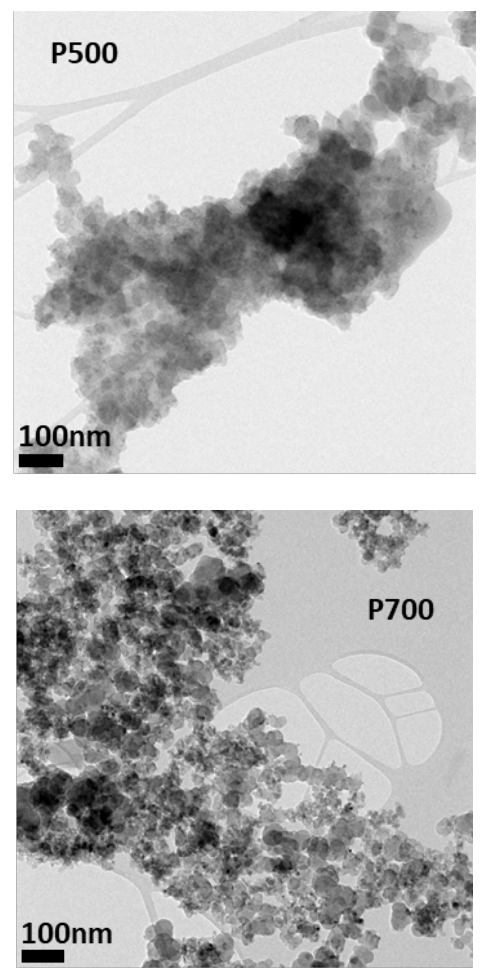

Figure 4.2.5 TEM images of carbon black N660 and recovered carbon blacks P500, P600 and P700. 
In Figure 4.2.5, N660 shows a uniform primary particle size in the range of $55 \mathrm{~nm}$ to $65 \mathrm{~nm}$. The different grades of rCBs possess a broader range of particle sizes as mainly visible in P600 and P700. Different particle sizes in rCBs are due to the fact that they are recovered from used tires, in which various grades of carbon black with particle sizes ranging from $20 \mathrm{~nm}$ to $60 \mathrm{~nm}$, and silica with particle size from $7 \mathrm{~nm}$ to $15 \mathrm{~nm}$, were originally added. In P500, a higher amount of deposited or remaining impurities is visible, while $\mathrm{P} 600$ and $\mathrm{P} 700$ are relatively less contaminated revealing the more characteristic shape of carbon black. In these rCBs, most of the primary particles appear to be smaller in size than in N660, showing that small size carbon blacks and silica are relatively more abundant. Impurities are remaining from or deposited during the pyrolysis process. These impurities are either unconverted rubber, volatiles from rubber degradation or ash from minerals which were added during rubber manufacturing. Besides this, N660 exhibits a highly branched structure with voids present within the structure. In contrast, $\mathrm{rCBs}$ exhibit a lower structure with possibly impurities blocking voids. Especially P500 has a higher degree of contaminations, appearing as the whole aggregate structure encapsulated in volatile matter or unconverted rubber shell responsible for the actual morphology. 

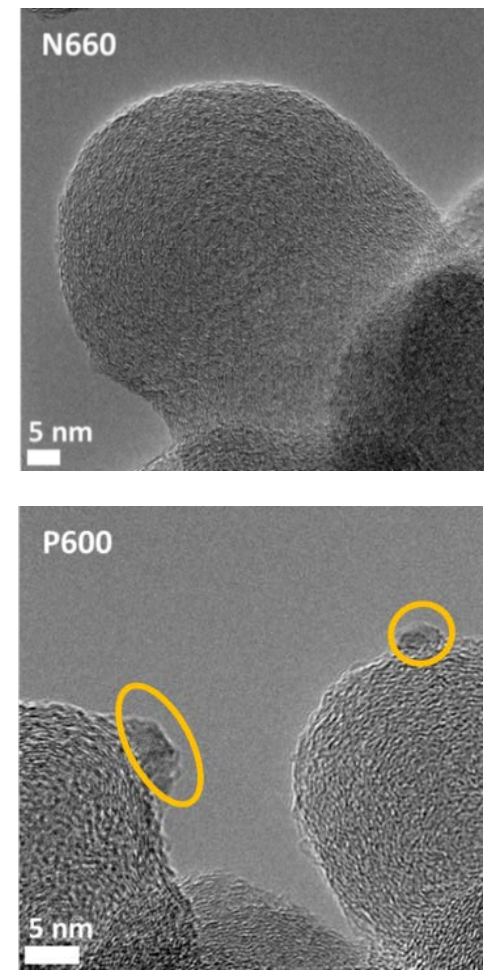
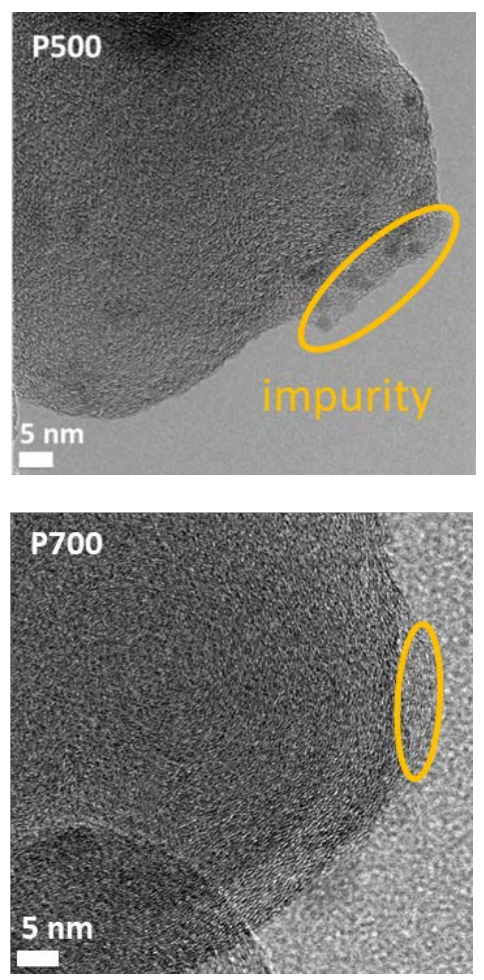

Figure 4.2.6 Magnified TEM images for particle morphology of carbon black N660 and recovered carbon blacks P500, P600 and P700.

In Figure 4.2.6, a magnified image of a single primary particle is shown. Concentric graphitic layer stacking is evident in all cases. However, the rCB surfaces contain nano-sized impurities. The elemental origin of these nano-sized impurities was investigated by elemental mapping using Energy Filtered Transmission Electron Microscopy (EFTEM). An area of the $\mathrm{rCB}$ sample P600, in which nano-sized impurities are visible, was focused and elemental mapping performed for carbon, silicon and sulfur. 
(a)

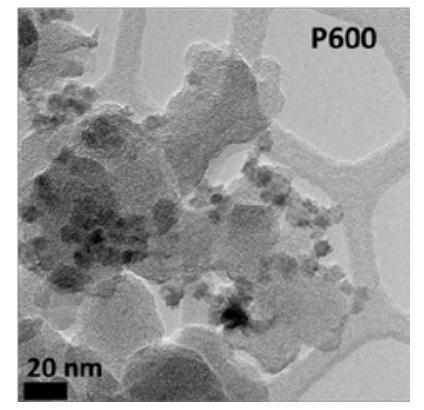

(b)
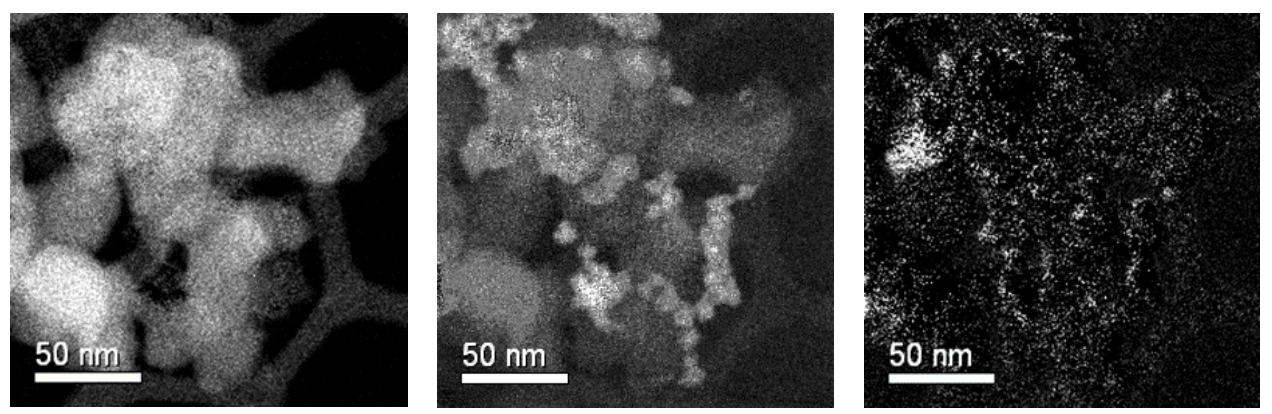

(c)

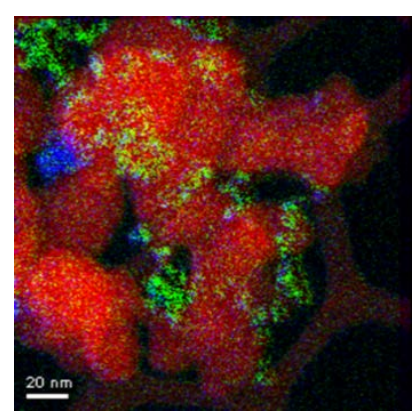

Figure 4.2.7 (a) TEM image of recovered carbon black P600. (b) EFTEM elemental detection of carbon, sulfur and silicon (left $\rightarrow$ right). (c) P600 elemental map of carbon (red), sulfur (green) and silicon (blue). 
In Figure 4.2.7 (b), the carbon map (left) shows that the larger nano particles consist mainly of carbon, while the sulfur map (middle) indicates the presence of sulfur concentrated in smaller particles on the carbon surface. These nano-sized sulfur impurities could be different sulfur species such as zinc sulfide or sulfur-carbon complexes formed during pyrolysis. The silicon map (right) shows the presence of silica clusters. In Figure 4.2.7 (c), elemental mapping shows that the carbon black surface (red) is partially covered with sulfur based impurities (green). Besides, zinc cannot be accurately detected with this technique since it needs longer electron beam exposure time which leads to sample drifting due to higher electron energy.

\subsubsection{Specific surface area of recovered carbon blacks}

The surface area of carbon black is usually measured by nitrogen adsorption using Brunauer-Emmett-Teller (BET) measurements; the most widely used method. Since this method requires 1 hour of degassing at $300^{\circ} \mathrm{C}$, it cannot be used for $\mathrm{rCBs}$ containing a high amount of volatiles. At $300^{\circ} \mathrm{C}$, the lighter hydrocarbon based volatiles can be released creating a cleaner surface; therefore, the degassing step would change the actual surface area of $\mathrm{rCB}$. The release of volatile fumes during the degassing step also damages the equipment.

Another specific surface area of six rCBs produced in a temperature range from $500^{\circ} \mathrm{C}$ to $700^{\circ} \mathrm{C}$ were measured using the lodine Adsorption Number (IAN) method. This method is commonly used for surface area measurements of virgin furnace blacks ranging from $30 \mathrm{mg} / \mathrm{g}$ (N772) to $160 \mathrm{mg} / \mathrm{g}(\mathrm{N} 115)^{9}$. In Figure 4.2.8, the IAN of rCBs show an increase in surface area with increasing pyrolysis temperature from $500^{\circ} \mathrm{C}$ to $600^{\circ} \mathrm{C}$ to $700^{\circ} \mathrm{C}$. The increase in IAN with increasing pyrolysis temperature is due to the increased rate of volatile removal revealing a larger surface area to interact with. Besides, the IAN numbers of rCB range from $21 \mathrm{mg} / \mathrm{g}$ to $95 \mathrm{mg} / \mathrm{g}$. Compared to virgin carbon black, this indicates the presence of semi-reinforcing N700 carbon black: lower values, to high reinforcing N300 CB; higher values. 


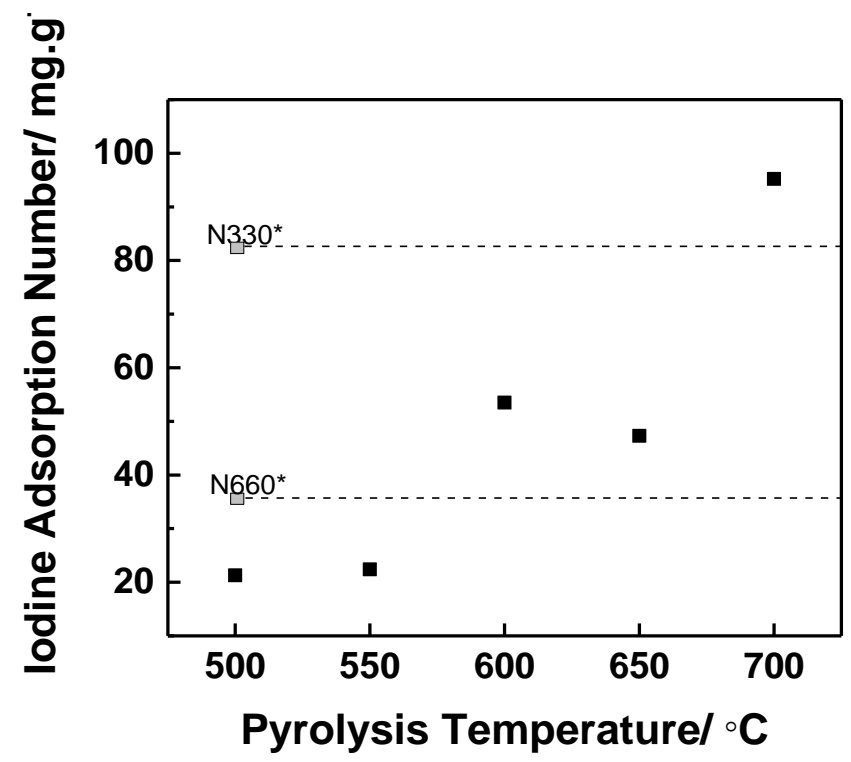

Figure 4.2.8 lodine adsorption number of $\mathrm{rCBs}$ produced at different temperatures. Literature values ${ }^{*}$ ) of IAN for semi-reinforcing carbon black N660 and reinforcing carbon black N330.

\subsubsection{Recovered carbon black structure}

The carbon black aggregate structure is one of the key parameters in defining their application as reinforcing filler. In the tire industry, higher structured and branched carbon blacks are preferred due to their better dispersibility in the rubber matrix. The structure of conventional carbon blacks is commonly measured by the Oil Adsorption Number (OAN) and Void Volume (VV). Both methods are used in this study for determining the recovered carbon black structure. 

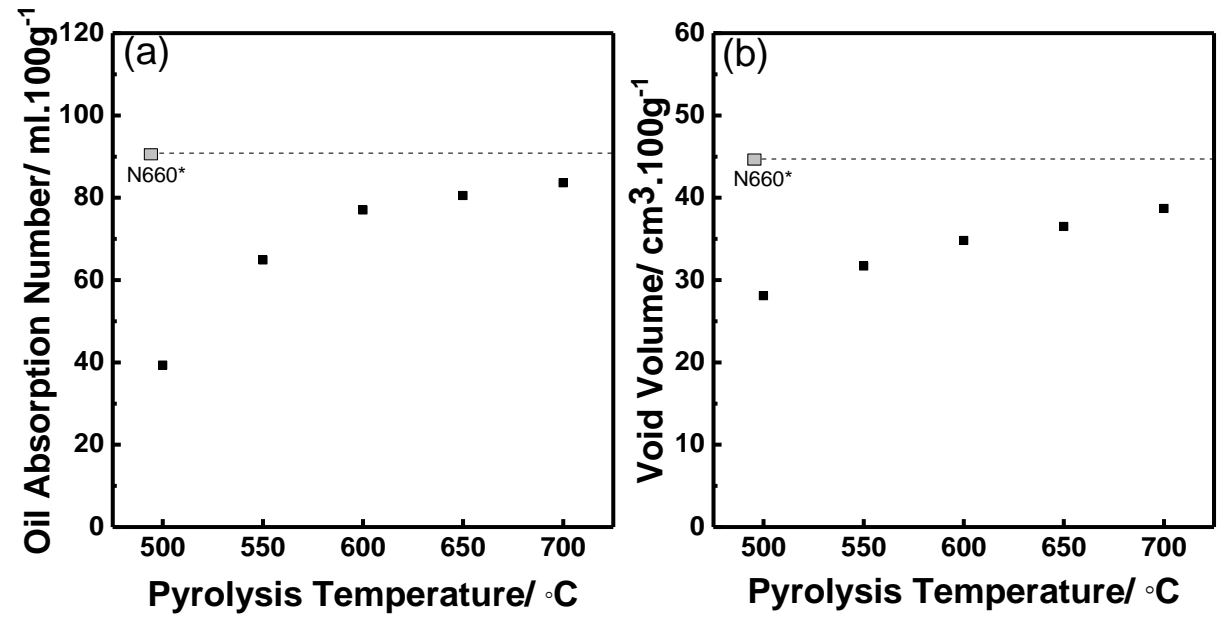

Figure 4.2.9 (a) Oil Absorption Number and (b) Void Volume of rCBs produced at different temperatures.

In Figure 4.2.9 (a), the OAN values show an improvement in $\mathrm{rCB}$ structure with increasing pyrolysis temperature. The major improvement in structure is from $500^{\circ} \mathrm{C}$ to $600^{\circ} \mathrm{C}$, after which it slows down. The positive effect of pyrolysis temperature on the structure was expected: at higher pyrolysis temperatures, the volatiles removal rate is increased, and this leads to opening of internal voids and pores, which in turn improve the oil absorption. Similar trends are seen in the void volume measurement: Figure 4.2.9 (b). Comparing the rCB structure with the conventional carbon black, both OAN and VV suggest that the highest $\mathrm{CCB}$ structure value is achieved at $700^{\circ} \mathrm{C}$, but slightly lower than the value for semi reinforcing carbon black N660 with an OAN value of $88 \mathrm{~cm}^{3} / 100 \mathrm{~g}$ and $\mathrm{VV}$ of $44.7 \mathrm{~cm}^{3} / 100 \mathrm{~g}$, as reported in the ASTM standard 10 and literature ${ }^{11}$, respectively.

The tint strength of carbon black is its efficiency to decrease reflectance when mixed with white pigment, or in other words, the blackness of carbon black. For conventional carbon blacks particle size and structure influence their tint strength. Since tint strength is dependent on carbon black parameters which define the reinforcement in rubber applications, it is readily used in industry for quality control ${ }^{12}$. 


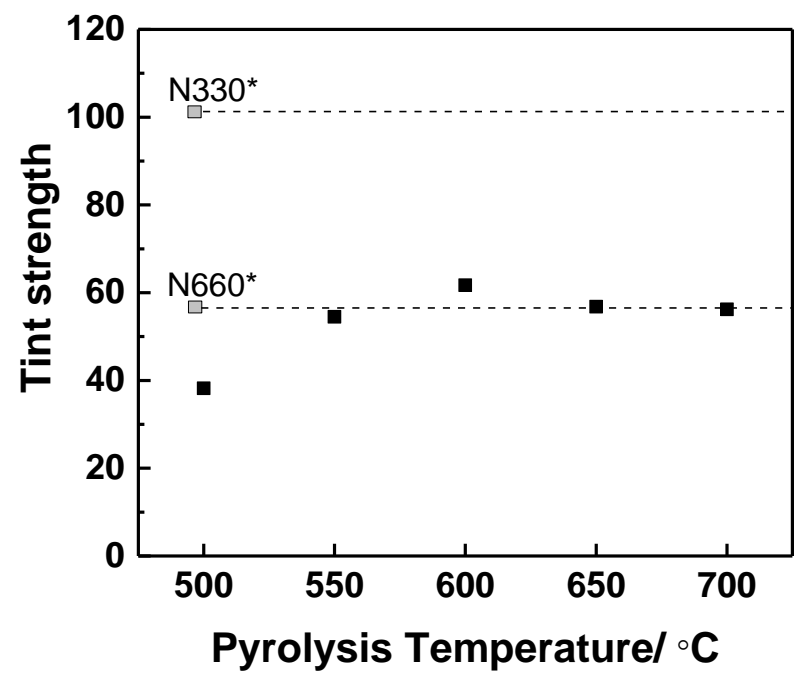

Figure 4.2.10 Tint strength of rCBs produced at different pyrolysis temperatures.

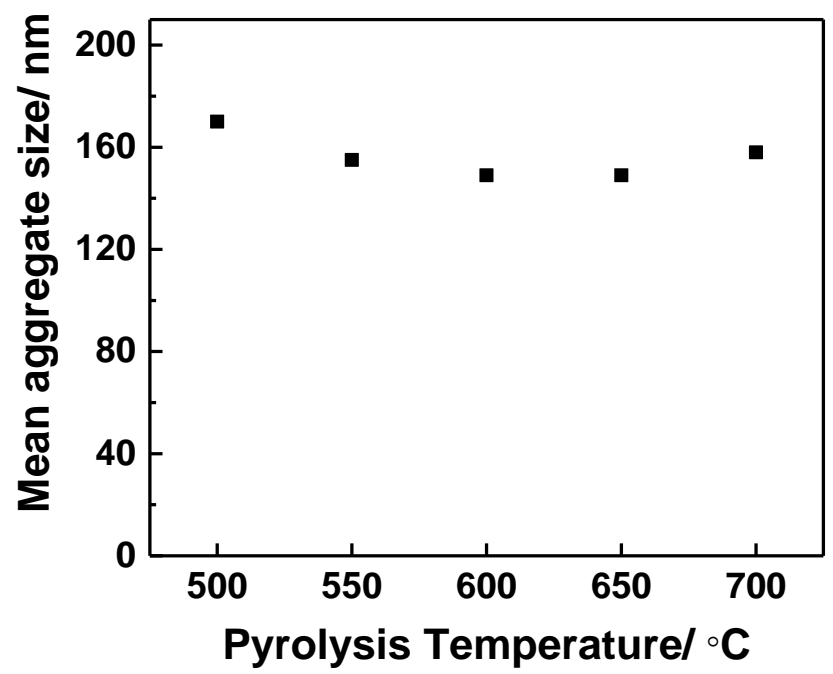

Figure 4.2.11 Mean aggregate size of $\mathrm{rCBs}$ produced at different pyrolysis temperatures. 
The tint strength of $\mathrm{rCB}$ in Figure 4.2.10 is improved with increasing pyrolysis temperature up to $600^{\circ} \mathrm{C}$, while above $600^{\circ} \mathrm{C}$ it remained more or less the same up to $700^{\circ} \mathrm{C}$. The best tint strength achieved for $\mathrm{rCB}$ is similar to the semi reinforcing carbon black series of $\mathrm{N} 600$.

The effect of pyrolysis temperature on the $\mathrm{rCB}$ aggregate size was also measured. In Figure 4.2.11, the mean aggregate size decreases with increasing pyrolysis temperature. This improvement with temperature is similar to what is previously seen in tint strength. In Figure 4.2.12, a correlation between these properties is depicted. Although the correlation is not strong $\left(\mathrm{R}^{2}=87 \%\right)$, a clear trend of improving tint strength with reducing aggregate size can be seen. To draw a conclusive statistical relationship between these properties, more data points at different pyrolysis conditions must be added.

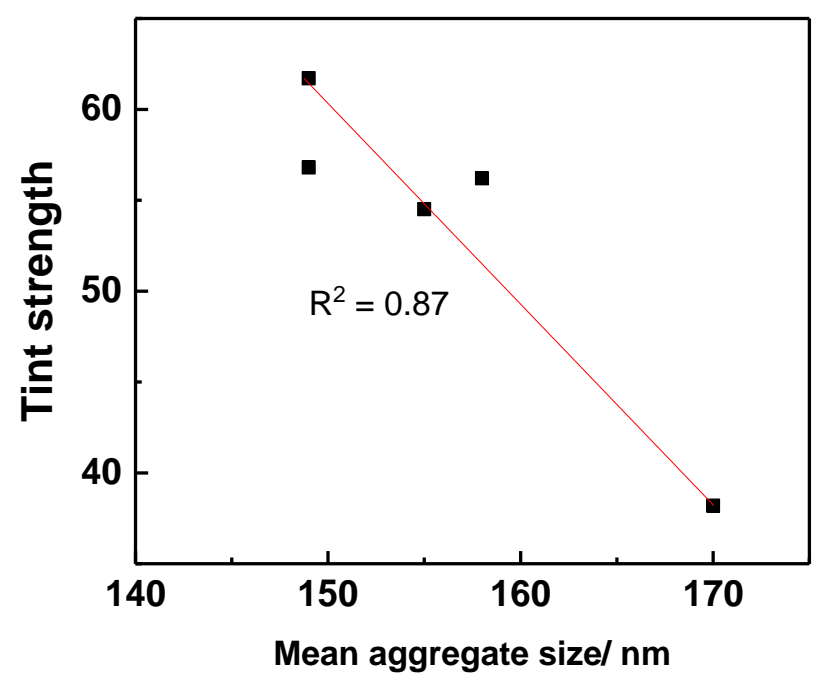

Figure 4.2.12 Correlation between tint strength and mean aggregate size of rCBs.

\subsubsection{Surface functionalities on recovered carbon black}

XPS was used to characterize the chemical nature of carbon on the recovered carbon black surface. It also yields information about the chemical nature of the different non-carbon components present on the rCB surface. Initially, survey scans were recorded to detect surface carbon and non-carbon components. A 
representative survey scan of the reference $\mathrm{CB} N 660$ and $\mathrm{rCB}$ produced at $500^{\circ} \mathrm{C}$ (P500) is shown in Figure 4.2.13 and Figure 4.2.14, respectively. In order to analyze the chemical nature of the surface elements, elemental spectra scans were recorded for each element detected. N660 is pure carbon, therefore only a small amount of oxygen and traces of sulfur are detected. However, in the rCB survey scan, inorganic impurities such as silicon, zinc, sulfur and oxygen are detected.

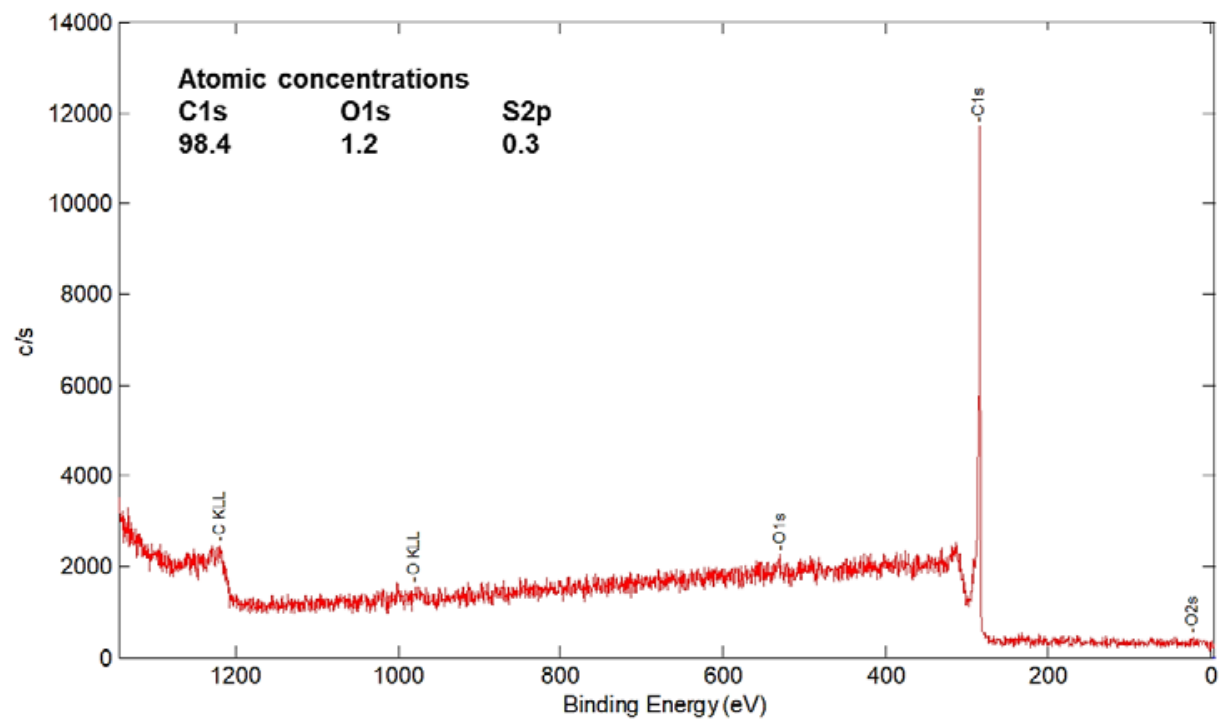

Figure 4.2.13 XPS survey spectra of N660. 


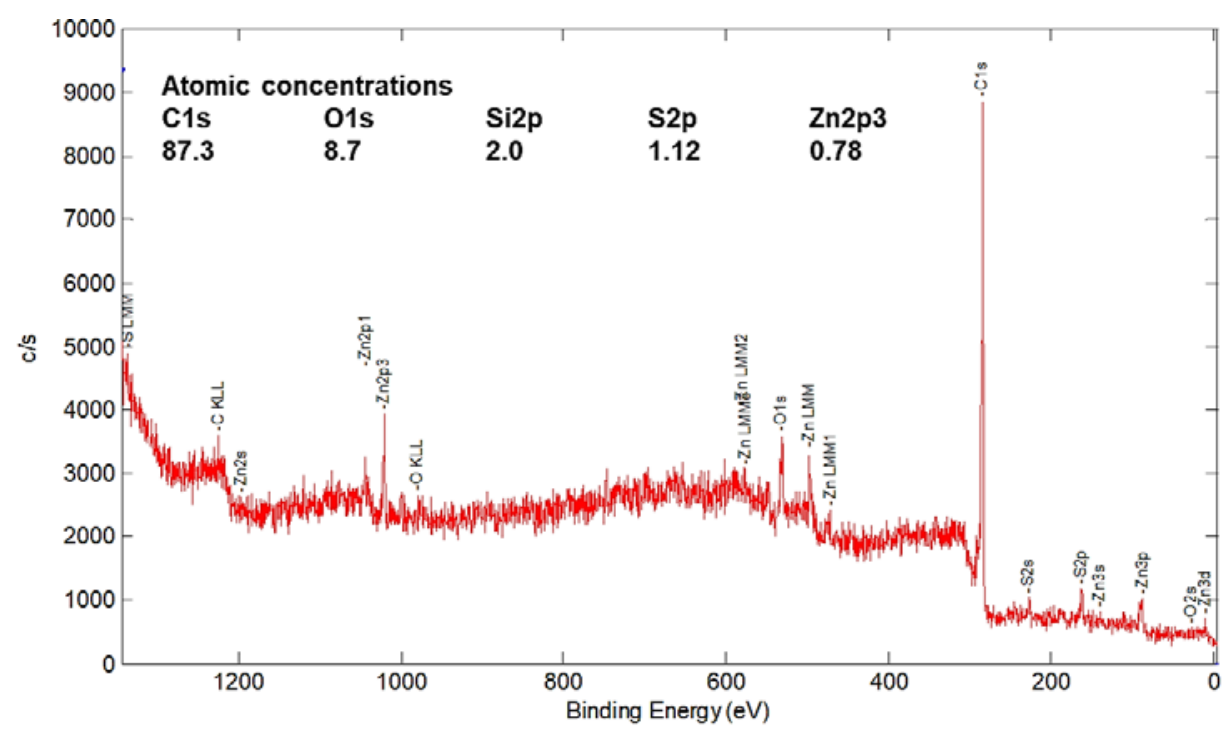

Figure 4.2.14 XPS survey spectra of rCB P500.

\subsubsection{Surface functionality of carbon in recovered carbon black}

In Figure 4.2.15, a carbon element spectrum of pure carbon N660 is presented including the curve fittings. The N660 spectrum is a classical carbon black with a main peak at $284.5 \mathrm{eV}$, which broadens at higher binding energies. The main peak of the N660 spectrum suggests, that the major part is graphitic carbon, while the broadening higher energies is due to remaining carbon with oxygen functionalities. At higher energies, four peaks are fitted representing surface functional groups including $\mathrm{C}-\mathrm{O}, \mathrm{C}=\mathrm{O}, \mathrm{COH}$ and $\mathrm{COOH}$. 


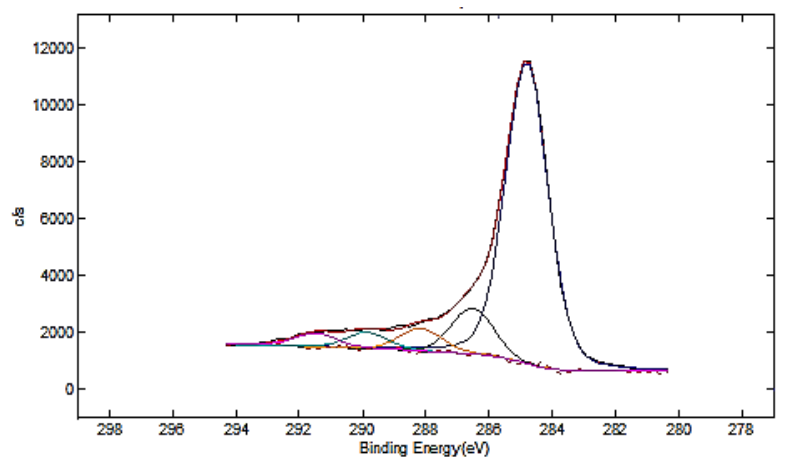

Figure 4.2.15 XPS C1s spectrum (red line) for N660. The fitting peak in blue represents graphitic carbon. Other small peak fittings represent carbon-oxygen functionalities.

In Figure 4.2.16, the carbon element spectra of N660 is compared with the spectra of recovered carbon blacks produced at different temperatures. The baseline and C1s peak intensity is normalized in order to determine the differences in surface functionalities among rCBs and with the reference N660. In all rCBs, the representative graphitic carbon peak at $284.5 \mathrm{eV}$ is visible due to the presence of carbon black, which was originally used in the tire compounds. Nevertheless, only the spectrum of rCB P500 shows peak broadening at lower binding energies. The presence of hydrocarbons on most of the P500 surface has caused a carbon peak shift to lower binding energies resulting in broadening of the main peak. Additionally, since most of the carbon black surface of P500 is blocked with hydrocarbon based contaminants, no oxygen based functionality was detected at higher binding energies. In the case of rCB P600, P650 and P700, the hydrocarbon based peak shift is absent, showing a more clean surface of the carbon black being present. Besides, peak broadening at higher binding energies is also visible in the P600 spectrum indicating a similar kind of surface functionality as N660. This XPS carbon spectra analysis qualitatively shows that a higher pyrolysis temperature causes removal of contaminants (hydrocarbon based volatiles), consequently resulting in surface functionalities similar to virgin carbon black. 


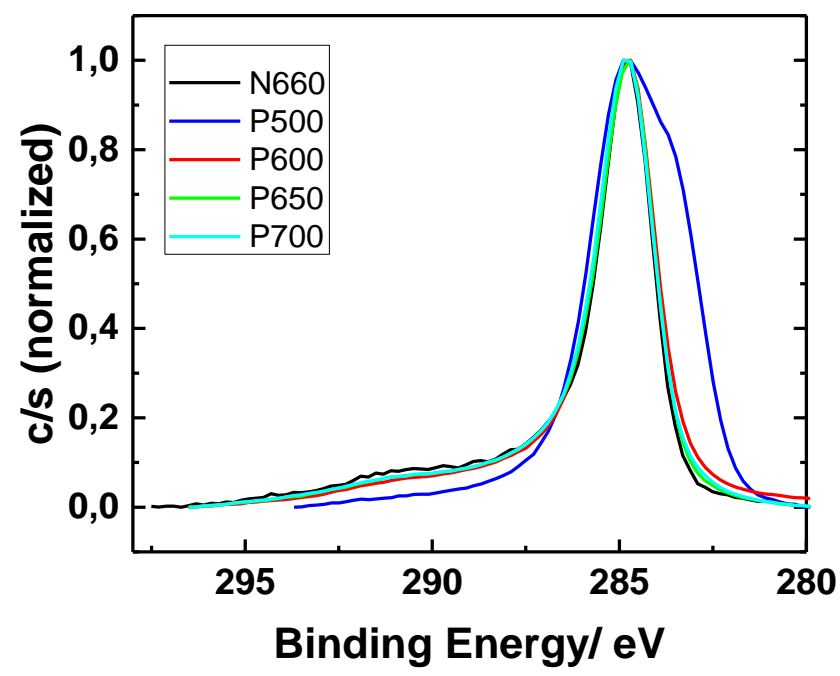

Figure 4.2.16 Carbon element spectra of N660 and recovered carbon blacks produced at different temperatures.

\subsubsection{Compositional analysis of the ash content of recovered carbon black}

In Chapter 4.1, the elemental composition of the ash was analyzed (Table 4.1.4). The ash consists mainly of oxygen, silicon, zinc and sulfur with no influence of pyrolysis temperature on their respective quantities. In the present section, the ash content is further characterized to understand the compounds formed by these elements at different pyrolysis temperatures. In Table 4.2.3, band fittings used for all elements present are reported. For N660, oxygen is fitted with two bands at $532 \mathrm{eV}$ and $534 \mathrm{eV}$ representing different carbon-oxygen functionalities. However, all $\mathrm{rCB}$ oxygen areas are $100 \%$ fitted with a single band in the range of $532 \mathrm{eV}$ to $532.3 \mathrm{eV}$. The O1s positions of $\mathrm{rCB}$ show that oxygen is either attached to the silicon in the form of $\mathrm{SiO}_{2}$ or to hydrocarbons.

Sulfur is also fitted with two bands, with one band covering the major area (67\%) fitted at $162 \mathrm{eV}$ and the remaining area at $163 \mathrm{eV}$. The major area of the sulfur peak represents sulfur attached to zinc as zinc sulfide (ZnS). However, a smaller amount of sulfur is attached to hydrocarbons, which could be in the form of sulfur complexes.

The binding energy of the zinc compound is in the range of $1022 \mathrm{eV}$ to $1022.80 \mathrm{eV}$, which indicates either $\mathrm{ZnO}$ or $\mathrm{ZnS}$. However, if zinc is present in the form of an oxide, there must be a shoulder in the oxygen spectra at lower binding energies of $528 \mathrm{eV}$ 
to $530 \mathrm{eV}$, see Figure 4.2.1, which is not the case. Besides, the sulfur spectra support the presence of zinc sulfide. Additionally, P650 shows zinc presence at $1022.8 \mathrm{eV}$, which indicates that zinc is not only present as sulfide, but that other zinc complexes are also present. Zinc oxide is used in tire manufacturing as vulcanization activator, which along with the accelerator forms zinc complexes. These complexes react with sulfur $\left(\mathrm{S}_{8}\right)$ and form active sulfurating agents for efficient vulcanization. After activation of the vulcanization process, zinc complexes form sulfides and zincsalts ${ }^{13-14}$.

The silicon spectra are fitted by two energy bands of $102.4 \mathrm{eV}$ and $103 \mathrm{eV}$. In all rCBs, silicon is present as silica $(103 \mathrm{eV})$ or silica covered with hydrocarbons (102.4 eV).

Spectral analysis of rCB carbon and non-carbon spectra confirm the presence of hydrocarbons on both, the carbon black and the silica surface. The sulfur spectra also show the presence of hydrocarbons indicating the formation of carbon-sulfur compounds. These complexes with high temperature stability can be formed at high temperatures by the chemisorption of sulfur vapors onto the carbon black surface. These complexes are also evident in elemental mapping: Figure 4.2.7, mostly attached to the carbon black surfaces. From the oxygen, sulfur and zinc spectra, it can be concluded that zinc is mainly present in the form of sulfides and complexes and not in the oxide form. The influence of the pyrolysis temperature is mainly observed as the presence of hydrocarbons, which is reduced with increasing temperature, while inorganic components remain more or less unaffected.

Table 4.2.3 Binding energies of fitted bands for oxygen, sulfur, zinc and silicon spectra analysis.

\begin{tabular}{|c|c|c|c|c|}
\hline Samples & $\begin{array}{c}\text { O1s } \\
\text { Binding } \\
\text { energy (eV) }\end{array}$ & $\begin{array}{c}\text { S2p } \\
\text { Binding } \\
\text { energy (eV) }\end{array}$ & $\begin{array}{c}\text { Zn2p3 } \\
\text { Binding } \\
\text { energy (eV) }\end{array}$ & $\begin{array}{c}\text { Si2p } \\
\text { Binding } \\
\text { energy (eV) }\end{array}$ \\
\hline N660 & $532.2,534$ & - & - & - \\
\hline P500 & 532.2 & 162,163 & 1022 & 102.4 \\
\hline P600 & 532 & 162,163 & 1022.3 & $102.4,103$ \\
\hline P650 & 532 & 162,163 & 1022.8 & $102.4,103$ \\
\hline P700 & 532.3 & 162,163 & 1022.3 & $102.4,103.2$ \\
\hline
\end{tabular}




\subsubsection{Surface activity of recovered carbon black}

The surface activity of fillers in chemical sense can be seen as the presence of different functional groups on the surface. In physical terms, it is related to the surface energy variations which determine the adsorptive capacity and energy of adsorption. In rubbers, the carbon black surface chemistry is mainly responsible for the basic or acidic nature of this filler and is of significance only for the vulcanization process; however, the mechanical properties are dictated by the surface energy of this filler ${ }^{15}$.

Surface energies of carbon black N660 and recovered carbon blacks produced at the various reactor temperatures were measured by inverse gas chromatography at infinite dilution. The dispersive energy component was calculated by the slope of the straight line obtained from the plot of the value of $\Delta G_{a}$ for the different $n$-alkanes versus their number of carbon atoms as shown in Figure 4.2.17. It is clear that the slope of the line of the $\Delta \mathrm{G}_{a}$ versus the methylene groups $\left(-\mathrm{CH}_{2}\right)$ for $\mathrm{N} 660$ is the highest compared to the slopes of the lines for all recovered blacks. This noticeable difference shows that $\mathrm{N} 660$ has the highest degree of interaction with the $-\mathrm{CH}_{2}$ group, and that it consequently results in the highest disperse surface energy.

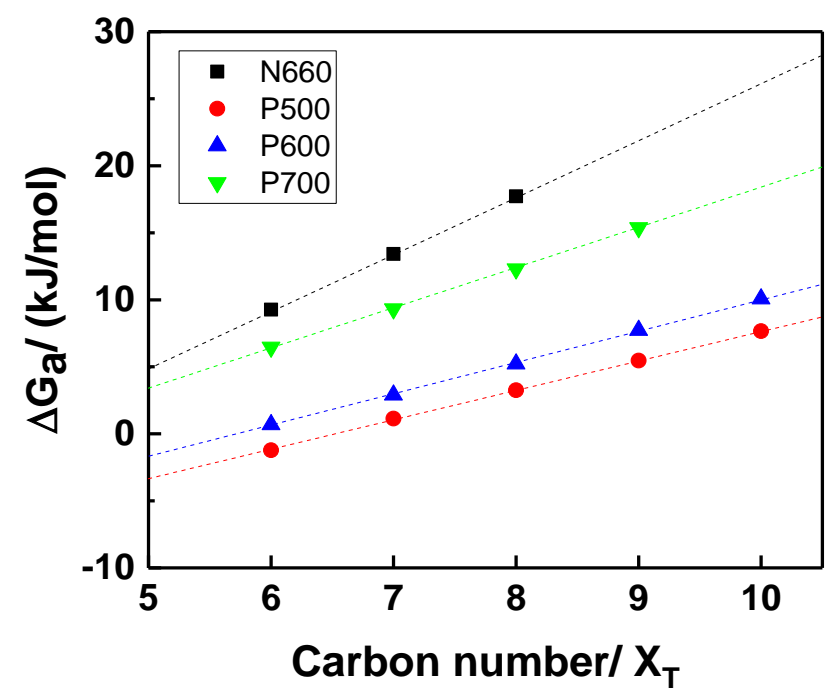

Figure 4.2.17 Free energy of adsorption $\left(\Delta \mathrm{G}_{\mathrm{a}}\right)$ versus the number of $-\mathrm{CH}_{2}$ - groups of n-alkanes obtained at $150^{\circ} \mathrm{C}$ for carbon black $\mathrm{N} 660$ and recovered carbon blacks produced at different temperatures. 
Table 4.2.4 Slope of the $n$-alkane straight lines and the dispersive energy components of N660 and recovered carbon blacks.

\begin{tabular}{|l|l|l|l|}
\hline Carbon blacks & $\begin{array}{l}\Delta \mathbf{G}_{\mathrm{a}}\left(\mathbf{C H}_{2}\right) \\
(\mathbf{k J} / \mathbf{m o l})\end{array}$ & $\mathbf{Y s}^{\mathrm{d}}\left(\mathbf{m J} / \mathbf{m}^{2}\right)$ & $\mathbf{r}^{2}$ \\
\hline $\mathbf{N 6 6 0}$ & $4.229 \pm 0.044$ & $122.1 \pm 2.5$ & 0.9999 \\
\hline P500 & $2.209 \pm 0.020$ & $33.3 \pm 0.6$ & 0.9997 \\
\hline P600 & $2.358 \pm 0.028$ & $38.0 \pm 0.9$ & 0.9996 \\
\hline P700 & $2.974 \pm 0.028$ & $60.4 \pm 0.9$ & 0.9999 \\
\hline
\end{tabular}

The values of the slopes $\left(\Delta \mathrm{G}_{\mathrm{a}}\left(\mathrm{CH}_{2}\right)\right)$, the corresponding dispersive components of the surface energy $\gamma_{s}{ }^{d}$, and the correlation coffiecient $\left(r^{2}\right)$ of the $n$-alkane lines are given in Table 4.2.4. The dispersive energy values are also plotted in Figure 4.2.18 for the visualization of differences within rCBs and with N660. For the recovered carbon blacks the pyrolysis temperature played an important role: an increasing slope and dispersive energy is observed with rise in temperature. Higher pyrolysis temperatures lead more volatile removal and cleaner carbon surfaces which reveal more of the crystalline surface defects. In these defects, alkane probes may logded in, so improving the dispersive component of rCBs. 


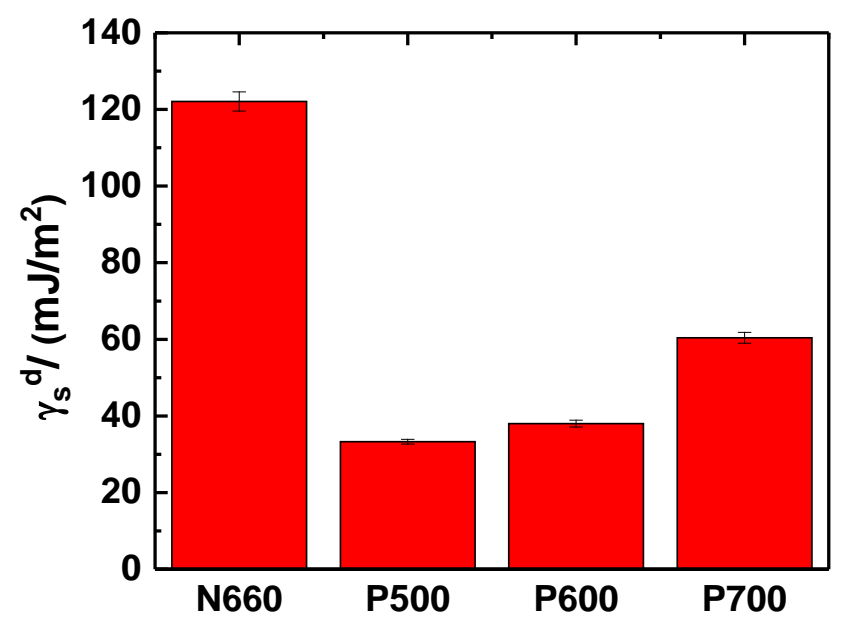

Figure 4.2.18 Dispersive component of the surface energy $\left(\gamma_{s}{ }^{d}\right)$ of N660 and rCB's $\mathrm{P} 500, \mathrm{P} 600$ and P700.

Improvement of $\gamma_{s}{ }^{d}$ with respect to the pyrolysis temperature is evident: the highest $\gamma_{s}{ }^{\mathrm{d}}$ value is achieved at $700^{\circ} \mathrm{C}$, and this value is close to the value reported in literature for thermal black $\mathrm{N} 990\left(71.9 \mathrm{~mJ} / \mathrm{m}^{2}\right)^{15}$. Comparing carbon blacks $\mathrm{N} 660$ and $\mathrm{N} 990$, the latter one is produced from natural gas or aromatic oils by thermal black process and has a much larger particle size, higher crystallite dimensions with less crystal defects leading to fewer energetic sites.

As seen in the TEM images, a broad range of carbon blacks with different particle sizes are present in $\mathrm{rCB}$; however, the energetic sites of these carbon blacks are apparently less exposed. In Chapter 4.1, the toluene transmittance results and elemental analyses demonstrated that even after pyrolysis at $700^{\circ} \mathrm{C}, \mathrm{rCB}$ still contained more organic impurities compared to the virgin carbon blacks. This means that the rCB surface is still (partly) covered with organics hindering the high energy sites. The nature and the influence of these sites will be discussed later in the nanoroughness analysis.

The specific interaction parameter (IsP) is also determined to understand the polar contributions of rCBs. The free energy of adsorption values of polar probes are plotted together with the extrapolated n-alkane straight line in Figure 4.2.19 for the IsP calculation. Since polar interactions involve many contributions such as $\pi-\pi-b o n d$ 
interactions and hydrogen bonding, several polar probes responsible for different types of polar interactions were injected.

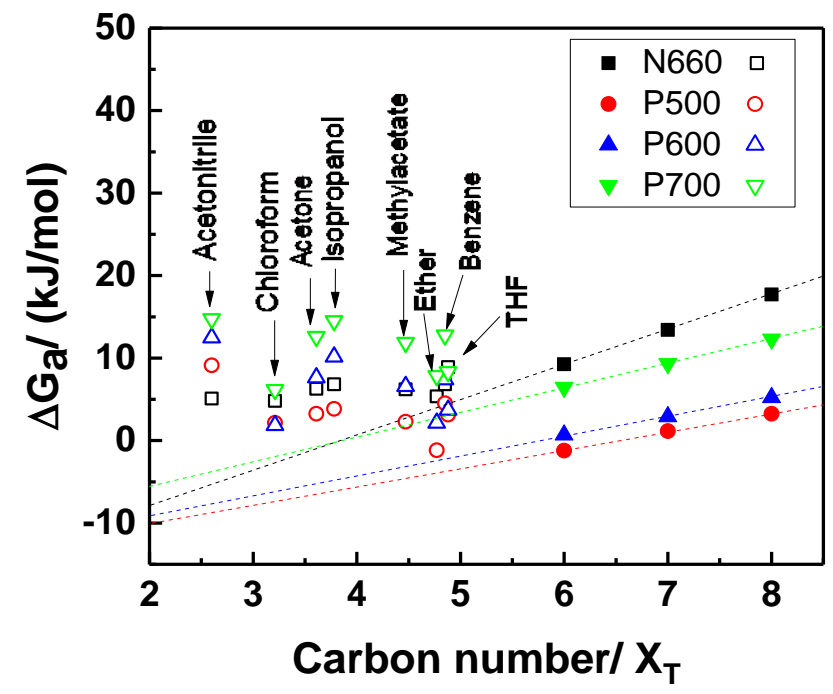

Figure 4.2.19 The free energy of adsorption $\left(\Delta \mathrm{G}_{\mathrm{a}}\right)$ versus the number of $\mathrm{CH}_{2}$ of $\mathrm{n}$-alkanes and polar probes for the Isp determination.

The behavior of the different carbon blacks towards the polar probes is summarized in Table 4.2.5. In N660, Isp values of acetonitrile, chloroform, acetone and isopropanol are higher than the other polar probes indicating hydrogen bonding with oxygen functional groups on the N660 surface. Another relatively strong interaction in N660 is with benzene due to the specific interaction with the $\pi$ bond. The $\mathrm{rCB}$ produced at $500^{\circ} \mathrm{C}$ (P500) exhibits relatively higher Isp values compared to N660, which is further increased with higher pyrolysis temperatures.

Higher specific interactions in rCBs, especially in terms of hydrogen bonding, were expected due to the presence of polar silica. The interaction via hydrogen bonding between polar probes and silica is illustrated in Figure 4.2.20. 
Chapter 4.2

Table 4.2.5 Specific interaction parameter (ISP) of different probes used for $N 660$ and recovered carbon blacks produced at different temperatures.

\begin{tabular}{|c|c|c|c|c|}
\hline Isp [kJ/mol] & N660 & P500 & P600 & P700 \\
\hline Acetonitrile & $10.2 \pm 0.2$ & $17.8 \pm 0.3$ & $19.9 \pm 0.3$ & $18.5 \pm 0.2$ \\
\hline Chloroform & $7.4 \pm 0.2$ & $9.5 \pm 0.2$ & $7.8 \pm 0.2$ & $8.0 \pm 0.2$ \\
\hline Acetone & $7.1 \pm 0.2$ & $9.7 \pm 0.3$ & $12.7 \pm 0.2$ & $13.3 \pm 0.2$ \\
\hline Isopropanol & $7.0 \pm 0.1$ & $9.9 \pm 0.3$ & $14.8 \pm 0.3$ & $14.7 \pm 0.2$ \\
\hline Methyl acetate & $3.4 \pm 0.2$ & $6.8 \pm 0.2$ & $9.6 \pm 0.2$ & $10.0 \pm 0.2$ \\
\hline Diethyl ether & $1.3 \pm 0.2$ & $2.7 \pm 0.2$ & $4.4 \pm 0.1$ & $5.1 \pm 0.2$ \\
\hline Tetrahydrofurane & $2.4 \pm 0.3$ & $8.2 \pm 0.2$ & $9.5 \pm 0.2$ & $9.8 \pm 0.2$ \\
\hline Benzene & $4.4 \pm 0.3$ & $6.8 \pm 0.2$ & $5.8 \pm 0.2$ & $5.3 \pm 0.3$ \\
\hline
\end{tabular}


Acetonitrile<smiles>CC1CCCCC1O[Si]</smiles>

Isopropanol

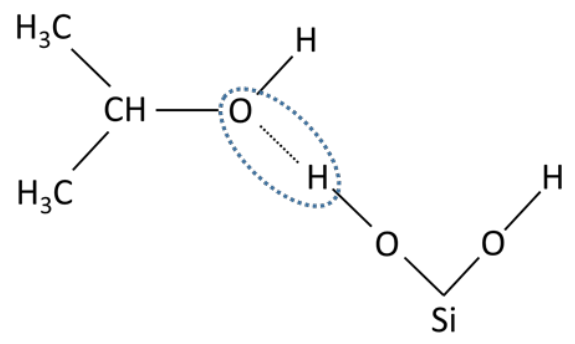

Acetone

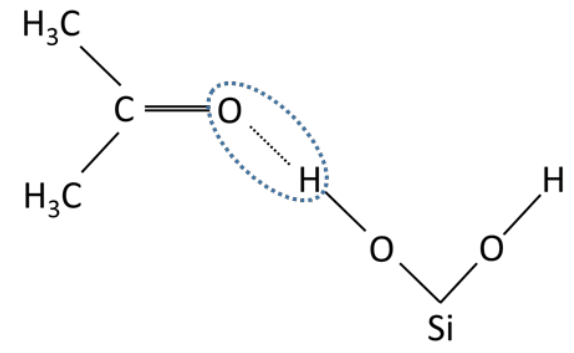

Chloroform

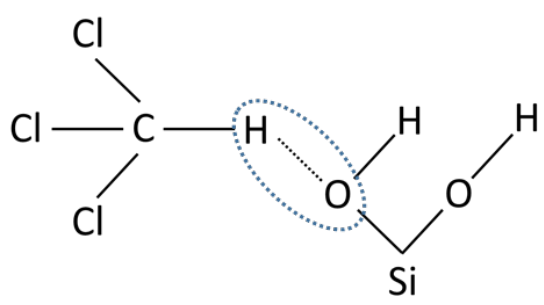

Figure 4.2.20 Hydrogen bonding of silica with different polar probes.

The $\pi$ bond interactions of $\mathrm{rCB}$ represented by benzene probe values show a decreasing trend with increasing pyrolysis temperature, although still higher than the values for N660. Besides, higher interaction of $\mathrm{rCB}$ with electron donor probes such as di-ethyl ether and tetrahydrofuran indicates a basic character of $\mathrm{rCB}$, which is further enhanced with increasing temperature. Such influence of temperature on the basicity of $\mathrm{rCB}$ has been previously reported by other authors ${ }^{16-17}$, mentioning higher pyrolysis temperatures responsible for removing acidic groups. Moreover, higher temperatures remove more volatiles from the carbon surface exposing the basic pyrone-like structures of the carbon black surface.

For the overall surface polarity, the sum of all interaction parameters from these probes ( $\left.\Sigma I_{s p}\right)$ is plotted in Figure 4.2.21. N660 shows the lowest polarity due to the small amount of polar groups, while all rCBs show a stronger polar nature due to the presence of impurities. The increase in the specific interactions of rCBs from P500 to $\mathrm{P} 600$ is due to the increased rate of volatile removal at higher temperatures from the polar components in $\mathrm{rCB}$ such as silica. This allows polar surfaces to contribute more in the specific energy part. 


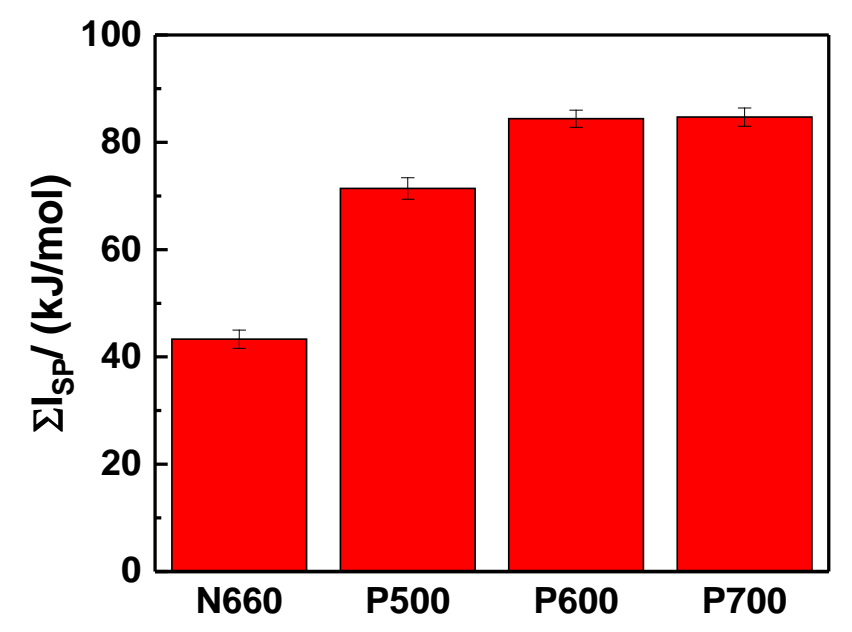

Figure 4.2.21 $\Sigma I_{\mathrm{Sp}}$ values of $\mathrm{N} 660$ and recovered carbon blacks produced at different temperatures.

The surface energies of fillers can be used as a tool to predict their behavior in a rubber matrix. Wang et al. ${ }^{15}$ used the energy of adsorption of polar acrylonitrile and non-polar hexane to respectively demonstrate the filler-filler and polymer-filler interactions. A similar approach is used in Figure 4.2.22 to visualize the behavior of $\mathrm{N} 660$ and rCBs in the rubber matrix. An increase along the $y$-axis value represents strong filler-filler interactions and reduced compatibility with the rubber, while improvement on $\mathrm{x}$-axis would mean higher filler-polymer interactions. 


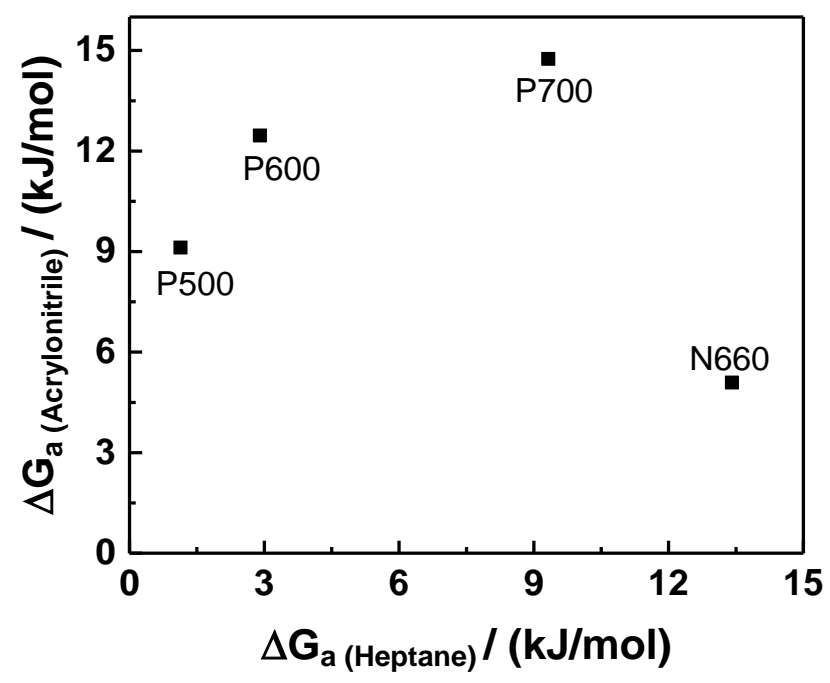

Figure 4.2.22 Free energy of adsorption of acrylonitrile versus heptane for N660 and recovered carbon blacks produced at different temperatures.

N660 shows the lowest filler-filler and the highest filler-polymer interactions as illustrated in terms of free energies of polar (acrylonitrile) and non-polar (heptane) species in Figure 4.2.22. In rCBs, both non-polar ( $x$-axis) and polar ( $y$-axis) interactions are increased with higher pyrolysis temperature. The improvement of rCB polymer-filler interactions at higher temperatures is due to the cleaner carbon black surface interacting with the non-polar rubber. The surface of polar impurities of $\mathrm{rCB}$ such as silica is also more exposed at higher temperatures contributing to higher filler-filler interactions. Therefore, a higher pyrolysis temperature will improve the rCB compatibility with rubber; however, at the same time, this compatibility is supressed due to the increased filler-filler interactions.

\subsubsection{Surface roughness of recovered carbon black}

As a nano-material, carbon black exhibits a large specific surface areas to interact with its surroundings. The reinforcing potential of carbon black as active filler is not only dependent on its surface area, but also on its microstructure or nano roughness. Crystal defects and disordered surface graphitic layer arrangements are responsible for such a structure on nano-scale. The different surface components of carbon black 
are visualized in Figure 4.2.23 as (I) low energy graphitic planes and (II-IV) high energy sites including amorphous carbon, edges and cavities ${ }^{18}$.

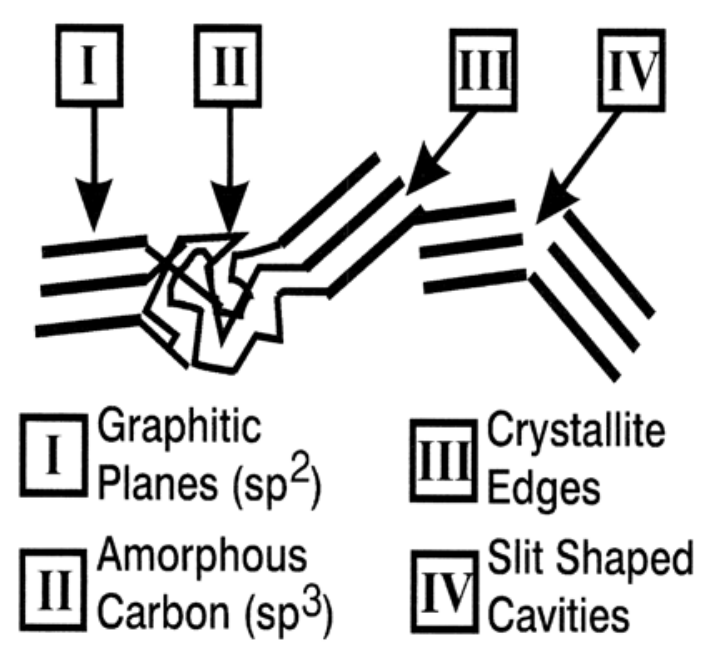

Figure 4.2.23 Attribution of energy sites to surface microstructure ${ }^{18}$.

For such an analysis, IGC is a useful technique in which the surface accessibility of IGC probes depends on the surface morphology as well as on the bulkiness of the probes themselves. On ideal molecularly flat surfaces, knowing the retention times of $n$-alkanes, the retention times of branched and cycloalkanes can be predicted using the topology index $\left(\chi_{\mathrm{T}}\right)$. However, when similar probes are applied to nanorough surfaces, retention time will become shorter due to the hindered access of bulky solutes ${ }^{19}$. This size exclusion effect can be further seen in the index of morphology (IM). The calculation of the $\chi_{T}$ and IM was defined in Section 4.2.2.8. 


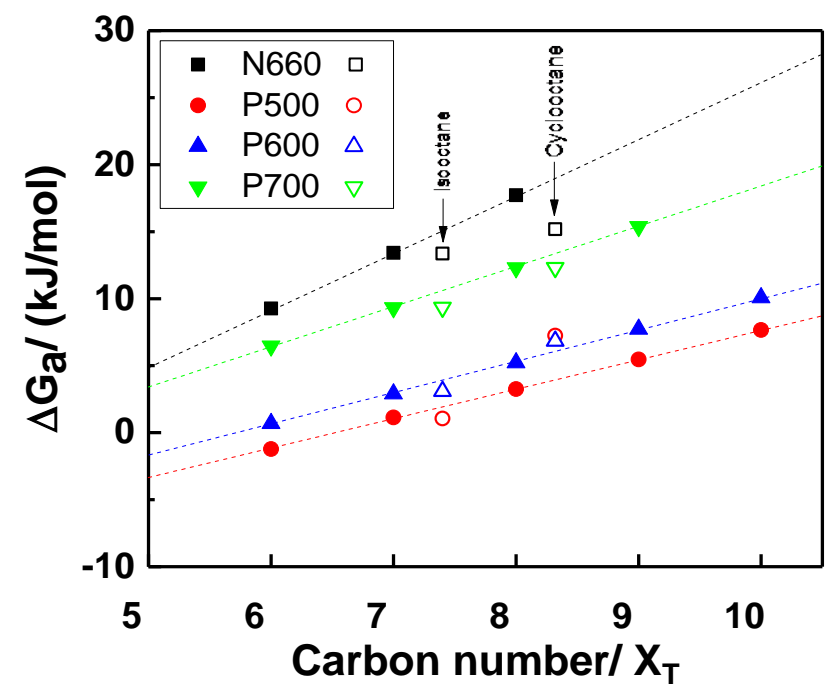

Figure 4.2.24 Branched (isooctane) and cyclic (cyclooctane) alkane adsorption energies on $\mathrm{N} 660$ and recovered carbon blacks.

In Figure 4.2.24, the behavior of branched and cyclic alkanes towards virgin and recovered carbon blacks is shown. Both $\mathrm{N} 660$ and $\mathrm{rCB}$ produced at $700^{\circ} \mathrm{C}(\mathrm{P} 700)$, show lower adsorption energies of branched and cyclic alkanes compared to their respective energies estimated from the extrapolation of the $n$-alkane line. This size exclusion effect is due to the surface roughness: only a part of the surface is accessible for linear alkanes, but hindered for bulky alkanes. The size exclusion effect of a nano-rough surface is illustrated in Figure 4.2.25.

In contrast to P700, P500 and P600 both show negligible reduction in the measured energy of branched alkanes; an indication of absence of a size-exclusion effect. Besides, an increase in the measured energy of cyclic alkanes is due to the dissolution effect. In other studies ${ }^{8,20}$, the latter behavior is also reported for surfaces covered with polymers which may dissolve the probes and give longer retention times. Similar to that, P500 and P600 contain large amounts of organics which might also dissolve the IGC probes resulting in such behavior. 


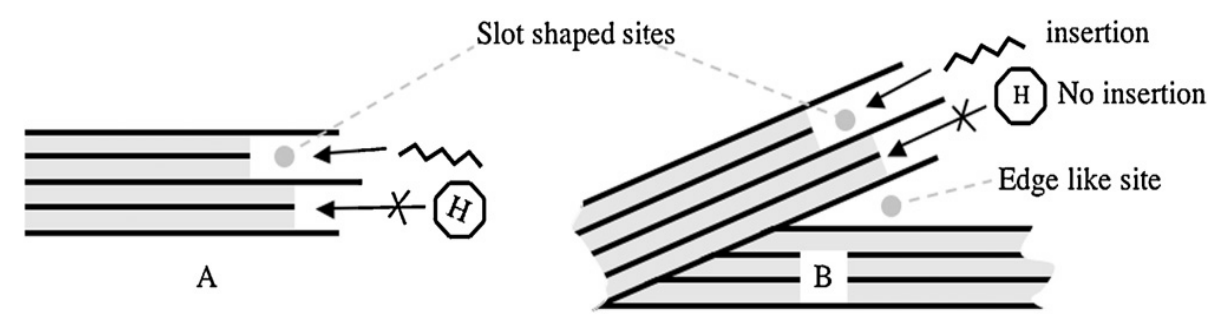

Figure 4.2.25 Illustration of size exclusion effect on different sites of a carbon black surface ${ }^{21}$.

In Table 4.2.6, the index of morphology (IM) are summarized for N660 and the rCBs, calculated as the ratio of the retention time of the branched/cyclic alkane molecule $\left(\mathrm{t}_{\mathrm{N}}\right)$ and the retention time of the same linear $\mathrm{n}$-alkane probe $\left(\mathrm{t}_{\mathrm{N}}{ }^{\mathrm{ref}}\right)$ as explained in Section 4.2.2.8.

Table 4.2.6 Morphology indices of isooctane and cyclooctane for N660 and recovered carbon blacks.

\begin{tabular}{|c|c|c|}
\hline & IM $^{*}$ (Isooctane) & IM $^{*}$ (Cyclooctane) \\
\hline N660 & $60.7 \pm 0.007$ & $32.8 \pm 0.003$ \\
\hline P500 & $77.7 \pm 0.005$ & $253.3 \pm 0.019$ \\
\hline P600 & $79.9 \pm 0.004$ & $124.6 \pm 0.013$ \\
\hline P700 & $72.1 \pm 0.007$ & $76.0 \pm 0.007$ \\
\hline
\end{tabular}

*100 index of morphology $(\mathrm{IM})=$ smooth surface as estimated by $n$-alkane line

The morphological index is a numerical representation of the size exclusion effect: the lower the index, the higher the size exclusion effect. The strongest size exclusion for branched and cyclic alkanes can be seen for N660 in Table 4.2.6. rCBs show a trend of enhanced roughness with increasing pyrolysis temperature as indicated by reducing IM values: when increasing the pyrolysis temperature, more volatiles are removed from the carbon surface exposing the original defects. However, even at 
the highest pyrolysis temperature, volatiles are still present due to which the roughness of rCBs is still lower than for N660.

\subsubsection{Conclusions}

Recovered carbon blacks produced at different temperatures and virgin carbon black N660 were characterized in terms of surface area, structure, surface chemistry, surface activity and surface nano-roughness. Microscopy techniques revealed the presence of both organic and inorganic contaminants in rCBs located on the carbon black surface. The presence of organics is more visible in samples produced at lower pyrolysis temperatures, covering the whole carbon aggregate structure. It is visible in all samples that $\mathrm{rCBs}$ exhibit a more closed structure than the virgin carbon black N660. A positive impact of increasing pyrolysis temperature is noticed as an increase of the surface area and improvement of the structure. This improvement is due to the fact that organic volatiles were removed from the structural voids to a higher extent at increased temperatures, resulting in an opening of the structure and hence increase of both properties. However, the $\mathrm{rCB}$ tint strength shows less dependence on pyrolysis temperature: it does not improve much above $600^{\circ} \mathrm{C}$. Additionally, the aggregate size is not much affected either by the process conditions.

The surface functionality characterization revealed the rCB carbon functionalities and the chemical nature of inorganics. An increasing pyrolysis temperature resulted in a growth in carbon functionalities, as the $\mathrm{C}-\mathrm{O}$ functionality became more prominent, while inorganics remained unaffected. From oxygen, sulfur and zinc spectral analysis it could be concluded that zinc is mostly present in the form of zinc sulfide, while sulfur compounds which are formed during pyrolysis are attached on carbon surface.

The surface activity of rCBs in terms of the non-polar dispersive component is improved with increasing pyrolysis temperature. This could be anticipated since less volatiles on the carbon surface at higher pyrolysis temperatures mean that more energetic sites are available on the $\mathrm{CCB}$ to interact. This explanation could also be validated by the observed improvement in the $\mathrm{CCB}$ surface nano roughness: the size exclusion effect was more visible for $\mathrm{rCB}$ produced at higher temperatures (P700). Nevertheless, the $\mathrm{rCB}$ dispersive energy and the nano-roughness was still much lower than for N660. The specific interactions of $\mathrm{rCB}$ with polar probes were higher than for N660 due to the presence of polar silica in the inorganics fraction.

To conclude, when replacing conventional carbon black by any of these rCBs in rubber compounds, it can be expected that rCBs have higher filler-filler interactions and lower compatibility with non-polar rubbers compared to their virgin counterpart. 


\section{References}

[1] E. Brendlé, and E. Papirer, J. Colloid. Interface Sci., 194, 217 (1997).

[2] www.adscientis.com

[3] J.H. de Boer, The dynamical Character of Adsorption, Oxford University Press, London, (1968).

[4] G.M. Dorris, and D.G. Gray, J. Colloid. Interface Sci., 71, 93 (1979).

[5] E. Papirer, E. Brendlé, F. Ozil, and H. Balard, Carbon, 37, 1265 (1999).

[6] H. Weiner, J. Am. Chem. Soc., 69, 17 (1947).

[7] C.S. Flour, and E. Papirer, J. Colloid. Interface Sci., 91, 69 (1983).

[8] M.P. Comard, H. Balard, and J.A. Dodds, Colloids Surface., 232, 269 (2004).

[9] Rubber blacks, TDS, Orion Engineered Carbons.

[10] ASTM D2414 - 21, " Standard Test Method for Carbon black - Oil Adsorption Number (OAN)", ASTM International (2011).

[11] G. Joyce, W.M. Henry, A.W. Thronton, and J.C. Hodgin, Rubber World, 244, 21 (2011).

[12] A. Medalia, and L.W. Richards, J. Colloid Interface. Sci., 40, 233 (1972).

[13] G. Heideman, R.N. Datta, J.W. Noordermeer, and B. van Baarle, Rubber Chem. Technol., 77, (512) (2004).

[14] B. Dogadkin, and I. Beniska, Rubber Chem. Technol., 31, 329 (1958).

[15] M.J. Wang, S. Wolff and J.B. Donnet, Rubber Chem. Technol., 64, 714, (1991).

[16] C. Roy, A. Rastegar, S. Kaliaguine, H. Darmstadt, and V. Tochev, Plast. Rubber Compost. Process. Appl., 23, 21 (1995).

[17] Y. Chun, G. Sheng, C.T. Chiou, and B. Xing, Environ. Sci. Technol., 38, 4649 (2004).

[18] A. Schröder, M. Klüppel, R.H. Schuster and J. Heidberg, Carbon, 40, 207 (2002).

[19] H. Balard, and E. Brendlé, Kautsch. Gummi Kunstst., 55, 464 (2002). 
[20] E. Brendlé, and E. Papirer, Surface Properties Characterization by Inverse Gas Chromatography (IGC) Applications, In Powders and Fibers, CRC Press, (2006).

[21] R. Calvet, S.D. Confetto, H. Balard, and J.B. Donnet, J. Chromatogr. A, 1253, 164 (2012). 
Chapter 4.2 
CHAPTER 5

\section{INFLUENCE OF PYROLYSIS PARAMETERS ON THE IN-RUBBER PERFORMANCE OF RECOVERED CARBON BLACK}

Recovered carbon blacks (rCBs) based on passenger car tire rubber from a new ultra-fast pyrolysis process are evaluated in terms of their rubber reinforcement potential. The influence of pyrolysis temperature (Chapter 5.1) and residence time (Chapter 5.2) on the in-rubber properties is studied using a formulation containing N660 carbon black as reference. The compound for testing the different carbon blacks is based on S-SBR rubber, and in-rubber properties are tested: viscosity, curing behavior, stress-strain properties, hardness, filler-filler and filler-polymer interactions.

The $\mathrm{rCB}$ reinforcement shows a clear correlation with pyrolysis temperature: the stress-strain properties improve with increasing temperature, at which the rCBs were recovered. The most significant $\mathrm{rCB}$ in-rubber performance improvement is achieved, when the pyrolysis temperature increased from $500^{\circ} \mathrm{C}$ to $600^{\circ} \mathrm{C}$, with a further slight improvement till $700^{\circ} \mathrm{C}$. The compounds with $\mathrm{rCB}$ show a decreasing curing rate with increasing $\mathrm{rCB}$ pyrolysis temperature. Filler-filler interactions as measured by the Payne effect turn out to be stronger for compounds containing rCBs obtained at increased pyrolysis temperatures, but at the same the time stress-strain properties and filler-polymer interactions are improved.

The $\mathrm{rCB}$ reinforcement is also improved when residence time is doubled at pyrolysis temperatures of $500^{\circ} \mathrm{C}$ and $600^{\circ} \mathrm{C}$, with no further improvement for a tripled residence time. In contrast, at $700^{\circ} \mathrm{C}$ longer residence times result in a negative influence on the $r C B$ stress-strain properties and stronger filler-filler interactions.

Compared to the reference compound containing N660 carbon black, compounds with $\mathrm{rCBs}$ pyrolyzed above $600^{\circ} \mathrm{C}$ or with double residence time possess higher fillerpolymer interactions despite poor filler dispersion. RCB recovered at $700^{\circ} \mathrm{C}$ with minimum residence time shows best in-rubber performance revealing optimum process conditions in view of rubber applications. The higher pyrolysis temperature 
Chapter 5

aids faster volatile removal, while shorter residence time prevents the formation of carbonaceous residues, resulting in relatively better filler-filler and filler-polymer interactions. 
CHAPTER 5.1

\section{INFLUENCE OF PYROLYSIS TEMPERATURE ON THE IN-RUBBER PERFORMANCE OF RECOVERED CARBON BLACK}

\subsubsection{Introduction}

Carbon black as reinforcing filler in rubber compounds enhances mechanical properties including tensile strength, tear strength, abrasion resistance and modulus $^{1}$. The potential of carbon black to reinforce the rubber matrix is dependent on its material characteristics defined during its production, including surface area, aggregate structure and surface activity ${ }^{2}$. Higher surface area and activity of a filler lead to increased filler-polymer interactions ${ }^{3-4}$. Moreover, branched aggregate structures result in easier filler dispersion and improved filler-polymer interactions by trapping polymer chains in their voids ${ }^{5-6}$. However, carbon black recovered from scrap tires by pyrolysis is not comparable to virgin carbon black: it not only contains the carbon black used during tire manufacturing, but also a considerable fraction of organics and inorganics (ash) which are dependent on the process parameters and type of feedstock, respectively ${ }^{7-8}$. The rCB ash content can vary from 5 to $25 \%$ depending on the type of feedstock; the ash mainly composed of zinc and sulfur compounds, and silica ${ }^{9-10}$.

Studies have shown that pyrolysis process parameters have a significant influence the on recovered product yield and quality. Recovered carbon black characteristics can vary significantly, especially the organic part is mainly influenced by altered process conditions. Cunliffe and Williams ${ }^{11}$ studied the influence of the process temperature in a fixed bed reactor and reported reduced volatile content and hydrogen content, and an increase in surface area with increasing pyrolysis temperature. Li et al. ${ }^{12}$ and Galvagno et al. ${ }^{13}$ reported similar findings while using a rotary kiln reactor. In addition, Darmstadt et al. ${ }^{14}$ used vacuum pyrolysis and reported no temperature influence on surface area, while they found enhanced carbonoxygen functionalities with higher amount of $C=O$ type oxygen as the process temperature was increased. In Chapter 4.2, rCB characteristics including volatile 
content, surface chemistry and area, structure and surface nano-roughness were extensively studied, and positive improvements in all properties were found with increasing pyrolysis temperature. However, a relationship between pyrolysis process parameters and in-rubber performance is still missing.

Another important pyrolysis process parameter is residence time. Various studies ${ }^{15-}$ 17 have shown that longer residence times lead to carbonaceous residue formation on the recovered carbon black surface. During thermal cracking of elastomers in pyrolysis, dehydrogenation occurs leading to complex polyaromatic structures. As the reaction continues, these complexes become less volatile and are very likely the precursors of carbonaceous residue formation. Norris ${ }^{18}$ and Van Oorschot ${ }^{19}$ reported significantly lower amount of $\mathrm{PAH}$ in various $\mathrm{rCBs}$ compared to pure carbon blacks which suggests that these aromatic structures are tightly bonded to the rCB surface and are non-extractables. The formation of carbonaceous residue at longer residence times is expected to lead to sintering of carbon black aggregates making them difficult to be broken up. This adversely affects their dispersibility in a rubber compound $^{20}$.

It is remarkable that the $\mathrm{rCB}$ specific surface area can reach the same level as reinforcing virgin carbon blacks grades such as N33021-22. However, even with a surface area comparable to the one of the originally used CB grades, rCB's showed inferior properties and have to be categorized as semi-reinforcing blacks when blended with rubber ${ }^{23-24}$. This disparity is explained by the influence of inorganics and condensed organics covering the high energetic sites of carbon black and lowering the surface activity, thereby negatively affecting filler-polymer interactions.

The consequences of the presence of silica in rCBs and its effect on in-rubber properties is further not fully understood. It is known from silica compounding in general, that silica shows stronger filler-filler interactions than carbon black, and that it is difficult to disperse this polar filler when mixed in rubber without a coupling agent. Moreover, it also adsorbs polar curatives such as N-tert-butyl-benzothiazole sulfenamide (TBBS) or 1,3-diphenylguanidine (DPG) via hydrogen bonding and releases them at a later stage of vulcanization, consequently affecting the cure behavior ${ }^{25-26}$. Therefore, it can be expected that its presence in rCB definitely not only affects the filler-polymer interactions, but also the curing behavior of rubber compounds wherein it is employed.

The novel ultra-fast pyrolysis process and the influence of its pyrolysis parameters on recovered carbon black characteristics are described in Chapter 4.1 and 4.2. In the present study, Chapter 5.1, the influence of the pyrolysis temperature at minimum residence time on the $\mathrm{CCB}$ in-rubber performance is highlighted. In Chapter 5.2 , the effect of residence time on the rubber properties will be discussed. In this 
study, the behavior of rCBs in rubber will be described and explained in terms of curing, filler-filler interactions, filler-polymer interactions and stress-strain properties.

\subsubsection{Experimental}

\subsubsection{Materials}

Rubber: The polymer used for in-rubber evaluation was an oil-extended solutionstyrene butadiene rubber (S-SBR); trade name Buna VSL 2538-2 and manufactured by ARLANXEO, Cologne, Germany. This S-SBR type contains $25 \%$ of vinyl groups and $38 \%$ styrene. It is oil extended with 37.5 parts per hundred rubber (phr) of treated distillate aromatic extracted (TDAE) oil.

Protective agents: Compounding ingredients N-(1,3-dimethylbutyl)-N'-phenyl-pphenylenediamine (6PPD) and 2,2,4-trimethyl-1,2-dihydroquinoline (TMQ) as antioxidants were provided by Flexys, Belgium. Wax for ozone protection was provided by Sasol Wax GmbH, Germany.

Cure package: This includes sulfur, zinc oxide $(\mathrm{ZnO})$ stearic acid and N-tert-butylbenzothiazole sulfenamide (TBBS) from Sigma Aldrich.

Reference carbon black: A semi-reinforcing commercial grade of carbon black, N660, was used as reference. Corax N660 was provided by Orion Engineered Carbons, Frankfurt, Germany. N660 carbon black exhibits a BET specific surface area in the range of $35 \mathrm{~m}^{2} / \mathrm{g}-45 \mathrm{~m}^{2} / \mathrm{g}$.

Recovered carbon black (rCB): The feedstock used for pyrolysis was passenger car tires from Granuband, the Netherlands. The feedstock was pyrolyzed at different temperatures in an entrained flow reactor as explained in Chapter 4.1, and listed in Table 5.1.1. The average ash content in all rCBs was in the range of $22 \%$ to $25 \%$. 
Table 5.1.1 Notations used for recovered carbon blacks produced at different pyrolysis temperatures.

\begin{tabular}{|c|c|}
\hline $\begin{array}{c}\text { Recovered carbon } \\
\text { blacks }\end{array}$ & $\begin{array}{c}\text { Pyrolysis process } \\
\text { temperature }\left({ }^{\circ} \mathbf{C}\right)\end{array}$ \\
\hline P500 & 500 \\
\hline P550 & 550 \\
\hline P600 & 600 \\
\hline P650 & 650 \\
\hline P700 & 700 \\
\hline
\end{tabular}

\subsubsection{Grinding of recovered carbon blacks}

Prior to compounding, all rCBs were first ground in a ball mill model Pulverisette 5 by Fritsch, Germany. 25 grams of rCB per milling jar was ground at $250 \mathrm{rpm}$ for 10 minutes.

\subsubsection{Pelletizing of recovered carbon blacks}

The rather fluffy blacks after grinding cannot directly be mixed into rubber, therefore a suitable lab scale pelletizing unit was developed. In industry, pin mixers are used for this purpose, in which carbon black enters via a moving screw, and the pins of the mixers are used to keep it free flowing. During this state, a binder is sprayed for agglomeration of the particles at sub millimeter length scale. Since pin mixers (Figure 5.1.1) are only available for large amounts in the range of kilograms or tons, different methods were tested in the lab to make pellets out of the fluffy carbon black. 


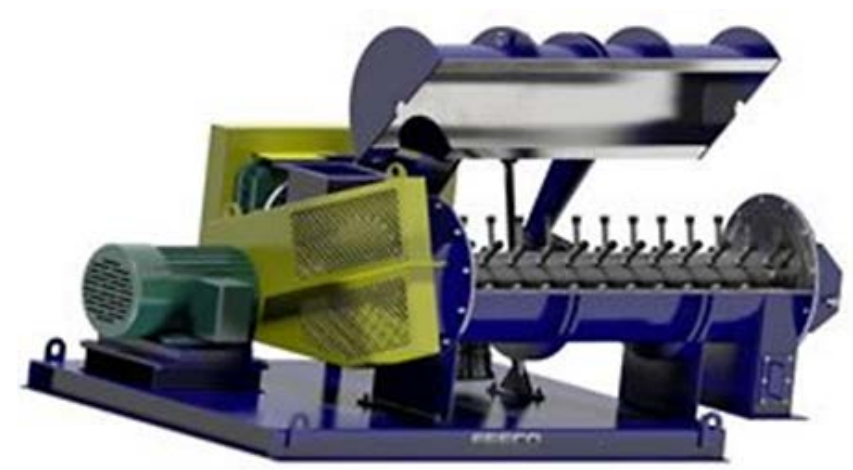

Figure 5.1.1 Industrial pin mixer for carbon black pelletizing 27 .

For pelletizing smaller quantities of $\sim 250$ grams per sample, the following methods were tested:

- Magnetic stirring

- Manual shaking

- Rotary evaporator

- $\quad$ Rotating disc pelletizer

- Ball mill

See Appendix I for a complete report of the pelletizing unit development and parameter optimization. After testing the above mentioned methods, the planetary ball mill previously also used for grinding turned out to be the most appropriate one. For pelletizing the fluffy char, no grinding balls were used in the milling jar. Water was added as a binding agent. After optimizing the variables including material content per jar, binder content, rotation speed and time, 30 grams of $\mathrm{rCB}$ per jar were pelletized at $300 \mathrm{rpm}$ for 5 minutes with $20 \mathrm{ml}$ of water.

The samples were dried for 24 hours at $120^{\circ} \mathrm{C}$ to remove the added water. The moisture content in the rCB pellets after drying is less around $0.5 \mathrm{wt} . \%$ as measured by Thermo-Gravimetric Analysis (TGA) at $100^{\circ} \mathrm{C}$ and shown in Figure 5.1.2. Further weight loss at higher temperatures is due to the removal of feedstock residues such as light oil fractions. The samples were heated in a nitrogen environment up to $300^{\circ} \mathrm{C}$ and the weight loss was measured. Lab scale pellets possessed a slightly lower moisture content than industrial pellets. 


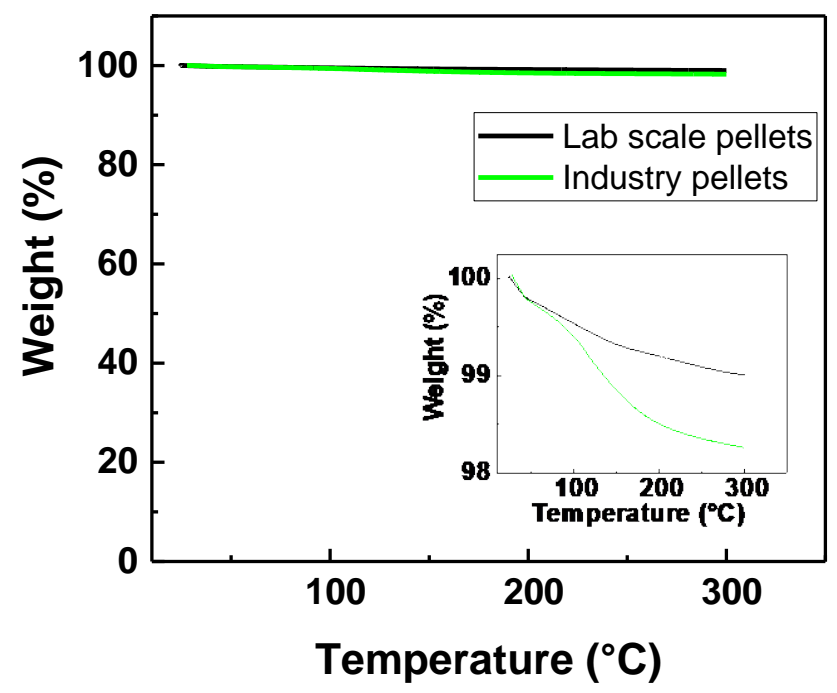

Figure 5.1.2 Moisture content of pellets made in the lab (black) and a commercial grade (green).

\subsubsection{Compounding}

The compound formulation used in this study is shown in Table 5.1.2. Since rCB contained $25 \%$ of ash, the amount of recovered carbon black was adjusted in order to have a similar amount of carbon black in both, the reference and the $\mathrm{rCB}$ compounds. No further adjustments for e.g. the presence of silica and $\mathrm{ZnO} / \mathrm{ZnS}$ were made.

Mixing of carbon black and recovered carbon black compounds was done according to the formulation given in Table 5.1.2. Mixing was carried out in a Brabender Plasticorder $350 \mathrm{~S}$ internal batch mixer. A two stage mixing procedure was followed as shown in Table 5.1.3. 
Table 5.1.2 Compound formulation for reference $N 660$ and rCB compounds.

\begin{tabular}{|c|c|c|c|}
\hline Mixing stage & Materials & $\begin{array}{c}\text { Reference } \\
\text { formulation for } \\
\text { N660 (phr) }\end{array}$ & $\begin{array}{c}\text { rCB formulation } \\
\text { (phr) }\end{array}$ \\
\hline 1 & $\begin{array}{c}\text { S-SBR oil } \\
\text { extended }\end{array}$ & 137.5 & 137.5 \\
\hline 1 & Carbon black & 60 & $75^{\star}$ \\
\hline 1 & 6PPD & 1.5 & 1.5 \\
\hline 1 & TMQ & 1 & 2.5 \\
\hline 1 & Wax & 2.5 & 3 \\
\hline 1 & Zinc oxide & 3 & 2 \\
\hline 1 & Stearic acid & 2 & 1.65 \\
\hline $\mathbf{2}$ & Sulfur & 1.65 & 0.7 \\
\hline $\mathbf{2}$ & TBBS & 0.7 & \\
\hline
\end{tabular}

*adjusted for $25 \%$ of ash content: total carbon content $=60$ phr. 
Table 5.1.3 Mixing sequence.

\begin{tabular}{|c|c|c|c|}
\hline \multicolumn{2}{|c|}{ First stage } & \multicolumn{2}{|c|}{ Second stage } \\
\hline \multicolumn{2}{|c|}{ Internal mixer } & \multicolumn{2}{|c|}{ Internal mixer } \\
\hline Steps & Time & Steps & Time \\
\hline Polymer addition & $00: 00-00: 20$ & \multirow{2}{*}{$\begin{array}{l}\text { Add } 1^{\text {st }} \text { stage } \\
\text { compound }\end{array}$} & \multirow[t]{2}{*}{$00: 00-00: 30$} \\
\hline Mastication & $00: 20-00: 50$ & & \\
\hline $1 / 2$ Carbon & $00: 50-01: 00$ & \multirow[t]{2}{*}{ Mastication } & \multirow[t]{2}{*}{$00: 30-00: 50$} \\
\hline Mixing & $01: 00-01: 30$ & & \\
\hline $1 / 2$ Carbon + additives & $01: 30-01: 40$ & \multirow[t]{2}{*}{ Curatives } & \multirow[t]{2}{*}{$00: 50-01: 10$} \\
\hline Mixing & $01: 40-02: 10$ & & \\
\hline Hopper cleaning & $02: 10-02: 20$ & \multirow[t]{2}{*}{ Mixing } & \multirow[t]{2}{*}{$01: 10-03: 10$} \\
\hline mixing & $02: 20-04: 20$ & & \\
\hline $\begin{array}{l}\text { Discharge and } \\
\text { sheeting off }\end{array}$ & - & $\begin{array}{l}\text { Discharge and } \\
\text { sheeting off }\end{array}$ & - \\
\hline
\end{tabular}

In the first stage, all ingredients were mixed except for the curatives. The internal batch mixer for the first stage mixing was operated at a rotor speed of $100 \mathrm{rpm}$, a fill factor of $75 \%$ and a set temperature of $90^{\circ} \mathrm{C}$. The dump temperature of the batches after first stage mixing was $145^{\circ} \mathrm{C}$. Curatives were added in the second stage of mixing. The same internal batch mixer was operated for the second stage mixing at a rotor speed of $80 \mathrm{rpm}$, a fill factor of $75 \%$ and a temperature of $50^{\circ} \mathrm{C}$; the dump temperature was $90^{\circ} \mathrm{C}$. The compounds were sheeted on a two roll mill. Each compound containing a certain type of carbon black was prepared three times to control the reproducibility of the results. The compounds are referred to according to the type of carbon black used. 


\subsubsection{In-rubber evaluation}

\subsection{Mooney viscosity}

The Mooney viscosity of the compounds was tested using a Mooney viscometer MV200VS from Alpha Technologies. Measurements were performed at $100^{\circ} \mathrm{C}$ with a large rotor according to ASTM D1646. The value is represented as $\mathrm{ML}(1+4) 100^{\circ} \mathrm{C}$.

\subsection{Uncured Payne effect}

A Rubber Process Analyzer (RPA) Elite from TA Instruments was used to measure the shear storage modulus (G') as a function of strain amplitude. A strain sweep was carried out at $100^{\circ} \mathrm{C}$ in the range of $0.56 \%-100 \%$ strain amplitude at $0.5 \mathrm{~Hz}$. The Payne effect $(\Delta G)$ was calculated according to Equation (5.1.1):

$$
\Delta G^{\prime}=G^{\prime}(0.56 \%)-G^{\prime}(100 \%)
$$

\subsection{Bound rubber}

Approximately $0.2 \mathrm{~g}$ of the rubber compounds without curatives, as obtained from the first mixing step, were cut into small pieces and immersed in toluene at room temperature for 7 days. Thereafter, the samples were removed from the toluene, dried at $100^{\circ} \mathrm{C}$ in a vacuum oven for $24 \mathrm{~h}$ and weighed. The bound rubber content was calculated according to Equation (5.1.2),

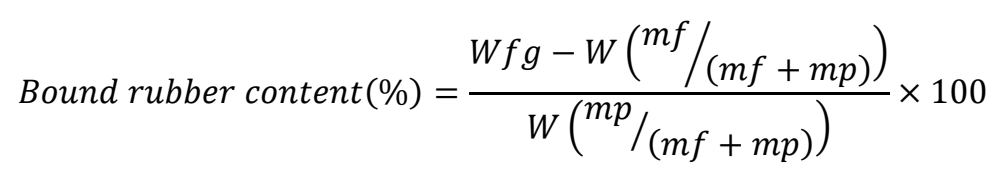

Where Wfg is the weight of filler plus bound rubber, $W$ is the original weight of the specimen, $\mathrm{mf}$ and $\mathrm{mp}$ are the weights of filler and polymer in the compound, respectively.

\subsection{Cure characteristics}

A Rubber Process Analyzer RPA Elite from TA Instruments was utilized for curing measurements according to ISO 3417. The increase in torque was measured for 
60 minutes. The total torque increase was calculated as the difference between the maximum and minimum torque, $\mathrm{S}_{\min }-\mathrm{S}_{\max }$. The scorch time was measured as the time required to increase the torque by $2 \mathrm{dN}$.m.

\subsection{Cure rate index}

Cure rate index (CRI) was calculated according to Equation (5.1.3):

$$
C R I\left(\mathrm{~min}^{-1}\right)=\frac{100}{T_{90}-T_{S 2}}
$$

Where $T_{90}$ is the time required for $90 \%$ curing and $T_{s 2}$ is the scorch time.

\subsection{Marching modulus intensity}

The marching modulus intensity (MMI) of all cure curves was calculated by Equation (5.1.4):

$$
\operatorname{MMI}\left(\frac{d N . m}{\min }\right)=\frac{T_{60}-T_{40}}{60 \min -40 \min }
$$

Where $T_{60}$ and $T_{40}$ are the torque values after 60 minutes and 40 minutes of curing in the RPA, respectively. This time range was selected as it was above the time required for $90 \%$ curing of compounds and represents only the marching behavior.

\subsection{Vulcanization}

Samples were vulcanized in a Wickert press WLP 1600 with a pressure of 100 bar at $160^{\circ} \mathrm{C}$ to sheets with a thickness of $2 \mathrm{~mm}$. All samples were vulcanized at 20 minutes. The vulcanization time was set to this period in order to have comparable results with the industrial trials of the industry partner. 


\subsection{Hardness}

For hardness measurements, round discs with a thickness of $6 \mathrm{~mm}$ and a diameter of $60 \mathrm{~mm}$ were vulcanized for 25 minutes at $160^{\circ} \mathrm{C}$.

\subsection{Tensile properties}

Type 2 dumbbell test specimens (2 mm thick) were prepared according to ISO 37 . Tensile properties including modulus at different strains, tensile strength, and elongation at break were tested with a Zwick tensile tester model Z1.0/TH1S ( Zwick Roell Group, Germany) at a cross-head speed of $500 \mathrm{~mm} / \mathrm{min}$.

For tensile properties, an average over five dumbbells was taken, while for the stress-strain graph, the median was chosen. 


\subsubsection{Results and Discussion}

In this section, the influence of pyrolysis temperature on $\mathrm{rCB}$ in-rubber behavior is covered in terms of filler-filler interactions, filler-polymer interactions, curing behavior and mechanical properties. These rCBs are compared with semi reinforcing carbon black N660.

\subsubsection{Filler-filler and filler-polymer interactions}

Figure 5.1.3 shows the influence of $\mathrm{rCBs}$ produced at different pyrolysis temperatures on the Mooney viscosity of the compounds. The compound with the reference carbon black N660 exhibits a Mooney viscosity similar to the compound containing rCB P550. This is surprising, as the $\mathrm{rCB}$ quantity was adjusted according to the ash content, meaning that $25 \%$ additional rCB was added. Therefore, higher Mooney viscosities would be expected for the rCB compounds due to the fact of an additional solid fraction, the ash content, leading to higher viscosities. For carbon blacks, above $30 \mathrm{phr}$ compound viscosity usually increases by $0.5 \mathrm{MU}$ to $1 \mathrm{MU}$ per $\mathrm{phr}^{28}$. The reason behind the low viscosities for $\mathrm{rCB}$ compounds is that the rCBs contain a significant amount of soft matter: light hydrocarbons and/or unconverted rubber (Chapter 4.1), hence the carbon black fraction in the strict sense of the word is lower compared to the N660 compounds.

The Mooney viscosities of the $\mathrm{rCB}$ compounds are increased with increasing pyrolysis temperature of the rCB's in the range of $42-50$ Mooney units up to $700^{\circ} \mathrm{C}$. From a pyrolysis temperature of $600^{\circ} \mathrm{C}$ onwards, the viscosities are higher than the viscosity of the reference compound. In carbon black compounds, increase in viscosity can be interpreted as enhanced filler-polymer interactions due to bound rubber content increase, as well as by increased filler-filler interactions due to poor dispersion ${ }^{29-30}$. Therefore, the increase in Mooney viscosity with higher pyrolysis temperature indicates more intensive $\mathrm{rCB}$ filler-filler interactions and possibly fillerpolymer interactions. 


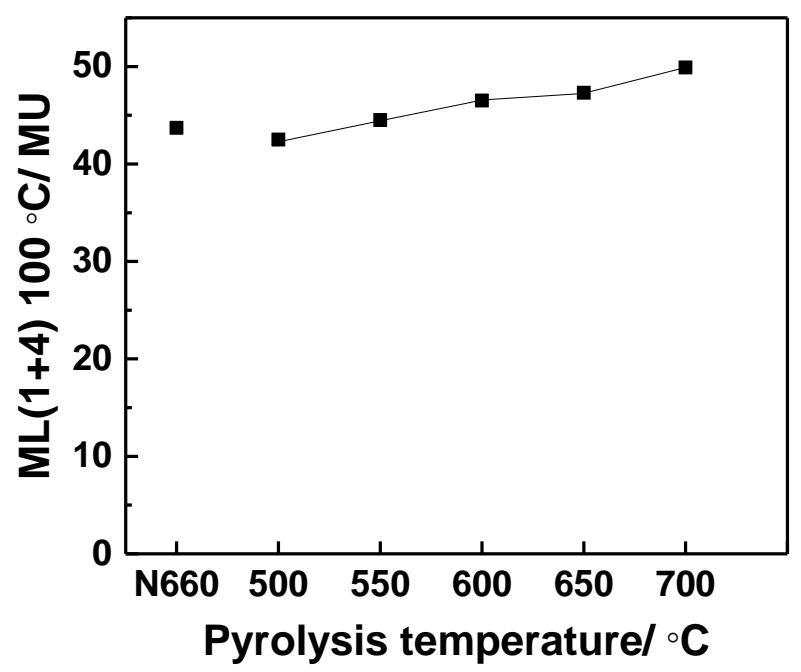

Figure 5.1.3 Mooney viscosity of compounds filled with CB N660 and rCBs produced at different temperatures.

In Figure 5.1.4, similar trends for the dump torque values are seen as for the Mooney viscosity with respect to pyrolysis temperature. Figure 5.1.5 shows a good correlation between the Mooney viscosity and the dump torque confirming the increase in rCB filler-filler interaction. The increases in torque and viscosity show that filler-filler interactions are getting stronger and the dispersion of the filler in rubber is becoming poorer. 


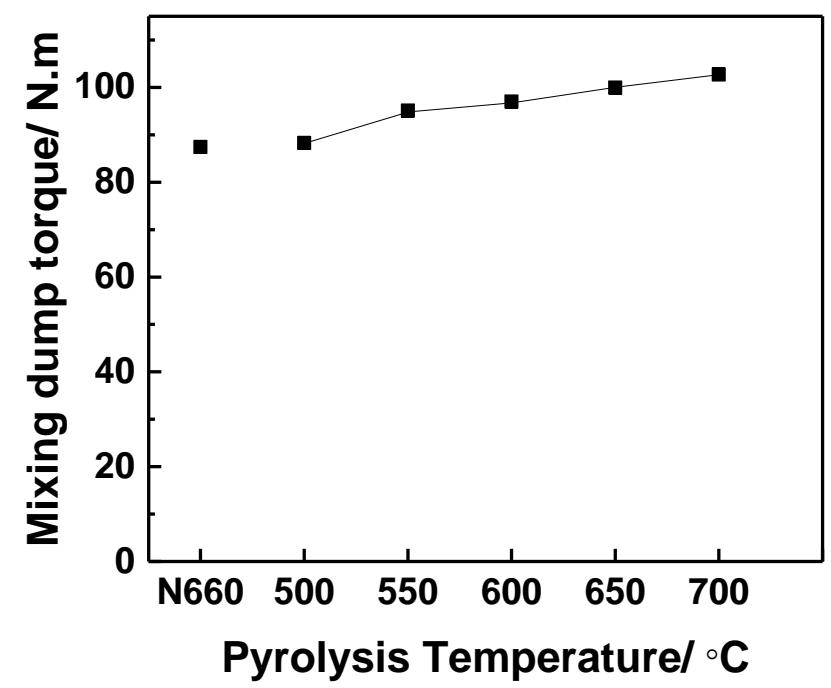

Figure 5.1.4 Mixing dump torque of the reference N660 and rCB filled compounds

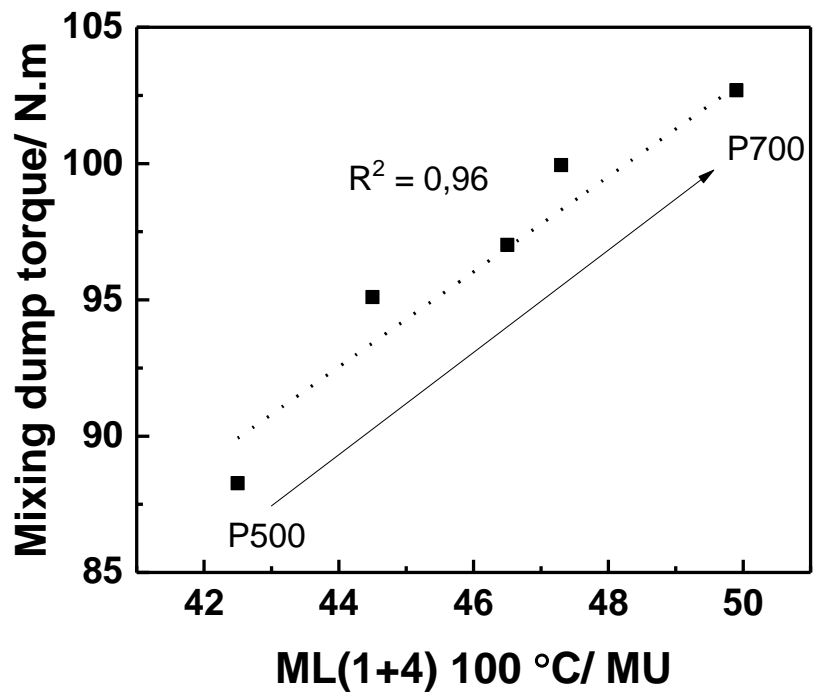

Figure 5.1.5 Correlation between Mooney viscosity and mixing dump torque.

Figure 5.1.6 (a) shows the strain dependent measurement of the storage modulus for the uncured reference compound filled with $\mathrm{N} 660$ and rCBs produced at different 154 
pyrolysis temperatures. In the strain dependent measurements, $G^{\prime}$ at low strain amplitudes ( $\left.G^{\prime}(0.56 \%)\right)$ and $G^{\prime}$ at high strain amplitudes ( $\left.G^{\prime}(100 \%)\right)$ usually illustrate the filler-filler interactions and the filler-polymer interactions, respectively. In Figure 5.1.6(a), at lower strain, the $\mathrm{N} 660$ filled compound exhibits a similar storage modulus $\left(G^{\prime}(0.56 \%)\right)$ as the rCB P550 filled compound. The rCB filled compounds in general show an increasing trend of $G^{\prime}$ with increasing pyrolysis temperature indicating a higher degree of $\mathrm{rCB}$ filler-filler interaction, as could also be concluded from the viscosity measurements. However, the increase in these interactions slow down above a pyrolysis temperature of $600^{\circ} \mathrm{C}$. At high strain, a similar trend is seen: Increase in $\mathrm{G}^{\prime}(100 \%)$ shows a slight improvement in rCB filler-polymer interactions with increasing pyrolysis temperatures. This improvement is clear, as the volatile content is decreased with increasing pyrolysis temperature, reducing the remaining coverage of $\mathrm{rCB}$ with organic matter. This results in a higher carbon black surface area which can interact with the polymer. Furthermore, rCB also contains sulfur in the ash, and in case that it is in some sort of an active form such as carbon-sulfur complex indicated in Chapter 4.2 (Table 4.2.3), it leads to pre-scorch and a higher storage modulus at higher deformations. As the volatiles in $\mathrm{rCB}$ are decreased with increasing temperature, the $\mathrm{rCB}$ components including sulfur would become more accessible to rubber, thus the probability of ash sulfur-polymer interaction becomes higher with reduced amount of volatiles.

Figure 5.1.6 (b) shows the Payne effect $\left(\Delta G^{\prime}\right)$ of the $N 660$ and rCBs filled compounds. The N660 filled material shows a low Payne effect suggesting a good filler dispersion in the polymer matrix. Only the P500 compound shows a lower Payne effect than the N660 compound. The Payne effect of rCB filled compounds is increased with increasing pyrolysis temperature up to $600^{\circ} \mathrm{C}$, after which it levels off. rCBs produced at or above $600^{\circ} \mathrm{C}$ show higher Payne effect values and higher G' at lower strains (Figure 5.1.6(a)), suggesting strong filler-filler interactions and expected poor dispersion in the polymer matrix. 

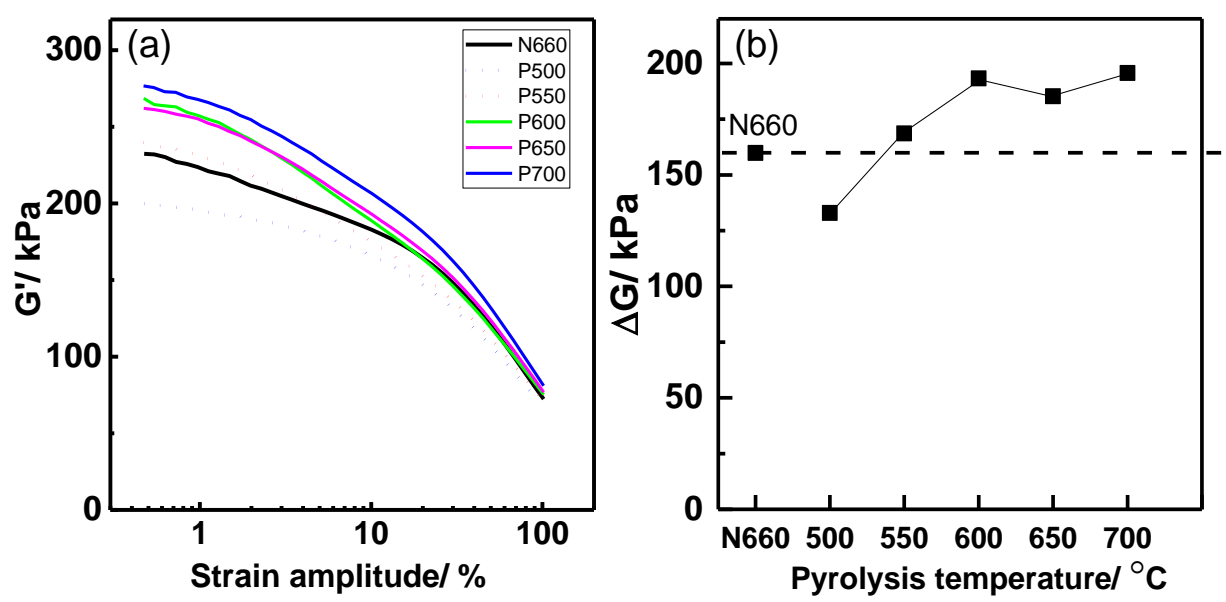

Figure 5.1.6 (a) Strain dependent measurement of the storage modulus on uncured N660 and rCB filled compounds; (b) Payne effect values of these compounds with respect to $\mathrm{rCB}$ pyrolysis temperature.

All three indicators for filler-filler interactions: viscosity, mixing torque and Payne effect, showed similar trends and a clear dependency on pyrolysis temperature. Compared to the reference N660 compound, all compounds with $\mathrm{rCBs}$ above $550^{\circ} \mathrm{C}$ have strong filler-filler interactions.

Figure 5.1.7 shows the bound rubber content of compounds with $\mathrm{N} 660$ and rCBs as indicative for filler-polymer interactions. N660 contains a similar amount of bound rubber as P600, indicating a similar level of filler-polymer interactions. For the rCBcontaining compounds, the bound rubber content is increased with increasing pyrolysis temperature till $700^{\circ} \mathrm{C}$ depicting improvement of the rCB interaction with the polymer matrix.

Strikingly speaking, the bound rubber content of the rCB P500 containing compound possessed a negative value. Since toluene was used to extract the unbound rubber, a negative bound rubber value suggests that the toluene extracts more than the rubber added to the compound. A negative value of bound rubber indicates that this rubber surplus originates from an incomplete pyrolytic conversion of the tire rubber at this temperature. Fragments of the not fully pyrolyzed polymer are attached to the rCB surface and will be extracted with toluene as well. This extraction of polymer segments was already evidenced in Chapter 4.1 as the toluene transmittance of P500 was the lowest. 
The trend of improved filler-polymer interaction with increased pyrolysis temperatures seen for bound rubber is in agreement with the storage moduli measured at higher strains $\left(G^{\prime}(100 \%)\right)$. Both, bound rubber content as well as storage modulus at higher strain show that P500 and P550 compounds exhibit lower filler-polymer interactions compared to the $\mathrm{N} 660$ compound; compounds containing rCB's pyrolyzed at temperatures of $600^{\circ} \mathrm{C}$ and higher exhibit relatively high fillerpolymer interactions.

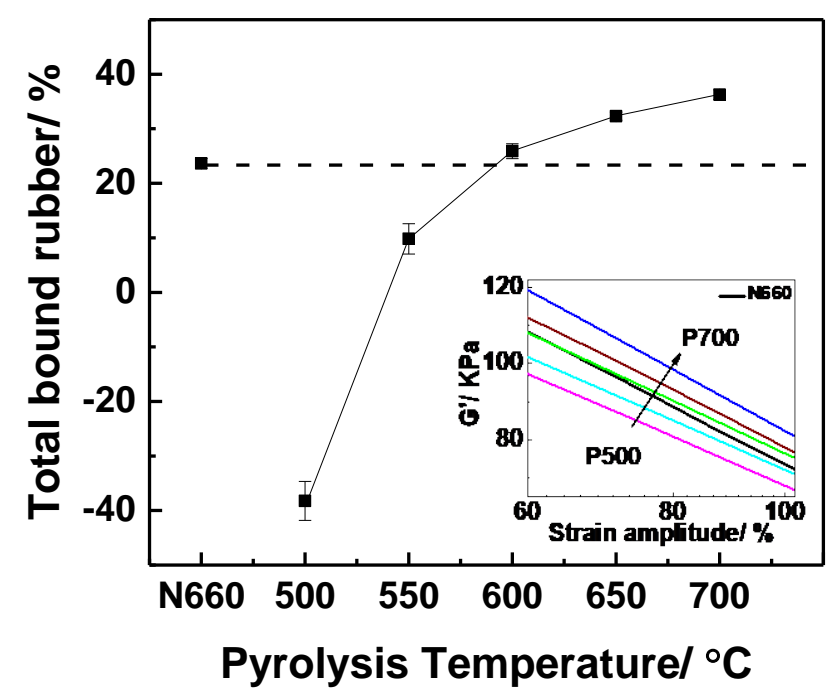

Figure 5.1.7 Total bound rubber content of compounds filled with the reference CB N660 and rCBs produced at different temperatures.

\subsubsection{Cure characteristics}

Figure 5.1 .8 shows the curing behavior of the $\mathrm{N} 660$ and $\mathrm{rCB}$ filled compounds. The differences among the rCB filled compounds and with the N660 compound are evident in terms of initial torque, scorch safety retardation, curing over time (cure rate) and final cure state (final and total torque). 


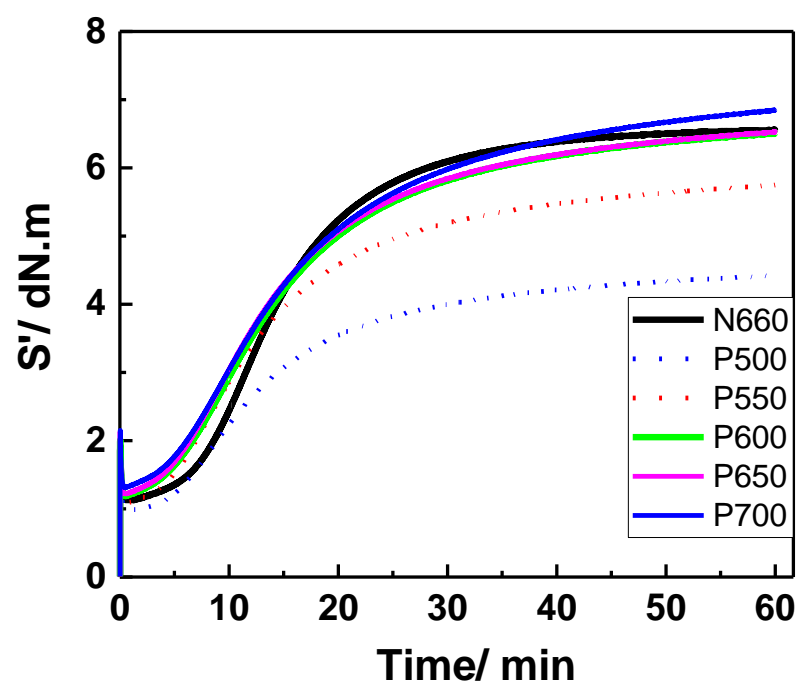

Figure 5.1.8 Cure curves of compounds containing CB N660 and rCBs produced at different temperatures.

The initial torque of the reference compound containing N660 is similar to the torque of the compound containing $\mathrm{rCB}$ produced at $550^{\circ} \mathrm{C}$. In the $\mathrm{rCB}$ compounds, the initial torque is increased with higher rCB pyrolysis temperature up to $600^{\circ} \mathrm{C}$, after which only a minimal increase occurs anymore. The increase in initial torque is generally due to the stronger filler-filler interactions; however, it must be considered that $\mathrm{rCB}$ also contains ash which mainly comprises silica, sulfur and zinc compounds. Therefore, the initial torque increase with increasing pyrolysis temperature is due to the stronger filler-filler interactions or to the presence of active sulfur causing pre-scorch. The aforementioned increase in minimum torque is similar to the trend seen for the Mooney viscosity as compared in Figure 5.1.9. Moreover, the final torque of $\mathrm{rCB}$ compounds increased with increasing pyrolysis temperature up to $600^{\circ} \mathrm{C}$ and reaches the same level as the $\mathrm{N} 660$ compound. Above $600^{\circ} \mathrm{C}$, a further but minimal increase in final torque is observed. Additionally, the N660 compound shows a plateau indicating optimum cure, while rCB compounds show marching modulus. This will be further discussed with Figure 5.1.11 along with the cure rate index. 


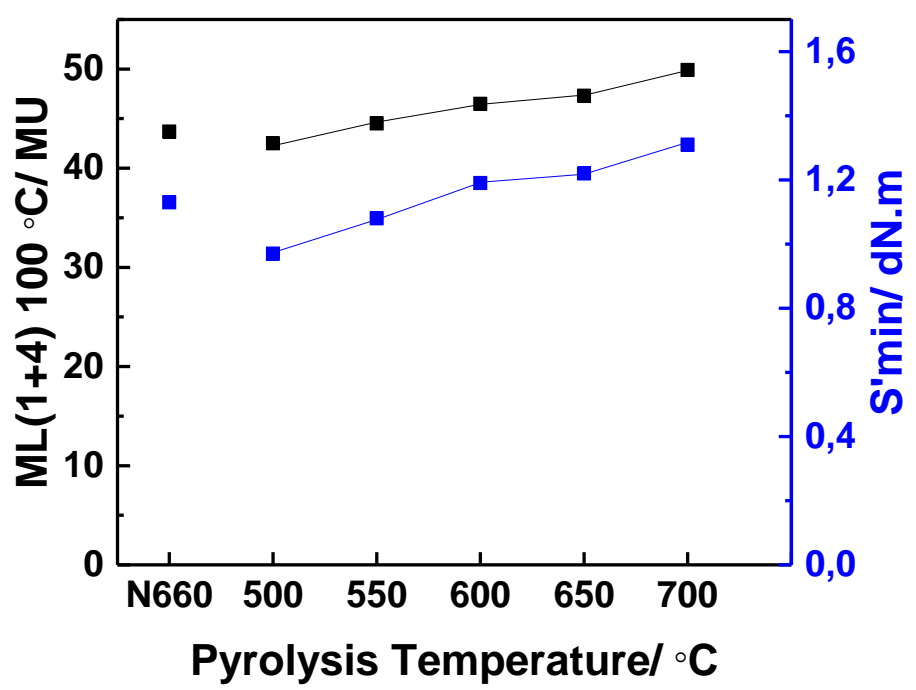

Figure 5.1.9 Trends of Mooney viscosity and minimum torque (S'min)

In Figure 5.1.10, it is clear that the scorch time is decreased for compounds containing rCB produced at temperatures of $500^{\circ} \mathrm{C}$ and $550^{\circ} \mathrm{C}$, and remain constant at higher pyrolysis temperatures: an indication of constant scorch safety. An increase of the delta torque is observed for samples with rCB's produced at temperatures up to $600^{\circ} \mathrm{C}$, after which it levels off and reaches the same level as the N660 compound. 


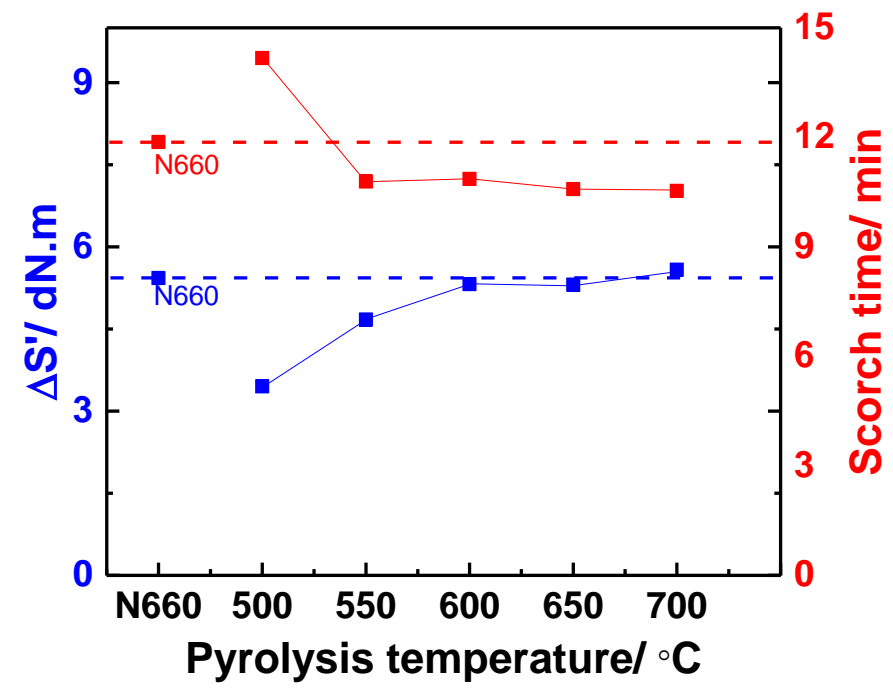

Figure 5.1.10 Total torque $\left(\Delta S^{\prime}\right)$ and scorch time of N660 and rCB filled compounds.

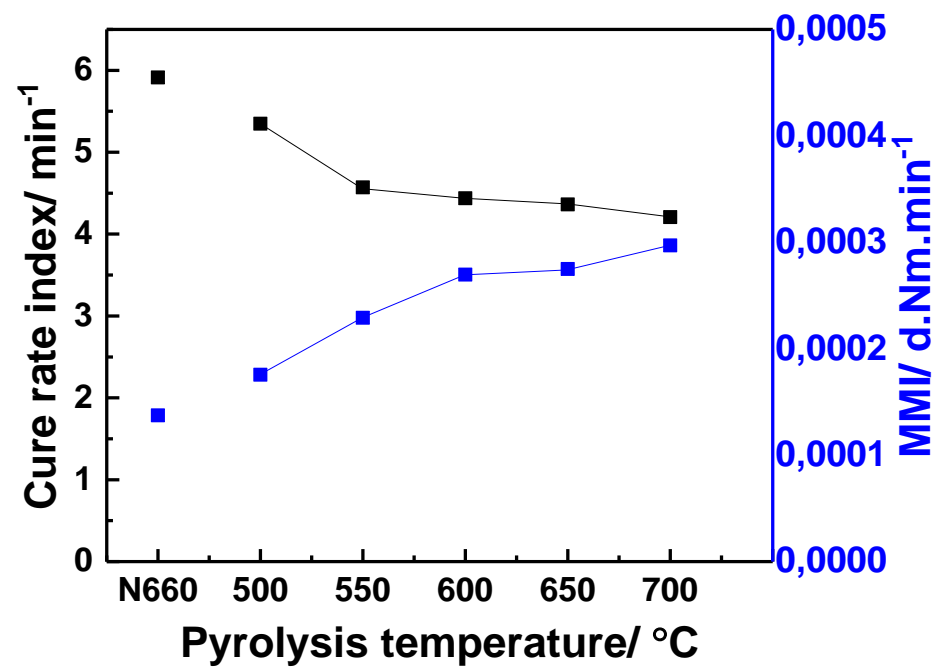

Figure 5.1.11 Cure rate index and marching modulus index MMI of compounds filled with $\mathrm{N} 660$ and with $\mathrm{rCB}$ produced at different temperatures. 
In Figure 5.1.11, the N660 filled compound exhibits the highest cure rate index (CRI), while in case of $\mathrm{rCBs}$ it is lower and decreases with increasing pyrolysis temperature. The marching modulus intensity (MMI) is also the lowest for the N660 compound, where rCB containing compounds showed an increasing MMI with rising pyrolysis temperature. The decreasing $\mathrm{CRI}$ and increasing $\mathrm{MMI}$ with higher pyrolysis temperature indicate the influence of temperature on ash activity: higher the pyrolysis temperature leads to a larger degree of removal of volatiles from the $\mathrm{rCB}$ surface can be expected; consequently, a cleaner surface of the recovered carbon black as well as less contaminated surface of the silica present in the ash fraction of rCB in terms of less volatiles. The cleaner surface of the silica results in a higher degree of adsorption of curatives, hence slowing down the curing process from the beginning, as well as releasing curatives after a certain time causing delayed crosslinking and leading to marching modulus.

\subsubsection{Mechanical properties}

Figure 5.1.12 shows the stress-strain behavior of compounds filled with rCB compared with the compound filled with N660. The N660 filled compound shows better stress-strain properties compared to all rCB filled compounds. Within the series of $\mathrm{rCB}$ compounds, the stress-strain properties improve with increasing pyrolysis temperature. The improvement is marginal above $650^{\circ} \mathrm{C}$, indicating that the optimal point with respect to process temperature and reinforcing capacity is approximately in this range. 


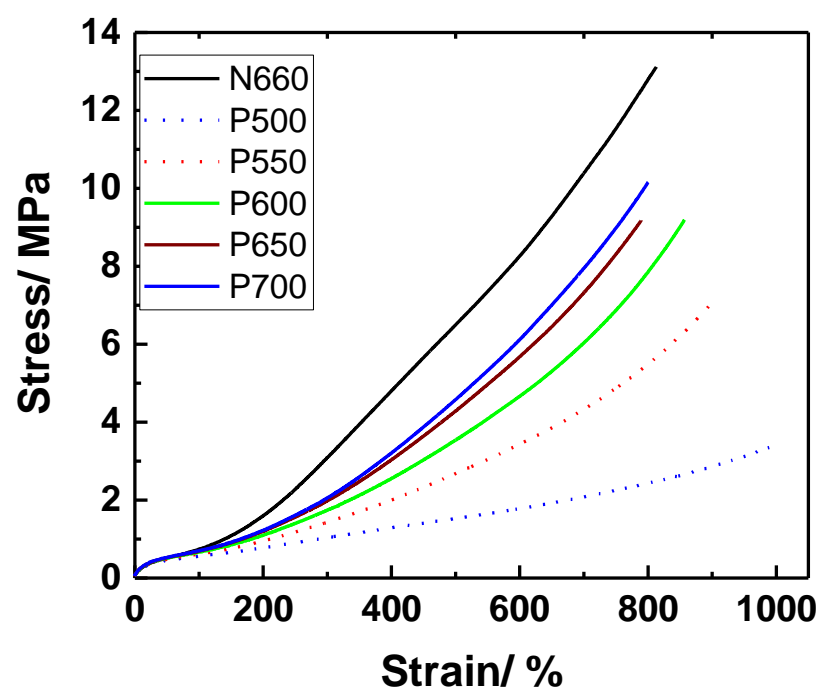

Figure 5.1.12 Stress-strain curves of $\mathrm{N} 660$ and rCB filled rubber.

In Table 5.1.4, the differences in physical properties are further elaborated. In rCB filled rubber, increasing pyrolysis temperature improves the physical properties . Modulus at $100 \%$ strain (M100) increases with increasing process temperature and reaches almost the same level as the $\mathrm{N} 660$ filled material at a pyrolysis temperature of $700^{\circ} \mathrm{C}$. This trend of improvement with increasing process temperature is also clear from the M300 and reinforcement index (M300/M100). However, unlike M100 and $\mathrm{M} 300$, the reinforcement index of $\mathrm{rCB}$ filled materials does not reach the same level as the N660 reinforced rubber. Tensile strength is also the highest for the N660 filled material. In rCB rubber, the tensile strength is improved with increasing process temperature until $650^{\circ} \mathrm{C}$, and after that remains more or less constant. Elongation at break of the $\mathrm{rCB}$ rubber is reduced until $650^{\circ} \mathrm{C}$. The hardness of $\mathrm{rCB}$ containing vulcanizates increases until $600^{\circ} \mathrm{C}$ and becomes also similar to the N660 containing material. 
Table 5.1.4 Physical properties of $\mathrm{N} 660$ and rCB filled rubber.

\begin{tabular}{|c|c|c|c|c|c|c|}
\hline & $\begin{array}{l}M 100 \\
\text { (MPa) }\end{array}$ & $\begin{array}{l}\text { M300 } \\
\text { (MPa) }\end{array}$ & $\begin{array}{l}\text { M300/ } \\
\text { M100 } \\
\text { (MPa) }\end{array}$ & $\begin{array}{l}\text { Tensile } \\
\text { strength } \\
\text { (MPa) }\end{array}$ & $\begin{array}{l}\text { Elongation } \\
\text { at break } \\
(\%)\end{array}$ & $\begin{array}{l}\text { Hardness } \\
\text { Shore A }\end{array}$ \\
\hline N660 & $\begin{array}{l}0.74 \\
\pm 0.01\end{array}$ & $\begin{array}{r}3.1 \\
\pm 0.15\end{array}$ & $\begin{array}{r}4.2 \\
\pm 0.13\end{array}$ & $\begin{array}{l}13.0 \\
\pm 1.1\end{array}$ & $\begin{array}{l}816 \\
\pm 48\end{array}$ & $\begin{array}{l}43 \\
\pm 1\end{array}$ \\
\hline P500 & $\begin{array}{l}0.55 \\
\pm 0.006\end{array}$ & $\begin{array}{l}1.0 \\
\pm 0.01\end{array}$ & $\begin{array}{l}1.9 \\
\pm 0.005\end{array}$ & $\begin{array}{r}3.3 \\
\pm 0.15\end{array}$ & $\begin{array}{l}977 \\
\pm 27\end{array}$ & $\begin{array}{l}38 \\
\pm 1\end{array}$ \\
\hline$P 550$ & $\begin{array}{l}0.60 \\
\pm 0.01\end{array}$ & $\begin{array}{l}1.4 \\
\pm 0.05\end{array}$ & $\begin{array}{r}2.3 \\
\pm 0.05\end{array}$ & $\begin{array}{l}7.0 \\
\pm 0.37\end{array}$ & $\begin{array}{l}900 \\
\pm 39\end{array}$ & $\begin{array}{l}41 \\
\pm 1\end{array}$ \\
\hline$P 600$ & $\begin{array}{l}0.66 \\
\pm 0.008\end{array}$ & $\begin{array}{l}1.7 \\
\pm 0.06\end{array}$ & $\begin{array}{l}2.6 \\
\pm 0.07\end{array}$ & $\begin{array}{l}8.6 \\
\pm 0.54\end{array}$ & $\begin{array}{l}840 \\
\pm 17\end{array}$ & $\begin{array}{l}43 \\
\pm 1\end{array}$ \\
\hline P650 & $\begin{array}{l}0.69 \\
\pm 0.007\end{array}$ & $\begin{array}{l}2.0 \\
\pm 0.01\end{array}$ & $\begin{array}{l}2.8 \\
\pm 0.009\end{array}$ & $\begin{array}{l}9.0 \\
\pm 0.59\end{array}$ & $\begin{array}{l}786 \\
\pm 32\end{array}$ & $\begin{array}{l}43 \\
\pm 1\end{array}$ \\
\hline P700 & $\begin{array}{l}0.7 \\
\pm 0.01\end{array}$ & $\begin{array}{l}2.0 \\
\pm 0.07\end{array}$ & $\begin{array}{r}2.9 \\
\pm 0.05\end{array}$ & $\begin{array}{l}10.0 \\
\pm 0.62\end{array}$ & $\begin{array}{l}790 \\
\pm 27\end{array}$ & $\begin{array}{l}44 \\
\pm 1\end{array}$ \\
\hline
\end{tabular}

Overall, the main differences between $\mathrm{rCB}$ and $\mathrm{N} 660$ are caused by the varied curing behavior, purity of the filler surface and dispersion of the carbon black. These properties are altered with pyrolysis temperature. In uncured compounds, the bound rubber content and 'G' at 100\% suggest higher filler-polymer interactions for rCBs produced at temperatures above $600^{\circ} \mathrm{C}$ compared to the semi-reinforcing carbon black N660. However, in cured compounds, the level of rCB reinforcement never reaches to the N660. This disparity in uncured and cured compounds can be explained by the curing behavior, which is altered by the ash activity. The N660 filled compound shows the highest curing rate compared to all rCB reinforced compounds. Since all compounds were cured for 20 minutes, the level of crosslinking in the N660 filled material was expected to be higher due to the higher curing rate; hence, leading to a more crosslinked polymer matrix with better mechanical properties. In rCBs, on 
the one hand, the compound properties are improved with increasing process temperature due to volatiles removal resulting in a more active filler surface and consequently better filler-polymer interaction. On the other hand, a cleaner silica surface in the rCB ash has the disadvantage that it slows down the curing process by adsorbing the curatives as discussed above. The lower tensile properties of the rCB filled materials compared to the $\mathrm{N} 660$ reinforced rubber is due to poor dispersion as shown by the Payne effect in Figure 5.1.6. On industrial scale, rCBs are ground by using different types of mills such as an impact mill, a jet mill or a combination of both. Impact grinding of rCB at high air jet velocities helps in achieving high fineness and could result in better dispersion when mixed into rubber.

The positive impact of increasing temperature on the $\mathrm{rCB}$ in-rubber performance is in-line with previous findings from Chapter 4.1. In that chapter, toluene transmittance was improved with increased pyrolysis temperature (Figure 4.1.4), indicating a higher degree of removal of volatiles. It was significantly improved up to $600^{\circ} \mathrm{C}$ after which it levelled off: a similar trend as the in-rubber performance. The surface chemistry analysis using XPS in Chapter 4.2 (Figure 4.2.14) showed a shift of the C$\mathrm{H}$ peak position to the atomic $\mathrm{C}$ peak and a more prominent shoulder of the $\mathrm{C}-\mathrm{O}$ functionality with increasing pyrolysis temperature, indicating a reduction of the presence of hydrocarbons (volatiles) and at the same time an improvement of the carbon functionalities.

\subsubsection{Conclusions}

The aim of the current study was to understand the influence of pyrolysis temperature on the in-rubber performance of recovered carbon black ( $\mathrm{rCB}$ ) obtained from an ultra-fast pyrolysis process. It turned out that process temperature has a profound effect on $\mathrm{rCB}$ rubber reinforcement: it is significantly improved with increasing process temperature. The alteration of compound curing behavior when increasing the $\mathrm{CCB}$ pyrolysis temperature gives insight into the trends seen for the rCB in-rubber behavior. The declining curing rate and increasing marching modulus is attributed to the influence of the ash content in $\mathrm{rCB}$ : At higher pyrolysis temperatures, volatiles are removed from the silica surface and thus it becomes available for interaction with the curatives. The silica in the rubber may adsorb the curatives leading to a slow curing process, and releases them at a later stage causing marching modulus. Moreover, along with slow curing, strong filler-filler interactions and poor dispersion of $\mathrm{rCB}$ is another issue which limits the reinforcement potential. The latter can be improved to some extent by rigorous grinding beforehand. However, despite poor dispersion and lower stress - strain properties than the $\mathrm{N} 660$ filled rubber, the rCB containing compounds show stronger 
filler-polymer interactions indicating the presence of active sulfur in the $\mathrm{rCB}$ ash content which cause pre-scorch and chemical filler-polymer coupling. The possibility of active sulfur presence in $\mathrm{rCB}$ will be further studied and discussed in Chapter 6 .

\section{References}

[1] E. Dannenberg, Rubber Chem. Technol., 48, 410 (1975).

[2] S. Wolff and M.J. Wang, Carbon Black Reinforcement of Elastomers, In Carbon Black: Science and Technology, 2nd ed., Marcel Dekker, New York (1993).

[3] M.J. Wang, Rubber Chem. Technol., 71, 520, (1998).

[4] M.J. Wang, S. Wolff and J.B. Donnet, Rubber Chem. Technol., 64, 714, (1991).

[5] A.I. Medalia, Rubber Chem. Technol., 45, 1171 (1972).

[6] A.I. Medalia, Rubber Chem. Technol. 47, 411 (1974).

[7] N. Probst, M. Löffler, and A. Lloyd, Kautsch. Gummi Kunstst., 65, 20 (2012).

[8] S. Karthikeyan, C. Sathiskumar, and R.S. Moorthy, NISCAIR-CSIR, 71, 309 (2012).

[9] .D. Martínez, N. Puy, R. Murillo, T. García, M.V. Navarro, and A.M. Mastral, Renew. Sust. Energ. Rev., 23, 179 (2013).

[10] P.T. Williams, Waste Manage., 33, 1714 (2013).

[11] A. Cunliffe and P.T. Williams, J. Anal. Appl. Pyrolysis, 44, 131 (1998).

[12] S.Q. Li, Q. Yao, Y. Chi, J.H. Yan and K.F. Cen, Ind. Eng. Chem. Res., 43, 5133 (2004).

[13] S. Galvagno, S. Casu, T. Casabianca, A. Calabrese, and G. Cornacchia, Waste Manage. 22, 917 (2002).

[14] H. Darmstadt, C. Roy and S. Kaliaguine, Carbon, 33, 1449 (1995).

[15] C. Roy, H. Darmstadt, B. Benallal, and C. Amen-Chen, Fuel Process. Technol., 50, 87 (1997).

[16] X. Dai, X. Yin, C. Wu, W.Zhang, Y.Chen, Energ., 26, 385 (2001).

[17] C. Roy, A. Rastegar, S. Kaliaguine, H. Darmstadt, and V. Tochev, Plast. Rubber. Compos. Process. Appl. 23, 21 (1995). 
[18] C. Norris, Presented at Recovered Carbon Black Conference, Berlin, (2019).

[19] A.V. Oorschot, Presented at European Carbon Black Summit, London, (2019).

[20] C. Norris and S. Renegar, Presented at International Rubber Conference (IRC), London, (2019).

[21] C. Roy, A. Chaala and H. Darmstadt, J. Anal. Appl. Pyrolysis, 51, 201 (1999).

[22] J.D. Martínez, R. Murillo, and T. Garcia, Bol Grup Español Carbón, 30, 10 (2013).

[23] C. Norris, M. Hale and M. Bennett, Plast. Rubber Compos., 43, 245 (2014).

[24] J.D. Martínez, N. Cardona-Ulribe, R. Murillo, T. Garcia, and J.M. Lopez, Waste Manage., 85, 574 (2019).

[25] A. Kosmalska, M. Zaborski, and L. Slusarski, Macromol. Symp,194, 269 (2003).

[26] S.S. Choi, J. Appl. Polym. Sci. 79, 1127 (2001).

[27] https://feeco.com/pin-mixers/.

[28] S. Chuayjuljit, A. Imvittaya, N. N-ranong, and P. Potiyaraj, 12, 51 (2002).

[29] S.S. Choi, J. Appl. Polym. Sci., 93, 1001 (2004).

[30] J. Brennan, T. Jermyn and B. Boonstra, J. Appl. Polym. Sci., 8, 2687 (1964). 
CHAPTER 5.2

\section{INFLUENCE OF PYROLYSIS RESIDENCE TIME ON THE IN-RUBBER PERFORMANCE OF RECOVERED CARBON BLACK}

\subsubsection{Introduction}

In this part of the study, the effect of residence time of granulated tire rubber in the ultra-fast pyrolysis entrained-flow reactor is studied. The temperature window was chosen based on the outcome of the first part of this study: $500^{\circ} \mathrm{C}, 600^{\circ} \mathrm{C}$ and $700^{\circ} \mathrm{C}$. At each temperature, $\mathrm{rCBs}$ were recovered at three residence times: $1 \mathrm{x}, 2 \mathrm{x}$ and $3 \mathrm{x}$, where $x$ pertains to the number of passes through the reactor. The same sample pre-treatment including grinding and pelletizing, rubber compounding and in-rubber tests as described in Chapter 5.1 and Appendix 1 was performed. 


\subsubsection{Experimental}

\subsubsection{Materials}

All materials used in this part are similar to the ones described in Chapter 5.1.

Recovered carbon black: The influence of residence time was studied for three different temperatures as listed in Table 5.2.1. One pass through the reactor equals approx. 6 seconds.

Table 5.2.1 Notations of recovered carbon blacks produced at different pyrolysis temperatures and residence times.

\begin{tabular}{|c|c|c|}
\hline $\begin{array}{c}\text { Recovered Carbon } \\
\text { Black }\end{array}$ & $\begin{array}{c}\text { Pyrolysis temperaturel } \\
{ }^{\circ} \mathbf{C}\end{array}$ & Residence timel $\mathbf{x}^{*}$ \\
\hline $\begin{array}{c}\text { P5001x, P5002x, } \\
\text { P5003x }\end{array}$ & 500 & $1 x, 2 x$ and 3x \\
\hline $\begin{array}{c}\text { P6001x, P6002x, } \\
\text { P6003x }\end{array}$ & 600 & $1 x, 2 x$ and 3x \\
\hline $\begin{array}{c}\text { P7001x, P7002x, } \\
\text { P7003x }\end{array}$ & 700 & $1 x, 2 x$ and 3x \\
\hline
\end{tabular}

${ }^{*} \mathrm{x}=$ number of passes through reactor.

\subsubsection{Compounding and in-rubber testing}

Compounding formulations and in-rubber testing methods were similar to the ones described in Chapter 5.1.

\subsubsection{Vulcanization}

All compounds were vulcanized for 20 minutes using the same conditions as described in Chapter 5.1. All compounds with rCB's produced at $700^{\circ} \mathrm{C}$ and with the reference N660 carbon black were vulcanized at 30 minutes and 40 minutes, and tensile properties were measured in order to see the effect of longer curing times. 


\subsubsection{Results and Discussion}

In this section, the influence of pyrolysis residence time at different temperatures on the rCB in-rubber behavior is covered in terms of filler-filler interactions, filler-polymer interactions, curing behavior and mechanical properties. These rCBs are compared with semi reinforcing carbon black N660.

\subsubsection{Filler-filler and filler-polymer interactions}

Figure 5.2.1 shows the Mooney viscosities of the compounds containing rCBs produced at three different temperatures: $500^{\circ} \mathrm{C}, 600^{\circ} \mathrm{C}$ and $700^{\circ} \mathrm{C}$. At each temperature, $\mathrm{rCBs}$ were produced at three residence times. The residence time was varied by putting the material 1,2 and 3 times $(1 x, 2 x, 3 x)$ through the reactor. One pass through the reactor equals about 6 seconds. A carbon black (N660) filled compound was used as reference. The concentration of the carbon filler was similar for all compounds.

The N660 filled compound shows the lowest Mooney viscosity, similar to the viscosity of the rCB P5001x filled compound and reported in Chapter 5.1. For the compounds with $\mathrm{rCBs}$ produced at this temperature but increasing residence time, the Mooney viscosity increase by 2 Mooney units per reactor pass. An increasing Mooney viscosity with longer residence time suggests rise in filler-filler and fillerpolymer interactions. For the 5003x sample, the compound viscosity reaches the same level as for the P6001x filled material. However, in the case of the $600^{\circ} \mathrm{C}$ series, the Mooney viscosity is more significantly increased from $1 x$ to $2 x$ residence time by 5 Mooney units, while it remains more or less constant for the $3 x$ residence time. Similarly, in the $700^{\circ} \mathrm{C}$ series, a noticeable jump in Mooney viscosity is observed for the material with doubled residence time, and only a slight further increase for the compound with $\mathrm{rCB} 3 \mathrm{x}$ residence time.

This small increase in Mooney from $2 x$ to $3 x$ residence time suggests that the optimum viscosity level had been achieved. In all cases, the trend of increasing Mooney viscosities of the $\mathrm{rCB}$ compounds with longer pyrolysis time was anticipated, since a higher residence time leads to a higher amount of volatiles removal. This in turn results in a cleaner $\mathrm{rCB}$ surface with higher filler-filler and filler-polymer interactions interactions. In carbon black compounds, increase in viscosity can be due to enhanced polymer-filler interactions expressing themselves in increased bound rubber content, however, it is worth mentioning that higher filler-filler interactions would also cause the same effect ${ }^{1-2}$. 


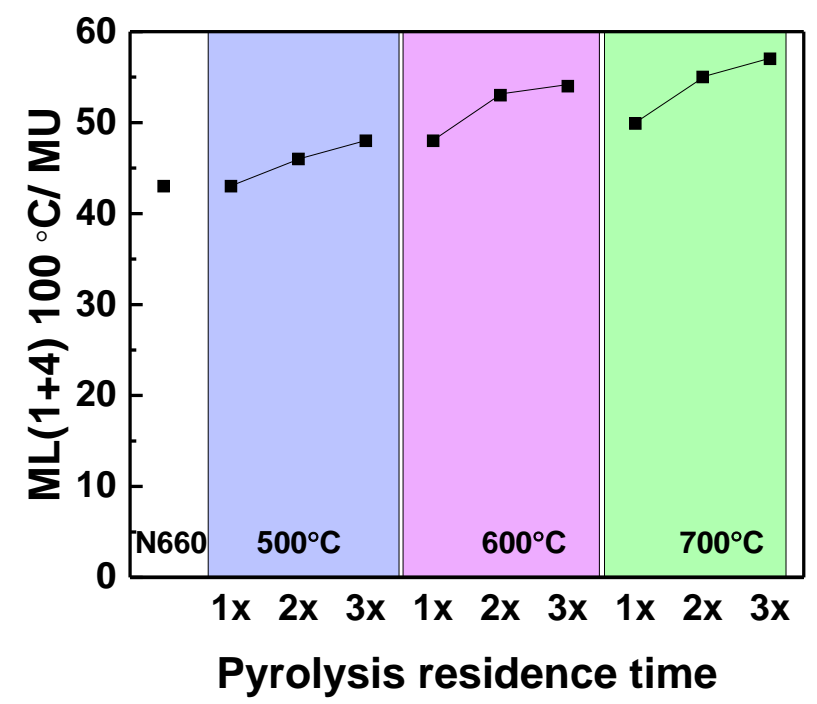

Figure 5.2.1 Mooney viscosity of compounds containing N660 and rCBs produced at different temperatures and residence times.

Figure 5.2.2 (a) shows the strain dependence of the storage modulus $G$ ' of the uncured reference compound filled with $\mathrm{N} 660$ and of the compounds filled with rCBs. This measurement indicates filler-filler interactions at $G^{\prime}(0.56 \%)$ and filler-polymer interactions at $\mathrm{G}^{\prime}(100 \%)$. The difference between the values of the storage modulus at $0.56 \%$ and $100 \%$ strain is the Payne effect $\left(\Delta G^{\prime}=G^{\prime}(0.56 \%)-G^{\prime}(100 \%)\right)$ which is indicative of filler dispersion.

In Figure 5.2.2(b), G'(0.56\%) and the Payne effect $(\Delta G)$ show similar trends for fillerfiller interactions and filler dispersion. In the $500^{\circ} \mathrm{C}$ series, both quantities are increased with longer residence time from $1 x$ to $2 x$. However, when raising the residence time from $2 x$ to $3 x$, there is no further change. In the $600^{\circ} \mathrm{C}$ series, this increase is rather small for the compounds containing the rCB's with residence time from $1 x$ over $2 x$ to $3 x$. The $700^{\circ} \mathrm{C}$ series shows a clear increase in both quantities with increasing residence time. Except for the compound filled with P5001x, all rCB reinforced compounds exhibit higher filler-filler interactions and consequently poorer dispersion compared to N660. This behavior is comparable to the previous findings in the temperature study (Chapter 5.1), in which increasing pyrolysis temperature lead to stronger filler-filler interactions. G' at higher strain amplitudes (100\%) is only increased by $20 \mathrm{KPa}$ from the sample containing rCB P5001x to P7003x. 

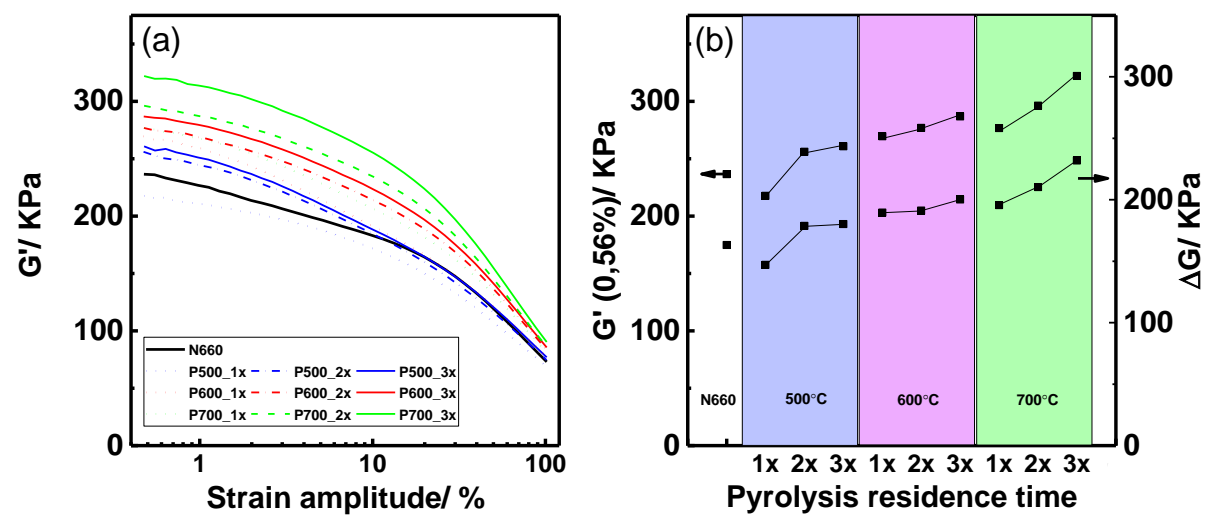

Figure 5.2.2 (a) Strain dependent measurement of the storage modulus of the uncured N660 and rCB filled compounds. (b) Storage modulus at low strains (left axis) and Payne effect (right axis) of these compounds.

Polymer-filler interactions were also measured as bound rubber content. In Figure 5.2.3, the bound rubber content of the carbon black N660 and rCBs containing compounds are shown. For the $500^{\circ} \mathrm{C}$ series, P5001x shows a negative bound rubber value. This negative value for $\mathrm{rCB}$ recovered at the lowest temperature and minimum residence time is caused by incomplete pyrolysis as discussed in the temperature study, Chapter 5.1. The sample with rCB P5003x exhibits a higher bound rubber content compared to the compound with N660, but similar to the P6001x containing rubber. In the $600^{\circ} \mathrm{C}$ and $700^{\circ} \mathrm{C}$ series, bound rubber is only increased slightly with longer residence time from $1 x$ to $2 x$. This increase in bound rubber with longer residence time clearly shows an improvement in polymer-filler interactions. From the $600^{\circ} \mathrm{C}$ and the $700^{\circ} \mathrm{C}$ series, $2 x$ residence time is the optimum pyrolysis time with the strongest improvement in filler-polymer interactions. Additionally, at $7002 x$ the highest bound rubber is measured among all samples. The higher bound rubber values in $\mathrm{rCB}$ containing compounds compared to the N660 filled one may also be due to the presence of silica in $\mathrm{rCB}$, which eventually increases the total filler content while reducing the relative polymer content. Besides, the sulfur present in the $\mathrm{rCB}$ ash can cause pre-crosslinking in the unvulcanized compound resulting in a higher bound rubber concentration. 


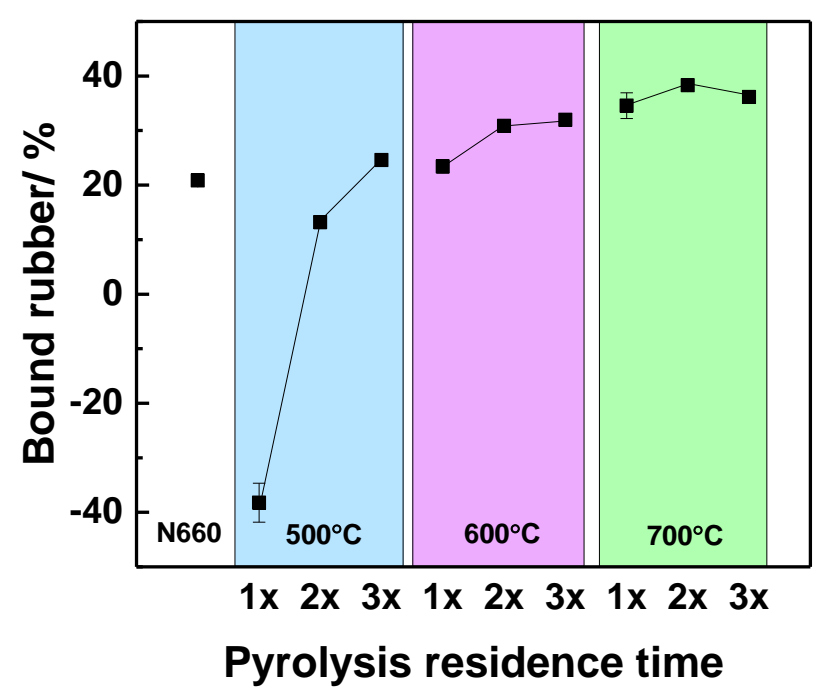

Figure 5.2.3 Bound rubber content of N660 and rCB filled compounds.

\subsubsection{Cure characteristics}

In Figure 5.2.4, the cure curves of the rCB and N660 filled compounds are shown. The differences in cure behavior are evident within the $\mathrm{rCB}$ reinforced compounds and in comparison with to the N660 containing compound. The initial torque S'min of the reference N660 compound is similar to the one of the compound with $\mathrm{rCB}$ produced at $500^{\circ} \mathrm{C}$ with $2 \times$ residence time. At all three temperatures, the initial torque is increased in a similar way as seen for Mooney viscosity and depicted in Figure 5.2.5. Increasing the residence time causes a larger volatiles removal from the recovered carbon as well as from the ash. Therefore, the initial torque increase seen for most samples relative to the lowest values may be due to increased filler-filler and filler-polymer interactions, as also indicated by the trends in Mooney viscosity. The increase in both interactions due to better volatiles removal is a similar finding as previously explained in Chapter 5.1. As discussed in Chapter 5.1, most of the sulfur present in the ash becomes accessible to rubber with higher volatiles removal, thus causing pre-scorch of the compounds. This leads to higher initial torque values as well as higher viscosities and bound rubber contents. 


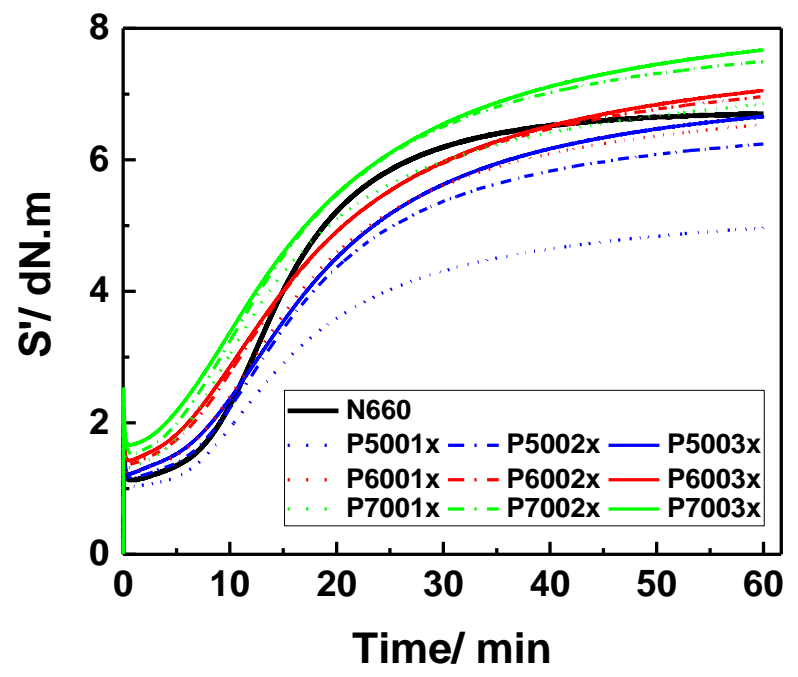

Figure 5.2.4 Cure curves of compounds containing N660 and rCBs produced at different temperatures and residence times.

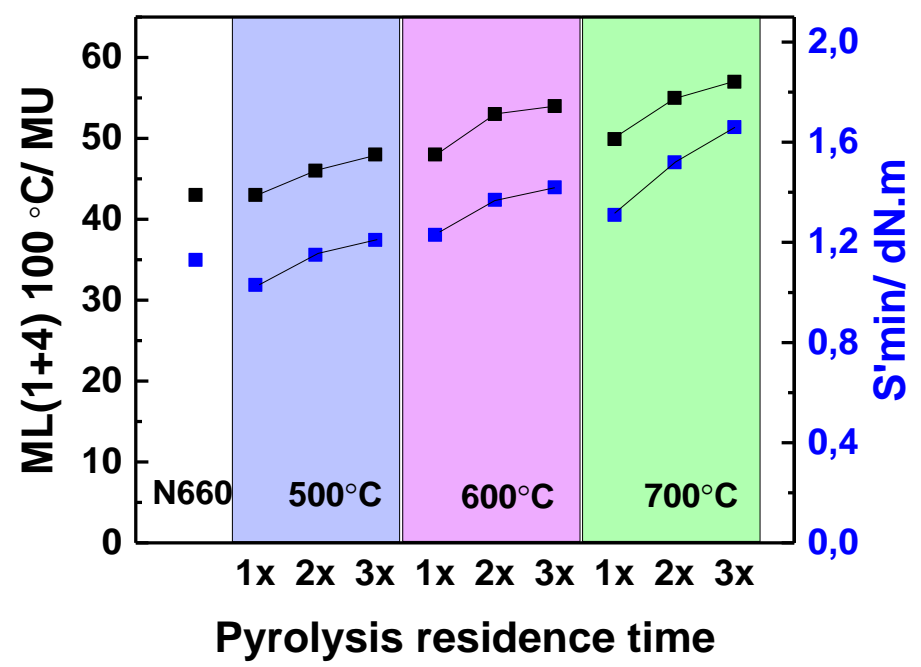

Figure 5.2.5 Trends of Mooney viscosity and minimum torque (S'min).

In Figure 5.2.6, the total torque increment of the compounds by vulcanization (left axis) shows an increase with longer residence time from $1 x$ to $3 x$ for rCB's produced 
at $500^{\circ} \mathrm{C}$. However, in the $600^{\circ} \mathrm{C}$ and $700^{\circ} \mathrm{C}$ series, only a slight or no increment is seen with respect to residence time, and the total torque increment is similar to the one of the N660 filled compound. The scorch times of the compounds containing rCBs of the $500^{\circ} \mathrm{C}$ and $600^{\circ} \mathrm{C}$ series show a decrease from $1 x$ to $2 x$ residence time, but remain the same when residence time is tripled. The $700^{\circ} \mathrm{C}$ series shows no scorch time dependency on residence time. Compared to the N660 compound, the rCB compounds have higher or similar scorch times up to $6003 \mathrm{x}$, while the $700^{\circ} \mathrm{C}$ series has relatively lower scorch times.

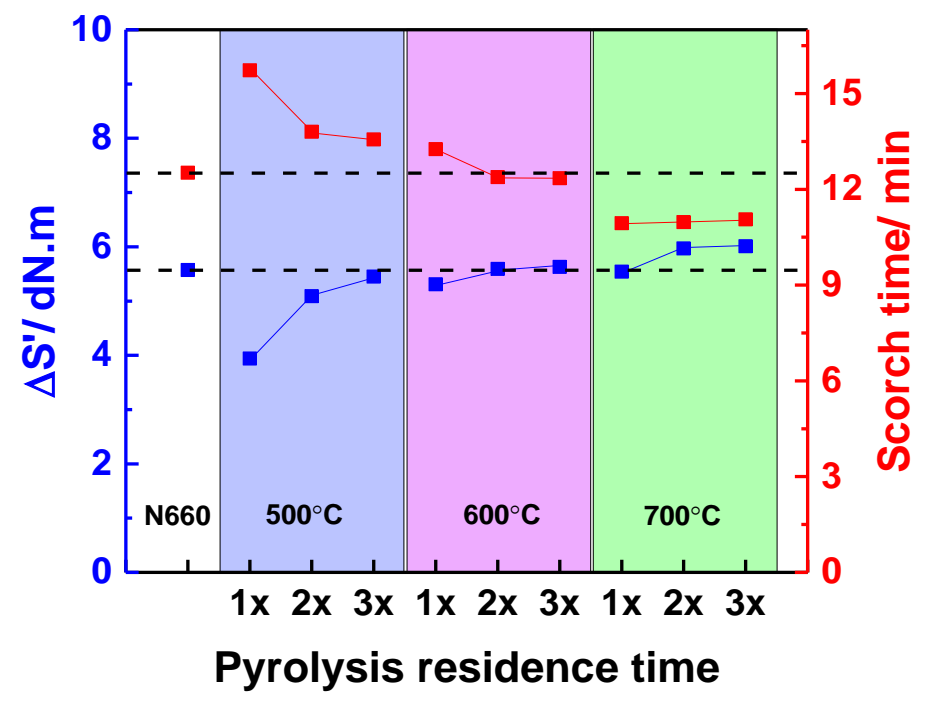

Figure 5.2.6 Total torque increase (left axis) and scorch time (right axis) of N660 and $\mathrm{rCB}$ filled compounds.

In Figure 5.2.7, the N660 filled compound exhibits the highest CRI and lowest MMI. In all temperature series, the cure rate decreases with longer residence time. At the same time, $\mathrm{MMI}$ is increased in a similar way. From these results it can be deduced that increasing the pyrolysis process temperature and residence time leads to a reduced curing rate and higher marching modulus as also previously seen in Chapter 5.1. This effect - again - is the result of better volatiles removal from the ash surface. A cleaner surface of the remaining silica in the $\mathrm{rCB}$ ash may result in adsorbtion of the curatives, hence slowing down the curing process in first instance while releasing the curatives after a certain time, which in turn causes delayed crosslinking and marching modulus. 


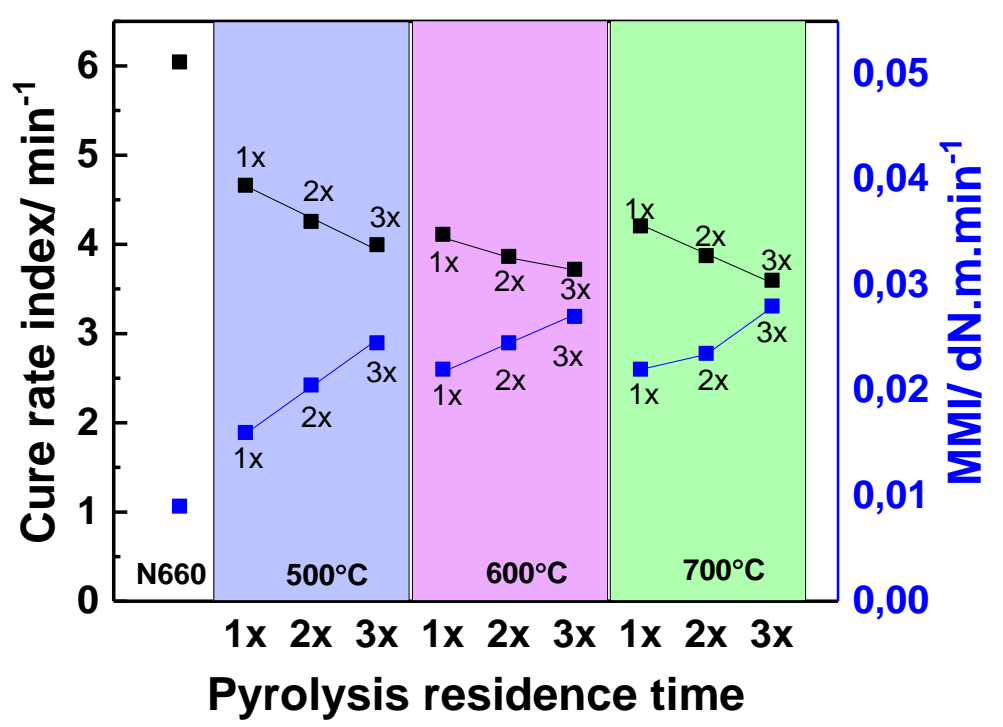

Figure 5.2.7 Influence of pyrolysis temperature and residence time on cure rate indices and marching modulus intensity (MMI) for the $\mathrm{rCB}$ and $\mathrm{N660}$ filled compounds.

\subsubsection{Mechanical properties}

Figure 5.2.8 shows the stress-strain behavior of rCBs filled compounds compared to $\mathrm{N} 660$. The latter clearly exhibits the best stress strain properties compared to all rCB filled materials. For the $\mathrm{rCB} 500^{\circ} \mathrm{C}$ and $600^{\circ} \mathrm{C}$ series, the influence of residence time is seen: Stress-strain properties are significantly improved by doubling the residence time. However, a further increase in residence time to $3 x$ does not affect the stressstrain behavior of the $\mathrm{rCB}$ filled material any further. In contrast to the $500^{\circ} \mathrm{C}$ and $600^{\circ} \mathrm{C}$ series, the $700^{\circ} \mathrm{C}$ series shows a decrease in tensile strength and elongation at break with longer residence time. 


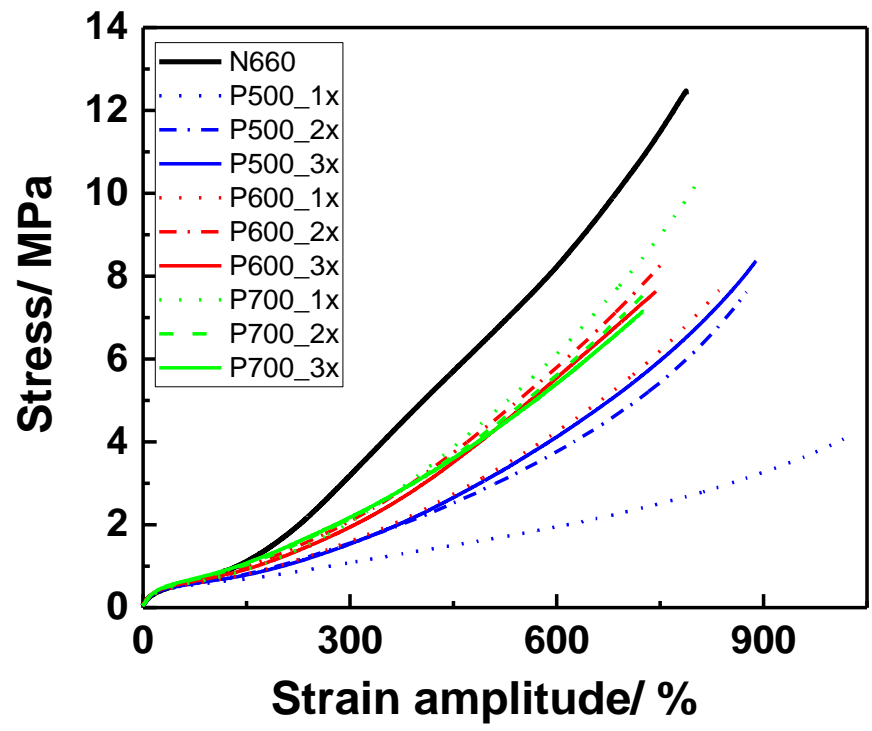

Figure 5.2.8 Stress-strain curves of compounds containing N660 and rCBs produced at different temperatures and residence times.

In Table 5.2.2, the mechanical properties of the $\mathrm{N} 660$ and $\mathrm{rCB}$ filled compounds are further elaborated. At a pyrolysis temperature of $600^{\circ} \mathrm{C}$ with $2 \mathrm{x}$ residence time, the M100 of the rCBs filled materials has reaches the same value as for N660. The effect of residence time on the M100 values it follows a similar trend as seen previously in Mooney viscosity and Payne effect. This trend with temperature and residence time again confirms the increase in filler-filler interactions.

The modulus at $300 \%$ strain (M300) is the highest for the N660 filled rubber while the rCB compounds are well below this level. In the $500^{\circ} \mathrm{C}$ and $600^{\circ} \mathrm{C}$ series M300 follows the trend of $\mathrm{M} 100$. However, in the $700^{\circ} \mathrm{C}$ series the residence time does not affect the M300 which remains constant. Since all compounds were cured for 20minutes, regardless of their curing behavior the lower M300 modulus of the rCB compounds compared to the N660 compound can be attributed to a lower level of crosslinking of the $\mathrm{rCB}$ compounds due to a slower curing rate, as seen before in Figure 5.2.5.

The reinforcement index follows the same trend as $\mathrm{M} 100$ and $\mathrm{M} 300$ for the $500^{\circ} \mathrm{C}$ and $600^{\circ} \mathrm{C}$ series. However, for the $700^{\circ} \mathrm{C}$ series, the reinforcement index decreases with longer residence time. This finding is in agreement with the trend seen in Mooney viscosity (Figure 5.2.1), which rose with longer residence time which 
confirms the enhanced filler-filler interaction. The residence time increase leads to a slowdown of the curing rate resulting in reduced crosslinking. Therefore, both increased filler-filler interactions and lower crosslinking affect the reinforcement index.

The tensile strength values for the rCB compounds from the $500^{\circ} \mathrm{C}$ and $600^{\circ} \mathrm{C}$ series are mainly improved with double residence time. At the same time elongation at break reduces. However, the $700^{\circ} \mathrm{C}$ series shows a decrease in tensile with longer residence time. Hardness is also mainly higher by double residence time. The influence of residence time on the tensile properties for the $500^{\circ} \mathrm{C}$ and $600^{\circ} \mathrm{C}$ series is in line with the trend of filler-polymer interactions as measured by the bound rubber contents. For the $700^{\circ} \mathrm{C}$ series the bound rubber results showed little or no improvement in polymer-filler interactions, while the Payne effect measurements indicated a significant increase in filler-filler interactions with longer residence time. The increase in filler-filler interaction lead to a poor filler dispersion, which worsens the ultimate strength. For all rCB filled compounds, the best overall tensile properties are achieved for a pyrolysis temperature of $700^{\circ} \mathrm{C}$ with $1 \mathrm{x}$ residence time. 
Table 5.2.2 Mechanical properties of $N 660$ and rCBs filled compounds.

\begin{tabular}{|c|c|c|c|c|c|c|}
\hline & $\begin{array}{l}\text { M100 } \\
\text { (MPa) }\end{array}$ & $\begin{array}{l}\text { M300 } \\
\text { (MPa) }\end{array}$ & $\begin{array}{l}\text { M300/M100 } \\
\text { (MPa) }\end{array}$ & $\begin{array}{l}\text { Tensile } \\
\text { strength } \\
\text { (MPa) }\end{array}$ & $\begin{array}{l}\text { Elongation } \\
\text { at break } \\
(\%)\end{array}$ & $\begin{array}{l}\text { Hardness } \\
\text { Shore A }\end{array}$ \\
\hline N660 & $\begin{array}{l}0.76 \\
\pm 0.02\end{array}$ & $\begin{array}{l}3.2 \\
\pm 0.16\end{array}$ & $\begin{array}{l}4.1 \\
\pm 0.08\end{array}$ & $\begin{array}{l}12.7 \\
\pm 0.87\end{array}$ & $\begin{array}{l}800 \\
\pm 30\end{array}$ & $\begin{array}{l}42 \\
\pm 1\end{array}$ \\
\hline $\begin{array}{l}P 500 \\
1 x\end{array}$ & $\begin{array}{l}0.60 \\
\pm 0.01\end{array}$ & $\begin{array}{l}1.1 \\
\pm 0.01\end{array}$ & $\begin{array}{l}1.8 \\
\pm 0.01\end{array}$ & $\begin{array}{l}4.0 \\
\pm 0.20\end{array}$ & $\begin{array}{l}1010 \\
\pm 25\end{array}$ & $\begin{array}{l}39 \\
\pm 1\end{array}$ \\
\hline $\begin{array}{l}P 500 \\
2 x\end{array}$ & $\begin{array}{l}0.66 \\
\pm 0.01\end{array}$ & $\begin{array}{l}1.6 \\
\pm 0.03\end{array}$ & $\begin{array}{l}2.4 \\
\pm 0.01\end{array}$ & $\begin{array}{l}7.6 \\
\pm 0.10\end{array}$ & $\begin{array}{l}870 \\
\pm 15\end{array}$ & $\begin{array}{l}42 \\
\pm 1\end{array}$ \\
\hline $\begin{array}{l}P 500 \\
3 x\end{array}$ & $\begin{array}{l}0.64 \\
\pm 0.008\end{array}$ & $\begin{array}{l}1.5 \\
\pm 0.04\end{array}$ & $\begin{array}{l}2.4 \\
\pm 0.04\end{array}$ & $\begin{array}{l}8.3 \\
\pm 0.38\end{array}$ & $\begin{array}{l}890 \\
\pm 11\end{array}$ & $\begin{array}{l}42 \\
\pm 1\end{array}$ \\
\hline $\begin{array}{l}P 600 \\
1 x\end{array}$ & $\begin{array}{l}0.65 \\
\pm 0.006\end{array}$ & $\begin{array}{l}1.6 \\
\pm 0.01\end{array}$ & $\begin{array}{l}2.4 \\
\pm 0.03\end{array}$ & $\begin{array}{l}7.6 \\
\pm 0.80\end{array}$ & $\begin{array}{l}850 \\
\pm 44\end{array}$ & $\begin{array}{l}43 \\
\pm 1\end{array}$ \\
\hline $\begin{array}{l}P 600 \\
2 x\end{array}$ & $\begin{array}{l}0.75 \\
\pm 0.01\end{array}$ & $\begin{array}{l}2.0 \\
\pm 0.07\end{array}$ & $\begin{array}{l}2.7 \\
\pm 0.03\end{array}$ & $\begin{array}{l}8.2 \\
\pm 0.58\end{array}$ & $\begin{array}{l}760 \\
\pm 38\end{array}$ & $\begin{array}{l}43 \\
\pm 1\end{array}$ \\
\hline $\begin{array}{l}P 600 \\
3 x\end{array}$ & $\begin{array}{l}0.72 \\
\pm 0.008\end{array}$ & $\begin{array}{l}2.0 \\
\pm 0.05\end{array}$ & $\begin{array}{l}2.7 \\
\pm 0.04\end{array}$ & $\begin{array}{l}7.6 \\
\pm 0.27\end{array}$ & $\begin{array}{l}740 \\
\pm 14\end{array}$ & $\begin{array}{l}44 \\
\pm 1\end{array}$ \\
\hline $\begin{array}{l}P 700 \\
1 x\end{array}$ & $\begin{array}{l}0.71 \\
\pm 0.01\end{array}$ & $\begin{array}{l}2.1 \\
\pm 0.07\end{array}$ & $\begin{array}{l}2.9 \\
\pm 0.05\end{array}$ & $\begin{array}{l}10.0 \\
\pm 0.62\end{array}$ & $\begin{array}{l}790 \\
\pm 27\end{array}$ & $\begin{array}{l}42 \\
\pm 1\end{array}$ \\
\hline $\begin{array}{l}P 700 \\
2 x\end{array}$ & $\begin{array}{l}0.76 \\
\pm 0.02\end{array}$ & $\begin{array}{l}2.1 \\
\pm 0.07\end{array}$ & $\begin{array}{l}2.8 \\
\pm 0.04\end{array}$ & $\begin{array}{l}7.8 \\
\pm 0.14\end{array}$ & $\begin{array}{l}760 \\
\pm 18\end{array}$ & $\begin{array}{l}45 \\
\pm 1\end{array}$ \\
\hline $\begin{array}{l}P 700 \\
3 x\end{array}$ & $\begin{array}{l}0.8 \\
\pm 0.02\end{array}$ & $\begin{array}{l}2.1 \\
\pm 0.10\end{array}$ & $\begin{array}{l}2.7 \\
\pm 0.06\end{array}$ & $\begin{array}{l}7.2 \\
\pm 0.23\end{array}$ & $\begin{array}{l}740 \\
\pm 23\end{array}$ & $\begin{array}{l}46 \\
\pm 1\end{array}$ \\
\hline
\end{tabular}

In order to further explore the potential of $\mathrm{rCB}$ rubber reinforcement and to eliminate the influence of various levels of crosslinking due to the different curing rates, the $700^{\circ} \mathrm{C}$ series filled compounds and the reference N660 compound were also cured for 30 minutes and 40 minutes relative to the 20 minutes used before. The influence 178 
of curing time on tensile properties is shown in Figure 5.2.9. The improvement in tensile properties with increased cure time from 20 minutes to 30 minutes is much more pronounced in the rCBs containing compounds compared to the $\mathrm{N} 660$. Although the trend within the $\mathrm{rCB}$ compounds remains the same: 7001x results in general better tensile properties than 7002x and 7003x. However, the differences between the 7001x and N660 reinforced materials decreases significantly when the curing is raised time from 20 minutes to 30 minutes: M300 and reinforcement index of $7001 x$ are improved by $42 \%$ and $17 \%$, respectively. In case of N660 these quantities are improved by $25 \%$ and $8 \%$, as depicted in Figure 5.2.10. The tensile strength of $\mathrm{N} 660$ remained mainly unaffected by the curing time, while for $7001 \mathrm{x}$ is improved by $15 \%$ and reached the value of the N660 reinforced rubber within the error margin. In all cases, elongation at break decreases while other properties are improved with raised curing time. At 40 minutes, a minor increase in modulus and tensile strength with no further decrease in elongation at break indicates that optimum curing is approached at 30 minutes. 

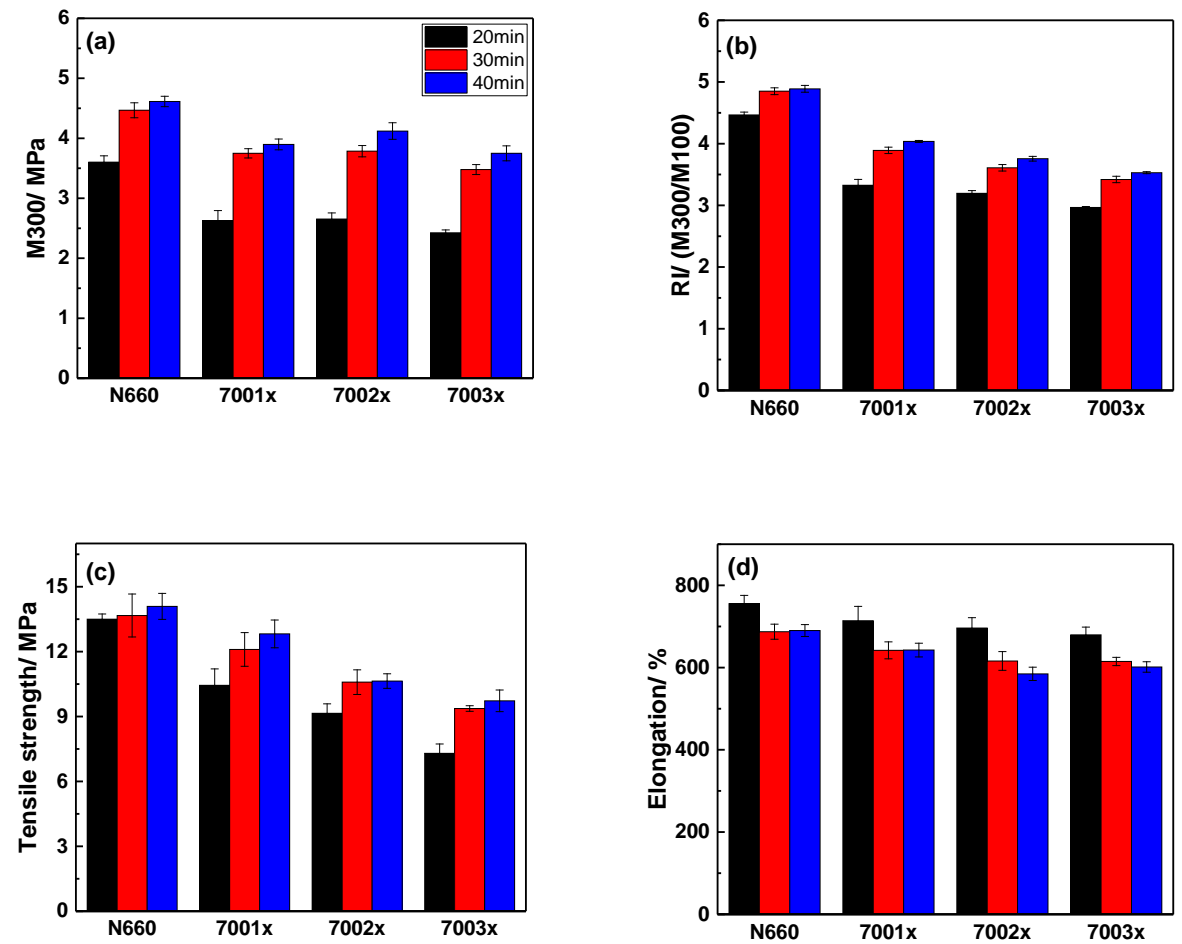

Figure 5.2.9 Tensile properties of the rubbers filled with N660 and rCB's pyrolyzed at a temperature of $700^{\circ} \mathrm{C}$ depending on curing time; (a) M100; (b) reinforcement index; (c) tensile strength; (d) elongation at break. 


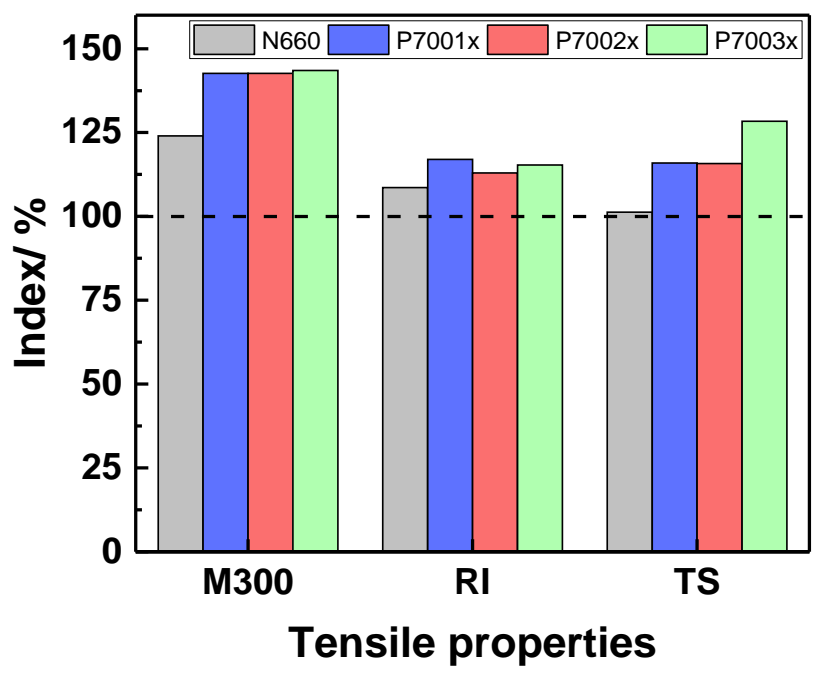

Figure 5.2.10 Index improvement in tensile properties after curing for 30minutes. 20 minutes curing is used as $100 \%$ index.

To conclude, the in-rubber evaluation of the rCBs shows a significant impact of residence time at different pyrolysis temperatures. The improvement in reinforcement properties in relation to longer residence time is mainly seen in the $500^{\circ} \mathrm{C}$ and $600^{\circ} \mathrm{C}$ series from $1 x$ to $2 x$ residence time with no further enhancement from $2 x$ to $3 x$, indicating that $2 x$ residence time is the optimum for both temperatures. In case of the $700^{\circ} \mathrm{C}$ series increasing residence time has a negative impact on reinforcement. This is understood as the effect of carbonaceous residue formation at higher temperatures and residence times as shown in Chapter 4.1 Figure 4.1.20.

This formation of carbonaceous residue at higher temperatures and residence times leads to sintering of carbon black aggregates making them difficult to disintegrate during mixing. This adversely affects their dispersibility in the rubber compound. In the $700^{\circ} \mathrm{C}$ temperature series, the evidence of carbonaceous residue formation with longer residence time can be seen in the Payne effect measurements, where the filler-filler interactions increased with longer residence time causing poor dispersion.

A longer residence time slows down the rubber curing process due to a cleaner and more active rCB-silica surface, onto which curatives became adsorbed. It was demonstrated that optimum curing of the $\mathrm{rCB}$ compounds containing P7001x gives similar properties as the $\mathrm{N} 660$ reference material. Therefore formulation adjustments for rCB compounds are recommended for faster curing. 


\subsubsection{Conclusions}

The influence of pyrolysis time at different temperatures on the recovered carbon black in-rubber performance was studied. It revealed that similar qualities of recovered carbon black can be achieved by either increasing the temperature from $500^{\circ} \mathrm{C}$ to $600^{\circ} \mathrm{C}$ or the residence time from $1 \mathrm{x}$ to $3 \mathrm{x}$. RCB recovered at a process temperature of $500^{\circ} \mathrm{C}$ with $3 x$ residence time exhibited similar properties as $\mathrm{rCB}$ recovered at $600^{\circ} \mathrm{C}$ with $1 \mathrm{x}$ residence time. Another major finding was the drop of the $\mathrm{rCB}$ in-rubber performance at $700^{\circ} \mathrm{C}$ with longer residence times. This drawback of longer residence times at $700^{\circ} \mathrm{C}$ is due to the formation of carbonaceous residues on the $\mathrm{rCB}$ surface resulting in higher filler-filler interactions and poor in-rubber dispersion. Since rCBs exhibit strong filler-filler interactions, pre-treatment such as strong milling should be performed to reduce these interactions as much as possible. The role of rCB-silica becoming more active at all temperatures with longer residence time and reduced volatiles content is noticed by its influence on the curing process.

At a cure time of 20 minutes, all rCB compounds show inferior in-rubber performance compared to the reference N660 compound due to the slower curing rates. Therefore, the in-rubber performance was improved by curing the $\mathrm{rCB}$ compounds for longer times, and properties comparable to those the N660 filled rubber are achieved for the best rCB grade. It is recommended to adjust the formulations for rCB compounds in order to achieve good mechanical properties with short curing times.

\section{References}

[1] S.S. Choi, J. Appl. Polym. Sci., 93, 1001 (2004).

[2] J. Brennan, T. Jermyn and B. Boonstra, J. Appl. Polym. Sci., 8, 2687 (1964). 


\section{ACTIVITY OF SULFUR PRESENT IN RECOVERED CARBON BLACK}

In the studies described in the previous Chapters 3 and 5, recovered carbon blacks (rCBs) showed higher polymer-filler interactions compared to carbon black N660 in uncured compounds, while in cured rubber, they exhibited lower mechanical properties. This disparity in Chapter 3 and Chapter 5 was previously postulated as being the result of the influence of sulfur present in $\mathrm{rCB}$ as inorganic impurity.

The role of sulfur present in rCBs on in-rubber properties is investigated in this chapter: Compounds containing $\mathrm{rCB}$ or $\mathrm{N} 660$ without curatives are analyzed concerning possible reactions of this sulfur. The present work confirms the presence of active sulfur in rCBs, which interacts with the rubber matrix causing either prescorch or chemical polymer-filler coupling as indicated by bound rubber and specific cure characteristics. Furthermore, elemental mapping of $\mathrm{CCB}$ demonstrates a high concentration of sulfur deposited on the silica surface, a component in the ash content of $r C B$. Formation of sulfur compounds on the silica surface is confirmed by investigating the surface functionality of recovered silica from the pyrolysis of a silica filled compound. 


\subsection{Introduction}

Recovered carbon black ( $\mathrm{rCB}$ ) contains inorganic impurities known as ash content, primarily consisting of silicon, oxygen, zinc and sulfur compounds. In previous studies $^{1-2}$ and Chapter 4.2 of this thesis, these inorganics were characterized as silica, zinc compounds: zinc sulfide and zinc oxide, and sulfur-carbon complexes. The ash content was seen as an impairment for $\mathrm{rCB}$ rubber applications and described as an inert cover of active sites on carbon black hindering filler-polymer interactions ${ }^{3-4}$. However, while Martinez et al. ${ }^{5}$ reduced the rCB ash content by $67 \%$ using acid demineralization, they found only a slight improvement in its rubber performance.

In Chapter 3, the influence of different ash contents on rubber properties was studied. It turned out that the cure behavior was significantly influenced by the ash content, but it did not affect the tensile properties of the rubber. The strong influence on cure behavior was explained as the influence of silica present in the $\mathrm{rCB}$ ash, which adsorbs curatives and releases them at a later stage leading to a slower curing rate and marching modulus, respectively. However, the role of the sulfur compounds in $\mathrm{rCB}$ on the rubber properties is still not clear.

In carbon black compounds, filler-polymer interactions are mainly physical of nature, where an increase in bound rubber results in an improvement in tensile properties ${ }^{6}$. rCB compounds, when compared to $\mathrm{N} 660$ compound, showed significantly higher filler-polymer interactions in terms of bound rubber and Payne effect measurements as discussed in Chapter 5.1 and Chapter 5.2. However, after curing the tensile properties of rCB filled rubber were lower or at best similar to N660. In these chapters, it was postulated that this disparity between uncured and cured rCB-filled rubber is due to the presence of active sulfur compounds, which may cause prescorch or chemical polymer-filler coupling leading to apparently higher values of bound rubber. The interaction of these sulfur compounds with the rubber matrix is not yet understood, as no studies have considered the role of these components for explaining the $\mathrm{rCB}$ in-rubber behavior. In the present Chapter, the role of the sulfur components in the $\mathrm{rCB}$ ash is investigated by analyzing rubber compounds without additional curatives. The presence of active sulfur in rCB is demonstrated by bound rubber and cure characteristics. 


\subsection{Experimental}

\subsubsection{Materials}

The masterbatches prepared in the temperature study (Chapter 5.1) and in the residence time study (Chapter 5.2) were utilized in this investigation as well. The masterbatches were those compounds taken after the $1^{\text {st }}$ stage of mixing, thus not containing curing agents (sulfur and accelerator). The compounding formulation, mixing procedure and conditions were defined in Chapter 5.1.

Notations used for rCB filled compounds are given in Table 6.1 (temperature study) and Table 6.2 (residence time study).

Table 6.1 Notations used for recovered carbon blacks produced at different pyrolysis temperatures.

\begin{tabular}{|c|c|}
\hline Recovered carbon black & $\begin{array}{c}\text { Pyrolysis process } \\
\text { temperature }\left({ }^{\circ} \mathbf{C}\right)\end{array}$ \\
\hline P500 & 500 \\
\hline P550 & 550 \\
\hline P600 & 600 \\
\hline P650 & 650 \\
\hline P700 & 700 \\
\hline
\end{tabular}


Chapter 6

Table 6.2 Notations for recovered carbon blacks produced at different pyrolysis temperatures and residence times.

\begin{tabular}{|c|c|c|}
\hline $\begin{array}{c}\text { Recovered Carbon } \\
\text { Black }\end{array}$ & $\begin{array}{c}\text { Pyrolysis temperaturel } \\
{ }^{\circ} \mathbf{C}\end{array}$ & Residence timel $\mathbf{x}^{*}$ \\
\hline $\begin{array}{c}\text { P500_1x, P500_2x, } \\
\text { P500_3x }\end{array}$ & 500 & $1 \mathrm{x}, 2 \mathrm{x}$ and 3x \\
\hline $\begin{array}{c}\text { P600_1x, P600_2x, } \\
\text { P600_3x }\end{array}$ & 600 & $1 \mathrm{x}, 2 \mathrm{x}$ and 3x \\
\hline $\begin{array}{c}\text { P700_1x,P700_2x, } \\
\text { P700_3x }\end{array}$ & 700 & $1 \mathrm{x}, 2 \mathrm{x}$ and 3x \\
\hline
\end{tabular}

${ }^{*} \mathrm{x}=$ number of passes through pyrolysis reactor.

Silica: Precipitated silica Ultrasil 7005 and Coupsil 8113 were provided by Evonik Industries, Cologne, Germany. Ultrasil 7005 has a BET surface area of $190 \mathrm{~m}^{2} / \mathrm{g}$, CTAB value of $171 \mathrm{~m}^{2} / \mathrm{g}$ and DBP number of $217 \mathrm{~g} / 100 \mathrm{~g}$. Coupsil is organo-silane TESPT treated Ultrasil VN3 silica with a BET surface area of $180 \mathrm{~m}^{2} / \mathrm{g}$, CTAB value of $165 \mathrm{~m}^{2} / \mathrm{g}$ and DBP number of $176 \mathrm{~g} / 100 \mathrm{~g}$.

Silica-filled natural rubber compound: A vulcanized NR compound filled with silica Ultrasil 7005 was used to specifically analyze the pyrolysis products formed in TGA. The complete formulation of the compound is given in Table 6.3. 
Table 6.3 Compound formulation.

\begin{tabular}{|c|c|}
\hline Materials & Formulation (phr) \\
\hline NR (SIR 20) & 100 \\
\hline Ultrasil 7005 & 55 \\
\hline TESPD & 4.5 \\
\hline ZnO & 2.5 \\
\hline Stearic acid & 1 \\
\hline 6PPD & 2 \\
\hline TDAE oil & 8 \\
\hline Sulfur & 1.4 \\
\hline CBS & 1.7 \\
\hline DPG & 1 \\
\hline
\end{tabular}

\subsubsection{Methods}

\subsubsection{Cure characteristics of masterbatches}

The cure characteristics of the masterbatches filled with carbon black N660 and rCBs studied in Chapter 5.1 (mentioned in Table 6.1) were evaluated using a Rubber process Analyzer (RPA-Elite by TA instruments). Since the masterbatches are not containing any curatives, the torque increase over time in these compounds is a result of active sulfur components present in the rCBs. Measurements were performed in shear mode at $160^{\circ} \mathrm{C}$, a frequency of $1.667 \mathrm{~Hz}$ and $42 \%$ strain amplitude. A large strain amplitude was applied to eliminate filler-filler interactions. Therefore, only filler-polymer interactions play a role in the resultant torque over time. The slope of the torque over time curve was calculated in the time range of 2 to 38 minutes as illustrated in Figure 6.1. 


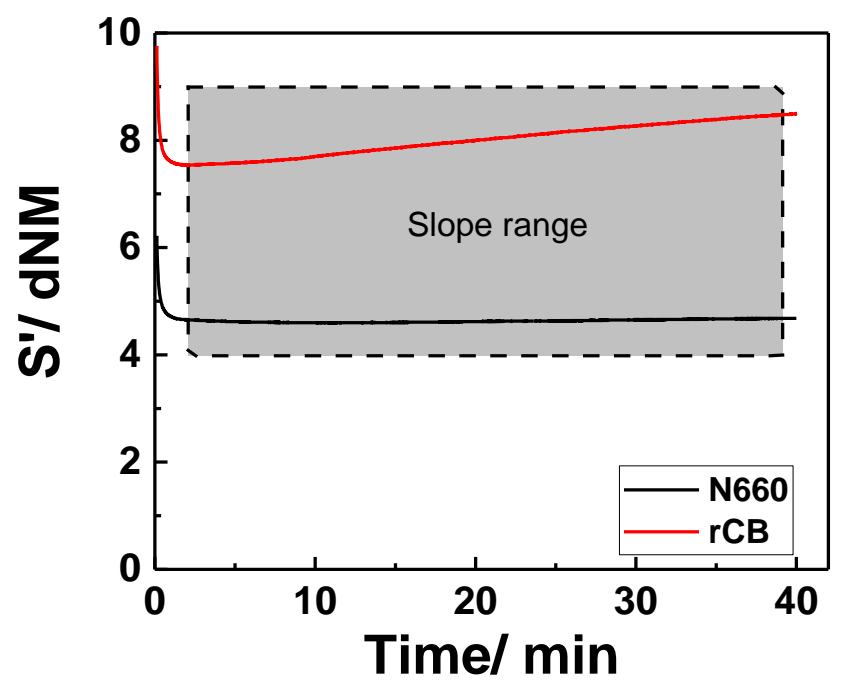

Figure 6.1 Rheogram of $\mathrm{N} 660$ and $\mathrm{rCB}$ filled masterbatch with the selected slope range.

\subsubsection{Bound rubber}

The bound rubber content of the masterbatches without curatives was measured under standard conditions (as explained in Chapter 5.1), and after heating.

After heating: Bound rubber was measured after heating of 5 grams of masterbatch at $160^{\circ} \mathrm{C}$ for 40 minutes in the RPA chamber.

\subsubsection{Elemental mapping}

TEM imaging and EFTEM elemental mapping was performed as explained in Chapter 4.2.

\subsubsection{Thermo-Gravimetrical Analysis}

Pyrolysis of the silica filled NR compound was performed in a TA Instrument Discovery TGA 550. The compound was pyrolyzed in a nitrogen environment with a gas flow rate of $40 \mathrm{ml} / \mathrm{min}$ in a temperature range of $25^{\circ} \mathrm{C}$ to $550^{\circ} \mathrm{C}$. The heating rate was set to $10^{\circ} \mathrm{C} / \mathrm{min}$. 


\subsubsection{X-ray Photoelectron Spectroscopy}

Photoelectron spectra were obtained using a Quantera SXM (Scanning XPS Microprobe) from Physical Electronics. The measurement method was the same as the one described in Chapter 4.2, Section 4.2.2.7.

\subsubsection{Diffuse Reflectance Infrared Fourier Transform Spectroscopy (DRIFTs)}

DRIFT spectra were taken in the wavenumber range from $4000 \mathrm{~cm}^{-1}$ to $450 \mathrm{~cm}^{-1}$ with a Perkin-Elmer Spectrum 100 Series. A spectra-Tech DRIFT accessory equipped with an $8 \mathrm{~mm}$ diameter, $1 \mathrm{~mm}$ depth sample cup was used.

Sample preparation: $\mathrm{KBr}$ was ground in an agate mortar and used as reference. The silica sample was prepared by mixing $10 \mathrm{wt} . \%$ of silica and $90 \mathrm{wt} . \%$ of $\mathrm{KBr}$ and ground in the same mortar and then transferred to the sample holder cup. The mixture filled the DRIFTS accessory sample holder cup and the top was leveled off.

Measurement: The sample cup with the Reference $\mathrm{KBr}$ was inserted into the DRIFTS equipment, and the reference spectrum was taken before each measurement. Before a spectrum was measured, the height of the sample cup was adjusted by using the alignment routine provided in the software. All spectra were collected at a nominal resolution of $4 \mathrm{~cm}^{-1}$ with 128 scans per sample. 


\subsection{Results and Discussion}

Previous results from Chapter 5.1 are shown in Figure 6.2. In Figure 6.2(a), uncured rCB compounds filled with rCB P650 till P700 show higher filler-polymer interactions than the reference, the uncured compound with N660, in terms of bound rubber and storage modulus at $100 \%$ strain. Commonly, higher polymer-filler interactions in the uncured compounds lead to enhanced tensile properties in cured rubber ${ }^{6}$.

However, all rCB cured rubbers show lower tensile properties compared to the N660 filled ones as indicated in Figure 6.2(b) by the reinforcement index, which is the ratio of modulus at $300 \%$ strain to modulus at $100 \%$ strain. In Chapter 5.1 , it was postulated that this behavior of $\mathrm{rCB}$ is due to the presence of active sulfur, which causes pre-crosslinking of the rubber compound or chemical filler-polymer coupling leading to higher bound rubber. The lower reinforcement index of all cured compounds filled with rCBs compared to the compound with N660 was due to an insufficient curing time, as explained in Chapter 5.1, but also to other factors such as filler dispersion.

Similar trends were observed for bound rubber, Payne effect and reinforcement index in Chapter 5.2. Additionally, in the same chapter, compounds were cured for longer times to eliminate the influence of insufficient curing due to slower curing rates. Even after curing for 40 minutes, the tensile properties of $\mathrm{rCB}$ compounds were never higher than the ones of the N660 filled rubber. This is an indication that the contradiction between higher bound rubber values of uncured $\mathrm{rCB}$ compounds and their lower than expected in-rubber performance after vulcanization is not only originating from their cure behavior. 
Chapter 6

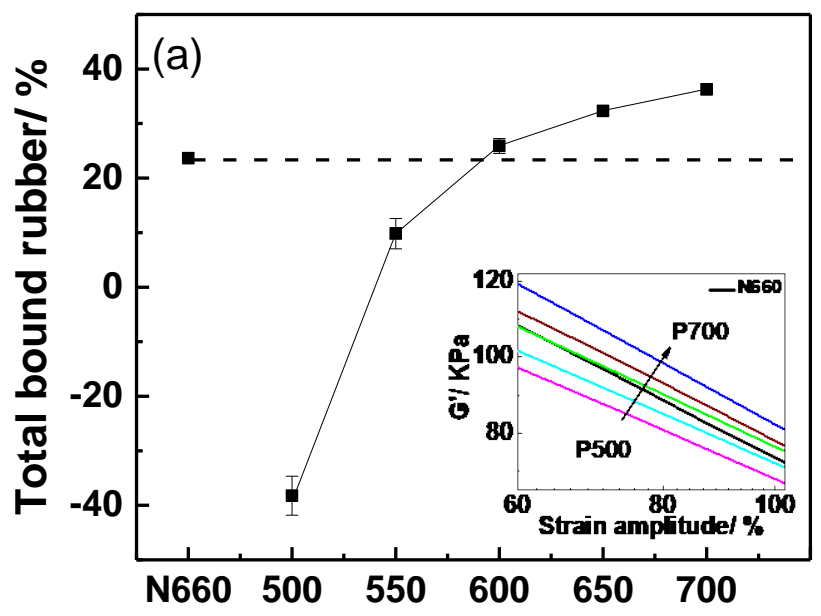

Pyrolysis Temperature/ ${ }^{\circ} \mathrm{C}$

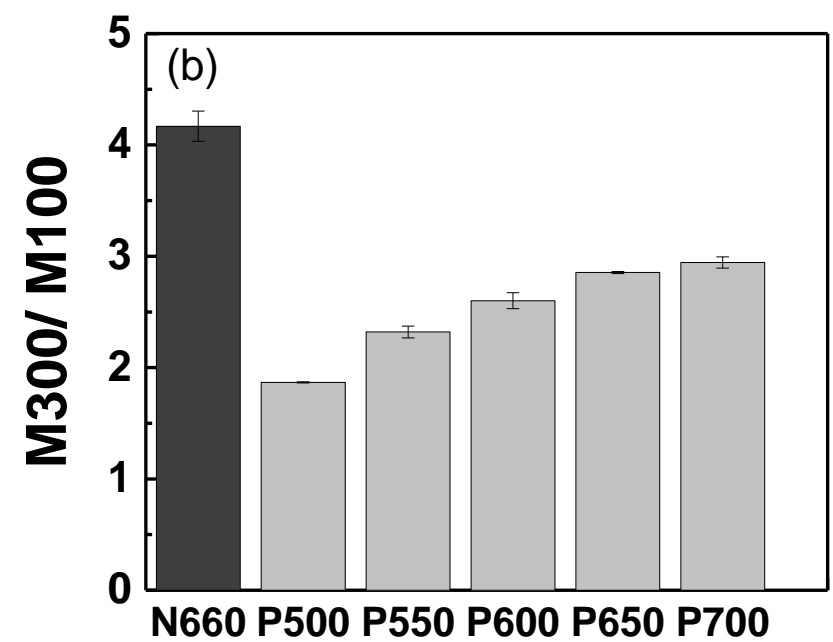

Figure 6.2 (a) Total bound rubber content measured for the uncured N660 compound and compounds with rCBs from different pyrolysis temperatures; and (b) the reinforcement index of the cured materials. 


\subsubsection{Cure characteristics of compounds without curatives}

Figure 6.3 depicts the torque over time curves of carbon black N660 and recovered carbon black ( $\mathrm{rCB}$ ) filled compounds. In Figure 6.3(a) and (b), the initial torque of the $\mathrm{rCB}$ batches is higher with increasing pyrolysis temperature and residence time, respectively. It was previously concluded (see Chapter 4.1) that increasing pyrolysis temperature and residence time lead to more volatiles removal from the $\mathrm{rCB}$ surfaces; therefore, it can be expected that sulfur based compounds in the rCB would be more easily accessible at higher pyrolysis temperatures and residence times. Therefore, this initial torque increase could be caused by the sulfur compounds contained in the $\mathrm{rCB}$ ash, contributing to either filler-polymer coupling or precrosslinking of the rubber matrix during mixing. The N660 compound shows no change in torque over time, while all rCBs show a slight increase in torque except for sample P500 with the highest volatile content. The abundance of volatile matter in P500 covers not only the carbon black surface, but also the ash particles and sulfur compounds present on their surface, reducing their activity by hindering interaction with the rubber matrix.

Cure characteristics in Chapter 5.1 showed no signs of filler flocculation in $C B$ and rCB filled compounds which could cause a torque increase. Additionally, to eliminate any such effect on a masterbatch torque increase, in the current measurements a higher strain amplitude was utilized. Since no accelerators were added to these compounds, even a slight increase in torque over time is a clear hint of ongoing polymer-polymer or polymer-filler crosslinking. 


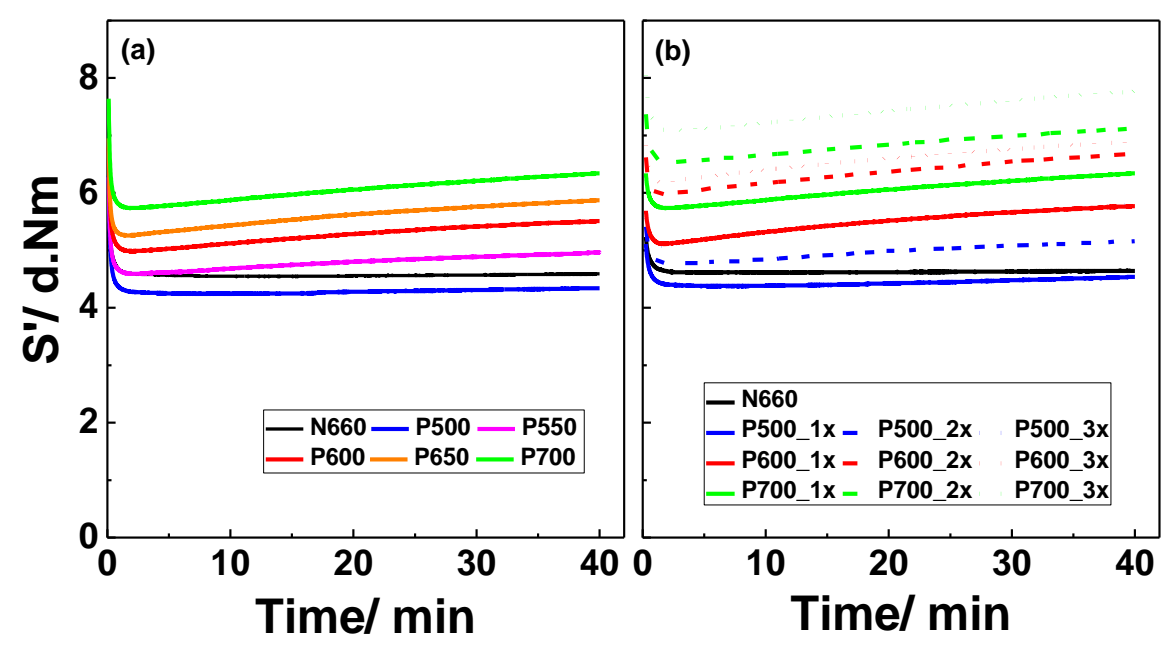

Figure 6.3 Torque as a function of time of uncured compounds without curatives with $\mathrm{N} 660$ and $\mathrm{rCBs}$ produced (a) at different temperatures and fixed residence time; and (b) at three fixed temperatures and varied residence time.

The slope of the high strain amplitude cure curves is plotted as a function of the pyrolysis temperature (Figure 6.4(a)) and residence time (Figure 6.4(b)). The carbon black N660 compound shows no change in absence of any curatives. However, the slope increase with increasing pyrolysis temperature and residence time confirms that $\mathrm{rCB}$ produced at a higher temperature contains more sulfur accessible for the polymer, and hence contributes to pre-crosslinking of the compounds in the first stage of mixing. 

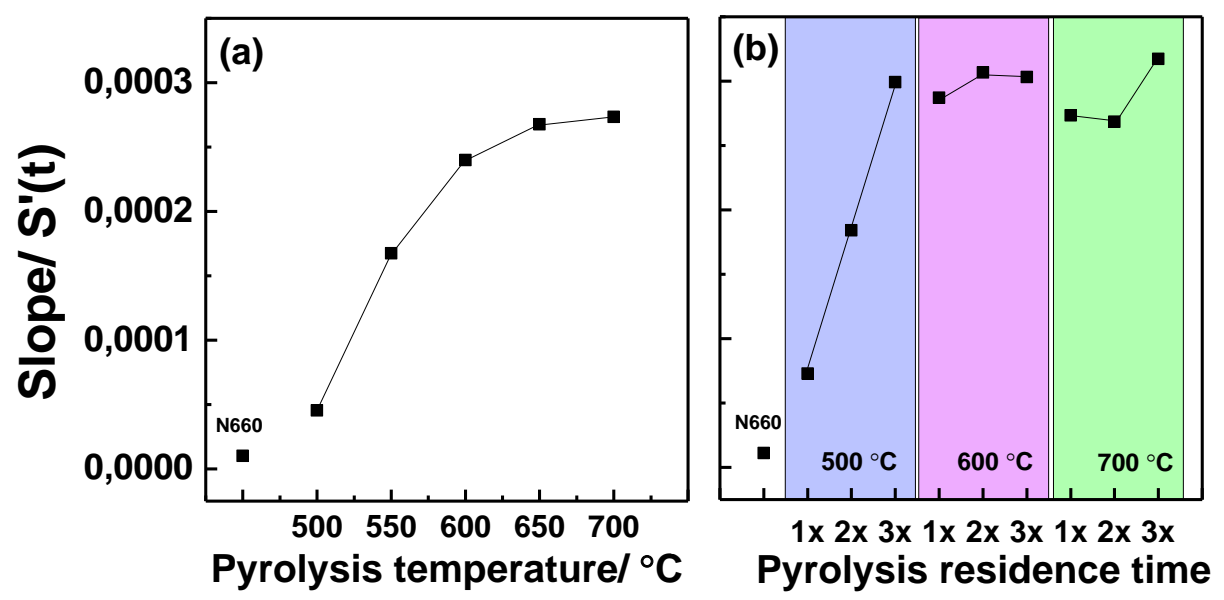

Figure 6.4 Slope of the torque over time curve for the uncured N660 compound and $\mathrm{rCB}$ filled compounds without curatives. (a) rCBs from different pyrolysis temperatures with fixed residence time; and (b) rCBs from different pyrolysis temperatures with varied residence time.

\subsubsection{Filler-polymer interactions}

Bound rubber was evaluated for the carbon black N660 compound and rCB filled compounds from both, the temperature study (Figure 6.5(a)) and the residence time study (Figure 6.5(b)). To understand the activity of sulfur present in $\mathrm{rCB}$, the bound rubber content of $\mathrm{rCB}$ compounds was measured after heating the compounds at $160^{\circ} \mathrm{C}$ for 40 minutes expecting the bound rubber to increase due to polymer chemically bound to the rCB filler. In this scenario, sulfur compounds on rCB are assumed to act as filler-polymer coupling agents. $\mathrm{rCB}$ sulfur could also act as a crosslinking agent and cause polymer-polymer crosslinking. This effect would also result in increased bound rubber since the crosslinked polymer, at a certain stage of crosslinking, is insoluble in toluene. Bound rubber would also increase if the polymer bound to $\mathrm{rCB}$ is crosslinked, and in this way one polymer-filler bond binds a number of crosslinked polymer chains via a sulfur bond. 

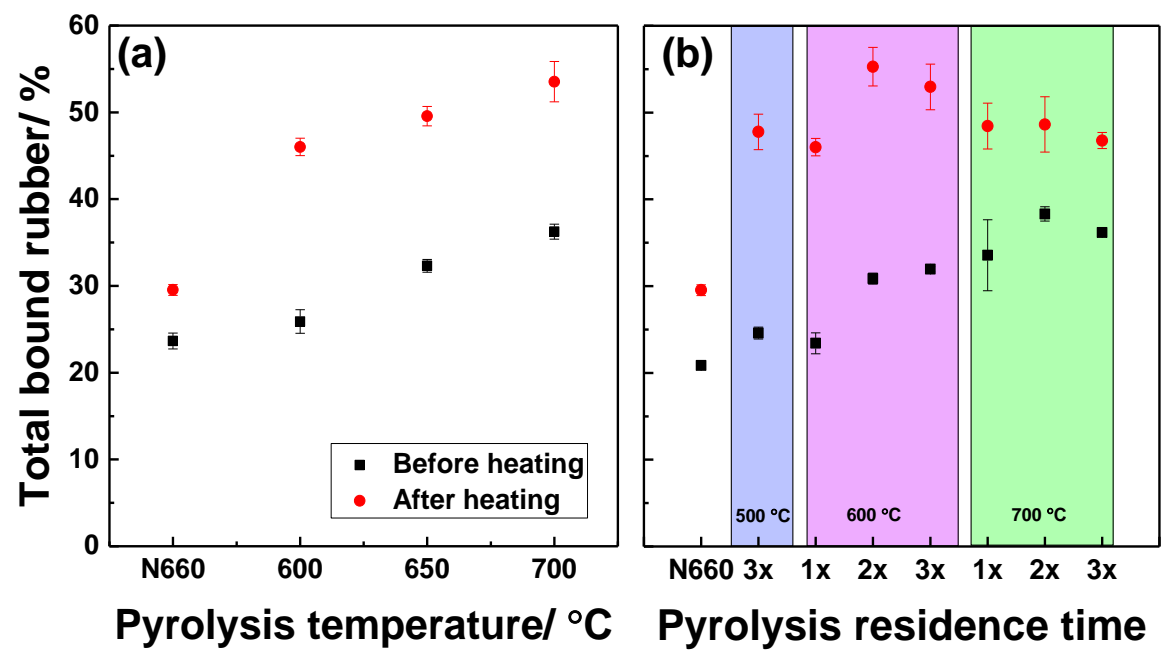

Figure 6.5 Bound rubber before and after heating of the uncured N660 and rCB compounds. (a) rCBs from different pyrolysis temperatures with fixed residence time; and (b) rCBs from three different pyrolysis temperatures with varied residence time.

The N660 based compound exhibits $5 \%$ to $6 \%$ increase in bound rubber after heating. Since there are no curatives present, this small increase in the N660 compound is attributed to a thermodynamic effect: In carbon black, bound rubber is formed by physical polymer-filler interactions. The polymer segments become adsorbed onto high energetic sites on the carbon black primary particle surface, as well as trapped in the aggregate structure. At higher temperatures and longer times of vulcanization, polymer chains have a higher mobility and probability to attach to the filler surface and penetrate into the structure, resulting in an increased bound rubber content. For almost all rCB filled compounds, the increase of bound rubber content after heating is in the range of $15 \%$ to $22 \%$, which is three to four times higher than for the N660 compound. Considering the compound containing P600, like other rCB compounds, the bound rubber content before heating is already $22 \%$, which is doubled in this case to $44 \%$ after heating. Such a drastic increase in bound rubber content during heating is probably due to the presence of active sulfur compounds in rCB causing either chemical filler-polymer coupling or polymer crosslinking.

However, from both, cure characteristics and bound rubber results, it is not yet clear which is the most probable: filler-polymer coupling or polymer-polymer crosslinking, 
since both phenomena would cause a similar effect. To answer this question, an attempt was made to locate the presence of sulfur by EFTEM imaging on rCB P700. In Chapter 4.2, sulfur was detected on the rCB-carbon surface by EFTEM in the form of nano-particles. This time, a silica cluster was analyzed in terms of the morphology of sulfur on the silica surface. After finding a suitable spot, elemental mapping was performed to locate sulfur, silicon and carbon.

\subsubsection{Elemental mapping}

In Figure 6.6(a), a TEM image of a recovered carbon black aggregate is shown. In Figure 6.6(b), the elemental mappings of the same image for carbon, silicon and sulfur are shown (left $\rightarrow$ right). Zinc cannot be accurately detected due to drifting of the sample at higher electron energies. In the carbon mapping picture, only the left part of the rCB in the TEM image is visible: this indicates the carbon black particles in the rCB. The right side of the image is visible in the silicon mapping: it is silica. In the sulfur mapping, this element is found in different parts of the agglomerate, but interestingly a higher amount of sulfur is present near to or on the silica surface. Figure 6.6(c) is a combination of all three elemental mappings, which shows the presence of a sulfur layer covering the major portion of the silica aggregate. 


\section{(a)}

(b)
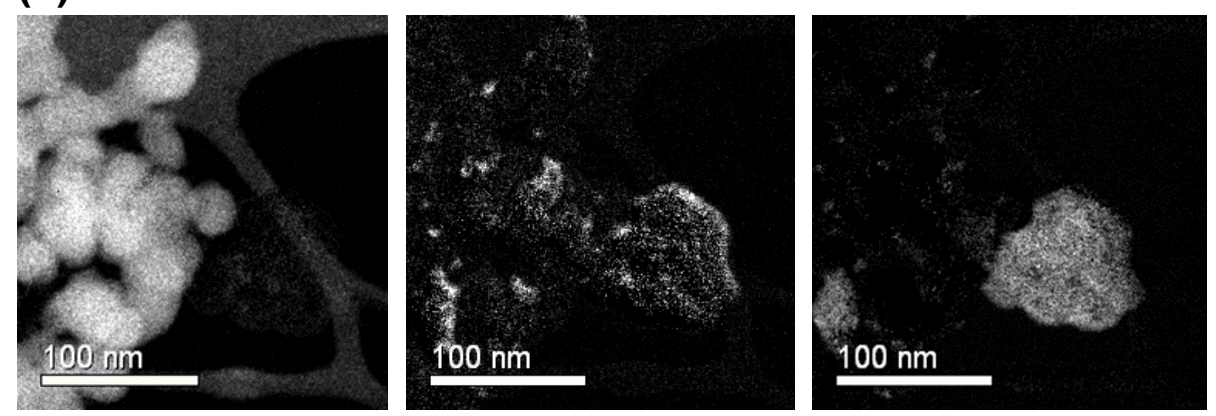

(c)

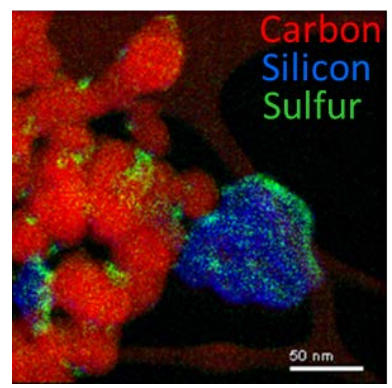

Figure 6.6 (a) TEM image of recovered carbon black P700; (b) EFTEM elemental detection of carbon, sulfur and silicon (left $\rightarrow$ right); (c) P700 elemental map of carbon (red), sulfur (green) and silicon (blue).

\subsubsection{Pyrolysis of a silica-filled compound}

A NR compound filled with silica as the only filler according to the formulation in Table 6.3, was pyrolyzed in a TGA as shown in Figure 6.7. The small weight loss of $\sim 0.5 \%$ around $100^{\circ} \mathrm{C}$ is the moisture removal of rubber compound. The first noticeable weight loss occurs at $-200^{\circ} \mathrm{C}$ with the decomposition of lighter hydrocarbon compounds such as oil fractions used as processing aids during compounding. From $\sim 300^{\circ} \mathrm{C}$ to $450^{\circ} \mathrm{C}$, a major weight loss occurs as the elastomer 
molecules degrade in this temperature range. Above this temperature, no further weight loss occurs, indicating the completion of pyrolysis at $\sim 450^{\circ} \mathrm{C}$. Strikingly, the white silica turned black after the pyrolysis, which clearly shows the formation of carbonaceous residue on its surface. The remaining weight is $32.6 \mathrm{wt} . \%$, while the silica content in the compound formulation was $31 \mathrm{wt} . \%$. The extra $1.6 \mathrm{wt} . \%$ is thus carbonaceous residue and other inorganics including zinc and sulfur compounds on the silica surface.

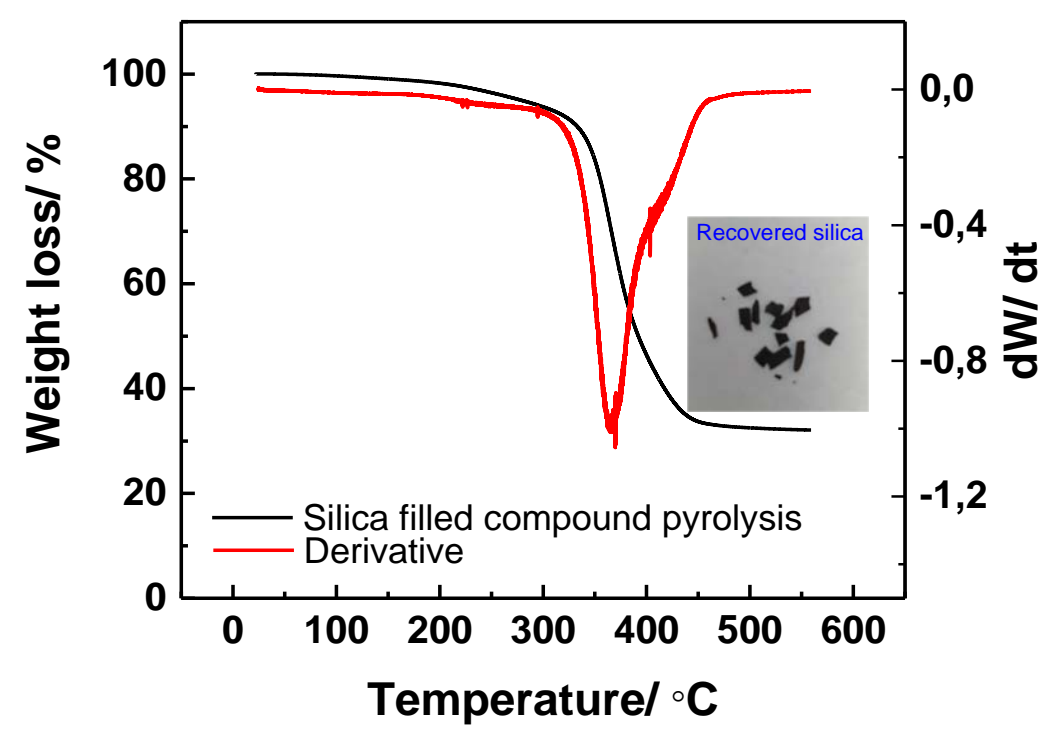

Figure 6.7 TGA pyrolysis curve of a silica compound.

\subsubsection{Elemental composition and chemical state}

XPS was used to characterize the elemental composition of pure and recovered silica as summarized in Table 6.4. The former contains $3 \%$ of carbon as contaminations, while after pyrolysis, the carbon content is doubled which confirms the formation of carbonaceous residue responsible for the black color previously seen in Figure 6.7. The lower O/Si ratio in recovered silica suggests less surface functional groups than for pure silica. Recovered silica also contains small quantities of sulfur and zinc from rubber compounding. To further understand the chemical nature of these elements, binding energies of fitted bands for all elements present are reported in Table 6.5 as derived from XPS. In both silica's, the major portion of carbon is in the form of C-C $(-75 \%)$ and $\mathrm{C}-\mathrm{O}(\sim 20 \%)$ bonds at $284.6 \mathrm{eV}$ and 198 
$286.3 \mathrm{eV}$, respectively. Since both carbon species on pure silica and in the carbonaceous residue on recovered silica would give similar peak positions, differentiating between them based on binding energies is not possible. The binding energies of silicon and oxygen in both, pure silica and recovered silica samples, are the same as most are in the form of $\mathrm{SiO}_{2}$. The peak position of sulfur in the recovered silica indicates two compounds: zinc sulfide and sulfur-carbon-silica based compounds. The binding energy of zinc compounds indicates its presence as $\mathrm{ZnO}$ and $\mathrm{ZnS}$. The differentiation between these compounds is not possible due to the similar energy position. However, the molar amount of zinc is higher than the one of sulfur, and part of the sulfur also resulted in compounds with carbon and silica. The presence of zinc oxide is also expected.

Table 6.4 Elemental analysis of pure silica and recovered silica.

\begin{tabular}{|c|c|c|c|c|c|}
\hline Sample & \multicolumn{5}{|c|}{ Elements (atomic wt.\%) } \\
\hline & C & Si & O & S & Zn \\
\hline Silica & 3 & 28.5 & 68.5 & - & - \\
\hline $\begin{array}{c}\text { Recovered } \\
\text { silica }\end{array}$ & 5.9 & 28.3 & 64.6 & 0.3 & 0.8 \\
\hline
\end{tabular}

Table 6.5 Binding energies of fitted bands for elements of pure silica and recovered silica.

\begin{tabular}{|l|c|c|c|c|c|}
\hline Sample & \multicolumn{5}{|c|}{ Elements binding energy (eV) } \\
\hline & C & Si & O & S & Zn \\
\hline Silica & 284.8 & 103.4 & 532.8 & - & - \\
& 286.3 & 104 & 534.8 & & \\
\hline Recovered & 284.8 & 103.4 & 532.8 & 161.5 & \multirow{2}{*}{1021.8} \\
silica & 286.3 & 104 & 534.8 & 162.5 & \\
\hline
\end{tabular}

\subsubsection{Surface functional groups on silica}

FTIR was used to further characterize the surface functionalities formed on the recovered silica surface, and these were compared with the ones on pure silica and silane-modified silica: Coupsil. For silica recovered from the silica filled compound, hydrocarbons and sulfur functionalities on the filler surface are expected after 
pyrolysis. In Figure 6.8, the characteristic peaks of silica including $\mathrm{Si}-\mathrm{OH}, \mathrm{SiO}_{2}$, Si$\mathrm{O}-\mathrm{Si}$ are visible in all samples. Coupsil contains an additional small $\mathrm{C}-\mathrm{H}$ peak around $3000 \mathrm{~cm}^{-1}$ due to the presence of hydrocarbons from the coupling agent. A weak signal in the same range is also present in recovered silica indicating the presence of hydrocarbon based carbonaceous residue as previously seen in the XPS and TGA results. Both, pure silica and silane-modified Coupsil, give a clear peak of Si-OH at $950 \mathrm{~cm}^{-1}$, while for recovered silica the peak at this position is merged with the broader of Si-O-Si peak. In Figure 6.9, the relative absorbance of recovered silica is shown by subtracting it's signal from the pure silica signal. The broadening of the silica peak due to an additional peak at $1030 \mathrm{~cm}^{-1}$ can now clearly be seen. This strong signal along with a weak signal at $1350 \mathrm{~cm}^{-1}$ indicates the presence of sulfur in the form of oxides on the silica surface. These sulfur compounds could be the carbon-sulfur complexes as proposed previously in Chapter 4.2 (Section 4.2.3.5) and in another study by Roy et al. ${ }^{2}$. Moving towards higher wave numbers, recovered silica has relatively less water and $\mathrm{Si}-\mathrm{OH}$ groups than pure silica. Recovered silica shows a stronger Si-O peak at $840 \mathrm{~cm}^{-1}$ compared to pure silica. The presence of this additional silicon-oxygen moiety in recovered silica suggests the formation of compounds with the silane, which was added to the compound as a filler-polymer coupling agent before pyrolysis. Formation of such compounds is also in-line with the XPS results in Table 6.5, which also indicates the formation of a carbon-sulfursilica compound with a binding energy of $162.5 \mathrm{eV}$. 


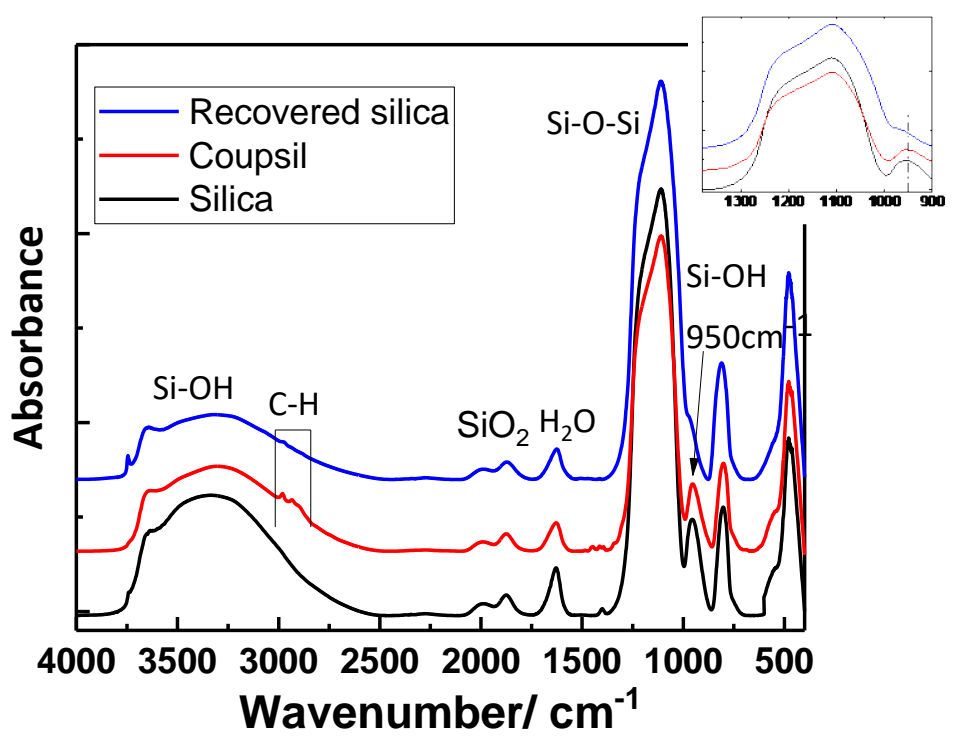

Figure 6.8 FTIR spectra of silica, Coupsil and recovered silica from rubber compound pyrolysis.

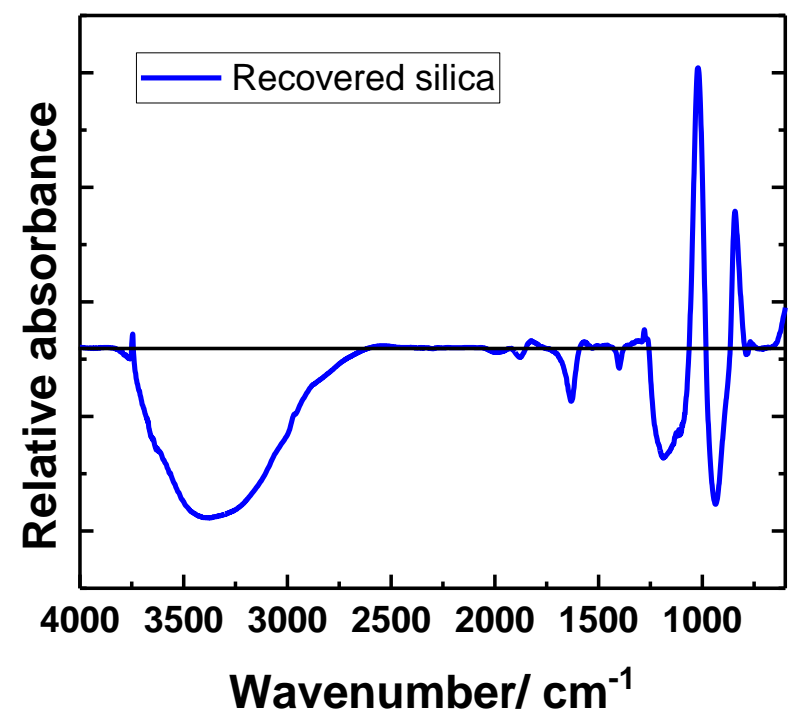

Figure 6.9 Absorbance of recovered silica relative to pure silica. 
These sort of compounds can be formed during pyrolysis as silane decomposes above $350^{\circ} \mathrm{C}$ and may react with sulfur vapors and hydrocarbon volatiles, which further condense on the silica surface. Higher concentrations of these compounds are clearly visible in the EFTEM images on the silica surface in Figure 6.6.

In order to further investigate the role of silane in forming these compounds, Coupsil: a silane-modified silica, was also pyrolyzed in TGA and then analyzed by FTIR for surface functionalities. In Figure 6.10(a), the weak signal of $\mathrm{C}-\mathrm{H}$ present in Coupsil diminishes after pyrolysis due to the removal of a major portion of hydrocarbons. Similar to recovered silica from rubber compound pyrolysis, the pyrolytic Coupsil also shows broadening of the Si-O-Si peak, which consequently merges with the $\mathrm{Si}-\mathrm{OH}$ peak at $950 \mathrm{~cm}^{-1}$. Furthermore, when the spectra of pyrolytic Coupsil is subtracted from the one of pure silica, the relative absorbance behavior in Figure 6.10(b) shows practically identical surface characteristics in the range of $1350 \mathrm{~cm}^{-1}$ to $850 \mathrm{~cm}^{-1}$ as seen in the case of recovered silica in Figure 6.9: additional peaks in the ranges $1350 \mathrm{~cm}^{-1}$ to $1250 \mathrm{~cm}^{-1}$ and $1020 \mathrm{~cm}^{-1}$ to $1040 \mathrm{~cm}^{-1}$ due to sulfur based compounds; and a stronger signal than pure silica at $950 \mathrm{~cm}^{-1}$ due to the presence of silicon oxide originating from silane. This investigation shows that silane plays an important role in forming chemical compounds with carbon volatiles and sulfur vapors on the silica surface during pyrolysis. 
Chapter 6
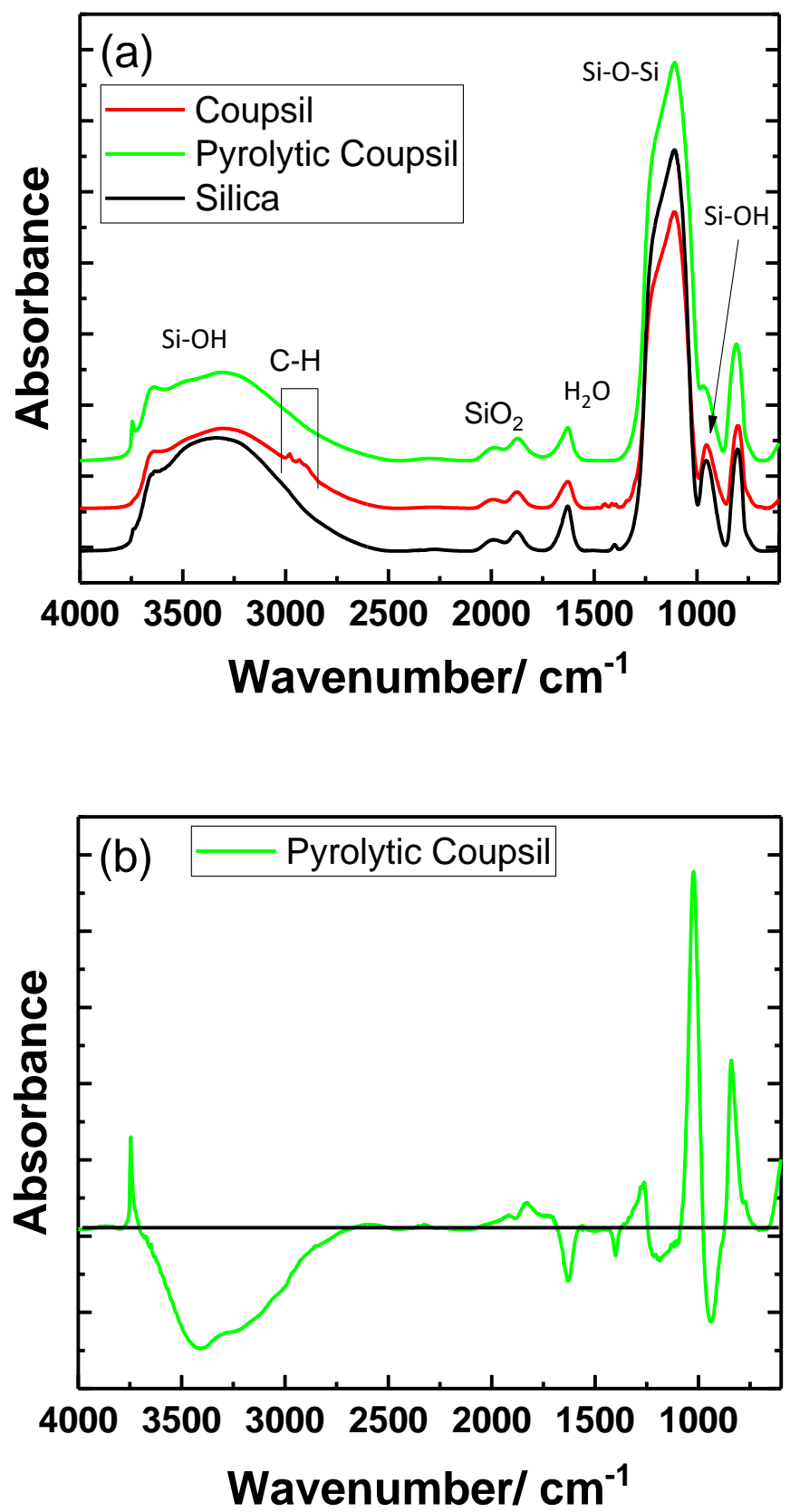

Figure 6.10 (a) FTIR spectra of pure silica, Coupsil and pyrolytic Coupsil. (b) Relative absorbance of pyrolytic Coupsil to pure silica. 
Recovered silica characterization confirms the presence of sulfur compounds attached to the silica surface. These compounds can form a sulfur-rubber covalent bond with the rubber matrix during compounding, resulting in a strong chemical fillerpolymer coupling. From XPS measurements (Table 6.5) along with the current recovered silica characterization it can be assumed that a part of the sulfur in $\mathrm{rCB}$ was in an "active form" of sulfur bound to the silica surface, and consequently formed chemical bonds between filler and polymer. This resulted in a higher initial torque and torque increase over time as well as bound rubber increase during heating.

Although, the present study focuses on the sulfur vulcanization mechanism by active sulfur species of rCB, other possibilities however cannot be ruled out. During the thermal degradation of rubber in pyrolysis, living radical species are formed which may remain as deposits in $\mathrm{rCB}$. These species could initiate radical crosslinking in a manner similar to peroxide crosslinking. In this type, peroxides decompose at vulcanization temperatures and form radicals. The radicals react with polymer chains and form polymeric radicals. These then combine with each other and form a direct chain-to-chain crosslink ${ }^{7}$. Silica present in $\mathrm{rCB}$, which is known for its radical catalytic functionality could also induce such vulcanization. Generally, radicals on silica are originated by direct contact of its freshly cleaved surface with oxides ${ }^{8}$, which could be a possibility during pyrolysis.

\subsection{Conclusions}

Starting point of this study was the contradiction of high polymer-filler interactions and low in-rubber performance of $\mathrm{rCB}$ compounds. The aim was to further elucidate and understand the nature and role of the sulfur compounds present in rCB.

Carbon black N660 and recovered carbon black filled compounds without additional curatives were analyzed concerning their curing activity: the presence of $\mathrm{rCB}$ resulted in a slight but constant increase of the torque during rheometer measurements. This demonstrated the active nature of the rCB sulfur component, which was confirmed by other compound properties: The profound effect on bound rubber content upon heating showed the possibility of chemically active sulfur compounds in rCBs. The presence of sulfur compounds and carbonaceous residues on the silica surface was illustrated by elemental analysis. Surface functionality analysis of recovered silica and pyrolytic Coupsil showed the role of silane in forming sulfur-carbon-silica compounds on silica surface. Moreover, radical crosslinking due to the presence of radical species in $\mathrm{rCB}$ was also mentioned as another possible case which needs to be further investigated. 


\section{References}

[1] H. Darmstadt, C. Roy and S. Kaliaguine, Carbon, 33, 1449 (1995).

[2] C. Roy, A. Rastegar, S. Kaliaguine, H. Darmstadt, and V. Tochev, Plast. Rubber Compost. Process. Appl., 23, 21 (1995).

[3] C. Roy, A. Chaala, H. Darmstadt, B. De. Caumia, H. Pakdel, and J. Yang, Conversion of used tires to carbon black and oil pyrolysis, In Rubber Recycling, CRC Press, Florida, (2005).

[4] A. Chaala, H. Darmstadt, and C. Roy, Fuel Process. Technol., 46, 1 (1996).

[5] J. D. Martinez, N.U. Cardona, R. Murillo, T. Garcia, and J.M. Lopez, Waste Manag., 85, 574 ()2019.

[6] E. M. Dannenberg, Rubber Chem. Technol. 59, 512 (1986).

[7] B. Rodgers, Rubber Compounding: Chemistry and Applications, CRC Press, Boca Raton, (2016).

[8] B. Fubini, E. Giamello, M. Volante, and V. Bolis, Toxicol. Ind. Health, 6, 571 (1990). 
Chapter 6 
CHAPTER 7

\section{MATERIAL CHARACTERISTICS VS. IN-RUBBER PERFORMANCE OF RECOVERED CARBON BLACK, A CORRELATION STUDY}

The colloidal properties including surface area and structure of conventional carbon blacks are commonly used to predict their rubber reinforcement potential. These properties of recovered carbon blacks ( $\mathrm{CCB}$ ) often match with the ones of conventional high-reinforcing carbon blacks such as N330; however, the reinforcement strength of $\mathrm{rCB}$ is mostly similar to or even lower compared to semireinforcing carbon black N660. In the present study, a potential correlation between rCB characteristics and their in-rubber behavior is investigated.

Initially, the tensile properties show a linear increase with decrease in volatile content, corresponding to an increase in toluene transmittance starting from $8 \%$ till $42 \%$. This relationship does not hold, when low-volatile rCBs with a transmittance above $85 \%$ are considered: a consequence of carbonaceous residue on the carbon black surface, which cannot be leached by toluene but still does affect the surface activity of $\mathrm{rCB}$. Different from toluene transmittance, the hydrogen content represents the total organic impurity content: volatiles and non-volatiles, and shows a better correlation with the tensile properties. Nevertheless, based on the drop in tensile properties at even low volatile and hydrogen contents, further investigation is needed concerning the transition of volatiles to non-volatiles and their impact on inrubber performance.

Recovered CBs having a high-volatiles content with a toluene transmittance of up to $42 \%$ show a strong linear relationship with in-rubber performance. Volatiles removal in this range substantially improves the $\mathrm{rCB}$ structure by opening voids and creating more possibilities for rubber chains to anchor. For these rCBs, surface area as measured by lodine adsorption number (IAN), does not show a strong influence on compound properties. The presence of several oxides in $\mathrm{rCB}$ may influence the adsorption of iodine on $\mathrm{rCB}$ and thus results in poor correlation with compound properties. 


\subsection{Introduction}

The addition of carbon black to a rubber compound substantially improves the physical properties of the material ${ }^{1}$. The three major factors are:

(i) loading of carbon black,

(ii) specific surface area,

(iii) structure ${ }^{2}$.

At a fixed loading, the specific surface area and structure are considered as the vital parameters for rubber reinforcement and are used for predicting the performance. ASTM D1765-86 defines the nomenclature of carbon black with respect to the particle size and the structure. This standard describes the filler by a combination of a letter and 3 digits i.e Nxyz, where $\mathrm{N}$ stands for normal curing or S for slow curing, while $x$ defines the mean primary particle size. The other two digits $y z$ are used to indicate the structure of aggregates. The smaller the size of the primary particle, the higher is the specific surface area. The structure of carbon black can be generalized as being lower or higher: a lower structure exhibits less voids, while a higher structure is more branched with more possibilities for rubber chains to be occluded and interact ${ }^{3-5}$.

The viscosity of uncured compounds increases with higher specific surface area and structure for a given loading of carbon black. The dispersion of carbon black in a rubber compound is enhanced by a higher structure and lower specific surface area. Low-strain properties are mainly influenced by surface area, and high-strain properties show better correlation with structure. So, Mooney viscosity and modulus at $300 \%$ strain are strongly dependent on aggregate structure as determined by Crushed Oil Adsorption Number (COAN) as shown in Figure 7.16-7. 

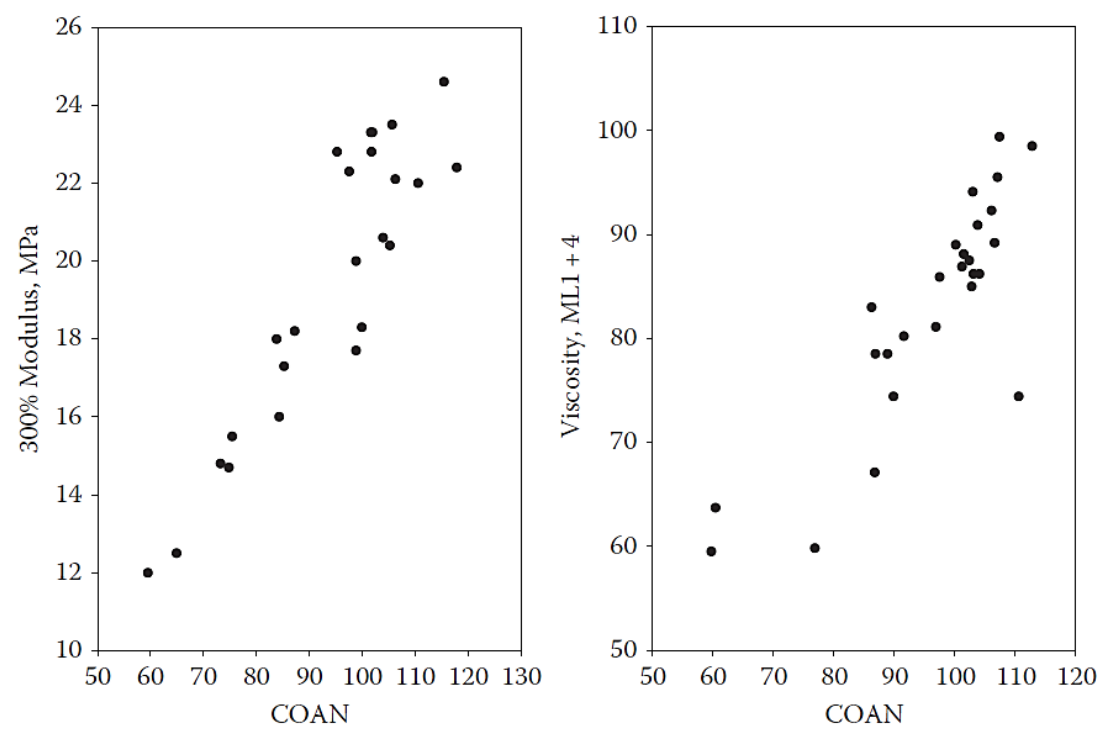

Figure 7.1 Relationship of the conventional carbon black structure measured as crushed oil adsorption number (COAN) with the tensile modulus at $300 \%$ strain and Mooney viscosity ${ }^{6}$.

Recovered carbon blacks differ from conventional carbon blacks in many ways: Carbon blacks used in the rubber industry are rather pure and have a very low content of volatiles with a toluene extract transmittance above $90 \%$. rCBs can exhibit a wider range of volatiles content leading to transmittances of their toluene extracts ranging from 0 to $100 \%{ }^{8}$. Furthermore, specific surface area and structure are controlled during production of conventional carbon blacks, whereas these characteristics for $\mathrm{rCB}$ are mainly dependent on the carbon blacks used in the feedstock and may improve to a certain extent as a consequence of volatile content reduction by adjusting the pyrolysis parameters. rCBs contain an additional nonvolatile organic impurity i.e. carbonaceous residues, which are formed and deposited onto the carbon surface during pyrolysis ${ }^{9-10}$. These residues modify the original surface microstructure of carbon black by covering the high energetic sites and hence affect the activity ${ }^{11-12}$. Due to the above mentioned differences between conventional and recovered carbon black, ASTM committee D36 is currently working on defining the rCB characteristics.

In the present study, relationships between different rCB characteristics and their inrubber performance are investigated. Organic impurity indicators including toluene transmittance and hydrogen content as well as structure and specific surface area are used to correlate with the in-rubber performance. Details of the characterizations and characteristics can be found in the preceding chapters. 


\subsection{Results and Discussion}

The material characteristics of recovered carbon blacks are compared with their key compound and in-rubber performance properties: organic impurities, surface area and structure of $\mathrm{rCBs}$ are correlated with Mooney viscosity, filler-filler interactions and stress-strain behavior.

\subsubsection{Recovered carbon black organic impurities / rubber performance relationship}

Commercially available carbon blacks for rubber applications are usually produced by incomplete combustion of oil and normally contain a small amount of organic volatiles. These volatiles are the remaining oil fragments and can be measured by the toluene extract transmittance according to ASTM standard D1618-99. The transmittance of the extract of conventional carbon blacks is generally above $90 \%$. In contrast, the toluene transmittance of carbon blacks recovered from waste tires by pyrolysis varies within the complete range from $0 \%$ to $100 \%$ and is strongly dependent on the pyrolysis process parameters ${ }^{8}$. Overall organic impurity matter can be measured as the hydrogen content from elemental analysis. Unlike transmittance measurements which only provide amounts of extractable volatiles, hydrogen content represents both volatiles and non-volatile organics. The non-volatile organics are low hydrogen cyclic structures and termed as carbonaceous residue.

\subsubsection{Toluene transmittance}

In Figure 7.2, the different rCBs from the temperature study detailed in Chapter 4.1 with minimum residence time are compared in terms of mechanical properties and transmittance. The rCB transmittance obtained in the range of $8 \%$ to $42 \%$ shows a linear correlation with tensile strength and reinforcement index $(\mathrm{RI})$ with $\mathrm{R}^{2}$ values of 0,95 and 0,99 respectively. This indicates that reducing the volatile content of rCBs is directly related to an enhancement of the rubber reinforcing ability. In Figure 7.3, the transmittance range is extended to $96 \%$ by adding the values of the rCBs with longer residence times. The tensile properties of the cleaner rCBs are lower than for the low transmittance samples, and the linear correlation does not hold anymore. This behavior suggests that removal of volatiles from $\mathrm{rCB}$ only improves the performance to a limited extent. When the $\mathrm{rCB}$ stays longer in the reactor, the formation of non-extractable carbonaceous structures happens. These residues modify the carbon black microstructure by covering its active sites, which are responsible for carbon-rubber interactions and in-rubber performance, resulting in a 
decreased in-rubber performance. Since these low-volatile rCBs exhibit a different microstructure, they do not follow the earlier trend.

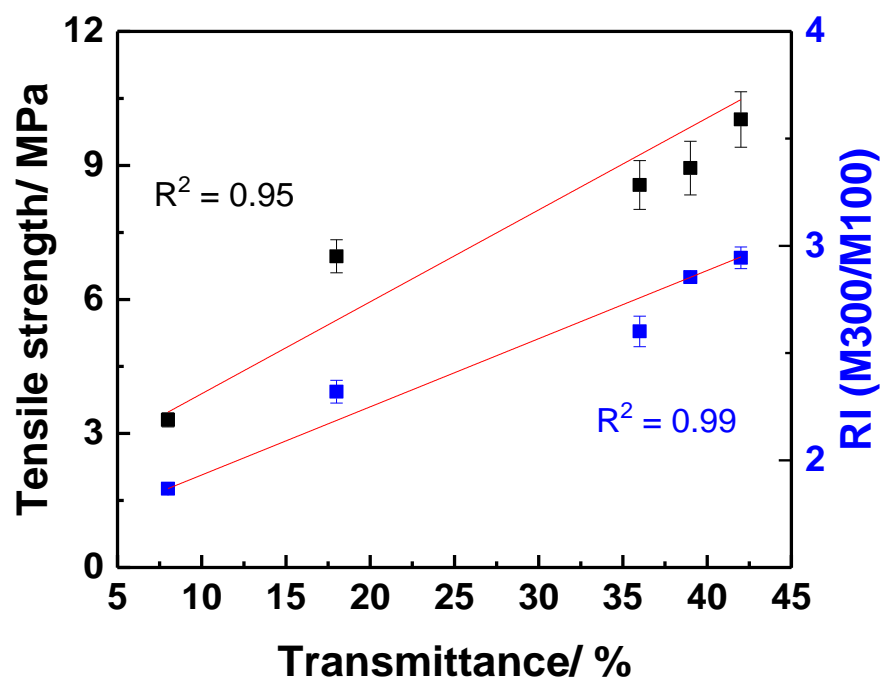

Figure 7.2 The relationship of the toluene transmittance of rCBs with tensile strength (left axis) and reinforcement index (right axis) in the high-volatiles region $(8 \%-42 \%)$ 


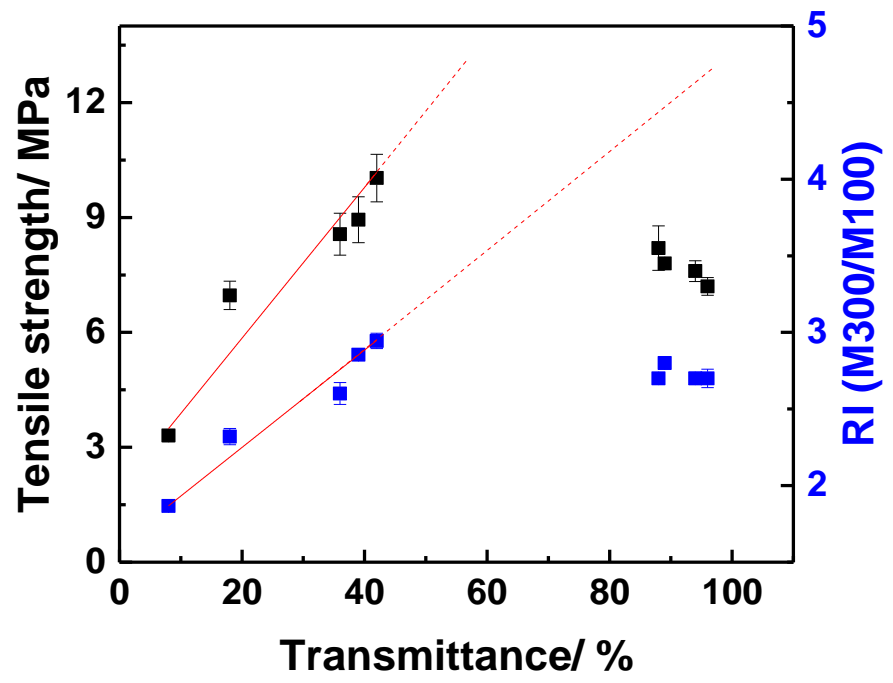

Figure 7.3 The relationship of toluene transmittance of rCBs with tensile strength (black symbols) and reinforcement index (blue symbols) over the whole volatiles concentration range (8\%-96\%)

\subsubsection{Hydrogen content}

As shown in Figure 7.4, tensile properties improve as hydrogen content is reduced from $2.5 \%$ to $0.6 \%$, and showing a strong linear correlation. In Figure 7.5 , when the hydrogen range is further reduced from $0.3 \%$ to $0 \%$, tensile properties deteriorate and hence the correlation is deviated. The drop in tensile properties for very low hydrogen content is due to the change of the carbon black microstructure by the nonvolatile carbonaceous residue formation. The relatively better correlation of tensile properties with higher hydrogen content compared to lower toluene transmittance is further elaborated in Figure 7.6. by investigating the relationship between these two organic impurity measurements. 


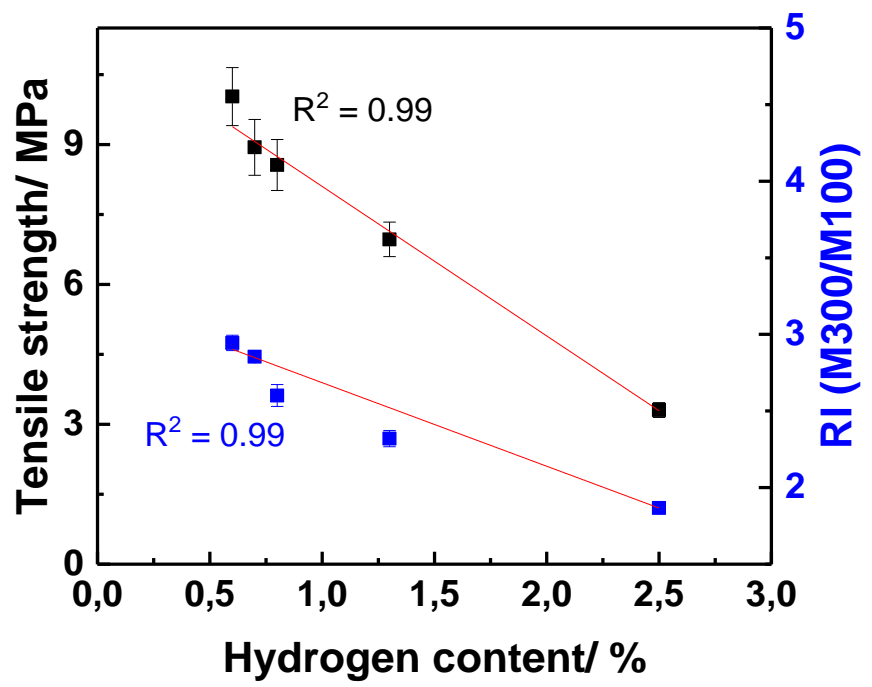

Figure 7.4 The relationship of the hydrogen content of $\mathrm{rCBs}$ with tensile strength (left axis) and reinforcement index (right axis) in the high-volatiles region.

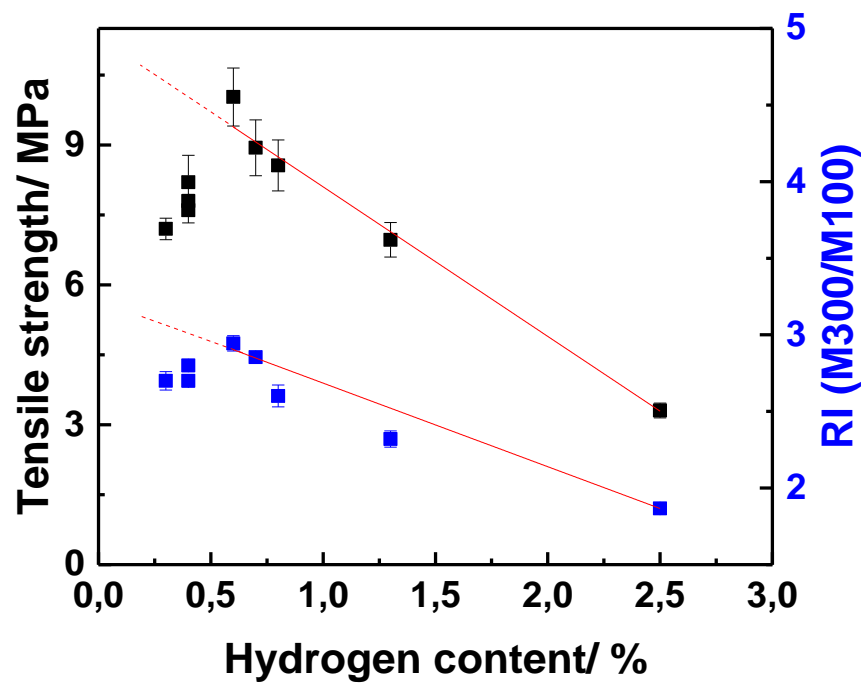

Figure 7.5 The relationship of the hydrogen content of $\mathrm{rCBs}$ with tensile strength (left axis) and reinforcement index (right axis) over the whole volatiles concentration range. 


\subsubsection{Transmittance vs hydrogen content}

As both, hydrogen content as well as toluene transmittance show a correlation with mechanical properties to a certain extent, the relationship between these two characteristics is further elaborated in Figure 7.6. A strong exponential correlation is seen, which shows an initial absolute improvement from $8 \%$ to $42 \%$ in transmittance with a corresponding substantial reduction in hydrogen content from $2.5 \%$ to $0.6 \%$. The transmittance further improves massively by $54 \%$ and reaches an absolute value of $96 \%$. However, in this range, the hydrogen content reduces only by $0.3 \%$ to a remaining concentration of $0.3 \%$. It is worth mentioning that this relation should not be confused with Beer's law in which concentration is related to transmittance in similar exponential manner. A range of hydrogen-based substances are present in rCB and toluene only extracts volatiles from rCB. However, elemental analysis uses a burn-off method; therefore, the hydrogen content is representative of the total organic impurity content: volatiles and non-volatiles such as carbonaceous residues. These residues are graphite-like structures formed on the rCB surface at longer residence time in the reductive pyrolysis environment as previously explained in Chapter 4.1. These depositions are permanent and change the surface microstructure of carbon black by covering the graphitic crystal defects, the active sites crucial for polymer-filler interaction and reinforcement. Therefore, the present property-performance correlation study was limited to the temperature-study samples with higher volatiles contents. These samples were recovered in a temperature range of $500^{\circ} \mathrm{C}$ to $700^{\circ} \mathrm{C}$ at the shortest residence time of 6 seconds as explained in Chapter 4.1. 


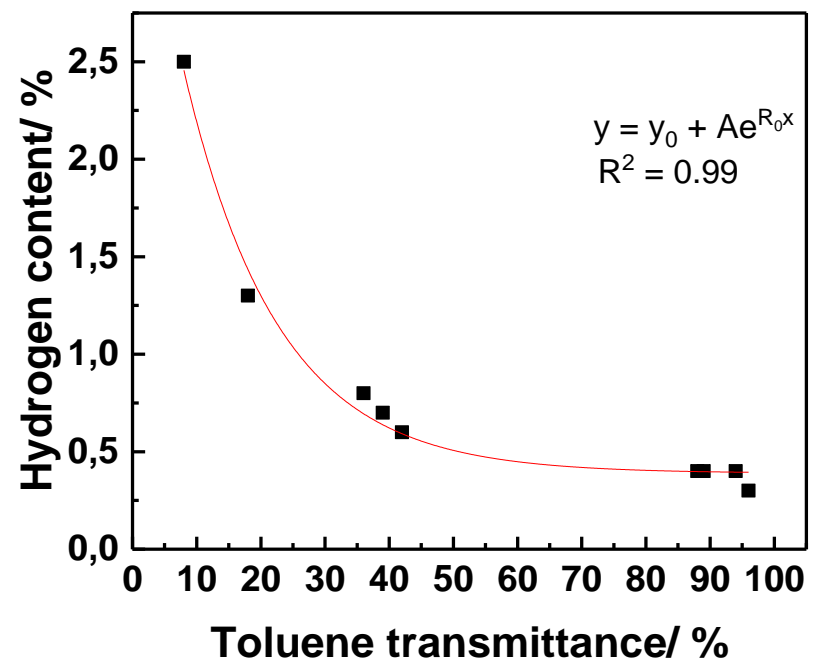

Figure 7.6 Correlation between hydrogen content and toluene transmittance of recovered carbon blacks.

\subsubsection{Recovered carbon black structure / rubber performance relationship}

\subsubsection{Compound viscosity}

The Mooney viscosity of compounds generally increases with a higher carbon black structure $^{6}$, see Figure 7.1. In Figure 7.7(a), the rCB structure measured by the oil absorption number (OAN) shows an exponential correlation with compound viscosity. In Figure 7.7(b), the relation between void volume and Mooney viscosity is linear. Though both structural measurements show strong correlations with compound viscosity, the correlations are different due to the various measurement principles: The oil absorption method relies on the molecule size of the oil which can penetrate into the small pores inaccessible to long rubber chains. Therefore, the initial increase in oil absorption number does not much affect the compound viscosity. Such behavior is also seen in Figure 7.1 for conventional carbon blacks, in which an initial increase in structure does not significantly affect the compound viscosity. An upturn in viscosity can be seen at carbon black structure values of $90 \mathrm{ml} / 100 \mathrm{~g}$, after which the relationship becomes more linear. Furthermore, the aggregated black structure also reduces during compound mixing to some extent which is not considered in the OAN measurement.

In the void volume measurement, the sample is compressed, and the degree of compression is taken as structural information ${ }^{13}$. The relationship between these two 
measurements can be seen in Figure 7.8 for the rCB samples under study. As expected, the initial increase in oil absorption capacity due to small voids filled with oil did not significantly change the void volume, while at higher values the relationship becomes more linear.
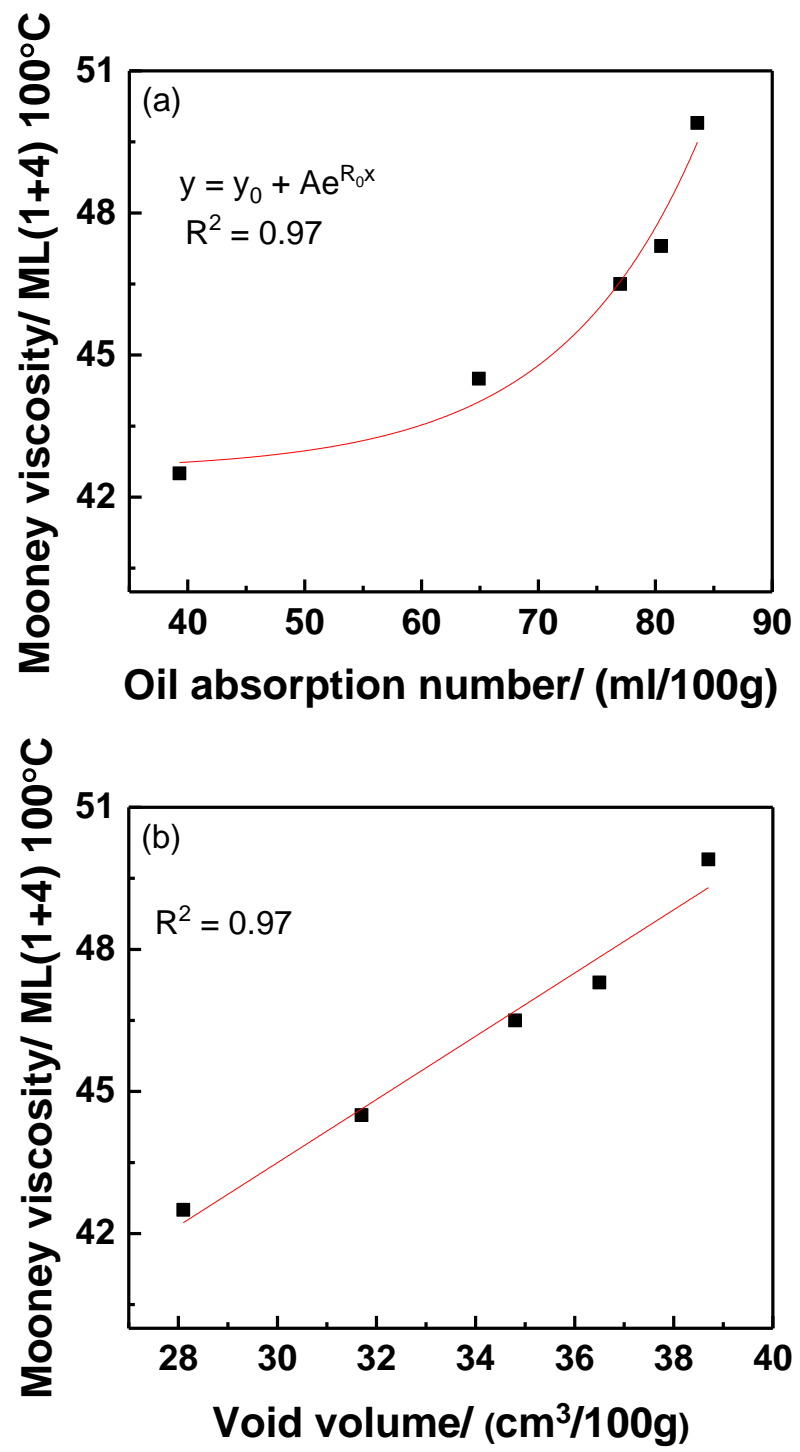

Figure 7.7 Relationship of structure with compound viscosity. (a) Structure measured by oil absorption and (b) by void volume measurements. 


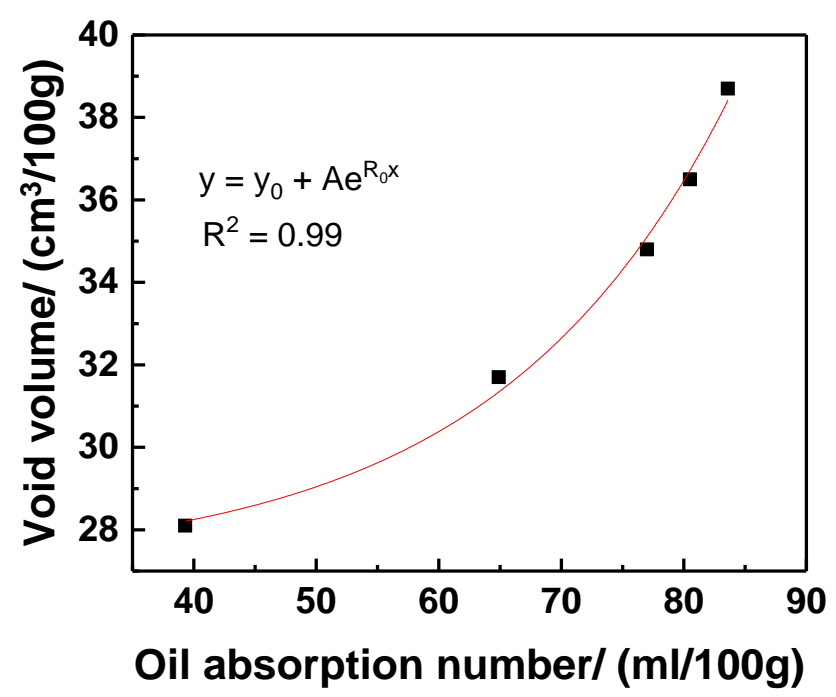

Figure 7.8 Relationship between void volume and oil absorption measurements.

\subsubsection{Filler-filler interactions}

Low-strain properties of carbon black filled compounds below $1 \%$ of deformation are dominated by filler-filler interactions. The storage modulus of the uncured compounds at low strain $\left(G^{\prime}(0.5 \%)\right)$ is therefore representative of filler-filler interactions ${ }^{2}$. For carbon black, the filler-filler interactions are not so much related to the structure, but to the surface area: $G^{\prime}(0.5 \%)$ increases with a larger surface area due to the stronger aggregation of smaller particles ${ }^{7}$. In Figure 7.9, linear correlations are seen between $G^{\prime}(0.5 \%)$ of $\mathrm{rCB}$ filled compounds and both types of structure measurements. These correlations exist as the structure enhancement is related to the removal of soft volatiles such as small rubber chain fragments. As a consequence of the cleaner surface, the inter-aggregate filler-filler interactions become more prominent and show a rise in $G^{\prime}(0.5 \%)$ with higher structure values. With further removal of volatiles, more and more carbonaceous residue is formed, and this will result in stronger filler-filler interactions. This was also reported by Norris et al. ${ }^{11}$. 

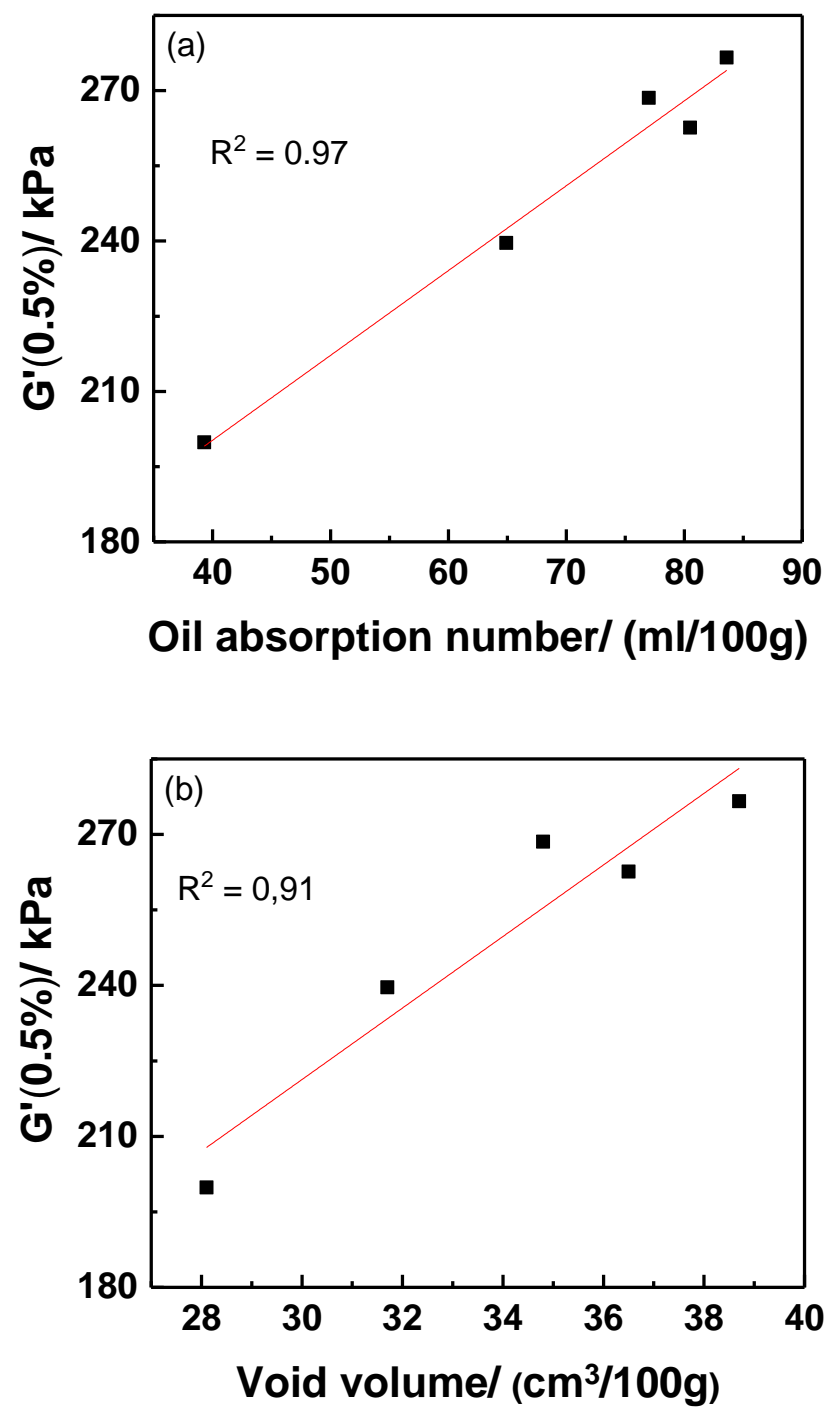

Figure 7.9 Relationship of the structure of $\mathrm{rCB}$ with the low-strain dynamic moduli of uncured compounds. (a) Structure by oil absorption; and (b) by void volume measurements.

\subsubsection{Tensile properties}

For conventional carbon blacks, structure measurements show a good relationship with mechanical properties: the higher the structure, the better the tensile 
properties $^{11}$, as demonstrated in Figure 7.1 already. In Figure 7.10, both structure measurements of $\mathrm{rCB}$ show a linear correlation with properties, including tensile strength and reinforcement index. As mentioned above, also in this set of data the improvement in structure is mainly due to the removal of volatiles leading to void openings, improving the reinforcement ability of rCBs. However, as seen in the toluene transmission data, this linear structure-property relation may not hold if the structure range extends to higher values. This can already be seen at higher void volume values, at which the influence of structure on tensile properties is reduced and tensile properties may even drop more as the structure range is further extended. Such a behavior is to be expected as the initial increase in the $\mathrm{rCB}$ reinforcement strength is dominated by void openings through volatiles removal. However, once carbonaceous residue is formed, the filler-filler interactions are increased and the reinforcement strength of $\mathrm{rCB}$ is reduced again. This effect has been explained before in Chapter 5.2, Figure 5.2.2, in which low-volatiles rCBs recovered at higher temperatures and longer residence times showed higher fillerfiller interactions. A slight upturn in tensile versus OAN data points above $80 \mathrm{ml} / 100 \mathrm{~g}$ is noticed; however, this does not represent a major deviation from the observed trend and would not lead to an exponential increase in tensile performance as might be expected from Figure 7.10(a). 

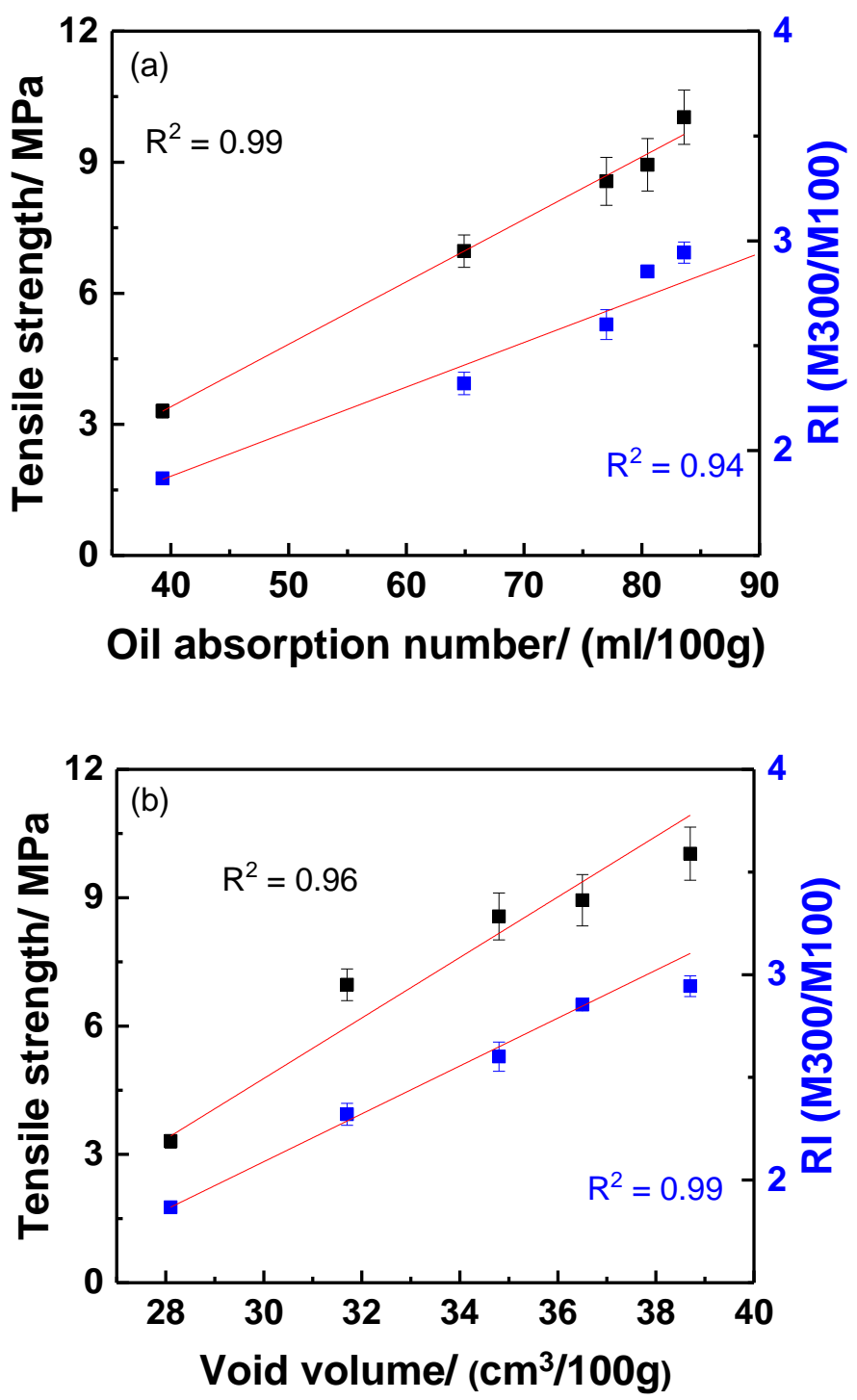

Figure 7.10 Relationship between rCB structure and tensile strength (left axis) and reinforcement index (right axis). (a) Structure measured by oil absorption, and (b) by void volume measurements.

\subsubsection{Recovered carbon black surface area / rubber performance relationship}

The specific surface area of carbon black is usually measured by nitrogen adsorption; Iodine Adsorption Number (IAN) can also be used. For furnace blacks 220 
with low amounts of oxygen-based functional groups it supplements with the nitrogen adsorption data ${ }^{14}$, while this relation does not hold for oxidized blacks: their IAN values are reduced due to lower adsorption of iodine in the presence of surface oxides $^{2}$. In rCBs, oxidized species are also present; especially silica which may affect the iodine adsorption and therefore the IAN surface area values. Nitrogen adsorption cannot be used for $\mathrm{rCBs}$ with a high volatile content, as the method comprises a degassing step at $300^{\circ} \mathrm{C}$. At this temperature, volatiles covering the surface of $\mathrm{rCB}$ start to decompose and eventually reveal the surface of carbon black and silica nano-particles, and consequently increase the specific surface area. Therefore the actual area of $\mathrm{rCB}$ with all volatiles still present cannot be measured. Moreover, volatiles removed from the surface can severely pollute and damage the equipment.

The surface area of carbon black plays an important role in defining its in-rubber properties. Compound Mooney viscosity, filler-filler interactions and tensile properties are enhanced with increasing surface area for conventional carbon blacks. In case of rCBs, these compound properties however do not show a strong dependence on surface area. In Figure 7.11, both low-strain filler-filler interactions and high-strain tensile properties show an initial dependence on surface area till IAN $\sim 50 \mathrm{mg} / \mathrm{g}$ and are much less affected onwards. Compound viscosity also does not show a regular trend with respect to the surface area. 

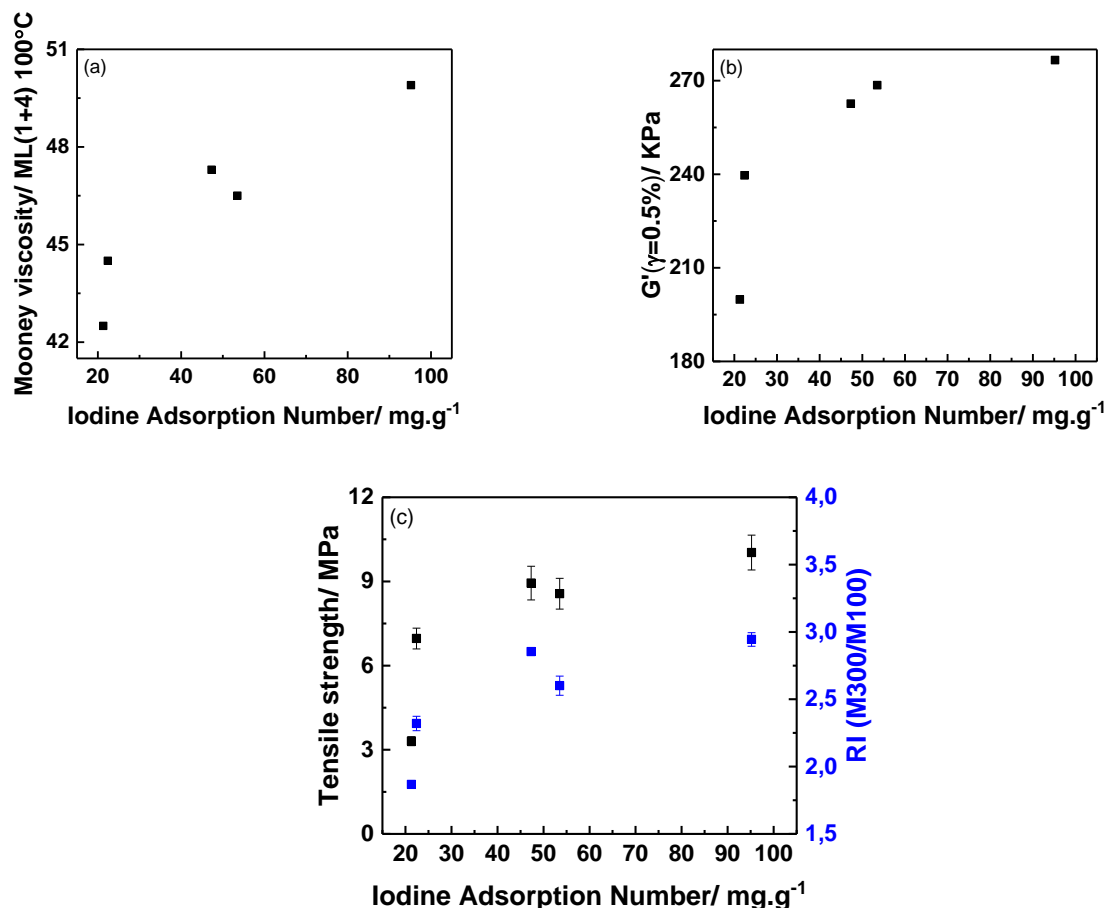

Figure 7.11 The relationship of surface area of rCBs with compound properties: (a) viscosity, (b) low-strain dynamic modulus, and (c) tensile strength (left axis) and reinforcement index (right axis).

So, the relationships between $\mathrm{rCB}$ characteristics and in-rubber performance are different compared to the correlations measured for conventional carbon blacks. For the latter, structure and particle size are defined during their manufacturing process by incomplete combustion of the hydrocarbon feedstock. The degree of carbon black aggregate branching is defined by the process parameters, while the rCB structure and particle size is not developed during the pyrolysis process but only becomes revealed as a consequence of volatiles removal. This means that the dominating factor for the $\mathrm{rCB}$ in-rubber performance is the volatiles content, which dictates both, the structure and surface area, and consequently the in-rubber performance. Furthermore, the work in standardizing $\mathrm{rCB}$ should also further pursue by quantification of the non-volatile carbonaceous residue which affects the surface microstructure of pyrolysis carbon blacks. rCBs are recovered from different types of tires with varying composition, and the variation in feedstock can so affect the formation of such impurities. By considering both, organic volatiles and non-volatiles, it is expected that the in-rubber properties of $\mathrm{rCB}$ can be better predicted. 


\subsection{Conclusions}

The relationship between the characteristics of recovered carbon blacks and their in-rubber performance was studied. The in-rubber properties of rCBs recovered using various process conditions were first compared with their organic impurities in terms of toluene extract transmittance and hydrogen content. The analyzed rCBs can be divided into two organic impurity ranges: high-volatile rCBs with toluene transmittance up to $42 \%$, and low-volatile rCBs showing a transmittance above $85 \%$. The high-volatile rCBs showed a strong correlation between organic impurities and tensile properties. This correlation did not hold when rCBs with low volatile contents were considered. This deviation was due to the formation of non-volatile carbonaceous residues which altered their surface microstructure of the blacks. Since hydrogen content represents both, volatile and non-volatile organic matter, it correlated relatively better with tensile properties than transmittance results.

For high-volatile rCBs, structure- and surface area-performance relationships were also studied. rCB structure information obtained by oil absorption number and void volume showed strong correlations with the properties of the uncured compound and cured rubber. However, these $\mathrm{rCB}$ compound properties were less dependent on surface area. The presence of oxides species in rCB could affect the measurement of surface area by the iodine adsorption method and was deduced as the main cause for lower surface area dependency.

\section{References}

[1] E. Dannenberg, Rubber Chem. Technol., 48, 410 (1975).

[2] J. B. Donnet, R. C. Bansal, and M. J. Wang, Carbon Black: Science and Technology, 2nd ed., Marcel Dekker, New York (1993)

[3] M.L. Studebaker, In Reinforcement of Elastomers: Compounding with Carbon Black, Ed. Intersci. NewYork (1965).

[4] C.R. Herd, G.C. McDonald and W.M. Hess, Rubber Chem. Technol., 65, 107 (1992).

[5] S. Wolff and M.J. Wang, Rubber Chem. Technol., 65, 329 (1992).

[6] B. Rodgers, W.H. Waddell and W. Klingensmith, Rubber Compounding, In Science and Technology of Rubber, Academic Press, 401-454, Cambridge, (2005).

[7] W.A. Wampler, T.F. Carlson, and W.R. Jones, Carbon Black, In Rubber Compounding: Chemistry and Applications, CRC Press, Boca Raton, (2016). 
[8] C. Norris, Presented at Recovered Carbon Black, Berlin, (2019).

[9] C. Roy, A. Rastegar, S. Kaliaguine, H. Darmstadt, and V. Tochev, Plast. Rubber Compost. Process. Appl., 23, 21 (1995).

[10] C. Roy, A. Chaala and H. Darmstadt, J. Anal. Appl. Pyrolysis, 51, 201 (1999).

[11] C. Norris, M. Hale and M. Bennett, Plast. Rubber Compos., 43, 245 (2014).

[12] C. Norris and S. Renegar, Presented at International Rubber Conference (IRC), London, (2019).

[13] G. Joyce, W.M. Henry, A.W. Thronton, and J.C. Hodgin, Rubber World, 244, 21 (2011).

[14] J.B. Donnet, A. Santini, D. Maafa, H. Balard, F. Padella, and A. La Barbera, Rubber Chem. Technol., 79, 120 (2006). 


\section{UPGRADING THE QUALITY OF RECOVERED CARBON BLACK, ARGON-PLASMA TREATMENT}

Recovered carbon black containing organic volatile impurities is etched by a lowpressure argon plasma in order to remove the volatiles and thus improve the rCBpolymer interaction. Optimization of the plasma process is carried out by varying three parameters: gas flow rate, radio frequency (RF) power, and treatment time. The amount of organic volatiles on the $\mathrm{rCB}$ surface as measured by transmittance of a toluene extract turned out to be $42 \%$, and it shows a maximum absolute improvement of $18 \%$ after plasma treatment. This consequently improves its nonpolar surface characteristics: enhanced dispersive energy and nano-roughness by revealing the carbon black microstructure. However, plasma etching is not selective to $\mathrm{rCB}$-carbon black surfaces, but also etches the surface of silica present in the ash as evidenced by an increase in polar energy.

The in-rubber evaluation shows that the activated $\mathrm{rCB}$-silica surface after plasma treatment has a profound effect on the curing behavior: a cleaner silica surface adsorbs the rubber curatives in the early stage of curing, thus slowing down the curing rate, and releases them at a later stage causing intensified marching modulus. The low curing activity of the plasma treated rCB filled compound slightly lowers the mechanical properties.

Another rCB grade with a low volatile content and a transmittance value of $97 \%$ is also plasma etched and evaluated in rubber. In this case, mechanical properties and cure properties remain the same after the plasma treatment. 


\subsection{Introduction}

Recovered carbon black from waste tire pyrolysis contains two major impurities: ash and organic residues. Ash consists of inorganics: mainly silica, as well as sulfur and zinc compounds ${ }^{1}$. The organic residues can be divided into two sub-categories:

(i) Volatiles remaining after pyrolysis due to insufficient cracking of polymer and being extractable by organic solvents such as toluene;

(ii) Carbonaceous residue, graphite like depositions that are formed on the rCB surface during pyrolysis by the dehydrogenation and cyclization of cracked polymer segments at high temperatures and long residence times. These compounds are non-volatile in nature and non-extractable by organic solvents ${ }^{2-4}$.

These organic and inorganic impurities cover the carbon black surface and hinder its potential re-use as active filler especially in rubber applications ${ }^{5}$.

Demineralization of coal6-7 by the use of acids and/or bases is a well-known method to obtain clean fuels. Similar attempts have been made for the ash content reduction in recovered carbon black. Chaala et al..$^{8}$ used sulfuric acid and a sodium hydroxide base for this purpose and reported a reduction of $57 \%$ of mineral matter. Zhang et al. ${ }^{9}$ used a combination of hydrochloric and hydrofluoric acid pickling under ultrasonic radiation and reduced the inorganics by $\sim 98 \%$. In this rCB treatment, the use of strong acids and intensive washing afterwards poses an environmental concern as it generates a lot of chemical waste. Recently Martinez et al. ${ }^{10}$ demineralized $\mathrm{rCB}$ by hydrochloric acid and studied its influence on rubber compound properties. In this study, the ash content was reduced by $67 \%$, while the in-rubber performance was only slightly improved.

The amount and type of organic impurities in rCB are highly process-dependent. Hydrocarbon volatiles are commonly reduced during or after pyrolysis by increasing temperatures and times, leading to the formation of new permanent organic impurities: carbonaceous residue ${ }^{4,11}$. Both, volatiles and carbonaceous residue cover the active carbon black sites lowering its surface activity ${ }^{5}$. In order to remove volatiles and carbonaceous residue, post-treatments are required.

For the present purpose, the use of argon plasma etching seems an appropriate technique which can be used to remove volatiles by the bombardment with high energy species without forming new residues. The benefit of such a technique is that it only modifies the surface without affecting the bulk properties. This technique is also environmentally friendly as it generates no waste. In the past ${ }^{12-15}$, various gases in elemental form and as polymer precursors (monomers) were utilized for carbon black surface treatment. Donnet et al. ${ }^{16}$ treated graphitized carbon black N550 in 
vacuum plasma with hydrogen, ammonia, argon and air, and reported creation of new active sites by formation of defects in the graphitic structure.

In the present study, two rCBs from passenger car tire pyrolysis recovered at different residence times are selected for plasma treatment. Argon is selected as the etching agent due to its inert nature. Low pressure argon plasma is applied to remove organic impurities from rCB: both volatiles and permanent carbonaceous residues.

\subsection{Experimental}

\subsubsection{Materials}

Rubber, protective agents and the cure package are explained in Chapter 5.1.

Reference carbon black: A semi-reinforcing commercial grade of N660 was used as reference (Corax, Orion Engineered Carbons, Frankfurt, Germany). This carbon black grade exhibits a BET surface area in the range of $35 \mathrm{~m}^{2} / \mathrm{g}$ to $45 \mathrm{~m}^{2} / \mathrm{g}$, and the surface area measured as iodine adsorption number (IAN) is $36 \mathrm{mg} / \mathrm{g}$. The aggregate structure value determined by the oil absorption number (OAN) is $91 \mathrm{ml} / 100 \mathrm{~g}^{17}$.

Recovered carbon blacks: $\mathrm{P} 7001 \mathrm{x}$ recovered at $700^{\circ} \mathrm{C}$ with a residence time of 6 seconds and $\mathrm{P} 7003 \mathrm{x}$ recovered at $700^{\circ} \mathrm{C}$ with tripled residence time were used for plasma treatment. The selected rCBs exhibit a toluene extract transmittance of $42 \%$ and $97 \%$. Detailed material characteristics of these two rCBs are given in Chapter 4.

Argon: Argon was purchased from Linde Gas Benelux BV, the Netherlands.

\subsubsection{Methods}

\subsubsection{Argon plasma etching}

Argon plasma etching of recovered carbon black was carried out in a radio frequency (RF) vertical plasma reactor. A schematic representation of this reactor is shown in Figure 8.1. The reactor setup consists of four parts:

- Impedance matching unit;

- Radio frequency (RF) generator;

- Magnetic stirrer;

- Vertical glass reactor. 


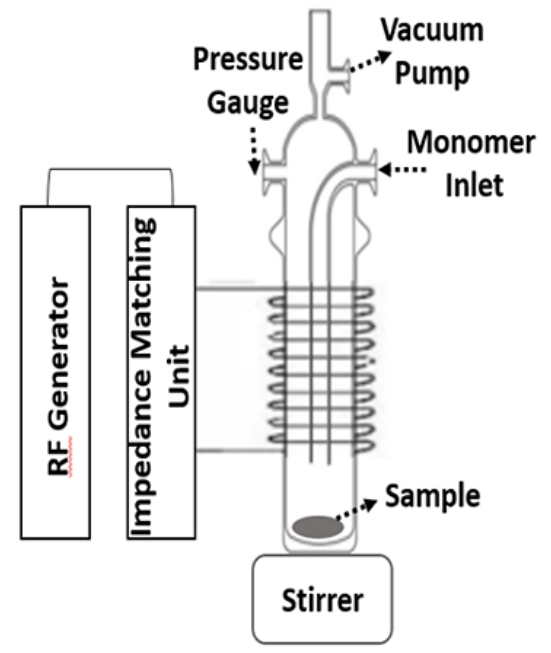

Reactor $\varnothing$ in $=60 \mathrm{~mm}$

Reactor $\varnothing$ out $=70 \mathrm{~mm}$

Monomer inlet $\varnothing$ in $=13 \mathrm{~mm}$

Monomer inlet $\varnothing$ out $=20 \mathrm{~mm}$

Vacuum pump $\varnothing$ in $=13 \mathrm{~mm}$

Pressure gauge $\varnothing \mathrm{in}=13 \mathrm{~mm}$

Figure 8.1 Schematic representation of the plasma reactor setup.

5 grams of recovered carbon were placed in the vertical reactor along with the magnetic stirrer. Argon gas was introduced in the reactor after maintaining a vacuum of $0.33-0.35 \mathrm{mbar}$. Introduction of gas lead to decrease in vacuum to $\sim 1.2 \mathrm{mbar}$. RF power was subsequently applied after vacuum stabilization at 0.9 mbar. The frequency was $13.56 \mathrm{MHz}$. The sample was stirred at $500 \mathrm{rpm}$ for homogeneous plasma etching. After shut down of the plasma, the inert argon gas flow was kept open for another 5 minutes to deactivate the remaining activated sites in order to avoid any adsorption while taking out the sample.

The process was initially optimized by varying the RF power and gas flow rate at a fixed treatment time of 30 minutes as shown in Table 8.1. A few experiments were repeated for checking the process reliability and standard deviation. After this, the treatment time was optimized. The efficiency of the plasma treatment under these conditions for sample etching was analyzed by toluene extract transmittance measurements. The process optimization was carried out on rCB P7001x, after which the optimized conditions were also applied for the treatment of P7003X. 
Table 8.1 Experimental conditions employed for plasma process optimization at fixed treatment time of 30 minutes.

\begin{tabular}{|c|c|c|c|c|}
\hline RF Power (Watt) & \multicolumn{4}{|c|}{ Gas flow rate (sccm) } \\
\hline 100 & 5 & 10 & 15 & 20 \\
\hline 200 & 5 & 10 & 15 & 20 \\
\hline 300 & 5 & 10 & 15 & 20 \\
\hline
\end{tabular}

After the optimization of RF power and gas flow as detailed in Table 8.1, treatment time was optimized for $10,20,30$, and 60 minutes.

\subsubsection{Transmittance}

The transmittance of toluene extract was measured as detailed in Chapter 4.1.

\subsubsection{Inverse gas chromatography}

A similar test protocol and evaluation as described in Chapter 4.2 was followed. Surface energies were measured for untreated and post-treated P7001x using the optimized conditions.

\subsubsection{Compounding}

A similar rubber formulation was used as mentioned in Chapter 5.1.

Mixing of carbon black and recovered carbon black compounds was carried out in a Brabender Plastograph $80 \mathrm{CC}$ internal batch mixer. A two stage mixing procedure was followed as shown in Table 8.2. 
Chapter 8

Table 8.2 Mixing sequence.

\begin{tabular}{|c|c|c|c|}
\hline \multicolumn{2}{|c|}{ First stage } & \multicolumn{2}{|c|}{ Second stage } \\
\hline \multicolumn{2}{|c|}{ Internal mixer } & \multicolumn{2}{|c|}{ Internal mixer } \\
\hline Steps & Time & Steps & Time \\
\hline Polymer addition & $00: 00-00: 20$ & \multirow{2}{*}{$\begin{array}{l}\text { Add } 1^{\text {st }} \text { stage } \\
\text { compound }\end{array}$} & \multirow[t]{2}{*}{$00: 00-00: 20$} \\
\hline Mastication & $00: 20-00: 40$ & & \\
\hline $1 / 2$ Carbon & $00: 40-01: 10$ & \multirow[t]{2}{*}{ Mastication } & \multirow[t]{2}{*}{$00: 20-00: 50$} \\
\hline Mixing & $01: 10-01: 40$ & & \\
\hline $1 / 2$ Carbon + additives & $01: 40-02: 00$ & \multirow[t]{2}{*}{ Curatives } & \multirow[t]{2}{*}{$00: 50-01: 10$} \\
\hline Mixing & $02: 00-05: 00$ & & \\
\hline \multirow{2}{*}{$\begin{array}{l}\text { Discharge and } \\
\text { sheeting off }\end{array}$} & \multirow[t]{2}{*}{ - } & Mixing & $01: 10-03: 10$ \\
\hline & & $\begin{array}{c}\text { Discharge and } \\
\text { sheeting off }\end{array}$ & - \\
\hline
\end{tabular}

\subsubsection{Vulcanization}

The compounds were vulcanized in a similar way as mentioned in Chapter 5. The curing time for all samples was 30 minutes. The vulcanization time was set to this period after determining this in Chapter 5.2 as the optimum time for rCB compounds.

\subsubsection{In-rubber evaluation}

Uncured Payne effect, bound rubber content, cure characteristics, and stress strain properties were measured as described in Chapter 5.1. 


\subsection{Results and Discussion}

$\mathrm{P} 7001 \mathrm{x}$ recovered from passenger car tire pyrolysis at $700^{\circ} \mathrm{C}$ with a residence time of 6 seconds was treated with argon plasma. After the plasma process optimization on small scale, larger samples of P7001x and P7003x were treated and their performance in rubber was evaluated.

\subsubsection{Optimization of plasma RF power and flow rate}

Figure 8.2 shows the toluene extract transmittance of untreated and argon plasma etched rCB P7001x depending on the gas flow rate: the post-treatment indeed shows an improvement of toluene extract transmittance. This improvement stems from the removal of volatiles during the etching process, which leads to a relatively cleaner rCB surface. The untreated sample exhibits a transmittance of $42 \%$, while all treated samples show an absolute improvement of $15 \%$ to $20 \%$. Generally, an increasing RF power leads to a rise in excitation and ionization reactions which gives a higher plasma efficiency. Higher flow rates to a certain extent also lead to a similar effect as the mean free path is reduced due to higher particle density ${ }^{18}$. At a fixed treatment time of 30 minutes, the influence of the different RF power values and flow rates on transmittance is not expected to be significant, as the difference in transmittance among various conditions is only $5 \%$. This is indicated by the transmittance results as described in Chapter 4.1, and the corresponding in-rubber evaluation given in Chapter 5.1: $5 \%$ of transmittance difference among rCBs did not largely influence their performance. Four conditions were repeated and the results are shown in Figure 8.3. The repeated results show a good repeatability and the average improvement in transmittance is $\sim 18 \%$ in all cases. 
Chapter 8

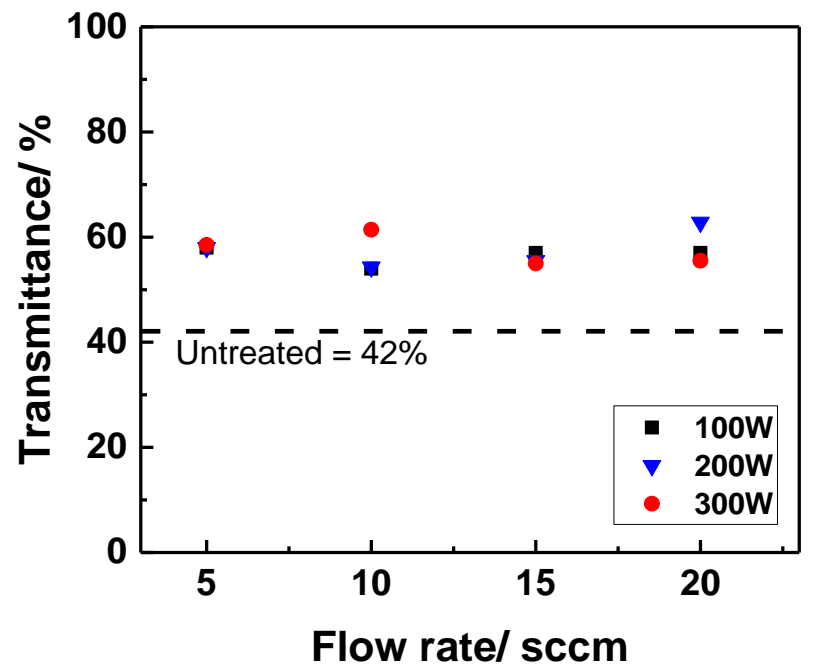

Figure 8.2 Toluene extract transmittance of untreated rCB P7001x (dashed line) and argon-plasma treated samples at different gas flow rates and RF powers.

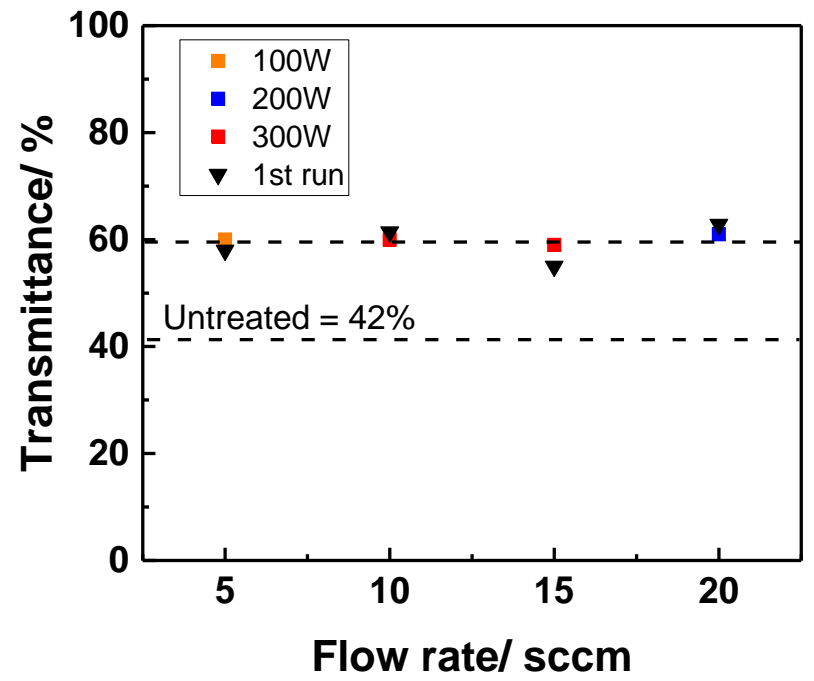

Figure 8.3 Process repeatability at different conditions. 


\subsubsection{Optimization of plasma treatment time}

Since the improvement is constant regardless of power and gas flow, the plasma treatment time was optimized at the lowest conditions of $100 \mathrm{~W}$ and $5 \mathrm{sccm}$. Treatment time was varied from 10, 20, 30 and 60 minutes. In Figure 8.4, the major rise in transmittance is already at the shortest time of 10 minutes, which further improves to 20 minutes while remaining at this value at 30 minutes. Further time increase only shows slight improvements. In the investigated process windows, the ability of the current plasma setup of removing volatiles from rCB is limited to an average of $18 \%$ to $20 \%$ transmittance improvement, which indicates that a complete removal of all types of volatiles is not possible. The current setup, within the analyzed parameters range, is efficient to a certain extent and may remove only relatively lighter volatiles/hydrocarbons. During pyrolysis, the volatiles which are initially formed by cracking elastomer segments are lighter hydrocarbons such as linear structures of olefins and parraffins. These compounds become less and less volatiles as the reductive environment of pyrolysis leads to their cyclization and consequently form complex polyaromatics ${ }^{4}$.

Based on these results, following optimized plasma treatment parameters are obtained. Under these conditions, P7001x and P7003x were prepared for in-rubber performance evaluation.

RF Power $100 \mathrm{~W}$

Flow rate $5 \mathrm{sccm}$

Treatment time 20 minutes 


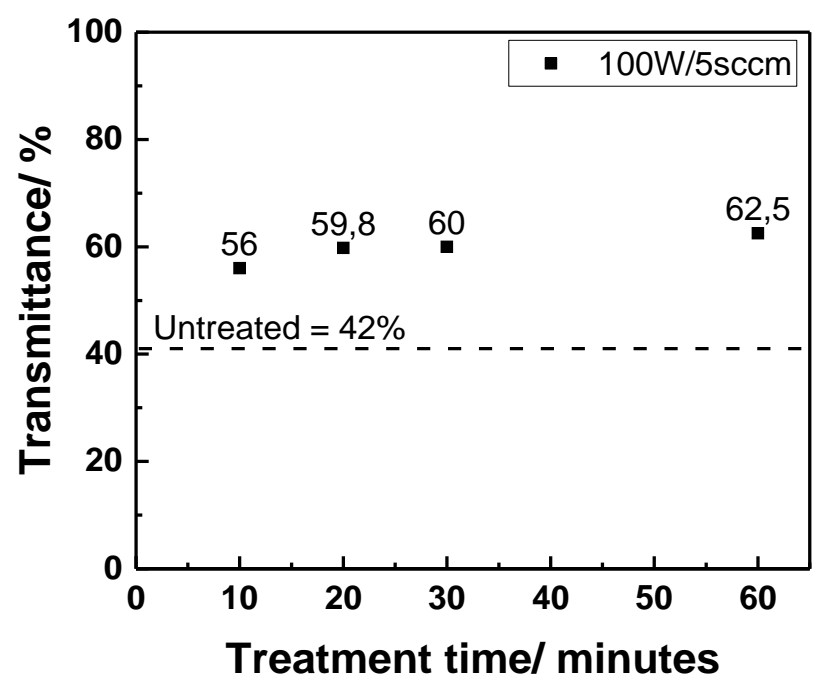

Figure 8.4 Toluene extract transmittance of argon-plasma treated samples using different treatment times.

\subsubsection{Influence of plasma etching on surface energy}

It is widely accepted that the surface energy of carbon blacks is of much greater importance for their use as reinforcing filler in rubber than their chemical nature. Their high dispersive energy makes them compatible with non-polar rubbers. The surface microstructure of carbon black contains crystal defects which act as physical attachment points for rubber segments. In contrast, silica is polar in nature due to the presence of hydroxyl groups. The high polarity of this filler makes it incompatible with the non-polar tire rubbers.

The surface energy of recovered carbon black depends on both aforementioned fillers, pure carbon black and silica as they both are components of rCB. In Chapter 4.2, cleaner rCBs showed a higher dispersive part of the surface energy and enhanced nano-roughness due to the removal of volatiles from active sites on the carbon black surface, as well as a higher specific part of the surface energy due to the cleaner silica surface. In the following, the influence of plasma etching on the rCB surface energies and nano roughness are discussed. 


\subsubsection{Dispersive part of surface energy and nano-roughness}

In Figure 8.5, the free energy of adsorption $\left(\Delta G_{a}\right)$ from inverse gas chromatography is plotted as a function of number of carbon atoms of injected $n$-alkane probes. The dispersive energy component was calculated as the slope of the straight line obtained from this plot. Nano roughness was determined by the deviation of branched (isooctane) and cyclic (cyclooctane) alkane from the alkanes straight line: The higher the deviation from the alkanes line, the lower the index of morphology and the higher the nano roughness. Lower morphology index values mean lower accessibility to branched and cyclic alkanes compared to linear alkanes due to the size exclusion effect.

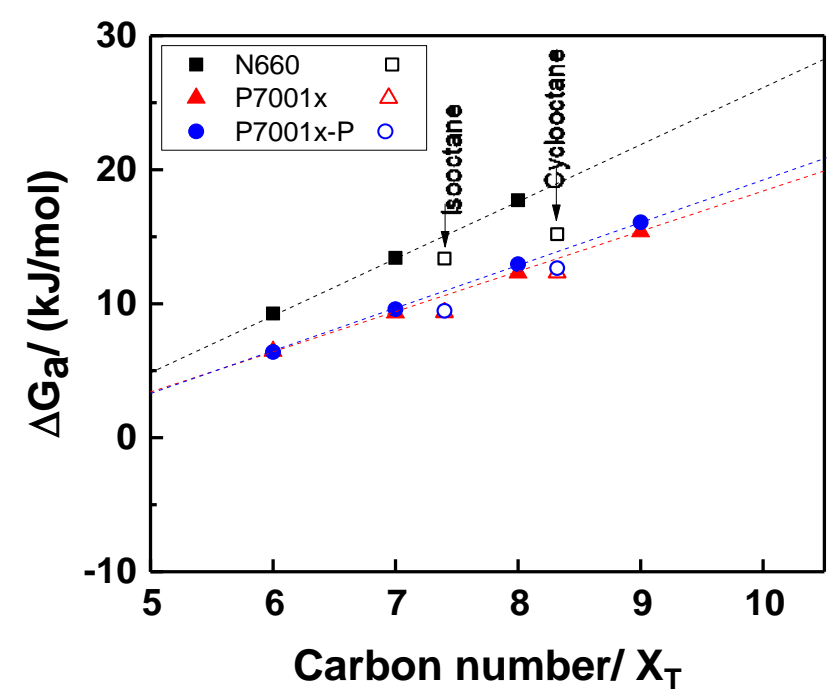

Figure 8.5 Free energy of adsorption $\left(\Delta \mathrm{G}_{\mathrm{a}}\right)$ versus the number of $-\mathrm{CH}_{2}$ - groups of n-alkanes obtained at $150^{\circ} \mathrm{C}$ for carbon black N660, rCB P7001x and plasma treated P7001x-P.

The dispersive energy $\left(\mathrm{Ys}_{\mathrm{s}}^{\mathrm{d}}\right)$ calculated from linear alkanes, and the indices of morphologies (IM) calculated from the branched and cyclic alkane are given in Table 8.3. The rCB after plasma etching shows a higher dispersive part. The reduction in morphological index values indicates enhanced nano-roughness. This is in line with previous transmittance results, which suggest that the improvement in surface nonpolar characteristics is a result of volatile removal from the active sites of carbon black during plasma etching. However, these differences between untreated and 
plasma treated rCBs are not significant, especially when compared to N660. N660 still exhibits the highest dispersive energy as well as nano-roughness, and the difference with plasma treated $\mathrm{rCB}$ is still quite large. This means that the improvement in the non-polar behavior of $\mathrm{rCB}$ after plasma treatment is still rather small.

Table 8.3 Dispersive part and indices of morphology of carbon black N660, untreated and plasma treated rCBs.

\begin{tabular}{|c|c|c|c|}
\hline Sample & $\mathbf{Y s}^{\mathbf{d}}\left(\mathbf{m} \mathbf{J} \mathbf{m}^{\mathbf{2}}\right)$ & $\mathbf{I M}^{*}$ (Isooctane) & $\mathbf{I M}^{*}$ (cyclooctane) \\
\hline N660 & 122 & 60.7 & 32.8 \\
\hline P7001x & 60 & 72.1 & 76.0 \\
\hline P7001X-P & 71 & 65.4 & 69.6 \\
\hline
\end{tabular}

\subsubsection{Specific interactions}

The influence of plasma treatment on the specific interactions of $\mathrm{rCB}$ were measured by injecting polar probes. In Table 8.4, N660 exhibits the lowest polar interactions originating from a small amount of polar functional groups present on the surface. The plasma treated $\mathrm{rCB}$ compared to its untreated counterpart, shows slightly higher interactions with probes responsible for hydrogen bonding. This shows that plasma etching enhances the activity of the silica in particular by removing volatiles from its surface. Plasma etching also improves the basic character of rCB as evidenced by relatively higher values for electron donor probes, THF and di-ethyl ether. Furthermore, the $\pi$-bond interactions of $\mathrm{rCB}$ represented by the benzene probe do not change. Overall, the global surface polarity of $\mathrm{rCB}$ is slightly increased by plasma treatment, which is mainly due to a cleaner silica surface. In rubber compounding, polar fillers without a coupling agent do not mix well with non-polar rubbers, and their poor dispersion in the rubber matrix results in lower mechanical properties. 
Table 8.4 Specific interaction parameters $\left(I_{s p}\right)$ of polar probes

\begin{tabular}{|c|c|c|c|}
\hline ISP [kJ/mol] & N660 & P7001x & P7001x-P \\
\hline Acetonitrile & $10.2 \pm 0.2$ & $18.5 \pm 0.2$ & $18.9 \pm 0.2$ \\
\hline Chloroform & $7.4 \pm 0.2$ & $8.0 \pm 0.2$ & $8.9 \pm 0.2$ \\
\hline Acetone & $7.1 \pm 0.2$ & $13.3 \pm 0.2$ & $13.4 \pm 0.2$ \\
\hline Isopropanol & $7.0 \pm 0.1$ & $14.7 \pm 0.2$ & $15.6 \pm 0.1$ \\
\hline Methyl acetate & $3.4 \pm 0.2$ & $10.0 \pm 0.2$ & $9.6 \pm 0.2$ \\
\hline Di-ethyl ether & $1.3 \pm 0.2$ & $5.1 \pm 0.2$ & $5.2 \pm 0.1$ \\
\hline Tetrahydrofurane & $2.4 \pm 0.3$ & $9.8 \pm 0.2$ & $10.4 \pm 0.1$ \\
\hline Benzene & $4.4 \pm 0.3$ & $5.3 \pm 0.3$ & $5.2 \pm 0.1$ \\
\hline$\Sigma I_{\text {SP }}$ (KJ/mol) & $43.3 \pm 1.4$ & $84.7 \pm 1.7$ & $87.3 \pm 1.1$ \\
\hline
\end{tabular}

\subsubsection{In-rubber evaluation}

\subsubsection{Filler-filler and filler-polymer interactions}

Strain-dependent measurements of the storage modulus were performed, and the Payne effect $(\Delta G)$ was calculated as the difference between the storage moduli at low and at high strains. A higher Payne effect indicates stronger filler-filler interactions. In Figure 8.6, both P7001x and P7003x show no significant influence of plasma treatment on Payne effect. For the polymer-filler interactions, bound rubber was measured. The plasma treated P7001x rCB contains less volatiles than its untreated counterpart as evident from transmittance results. This consequently means a cleaner surface and expectedly better interactions with the polymer matrix. In contrast, in Figure 8.7, the bound rubber values show minimal improvement in filler-polymer interactions indicating that the amount of volatiles removed during plasma treatment is not sufficient for an adequate improvement in filler-polymer interactions. 
Chapter 8

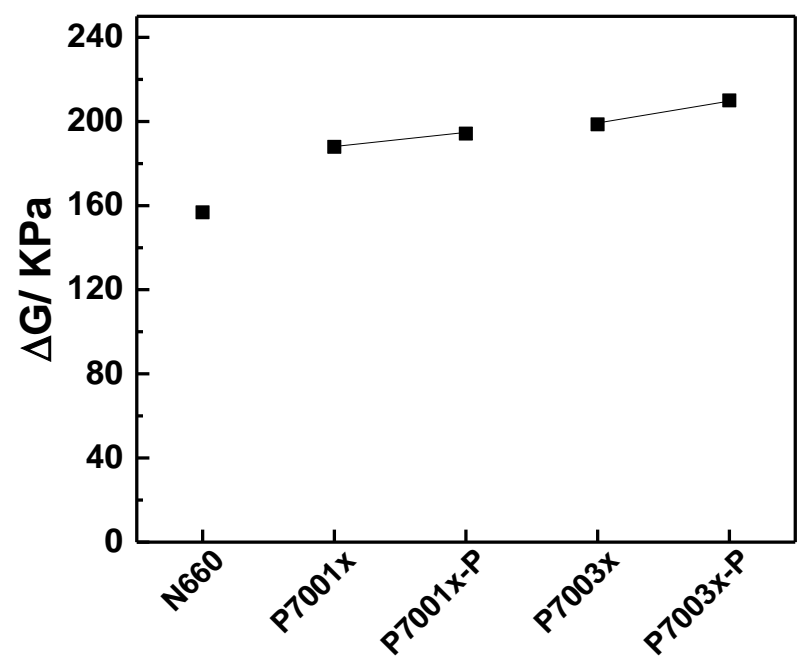

Figure 8.6 Payne effect of compounds filled with carbon black N660, untreated rCBs (P7001x, P7003x) and plasma treated rCBs (P7001x-P and P7003x-P).

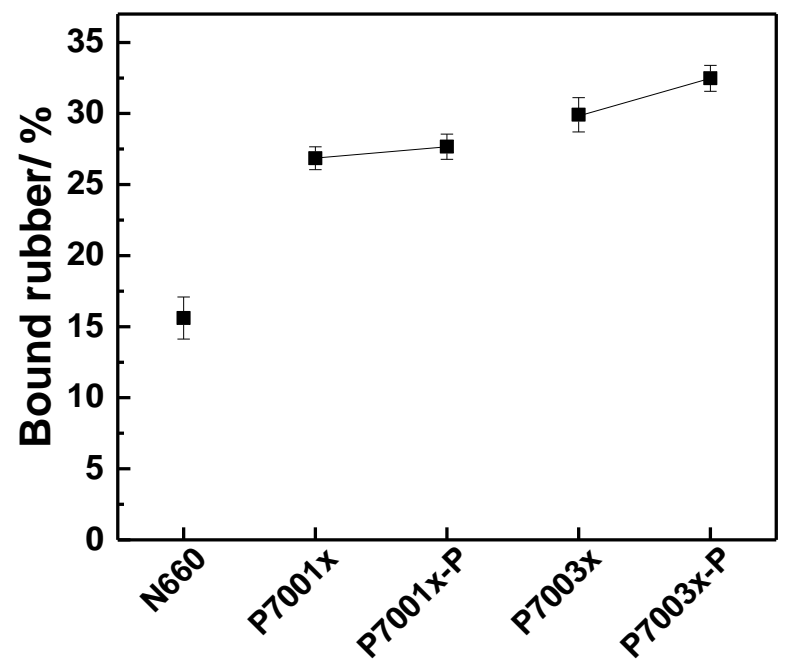

Figure 8.7 Bound rubber content of compounds filled with carbon black N660, untreated and plasma treated rCBs. 


\subsubsection{Cure characteristics}

The influence of plasma treatment on the cure behavior of compounds with rCB's was measured; the cure curves of compounds containing untreated and plasma treated P7001x and P7003x are shown in Figure 8.8. The compound with the plasma treated P7001X-P sample shows a slower torque increase in the time range of 10 minutes to 30 minutes compared to the one with the untreated sample. In Table 8.5 , compound cure properties are summarized which show little influence of plasma treatment.

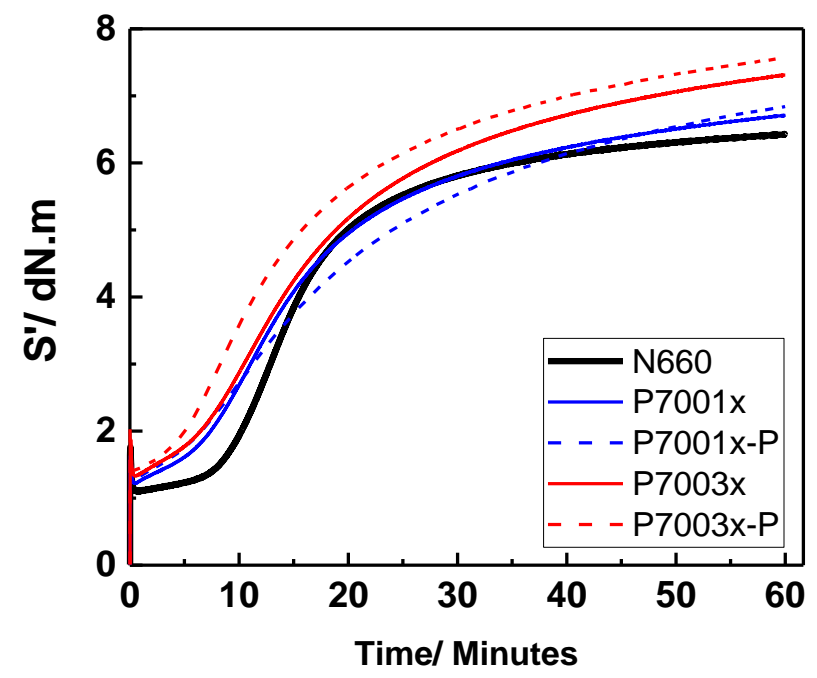

Figure 8.8 Cure curves of compounds filled with carbon black N660, untreated and plasma treated rCBs. 
Table 8.5 Cure characteristics of compounds filled with carbon black N660, untreated and plasma treated rCBs.

\begin{tabular}{|l|c|c|c|c|}
\hline & $\mathbf{M}_{\mathrm{L}}$ (dN.m) & $\mathbf{M}_{\mathrm{H}}$ (dN.m) & $\boldsymbol{\Delta} \mathbf{S}$ (dN.m) & Scorch (min) \\
\hline N660 & 1.1 & 6.43 & 5.33 & 13.1 \\
\hline P7001x & 1.22 & 6.7 & 5.5 & 11.8 \\
\hline P7001x-P & 1.29 & 6.8 & 5.5 & 12.6 \\
\hline P7003x & 1.33 & 7.3 & 6 & 11.5 \\
\hline P7003x-P & 1.41 & 7.5 & 6.1 & 9.5 \\
\hline
\end{tabular}

In Figure 8.9, the cure rate index and marching modulus intensity are shown. For the P7001x compound, the cure rate decreases and the marching modulus intensity rises when the filler is plasma-treated. Argon plasma etching removes the organic contaminants from the rCB surface which leads to a cleaner carbon black as well as silica surface. A less contaminated silica surface affects the curing rate and marching modulus by adsorbing curatives and releasing them at a later stage. Such an influence of the silica in $\mathrm{rCB}$ with reduced organic contaminations was also seen in Chapter 5.1. Since P7003x has only a negligible amount of volatiles, the toluene transmittance is $97 \%$, the influence of plasma treatment on cure rate and marching modulus is absent. Considering the effect of plasma etching on the P7003x compound, the missing influence on cure rate and marching modulus indicates that the activity of silica is not much changed. In case of P7001x, volatiles are adsorbed on the filler surface in high quantities as indicated by a toluene transmittance of $42 \%$. During plasma etching, both filler types, carbon black as well as silica, are affected: the volatiles are partly removed. This is clear from the decreased cure rate as well as intensified marching modulus due to the cleaner silica. This behavior is in-line with the surface energy characterization, which showed an increase in both, the nonpolar and polar part for rCB. 


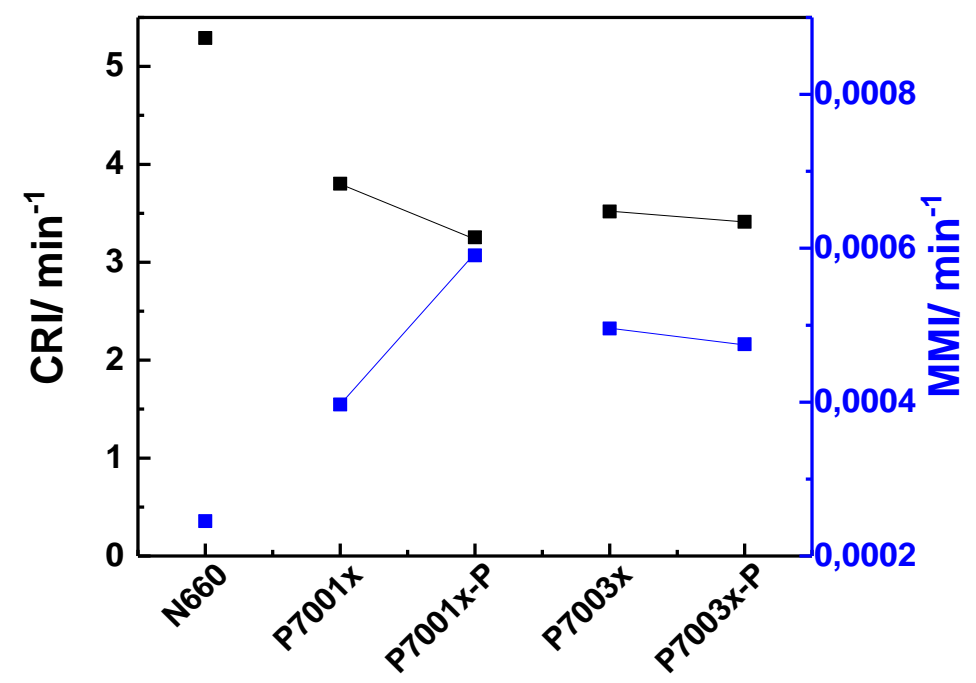

Figure 8.9 Cure rate index (left $y$-axis) and marching modulus intensity (right $y$ axis) of compounds filled with carbon black N660, untreated and plasma treated rCBs.

\subsubsection{Mechanical properties}

Stress-strain properties of the reference carbon black N660 filled compound and compounds filled with rCBs: P7001x, P7003x, and their plasma treated counterparts are shown in Figure 8.10. From the cure characteristics. and from the mechanical properties, it is clear that plasma treatment has a minimal effect on the in-rubber properties of the compound containing the low-volatiles containing P7003x rCB. For the P7001x containing compound, the tensile behavior is slightly affected by the post-treatment of rCB, see Figure 8.11. In Figure 8.11(a), the modulus at $100 \%$ strain of the sample filled with P7001x remains the same in both treated and untreated samples, while the reinforcement index of the treated sample decreases due to a lower modulus at $300 \%$ strain. Both untreated and treated samples were vulcanized for similar curing times, the treated sample exhibited a reduced cure rate, which leads to a lower degree of curing and thus reduced crosslinking. A rubber network with a low crosslink density results in low stiffness, which consequently affects the tensile strength and also leads to a higher elongation of the compound filled with the treated P7001x as shown in Figure 8.11(b). 


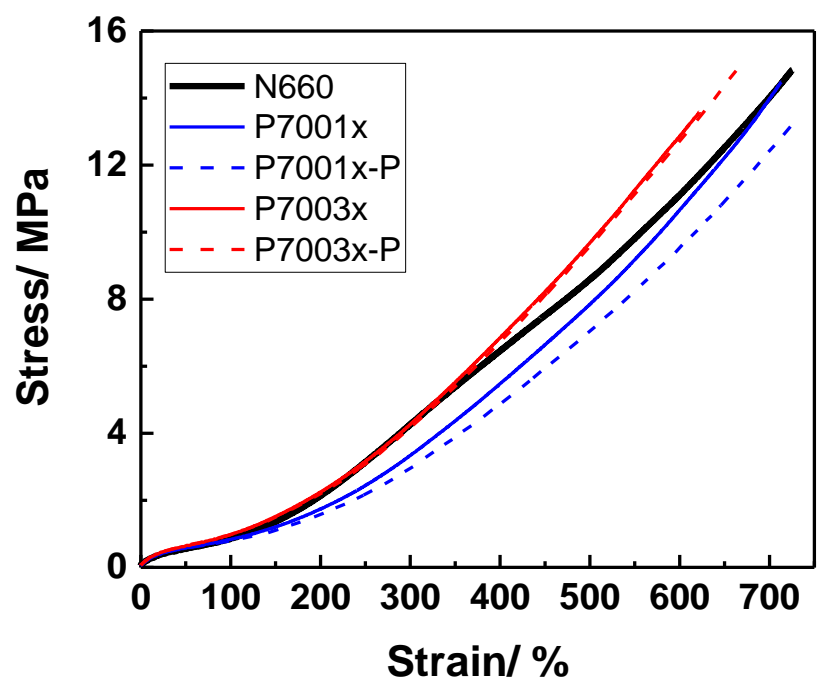

Figure 8.10 Stress-strain curves of compounds filled with carbon black N660, untreated and plasma treated rCBs.
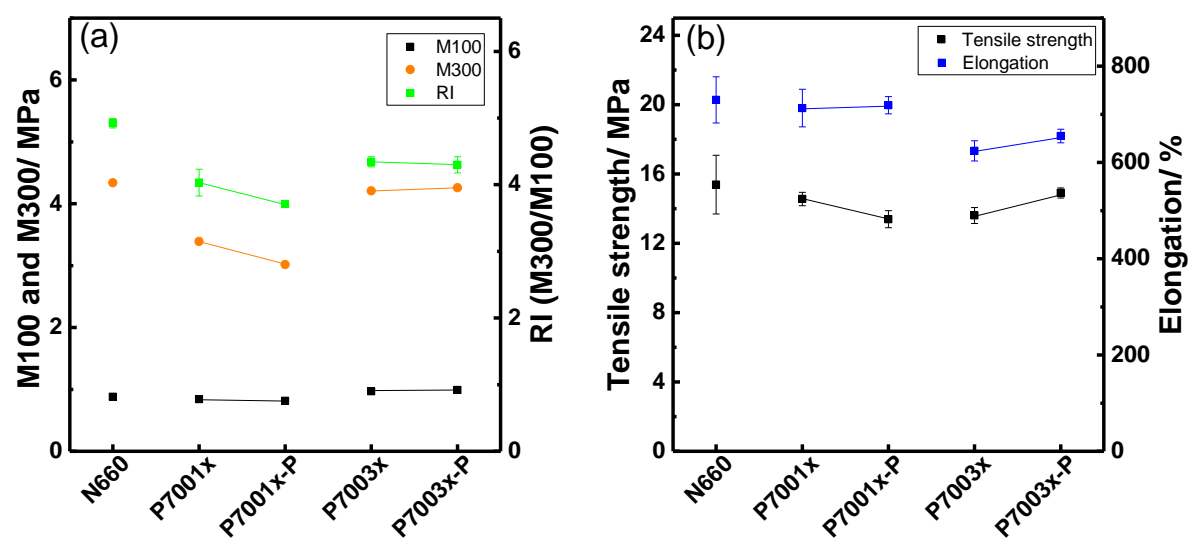

Figure 8.11 (a) Modulus at 100\% and 300\% strain (left y-axis), reinforcement index (right y-axis) (b) tensile strength (left y-axis) and elongation (right $y$-axis) of N660, rCBs and plasma treated rCBs filled compounds. 


\subsection{Conclusions}

A low-pressure argon plasma etching process was optimized for treating recovered carbon black. The process conditions including gas flow rate, RF power and treatment time were optimized for $\mathrm{rCB}$ P7001x with a toluene extract transmittance of $42 \%$. A part of the rCB volatiles were successfully removed as indicated by the improvement in toluene extract transmittance of $18 \%$. The reduced volatile content of plasma etched $\mathrm{rCB}$ resulted in better non-polar surface characteristics: higher dispersive energy and enhanced nano-roughness. The polar character was also increased by the plasma treatment due to a cleaner and more active silica surface.

The influence of plasma etching on the rCB in-rubber behavior was also investigated. Here, two rCBs were treated using similar plasma conditions: P7001x with a toluene transmittance of $42 \%$ and $P 7003 x$ with a toluene transmittance of $97 \%$. The rubber compound characteristics of $\mathrm{P} 7003 \mathrm{x}$ after plasma treatment were hardly affected by the plasma treatment as it contained a negligible amount of volatiles. Plasma treatment did significantly influence the cure characteristics of the P7001x containing compound. The removal of volatiles from $\mathrm{rCB}$ resulted in a cleaner $\mathrm{rCB}$ as well as silica surface, and the latter actively adsorbed curatives and released them at a later stage. This consequently slowed down the cure rate and intensified the marching modulus. No enhancement in mechanical properties was noticed as any improvement in filler-polymer interactions by a cleaner carbon black surface was counteracted by the silica surface effect on curing.

\section{References}

[1] J.D. Martínez, N. Puy, R. Murillo, T. García, M.V. Navarro, and A.M. Mastral, Renew. Sust. Energ. Rev., 23, 179 (2013).

[2] R. Murillo, E. Aylon, M. Navarro, M. Callen, A. Aranda and A. Mastral, Fuel Process. Technol., 87, 143 (2006).

[3] O, Senneca, P. Salatino and R. Chirone, Fuel, 78, 1575 (1999).

[4] C. Norris and S. Renegar, Presented at International Rubber Conference (IRC), London, (2019).

[5] C. Norris, M. Hale and M. Bennett, Plast. Rubber Compos., 43, 245 (2014).

[6] E. Bolat, S. Sağlam, and S. Pişkin, Fuel Process. Technol. 55, 101 (1998).

[7] H. Alam, A. Moghaddam, and M. Omidkhah, Fuel Process. Technol. 90, 1 (2009). 
[8] A. Chaala, H. Darmstadt, C. Roy, Fuel. Process. Technol. 46, 1 (1996).

[9] X. Zhang, H. Li, Q. Cao, L.E. Jin, and F. Wang, Waste Manage. Res., 36, 436 (2018).

[10] J. D. Martínez, N.U. Cardona, R. Murrillo, T. Garcia, and J.M. Lopez, Waste Manage., 85, 574 (2019).

[11] C. Roy, A. Chaala, H. Darmstadt, B. De Caumia, H. Pakdel, and J. Yang, In Rubber Recycling: Conversion of Used Tires to Carbon Black and Oil Pyrolysis, CRC Press, Florida (2005).

[12] G. Akovali, and I. Ulkem, Polym., 40, 7417 (1999).

[13] T. Mathew, R.N. Datta, W.K. Dierkes, A.G. Talma, W.J. Van Ooij, and J.W. Noordermeer, Macromol. Mater. Eng., 296, 42 (2011).

[14] N. Roy, R. Sengupta, and A.K. Bhowmick, Prog. Polym. Sci., 37, 781 (2012).

[15] S.J. Park, J.S. Kim, J. Colloid. Interface Sci., 244, 336 (2001).

[16] J.B. Donnet, W.D. Wang, A. Vidal, and M.J. Wang, Carbon, 32, 199 (1994).

[17] Corax, Technical Data Sheet, Orion Engineered Carbons.

[18] C. Guo, H. Zhibing, H. Xiaoshan, Z. Ling, and T. Yongjian, 强激光与粒子束, 28, 92004 (2016). 


\section{RECOVERED CARBON BLACK AS A SUBSTITUTE FOR FOSSIL RESOURCES BASED CARBON BLACK}

In this part of the study, the commonly used highly-reinforcing carbon black (CB) N330 filler, was replaced by recovered carbon black $(r C B)$ in different ratios. The compound for testing the $C B / r C B$ filler systems in different ratios is based on S-SBR rubber, and the following in-rubber properties are tested: mixing and curing behavior, stress-strain properties, dynamic properties, filler-filler and filler-polymer interactions.

The mixing dump torque rises as $r C B$ replaces $C B$ which indicates an increase in compound viscosity. This is due to the rising filler fraction as the ash contained in rCB was compensated by adding more $\mathrm{CCB}$. The cure properties are not significantly affected by the presence of $\mathrm{rCB}$, even up to the maximum $50 \%$ of $C B$ replacement. Stress-strain properties like moduli at $100 \%$ and $300 \%$ strain as well as the reinforcement index change marginally up to $33 \%$ of $C B$ substitution, but are significantly reduced for higher $\mathrm{CCB} / \mathrm{CB}$ ratios. A positive effect is noticed for the dynamic properties of the $\mathrm{rCB}$-containing rubber: they improve with increasing $\mathrm{r} C \mathrm{~B}$ content, indicating lower rolling resistance as well as higher ice skid resistance and wet traction than for pure virgin $C B$ filled rubber. This improvement is due to the lower physical filler-polymer interactions of $\mathrm{rCB}$, as well as chemical filler-polymer bonds due to the presence of silica in the ash content of $\mathrm{rCB}$. 


\subsection{Introduction}

Carbon black is the most widely used reinforcing filler in the rubber field. The incorporation of carbon black in rubber compounds improves mechanical and dynamic properties like modulus, tensile and tear strength, abrasion resistance, and skid resistance ${ }^{1}$. The ability of this filler to reinforce rubber depends on its primary particle size, specific surface area, structure and surface energy ${ }^{2-4}$. These properties depend on qualities defined during the production of carbon black by incomplete combustion of fossil oil. In view of depleting natural resources, it is important to find a substitute for this material, which can be obtained from a fossil-free resource, but at the same time with similar properties.

Compared to silica, which is replacing carbon black in passenger car tire treads to a high extent, the downside of adding carbon black to rubber is a reduced compound hysteresis at low temperatures and an increased hysteresis at high temperatures, causing lower wet grip and higher rolling resistance of a tire, respectively ${ }^{5}$. This consequently does not help in lowering the fuel consumption and to enhance driving safety. However, addition of silica to rubber compounds has its challenge: strong filler-filler interactions due to the presence of polar silanol groups on the particle surface make it difficult to disperse it in the non-polar tire rubbers. These polar groups are also responsible for adsorption of amine-based accelerators causing a retardation of the vulcanization reaction ${ }^{6}$. Such challenges can be overcome by the use of a silane acting as a filler-polymer compatibilizer and coupling agent.

In several studies, carbon black and silica based binary filler systems are regarded beneficial as it combines the advantages of both fillers. Atashi et al. ${ }^{7}$ partially substituted carbon black with silica/silane in a SBR/BR/NR blend system and noticed improvement in tear and crack growth resistance, while abrasion resistance was reduced. Feng et al. ${ }^{8}$ replaced carbon black with a small amount of silica without silane in the ratio of $45 / 5 \mathrm{phr}$ and observed decreased filler cluster branching and enhanced reinforcement. Recovered carbon black from waste tire pyrolysis contains $70 \%$ to $80 \%$ carbon black and $20 \%$ to $30 \%$ of ash content along with small quantities of carbonaceous residues formed during pyrolysis. The major component of the ash is silica, the more when it is recovered from passenger car tire feedstock ${ }^{9-11}$. The presence of both reinforcing fillers, silica and carbon black, which accounts for more than $90 \%$ of the total rCB portion, and the fact that this filler is resourced from waste tires instigates its use as a circular economy based filler system for rubber reinforcement.

In Chapter 5.2, rCB was compared to carbon black N660 and it showed similar inrubber performance. In the present study, the reference carbon black is a highlyreinforcing one: N330. Filler-filler interactions, filler-polymer interactions, cure 
behavior, stress strain and dynamic properties are investigated for a balanced replacement of virgin $\mathrm{CB}$.

\subsection{Experimental}

\subsubsection{Materials}

Rubber formulation including cure package was explained in Chapter 5.

Reference carbon black: A highly-reinforcing commercial grade of carbon black, N330, was used. Corax N330 was provided in pelletized form by Orion Engineered Carbons, Frankfurt, Germany. It exhibits a BET specific surface area of $78 \mathrm{~m}^{2} / \mathrm{g}$ and a primary particle size of $26 \mathrm{~nm}$ to $30 \mathrm{~nm}$.

Recovered carbon black ( $r C B$ ): $\mathrm{rCB} P 7001 \times$ recovered at $700^{\circ} \mathrm{C}$ with a residence time of 6 seconds was used as a replacement of reference CB N330. Process description and material characteristics of P7001x are described in Chapter 4.1 and 4.2.

\subsubsection{Compounding}

The compound formulation used in this study is shown in Table 9.1. Since rCB contained on average $25 \%$ of ash, the amount of recovered carbon black was adjusted in order to have a similar amount of carbon black in both, the reference and the rCB compounds. The adjusted amount of $\mathrm{rCB}$ according to the ash content is given in Table 9.2. No further adjustments for e.g. the presence of silica and $\mathrm{ZnO} / \mathrm{ZnS}$ were made. 
Chapter 9

Table 9.1 Compound formulation for N330 (reference) and rCB compounds.

\begin{tabular}{|l|c|c|c|c|c|c|c|}
\hline & \multicolumn{7}{|c|}{ Formulations (phr) } \\
\hline Materials & $\mathbf{6 0 / 0}$ & $\mathbf{5 5 / 5}$ & $\mathbf{5 0 / 1 0}$ & $\mathbf{4 5 / 1 5}$ & $\mathbf{4 0 / 2 0}$ & $\mathbf{3 0 / 3 0}$ & $\mathbf{0 / 6 0}$ \\
\hline $\begin{array}{l}\text { S-SBR oil- } \\
\text { extended }\end{array}$ & 137.5 & 137.5 & 137.5 & 137.5 & 137.5 & 137.5 & 137.5 \\
\hline CB N330 & 60 & 55 & 50 & 45 & 40 & 30 & - \\
\hline rCB P7001x & - & 6.25 & 12.5 & 18.75 & 25 & 37.5 & 75 \\
\hline 6PPD & 1.5 & 1.5 & 1.5 & 1.5 & 1.5 & 1.5 & 1.5 \\
\hline TMQ & 1 & 1 & 1 & 1 & 1 & 1 & 1 \\
\hline Wax & 2.5 & 2.5 & 2.5 & 2.5 & 2.5 & 2.5 & 2.5 \\
\hline Zinc 0xide & 3 & 3 & 3 & 3 & 3 & 3 & 3 \\
\hline Stearic acid & 2 & 2 & 2 & 2 & 2 & 2 & 2 \\
\hline Sulfur & 1.65 & 1.65 & 1.65 & 1.65 & 1.65 & 1.65 & 1.65 \\
\hline TBBS & 0.7 & 0.7 & 0.7 & 0.7 & 0.7 & 0.7 & 0.7 \\
\hline
\end{tabular}

*adjusted for $25 \%$ of ash content: total carbon content $=60$ phr.

Mixing was carried out in a Brabender Plastograph $80 \mathrm{CC}$ internal batch mixer. The mixing procedure as described in Chapter 8 was followed.

\subsubsection{Vulcanization}

Samples were vulcanized in a similar way as mentioned in Chapter 5.1. The curing time for all samples was 20 minutes. The vulcanization time was set to this period in order to be comparable with the large scale trial results of the industry partner.

\subsubsection{In-rubber evaluation}

Uncured Payne effect, bound rubber content, cure characteristics, and stress train properties were measured as described in Chapter 5.1. 


\subsubsection{Dynamic properties}

Dynamic properties, tan delta at $-20^{\circ} \mathrm{C}, 0^{\circ} \mathrm{C}$ and $60^{\circ} \mathrm{C}$, of the cured rubber compounds were determined using a Dynamic Mechanical Analyzer (GABO EPLEXOR 2000) in a temperature sweep in tension mode at a strain of $0.1 \%$ and a frequency $10 \mathrm{~Hz}$. Tan delta at $-20^{\circ} \mathrm{C}, 0^{\circ} \mathrm{C}$, and $60^{\circ} \mathrm{C}$ were taken as tire tread performance indicators for ice skid resistance, wet traction, and rolling resistance, respectively. 


\subsection{Results and Discussion}

\subsubsection{Mixing behavior}

The mixing torque profiles of N330/P7001x filled compounds with various ratios are shown in Figure 9.1(a). In Zone 1, the initial torque rise in all cases represents the addition of rubber in the mixing chamber, followed by the mastication step resulting in a reduction of the torque. In Zone 2, the addition of the first half of the solid filler at 50 seconds raises the torque due to the hydrodynamic effect. The torque further increases after 2 minutes with the addition of the second half of the filler along with other additives. At this point, the incorporation of pure $\mathrm{rCB}(0 / 60)$ shows a lower torque increase due to a poor compatibility with rubber compared to the more nonpolar N330, causing a decreased interfacial contact. As mixing continues over time, the torques of all compounds keep decreasing due to filler incorporation and dispersion. Interestingly, the compound with pure N330 (60/0) shows the sharpest drop in torque over time suggesting faster and better filler dispersion than the N330/P7001x blend compounds due to higher polymer-filler compatibility. In Figure 9.1(b), the dump torque, indicative of compound viscosity, rises with rCB addition in the compound. This effect is clear as a higher rCB content also increases the ash concentration, see Table 9.2. It means that an increase in $\mathrm{rCB} / \mathrm{CB}$ N330 ratio leads to a rise in ash content, which in turn results in a higher compound viscosity.
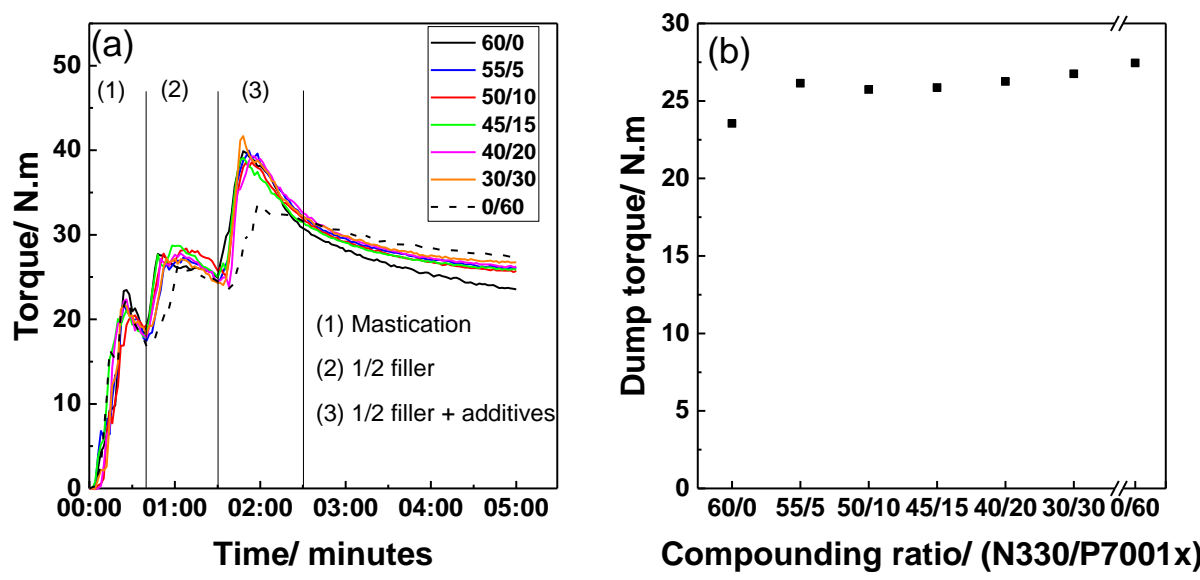

Figure 9.1(a) Masterbatch mixing profiles, and (b) final dump torque of N330/P7001x filled compounds. 


\subsubsection{Filler-filler and filler-polymer interactions}

Filler-filler interactions were determined by measuring the Payne effect and expressed as the difference between the storage moduli at low and at high strains: a higher Payne effect represents stronger filler-filler interactions. In Figure 9.2, the Payne effect decreases systematically as N330 is replaced by $\mathrm{rCB}$, showing a reduction in filler-filler interactions with increasing $\mathrm{rCB}$ content. For carbon black N330, the filler-filler interactions are associated with van der Waals attractive forces between the graphitic crystallite edges on the surface. In Chapter 4.1 it was demonstrated that rCB P7001x contains organic residues such as oil fractions and solid carbonaceous materials formed on the particle surface by the fragmentation of the polymer during the pyrolysis process. This residue covers the high by energetic sites on the rCB surface and leads to lower filler-filler interactions ${ }^{12}$.
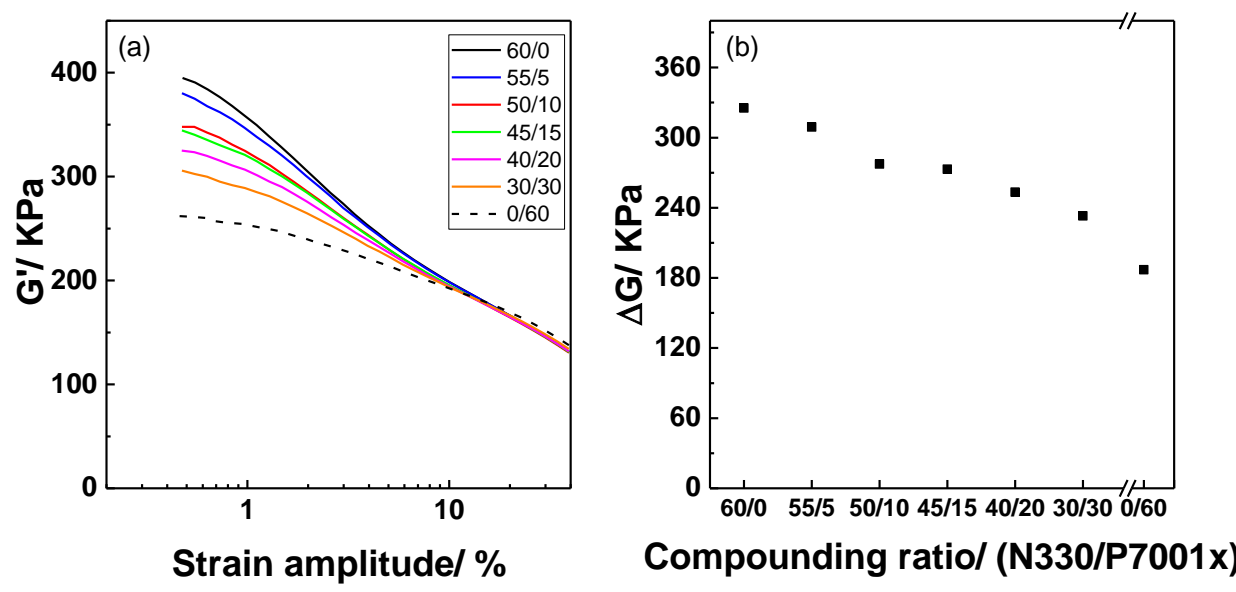

Figure 9.2(a) Strain dependent measurement of the storage modulus, and (b) Payne effect of N330/P7001x filled compounds.

Filler-polymer interactions were determined by measuring the bound rubber content. In Figure 9.3, the bound rubber content slightly increases as more and more N330 is replaced by $\mathrm{rCB}$ indicating an improvement in filler-polymer interactions. Possible contributions to this increase in bound rubber are physical interactions of the polymer with the $\mathrm{rCB}$ surface and chemical interactions associated with the presence of active sulfur causing pre-scorch of the rubber or chemical polymer coupling with the silica content in rCB as discussed in Chapter 6. 


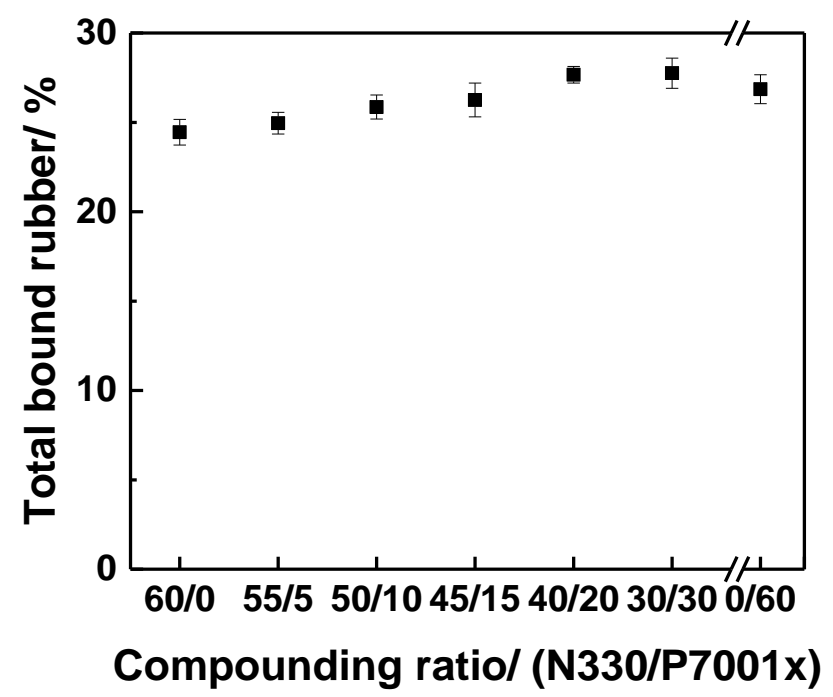

Figure 9.3 Bound rubber content of N330/P7001x filled compounds.

\subsubsection{Cure characteristics}

The influence of the N330/P7001x blend ratio on the cure behavior was determined; the cure curves of these compounds are shown in Figure 9.4. The differences between the N330/P7001x filled compounds at different ratios are not significant. Significantly different are the compounds to which only N330 or pure rCBs were added. The final torque of the N330 filled compound is slightly higher than the one of the N330/P7001x blend compounds. A pronounced difference in cure behavior can also be seen when N330 is completely replaced with rCB P7001x. This is even more clear from Figure 9.5: the delta torque is significantly reduced for this compound. As previously established in Chapters 3,5.1 and 5.2, the cure behavior of $\mathrm{rCB}$ filled compound is strongly influenced by the ash content. The presence of silica as major component in the ash leads to a reduction of the cure rate due to adsorption of curatives and causes marching modulus behavior by releasing them at a later stage. However, in the N330/P7001x containing compounds, the cure behavior is mainly dominated by the alkaline CB N330 and is not affected by the small amount of ash coming from the rCB portion. 
Chapter 9

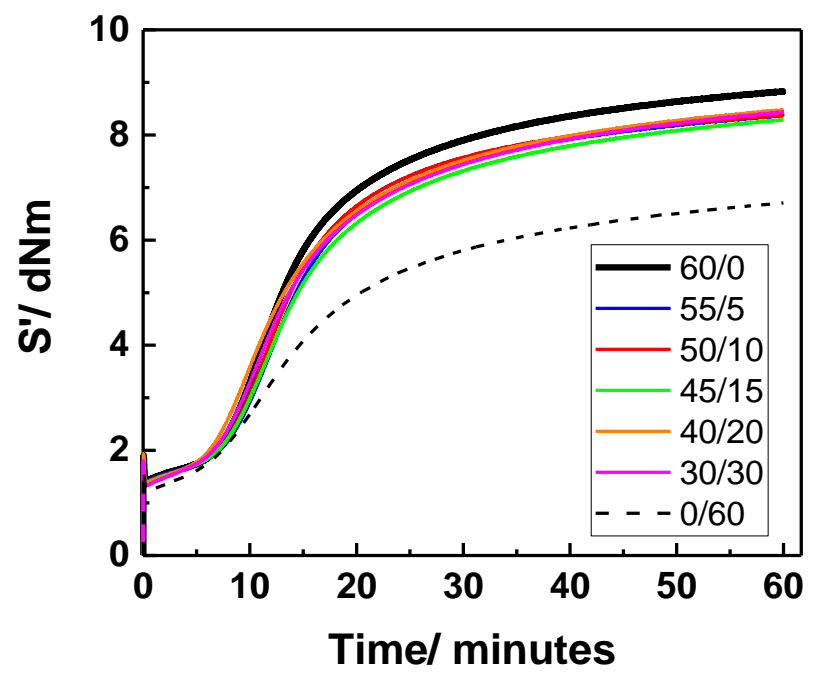

Figure 9.4 Cure characteristics of N330/P7001x filled compounds.

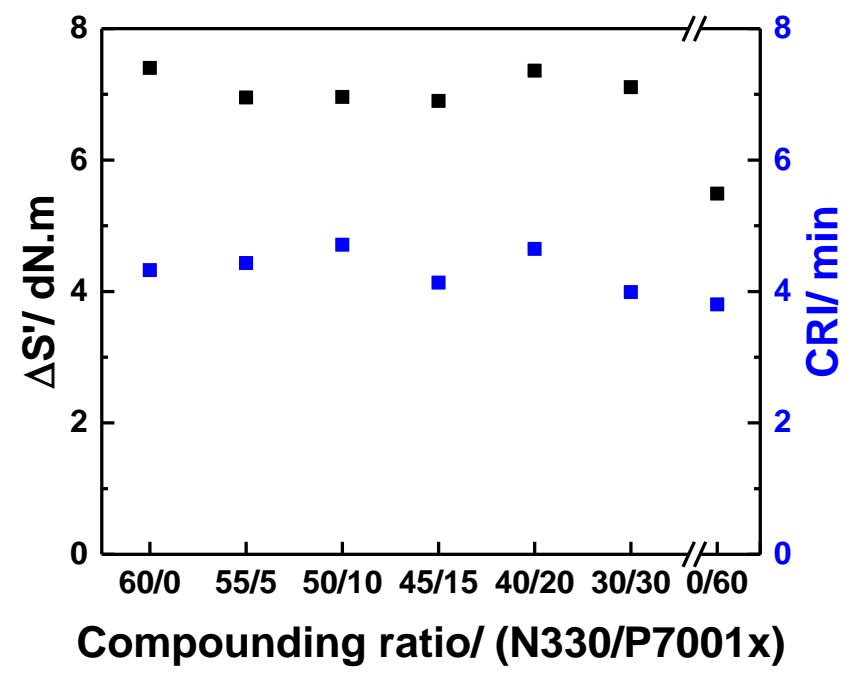

Figure 9.5 Total torque (left $y$-axis) and cure rate index (right $y$-axis) of N330/P7001x filled compounds. 


\subsubsection{Mechanical properties and filler macro-dispersion}

Stress-strain properties of compounds filled with N330, rCB P7001x, and their blends in different ratios are shown in Figure 9.6. The compounds filled with N330/P7001x blends up to a 40/20 phr ratio show small deviations in stress-strain behavior compared to N330 filled compound (60/0) as it is within the error margins which is further depicted in Figure 9.7(a). Above this ratio, further increase in $\mathrm{rCB}$ content leads to a deterioration of the stress-strain properties.

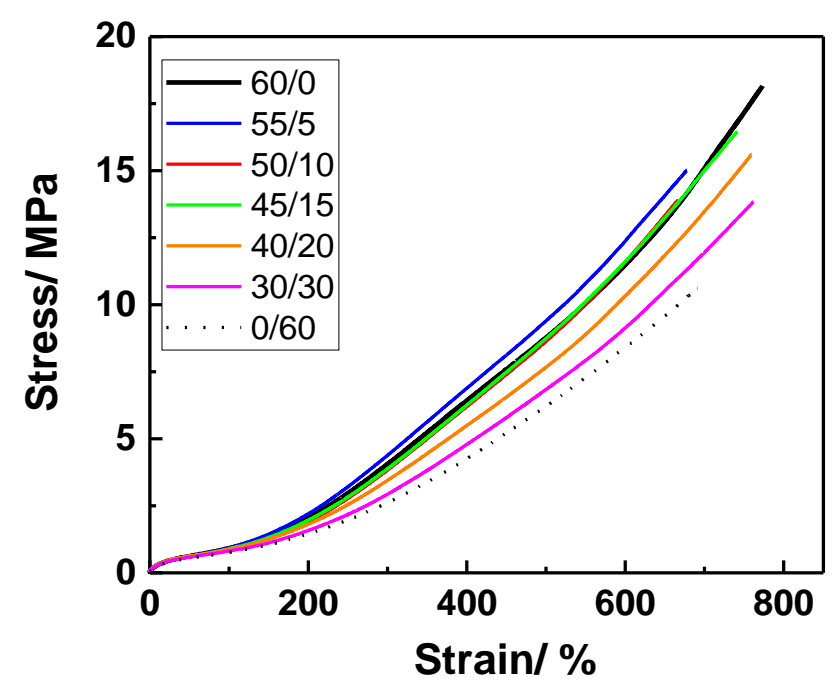

Figure 9.6 Stress-strain curves of N330/P7001x filled compounds.

In Figure 9.7(a), modulus at 100\% strain (M100), 300\% strain (M300), reinforcement index (RI), and tensile strength at break (TS) are compared more in detail. The first three quantities remain unaffected up to a 40/20 N330/P7001x phr ratio. The tensile strength at break reduces with increasing $\mathrm{rCB}$ content. The dominant factor of lower tensile strength up to a ratio of 40/20 is their lower elongation than CB N330 as shown in Figure 9.7(b). Above this ratio when $\mathrm{CCB}$ content is further increased, reduction in strength with higher $\mathrm{CB}$ replacement is mainly due to the $\mathrm{rCB}$ poor disperion: In Figure 9.8, the macro-dispersion of the N330/P7001x filled compounds is shown. It is clear that the addition of $\mathrm{rCB}$ worsens the dispersion due to its low structure and impurities especially carbonaceous residues as discussed in Chapter 4.1, 4.2, and reported elsewhere ${ }^{12}$. Considering M100, M300, and reinforcement 
index values, N330 can be replaced up to 33\% (40/20 phr ratio) without significantly affecting these properties.

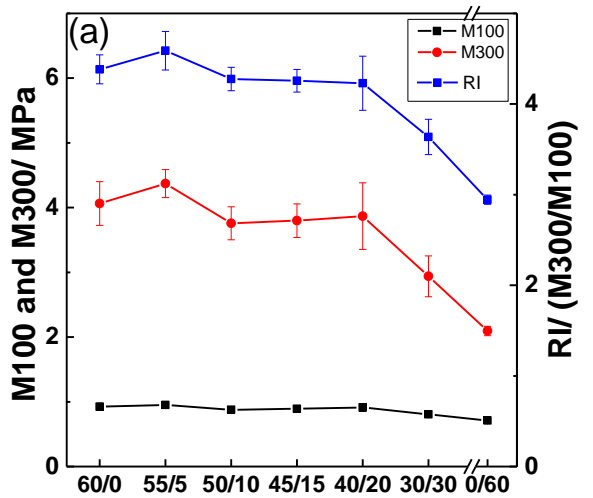

Compounding ratiol (N330/P7001x)

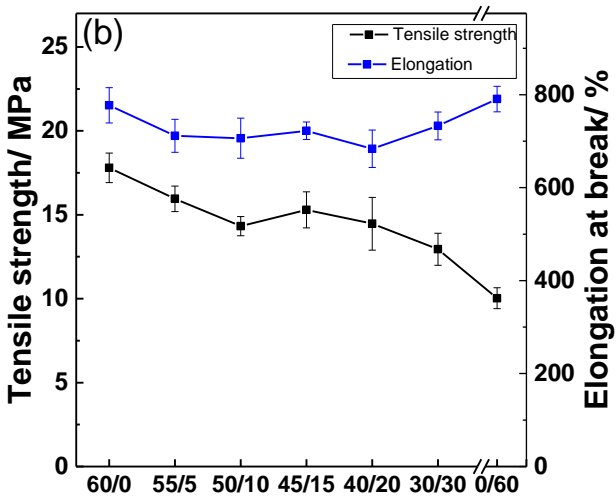

Compounding ratiol (N330/P7001x)

Figure 9.7(a) Modulus at a strain of 100\% (M100) and 300\% (M300), reinforcement index (M300/M100), tensile strength, and (b) Elongation at break of N330/P7001x filled compounds.
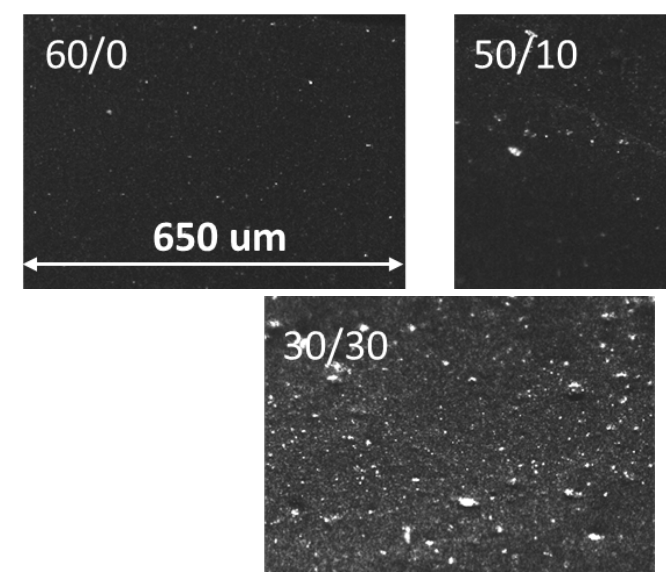

Figure 9.8 Macro-dispersion of N330/P7001x filled compounds.

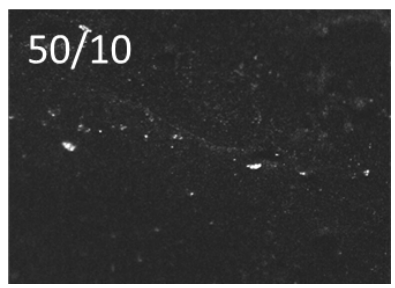

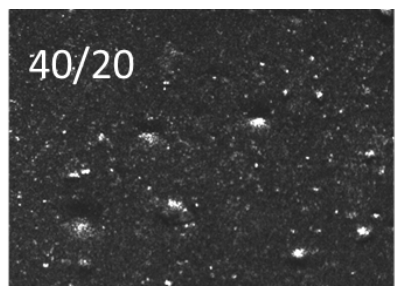

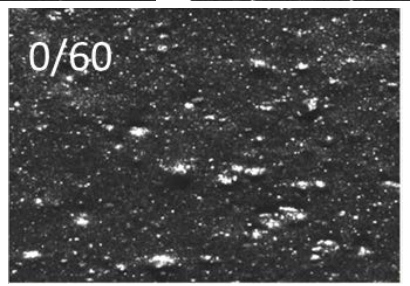




\subsubsection{Dynamic mechanical properties}

Dynamic mechanical analysis was used to predict tire performance by measuring the tan delta values on cured samples at different temperatures. Tan delta is the loss angle, thus a measure for the loss energy under dynamic deformations, and is commonly employed to predict ice grip when measured at $-20^{\circ} \mathrm{C}$, wet traction at $0^{\circ} \mathrm{C}$, and rolling resistance at $60^{\circ} \mathrm{C}$ of tire treads. Higher values of tan delta at both lower temperatures ensure safety, while a lower tan delta is desired $60^{\circ} \mathrm{Cas}$ it indicates lower fuel consumption. Figure 9.9(a) and (b) show the tan delta values of the N330/P7001x filled compounds at $-20^{\circ} \mathrm{C}$ and $0^{\circ} \mathrm{C}$, respectively. An increase in rCB content shows positive trends: a rise in tan delta at both temperatures with increasing $\mathrm{rCB}$ content, indicating improvement in ice grip and wet traction. At $60^{\circ} \mathrm{C}$, Figure 9.9(c), the tan delta values decline the more $\mathrm{rCB}$ is used as replacement of CB N330, thus indicating a reduction in rolling resistance. It is well known for carbon black filled rubbers, that filler-polymer interactions in these systems are of physical nature. The physical adherence of rubber chains on the edges of carbon black graphitic crystal defects is more pronounced for smaller particle size carbon black reinforcing grades, which leads to lower hysteresis at low temperatures $\left(-20^{\circ} \mathrm{C}\right.$ to $0^{\circ} \mathrm{C}$ ) and higher hysteresis at high temperatures $\left(60^{\circ} \mathrm{C}\right)^{3}$. The low temperature hysteresis is further associated with the glass transition of SBR rubber which is hampered by the immobilization of rubber chain segments adhered on the carbon black surface. The high temperature hysteresis is caused by the attachment and detachment of rubber segments from the filler surface. When semi-reinforcing $\mathrm{rCB}$ P7001x is used to replace the reinforcing N330 grade, the low temperature hysteresis of a rubber compound improves due to lower filler-polymer interactions. This consequently leads to less rubber chain segments immobilizations, which means less effect on rubber glass transition and, thus higher hysteresis. At high temperature the lower filler-polymer interaction leads to reduced mutual friction and thus lower hysteresis. Moreover, as previously discussed in Chapter 6, a part of the filler-polymer interactions in $\mathrm{rCB}$ compounds are of chemical nature due to the presence of silica and sulfur compounds, which also promote the improvement of dynamic properties due to a strong chemical coupling of the filler to the polymer chains. For the N330/P7001x compound at a ratio of 40/20, the indications for ice skid resistance, wet traction and rolling resistance are improved by $24 \%, 9 \%$, and $12 \%$, respectively. Such improvement is deemed significant as mentioned in other studies for different filler systems ${ }^{3,13-14}$. 

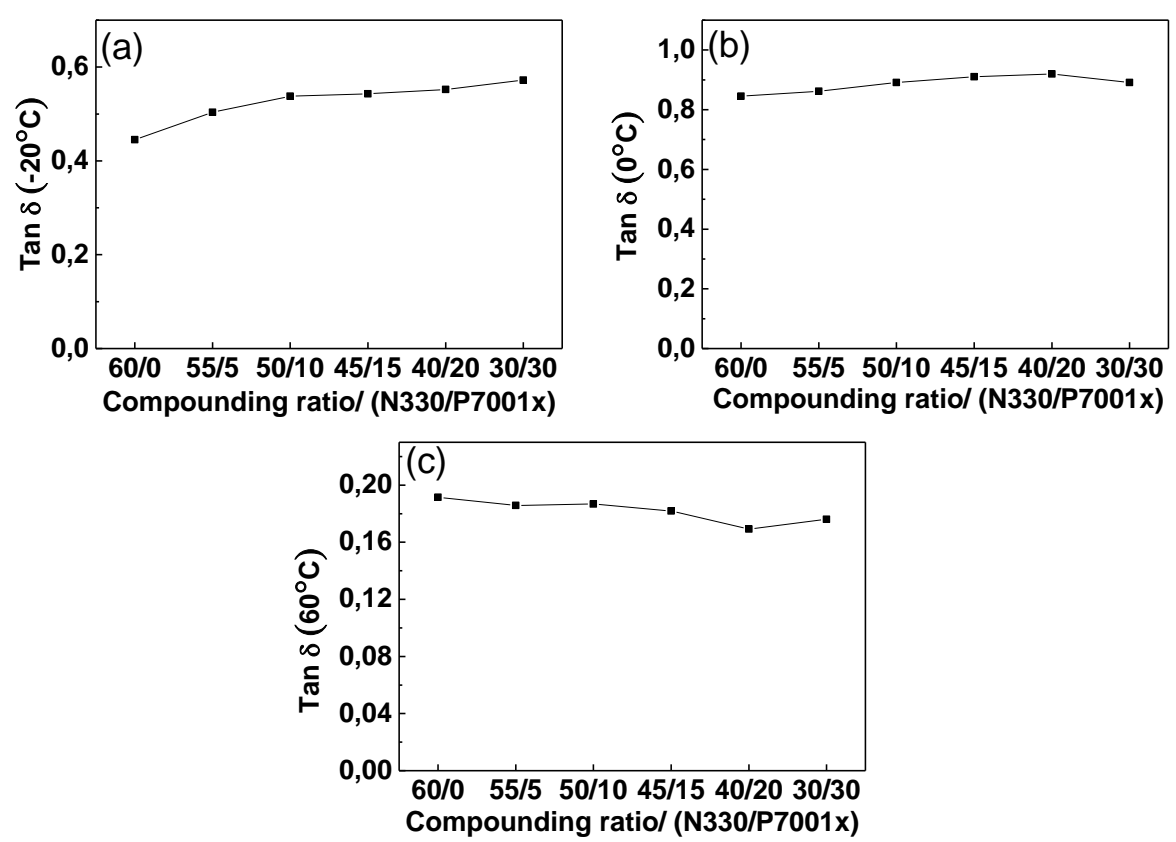

Figure 9.9(a) Tan delta at $-20^{\circ} \mathrm{C}$ as indicator for ice skid resistance, (b) Tan delta at $0^{\circ} \mathrm{C}$ as indicator for wet traction, (c) Tan delta at $60^{\circ} \mathrm{C}$ as indicator for rolling resistance of N330/P7001x filled compounds.

\subsection{Conclusions}

In a SBR rubber compound, reinforcing CB N330 was replaced in various ratios by rCB generated from passenger car tires in an ultra-fast pyrolysis process with 6 seconds of residence time at $700^{\circ} \mathrm{C}$. An increasing content of $\mathrm{rCB}$ in this rubber compound leads to a rise in viscosity due to poor dispersion of $\mathrm{rCB}$, as also seen in the macro-dispersion analysis. Cure characteristics were marginally affected by $\mathrm{rCB}$ up to $50 \%$ replacement. Filler-filler interactions were reduced, as more and more virgin $\mathrm{CB}$ was replaced by $\mathrm{rCB}$ due to the coverage of highly energetic sites on the $\mathrm{rCB}$ by carbonaceous matter formed during pyrolysis. Bound rubber content showed an increase, indicating an improvement in filler-polymer interactions. However, filler macro-dispersion was negatively influenced with $\mathrm{rCB}$ addition, and tensile properties significantly decreased above $33 \%$ of CB replacement. The disparity among rCB's better filler-polymer interactions and lower dispersion and tensile properties can be explained by the presence of active sulfur in the recycled filler as discussed in Chapter 6. 
Dynamic properties indicate improvements in tire performance: ice skid resistance, wet traction, and rolling resistance are expected to be improved with increasing $\mathrm{rCB}$ content due to a higher hysteresis at low temperatures and vice versa. The improvements in the tire performance indicators are promoted by the semireinforcing nature of $\mathrm{rCB}$ and the presence of active sulfur in $\mathrm{rCB}$, which can lead to chemical polymer-filler coupling.

In conclusion, $\mathrm{rCB}$ can partially replace the high-reinforcing carbon black N330, and the best balance for the different properties was found for a 33\% CB replacement, or a $40 \mathrm{phr} / 20 \mathrm{phr}$ N330/P7001x ratio. Processing and mechanical properties are still sufficient, and dynamic properties van be improved. This shows the potential of rCB from flash pyrolysis for re-use in tire tread compounding.

\section{References}

[1] E. Dannenberg, Rubber Chem. Technol., 48, 410 (1975).

[2] S. Wolff and M.J. Wang, Carbon Black Reinforcement of Elastomers, In Carbon Black: Science and Technology, 2nd ed., Marcel Dekker, New York (1993).

[3] M.J. Wang, Rubber Chem. Technol., 71, 520, (1998).

[4] M.J. Wang, S. Wolff and J.B. Donnet, Rubber Chem. Technol., 64, 714, (1991).

[5] H.D. Luginsland, and W. Niedermeier, Rubber World, 228, 34 (2003).

[6] M. Morton, Rubber Technology, Springer Science \& Business Media, Dordrecht, (2013).

[7] H. Atashi, and M. Shiva, Asian J. Chem., 22, 7519 (2010).

[8] W. Feng, Z. Tang, P. Weng, and B. Guo, Rubber Chem. Technol. 88, 676 (2015).

[9] R. Murillo, E. Aylon, M. Navarro, M. Callen, A. Aranda and A. Mastral, Fuel Process. Technol., 87, 143 (2006).

[10] J.D. Martínez, N. Puy, R. Murillo, T. García, M.V. Navarro, and A.M. Mastral, Renew. Sust. Energ. Rev., 23, 179 (2013).

[11] O, Senneca, P. Salatino and R. Chirone, Fuel, 78, 1575 (1999).

[12] C. Norris, M. Hale and M. Bennett, Plast. Rubber Compos., 43, 245 (2014).

[13] S. Sattayanurak, J.W. Noordermeer, K. Sahakaro, W. Kaewsakul, W. K. Dierkes, and A. Blume, Adv. Mater. Sci. Eng., 1, 1 (2019). 
[14] S. Sattayanurak, K. Sahakaro, W. Kaewsakul, W. K. Dierkes, L. A. Reuvekamp, A. Blume, and J.W. Noordermeer, Polym. Test., 81, 106173 (2019). 
Chapter 9 
CHAPTER 10

\section{CONCLUDING REMARKS AND SUMMARY}

This chapter concludes the findings of this research. The chapter states the motivation of the described work and summarize the outcomes of each study. 
The primary motivations for this research were:

1) Better understanding about the physico-chemical nature of recovered carbon black ( $\mathrm{rCB})$.

2) Elucidation of the influence of pyrolysis parameters on characteristics and performance of $\mathrm{rCB}$.

3) Development of an after-treatment to further enhance the potential of $\mathrm{rCB}$ as a circular material.

4) Use of rCB as a replacement of fossil-based carbon black.

In the past, scrap tire pyrolysis was essentially focused on the gaseous and liquid fractions, their yield and quality. The growing interest in safeguarding the environment and the more and more strict legislations concerning circularity of materials has drawn attention to recovered carbon black. Its potential reuse for rubber reinforcement as a substitute for fossil-based carbon black has recently attracted tire manufacturers. rCBs described in literature are recovered from various pyrolysis processes. All these processes have different parameters which influence the rCB characteristics and consequently the reusability. The composition of rCB is dependent on the type of feedstock from which it is recovered. Whenever a new process for tire pyrolysis is developed, parameter studies are needed in order to understand their influence on the $\mathrm{rCB}$ characteristics. In this study, based on the current state-of-the-art knowledge, an ultra-fast pyrolysis process was selected for $\mathrm{rCB}$ recovery from passenger car tires.

\section{Summary}

Common tire recycling practices including both, physical and chemical processes, were reviewed in Chapter 2. The main focus was on pyrolysis of scrap tires. Pyrolysis reactors used for this purpose were considered, and their pros and cons were discussed. Pyrolysis products, especially recovered carbon black, were reviewed. The knowledge of fundamentals of $\mathrm{rCB}$, the in-rubber performance and the available post-treatments were covered. As a conclusion, a lack in knowledge of the influence of pyrolysis parameters on both, rCB characteristics and in-rubber performance, and their correlation was identified.

In a preliminary study, samples of commercially available rCB samples were characterized and tested in rubber, see Chapter 3. The characterized rCBs contained various amounts of organic as well as inorganic impurities. The study reaffirmed earlier findings about the disparity between high surface area values of rCB which are similar to highly reinforcing N300 carbon blacks, and their low inrubber performance which is similar to semi-reinforcing N600 carbon blacks. The 
study revealed a major influence of the type of feedstock on the curing behavior of the rubber. For passenger car tires compared to truck tires as feedstock, the inorganic content of $\mathrm{rCB}$ was increased due to a higher silica content. This resulted in reduced curing rates and higher marching moduli. To limit the variation in feedstock, the further research was carried out using post-consumer passenger car tires as feedstock only.

Based on the knowledge gained in Chapter 2 about various pyrolysis processes and their parametric influence on $\mathrm{rCB}$ characteristics, an entrained flow ultra-fast pyrolysis reactor with a residence time of 6 seconds was selected for the present study. In this process, a constant feed particle size, temperature and residence time are vital parameters in defining product qualities. In Chapter 4.1, the influence of these parameters on product yields and $\mathrm{rCB}$ volatiles content were elaborated. High process temperatures and long residence times showed promising results in reducing volatiles. At $700^{\circ} \mathrm{C}$ with two times of refeeding, rCB volatiles were reduced to negligible quantities, which were even lower than the ones measured on commercial fossil-based carbon black N660. However, the remaining hydrogen content of this $\mathrm{rCB}$ was higher than for N660, indicating the formation of non-volatile organics: carbonaceous residues.

Further in-depth characterization of $\mathrm{rCB}$ was performed in Chapter 4.2 to understand the physicochemical nature of $\mathrm{rCB}$ compared to virgin carbon black. The focus was on the influence of pyrolysis temperature on the key characteristics of rCBs for in-rubber performance: surface area, structure, surface chemistry and physical surface activity. A positive influence of a rising pyrolysis temperature was noticed, as all key performance characteristics were improved. The use of high temperatures lead to faster volatiles removal from the $\mathrm{rCB}$. This improved the structure and surface area by opening structural voids. Characterization of surface functionalities revealed the chemical nature of $\mathrm{rCB}$ carbon and presence of inorganics. At higher temperatures, $\mathrm{C}-\mathrm{O}$ functionalities on the surface of the rCBs became more prominent and similar to the ones of virgin carbon black, while inorganics remained unaffected. Zinc, which was added during tire manufacturing as zinc oxide, was mainly present as zinc sulfide. During pyrolysis, sulfur-carbon compounds were also formed and remained attached to the carbon surface. The surface activity in a physical sense was also improved at high temperatures as evident from an higher non-polar dispersive component of the surface energy and enhanced nano-surface roughness. However, this also resulted in cleaner and thus more polar silica surface, which resulted in a higher polar part of the surface energy of the rCB as well. Compared to carbon black N660, rCB recovered within this temperature study exhibited higher organic and inorganic impurities, a broader range of particle sizes, higher surface areas but relatively lower structures, a lower dispersive energy component and a higher polar part of the surface energy. 
The influence of pyrolysis temperature and residence time had a profound impact on the in-rubber performance as shown in Chapter $\mathbf{5 . 1}$ and 5.2, respectively. In Chapter 5.1, the $\mathrm{rCB}$ performance was improved by raising the pyrolysis temperature. It was clear from the characterization reported in Chapter 4.1 and 4.2, that lower volatiles at high pyrolysis temperatures resulted in a cleaner carbon surface and higher structure, which would lead to better filler-polymer interactions. However, the surface activity measurements described in Chapter 4.2 revealed an increase in polar energy due to a cleaner silica surface at high process temperatures. This consequently affected the curing behavior of $\mathrm{rCB}$ filled rubber: The cure rate was systematically reduced and marching modulus increased.

The residence time in the pyrolysis reactor had also a significant influence on $\mathrm{rCB}$ in-rubber performance. In Chapter 5.2, longer residence times lead to higher compound viscosities and filler-filler interactions. Similar as in the temperature study, the compound cure rates were reduced for longer residence times due to cleaner silica surfaces. For the tensile properties, this influence was however different at the various temperatures. At $500^{\circ} \mathrm{C}$ and $600^{\circ} \mathrm{C}$, a doubled residence time showed an improvement in $\mathrm{rCB}$ performance with no further improvement at tripled residence time. At the highest temperature of $700^{\circ} \mathrm{C}$, a longer residence time had a negative impact on tensile properties. This behavior was attributed to the effect of carbonaceous residues formed on the rCB surfaces. At high temperatures and longer residence times, the dehydrogenation and cyclization of cracked polymer chain segments eventually lead to formation of polyaromatics. These polyaromatics grow with time covering the $\mathrm{rCB}$ surface with stable non-volatile graphite-like deposits called carbonaceous residue or coke. These large aromatic structures change the microstructure of recovered carbon black particles by covering the active sites crucial for good filler-polymer interactions.

In both Chapters 5.1 and 5.2, a disparity was seen between rCB filler-polymer interactions and performance: Most $\mathrm{rCBs}$ showed much higher bound rubber contents than carbon black N660, but lower tensile properties. Two possible causes were formulated:

I. Insufficient curing of $\mathrm{rCB}$ filled compounds due to slow curing rates.

II. Presence of active sulfur which lead to compound pre-scorch and consequently higher bound rubber values.

In Chapter 5.2, the first case was tested by curing rCB and N660 filled compounds at longer times of 30 minutes and 40 minutes. The tensile properties of only one rCB filled compound reached closer to the ones of the N660 filled compound at 30 minutes of curing, but never went beyond as would have been expected from bound rubber measurements. 
The second possibility of active sulfur presence in rCB is elucidated in Chapter $\mathbf{6}$. Bound rubber of $\mathrm{rCB}$ and carbon black filled compounds was tested after heating at $160^{\circ} \mathrm{C}$ for 40 minutes. Since no additional sulfur was added, an increase in bound rubber must be due to active sulfur in $\mathrm{rCB}$. Indeed, bound rubber was significantly increased, and in some cases doubled which indicated the active nature of sulfur compounds in rCB. This argument was further supported by high strain measurements of these materials. Moreover, when the surface functionalities of pyrolyzed pure silica were characterized, sulfur compounds were detected on wavenumber similar to a silanized silica which may form a bond with rubber.

Colloidal properties of conventional carbon black are commonly used to predict its rubber reinforcement potential. Literature showed that these properties cannot be used for the performance prediction of rCBs. Chapter 7 focused on this issue, and the rCB key properties as characterized in Chapters 4.1 and 4.2 were correlated to the in-rubber performance evaluation in Chapters 5.1 and 5.2. This part of the present study revealed that the volatile and the hydrogen contents of rCBs from the temperature study with minimum residence time can be correlated with their inrubber performance. The correlation deviated when rCB with lower volatiles were considered. Since the initial removal of volatiles lead to a dominating performance factor of structural voids openings, the correlation to performance was therefore linear. However, when samples with a longer residence time, thus with a lower volatiles content, were considered, the correlation was not valid anymore as the change in microstructure of $\mathrm{rCB}$ due to the formation of non-volatile carbonaceous residues played an important role in reducing surface activity.

In terms of performance, a recovered carbon black quality similar to the one of semireinforcing $\mathrm{N} 660$ was achieved in Chapter 5.2 by varying pyrolysis parameters and longer curing times. The limiting factors in $\mathrm{rCB}$ performance were identified by extensive characterization and performance analysis in Chapter 4 and 5, respectively, and are summarized below,

I. Presence of inorganic ash, in particular silica.

II. Poor aggregate structure compared to virgin carbon black.

III. Presence of volatiles covering the carbon black surface.

IV. Formation of carbonaceous residues modifying the surface microstructure.

A suitable post treatment is needed to further improve the performance. In Chapter 2 , commonly used post treatments for ash leaching were reviewed, which were mainly solution based treatments. The problems with these treatments are the high costs of the treatment and the generation of a new waste stream in the form of acid/base solutions. For aggregate structure improvement, several attempts have been made by aggressive grinding of $\mathrm{rCB}$; however, it still remained a limitation due to a strong chemical bonding of particles. In Chapter 8, low-pressure plasma argon 
etching was chosen to reactivate the $\mathrm{rCB}$ surface. The technique was proven to be able to remove volatiles from rCB. Rubber curing was affected due to a much cleaner silica surface after etching. However, the in-rubber performance remained largely unaffected. The plasma as applied here was not strong enough to remove carbonaceous residues as they were strongly bonded to carbon surface.

Finally, the best quality $\mathrm{rCB}$ which was recovered at $700^{\circ} \mathrm{C}$ with minimum residence time was utilized to partially replace highly-reinforcing N330 carbon black in Chapter 9. This compounding study showed that $\mathrm{rCB}$ can replace up to $33 \%$ of N330 without significantly affecting the curing behavior and tensile properties. The addition of $\mathrm{rCB}$ lead to an additional benefit of improved dynamic properties: higher ice skid resistance, better wet grip, and lower rolling resistance of tire treads based thereon. 
De belangrijkste drijfveren voor dit onderzoek waren:

1) Beter begrip van de fysisch-chemische eigenschappen van gerecycleerde roet, in vaktermen 'recovered carbon black' (rCB).

2) Opheldering van de invloed van pyrolyseparameters op kenmerken en prestaties van rCB.

3) Ontwikkeling van een nabehandeling om het potentieel van rCB als circulair materiaal verder te vergroten.

4) Gebruik van rCB als vervanging van conventionele roet op basis van fossiele grondstoffen.

In het verleden was pyrolyse van oude banden vooral gericht op de gasvormige en vloeibare fracties, hun opbrengst en kwaliteit. De groeiende belangstelling voor het beschermen van het milieu en de steeds strengere wetgeving rond circulariteit van materialen hebben de aandacht gevestigd op gerecycleerd carbon black. Het potentiële gebruik ervan voor rubberversterking als vervanger voor carbon black op basis van fossiele brandstoffen heeft onlangs meer en meer de aandacht van bandenfabrikanten getrokken. Diverse pyrolyseprocessen om rCB's te produceren worden in de literatuur beschreven. Verschillen in procesparameters beïnvloeden de rCB-kenmerken en daarmee de inzetbaarheid. Daarnaast is de samenstelling van rCB afhankelijk van het type grondstof waaruit het wordt gewonnen. Telkens wanneer een nieuw proces voor pyrolyse van bandenrubber word ontwikkeld, zijn parameterstudies nodig om de invloed op de rCB-eigenschappen op te helderen. In dit onderzoek is op basis van de huidige kennisstand gekozen voor een ultrasnel pyrolyseproces voor rCB-terugwinning uit rubber van personenwagenbanden.

\section{Samenvatting}

Verschillende manieren van bandenrecycling, zowel fysische als chemische processen, worden besproken in Hoofdstuk 2. De nadruk ligt vooral op pyrolyse van rubber van oude banden. Pyrolysereactoren, die voor dit doel worden gebruikt, worden beschreven en de desbetreffende voor- en nadelen besproken. Een overzicht van pyrolyseproducten wordt gegeven, in het bijzonder het teruggewonnen carbon black. De fundamentele kennis met betrekking tot $\mathrm{CCB}$, het gedrag in rubber en de beschikbare nabehandelingen komen eveneens aan bod. Deze literatuurstudie maakt duidelijk, dat met name kennis over de invloed van pyrolyseparameters op rCB-kenmerken en in-rubber prestaties, en hun onderlinge correlatie ontbreekt. 


\section{Samenvatting}

In een voorstudie worden monsters van commercieel verkrijgbare rCB-monsters gekarakteriseerd en getest in rubber, zie Hoofdstuk 3. De gekarakteriseerde rCB's bevatten verschillende hoeveelheden organische en anorganische bestanddelen. Deze studie bevestigt eerdere bevindingen over de tegenstrijdigheid van een groot oppervlak van $\mathrm{rCB}$, vergelijkbaar met het oppervlak van hoog-versterkende carbon black soorten zoals N300, en hun lage prestaties in rubber, vergelijkbaar met semiversterkende N600-carbon black types. Uit het onderzoek blijkt, dat het type banden gebruikt voor de pyrolyse, een grote invloed op het vulkanisatiegedrag van rubber met deze rCB heeft. Voor banden van personenwagens in vergelijking met banden van vrachtwagens als grondstof is het anorganische gehalte van rCB hoger door de aanwezigheid van grotere hoeveelheden silica. Dit resulteert in een lagere vulkanisatiesnelheid en sterkere marching modulus. Om de variatie in verschillende grondstoffen te beperken, is het verdere onderzoek uitgevoerd met alleen rubber van oude personenwagenbanden als grondstof.

Op basis van de kennis, die in Hoofdstuk 2 is opgedaan over verschillende pyrolyseprocessen en hun invloed op rCB-karakteristieken, is voor dit onderzoek een ultrasnelle doorstroom pyrolysereactor met een verblijftijd van ca. 6 seconden geselecteerd. In dit proces zijn - bij een constante deeltjesgrootte - temperatuur en verblijftijd essentiële parameters, die de productkwaliteit bepalen. In Hoofdstuk 4.1 wordt de invloed van deze parameters op productopbrengst en gehalte aan vluchtige stoffen onderzocht. Hoge procestemperaturen en lange verblijftijden resulteren in vermindering van de hoeveelheid vluchtige stoffen. Bij een pyrolysetemperatuur van $700^{\circ} \mathrm{C}$ en dubbele verblijftijd wordt het gehalte aan vluchtige bestanddelen van rCB gereduceerd tot verwaarloosbare hoeveelheden, die zelfs lager liggen dan de concentraties gemeten voor conventionele carbon black zoals N660. Het resterende waterstofgehalte van deze rCB is echter hoger dan voor N660, wat wijst op de vorming van niet-vluchtige organische stoffen: koolstof-houdende residuen.

Verdere diepgaande karakterisering van $\mathrm{rCB}$ word uitgevoerd in Hoofdstuk 4.2, om de fysisch-chemische eigenschappen van $\mathrm{rCB}$ te begrijpen in vergelijking met conventionele carbon black. De nadruk ligt hier op het bestuderen van de invloed van de pyrolysetemperatuur op de belangrijkste kenmerken van rCB's voor het gedrag in rubber: oppervlakte, structuur, chemische en fysische oppervlakteactiviteit. Hogere pyrolysetemperaturen hebben een positieve invloed, aangezien alle belangrijke eigenschappen worden verbeterd. Het gebruik van hoge temperaturen leidt tot een snellere verwijdering van vluchtige stoffen uit $\mathrm{rCB}$. Dit verbetert de structuur en het oppervlak door kleine poriën te openen. De karakterisering van oppervlaktefunctionaliteiten onthult de chemische aard van rCBkoolstof en de aanwezigheid van anorganische stoffen. Na pyrolyse bij hogere temperaturen worden meer C-O functionaliteiten aan het oppervlak van de rCB's aangetoond vergelijkbaar met conventionele carbon black, terwijl anorganische 
bestanddelen onveranderd blijven. Zink, dat aan de rubber wordt toegevoegd als zinkoxide, is voornamelijk aanwezig als zinksulfide. Tijdens de pyrolyse worden ook zwavel-koolstofverbindingen gevormd, die aan het carbon black oppervlak gebonden zijn. De oppervlakteactiviteit in fysische zin wordt eveneens verbeterd door hoge pyrolysetemperaturen zoals blijkt uit een hogere niet-polaire dispersieve component van de oppervlakte-energie en een hogere ruwheid op nanoschaal. Dit resulteert echter ook in een schoner en dus meer polair silicaoppervlak, wat op zijn beurt resulteert in een hoger polair deel van de oppervlakte-energie van rCB. Vergeleken met carbon black $\mathrm{N} 660$ vertoont $\mathrm{rCB}$, dat in dit temperatuuronderzoek werd teruggewonnen, hogere organische en anorganische bestanddelen, een bredere deeltjesgrootte verdeling, een groter oppervlak, maar relatief lage structuur, een lagere dispersieve energiecomponent en een hoger polair deel van de oppervlakte-energie.

Pyrolysetemperatuur en verblijtijd in de reactor hebben een grote invloed op het gedrag in rubber zoals gegeven in respectievelijk Hoofdstuk 5.1 en 5.2. In Hoofdstuk 5.1 wordt de prestatie van rCB verbeterd door de pyrolysetemperatuur te verhogen. Uit de karakterisering gerapporteerd in Hoofdstuk 4.1 en 4.2 werd duidelijk, dat een lager gehalte aan vluchtige stoffen bij hoge pyrolysetemperaturen resulteert in een schoner oppervlak en een hogere structuur, wat zou leiden tot betere vulstof-polymeer interacties. Echter de metingen van oppervlakteactiviteit beschreven in Hoofdstuk 4.2 lieten een toename van de polaire energie zien als gevolg van een schoner silica-oppervlak bij hoge procestemperaturen. Dit beïnvloedde bijgevolg het vulkanisatiegedrag van met rCB versterkt rubber: de vulkanisatiesnelheid werd systematisch verlaagd en de marching modulus verhoogd.

De verblijftijd in de pyrolysereactor had eveneens een grote invloed op het gedrag van $\mathrm{rCB}$ in-rubber. In Hoofdstuk $\mathbf{5 . 2}$ leiden langere verblijftijden tot hogere viscositeiten en vulstof-vulstof interacties. Net als bij de temperatuurstudie worden de vulkanisatiesnelheden verlaagd bij langere verblijftijden vanwege het schonere silica-oppervlak. Voor de trek-rek eigenschappen was deze invloed echter afhankelijk van de pyrolyse temperatur: $\mathrm{Bij} 500^{\circ} \mathrm{C}$ en $600^{\circ} \mathrm{C}$ vertoonde een verdubbelde verblijftijd een verbetering van de $\mathrm{rCB}$ kwaliteit zonder verdere verbetering bij een drievoudige verblijftijd. Bij de hoogste temperatuur van $700^{\circ} \mathrm{C}$ heeft een langere verblijftijd een negatief effect op de trek-rek eigenschappen. Dit gedrag wordt toegeschreven aan het effect van koolstof-residuen gevormd op de rCB-oppervlakken. Bij hoge temperaturen en langere verblijftijden leidt de dehydrogenering en cyclisatie van gekraakte polymeerketen-segmenten uiteindelijk tot de vorming van polyaromaten. Deze aromaten worden gevormd tijdens het verblijf in de reactor en bedekken het rCB-oppervlak met stabiele niet-vluchtige grafietachtige componenten. Deze polyaromatische structuren veranderen de 


\section{Samenvatting}

microstructuur van de rCB deeltjes door de actieve plaatsen te blokkeren, die cruciaal zijn voor goede vulstof-polymeer interacties.

Uit beide Hoofdstukken 5.1 en 5.2 blijkt een verschil tussen rCB-polymeer interacties en de kwaliteit van rCB: de meeste rCB's vertonen veel hogere bound rubber gehaltes dan conventionele carbon black N660, maar lagere trek-rek eigenschappen. Er worden twee mogelijke oorzaken geopperd:

I. Ondervulkanisatie van met $\mathrm{rCB}$ versterkte rubber door een vertraagde vernettingsreactie.

II. Aanwezigheid van actieve zwavel die leidt tot pre-scorch en bijgevolg hogere bound rubber waardes.

In Hoofdstuk 5.2 wordt het eerste geval getest door met rCB en N660 gevulde mengsels gedurende 30 en 40 minuten te vulkaniseren. De trek-rek eigenschappen van slechts één met rCB gevuld mengsel komt dichter bij die van het N660-gevulde mengsel na 30 minuten vulkanisatie, maar de eigenschappen worden nooit beter dan van N660-rubber, wat wel was verwacht op basis van de hogere bound rubber waardes voor rCB.

De tweede mogelijkheid van aanwezigheid van actieve zwavel in rCB wordt verder toegelicht in Hoofdstuk 6. De bound rubber van met rCB en conventionele carbon black gevulde mengsels word gemeten na 40 minuten verwarmen op $160^{\circ} \mathrm{C}$. Aangezien er geen extra zwavel was toegevoegd, moet een toename van bound rubber te wijten zijn aan actieve zwavel in rCB. Het gebonden rubber is inderdaad aanzienlijk toegenomen en in sommige gevallen verdubbeld, wat duidelijk de actieve aard van zwavelverbindingen in $\mathrm{rCB}$ aangeeft. Deze redenering word verder ondersteund door een hoge rek van deze materialen. Bovendien worden zwavelverbindingen aangetoond bij analyse van oppervlakte-functionaliteiten van de as van gepyrolyseerde silica-rubber, vergelijkbaar met gesilaniseerd silica, dat een binding kan vormen met rubber.

De colloïdale eigenschappen van conventionele carbon black worden vaak gebruikt om hun versterkingspotentieel te voorspellen. Uit de literatuur blijkt dat deze eigenschappen echter bij rCB niet kunnen worden gebruikt om hun gedrag te voorspellen. Hoofdstuk 7 concentreert zich op dit probleem, en de belangrijkste eigenschappen van rCB zoals beschreven in Hoofdstukken 4.1 en 4.2 worden gecorreleerd aan de evaluatie in rubber beschreven in Hoofdstukken 5.1 en 5.2. Dit deel van de studie onthult dat de gehaltes aan vluchtige stoffen en waterstof in rCB's uit de temperatuurstudie met minimale verblijftijd kunnen worden gecorreleerd met de prestaties in rubber. 
De correlatie wijkt af voor rCB's met een laag gehalte aan vluchtige stoffen. Aangezien de initiële verwijdering van vluchtige stoffen leidde tot een verbetering van de structuur door het ontstaan van poriën, was er een lineaire verbetering van de eigenschappen van de rubber met deze rCB's. Wanneer echter rCB's met een lange verblijtijd, dus met een laag gehalte aan vluchtige stoffen, worden beschouwd, dan geldt deze correlatie niet meer: De verandering van de microstructuur als gevolg van de vorming van niet-vluchtige koolstof-residuen speelt een belangrijke rol bij het verminderen van de oppervlakte activiteit.

Qua prestatie word een rCB kwaliteit bereikt, die vergelijkbaar is met die van een semi-versterkende N660 door de pyrolyseparameters te optimaliseren en langere vulkanisatietijden aan te houden zoals beschreven in Hoofdstuk 5.2. De beperkende factoren voor een verbetering van de rCB-kwaliteit worden duidelijk in de karakterisering als zodanig en in rubber in respectievelijk Hoofdstuk 4 en 5 , en zijn hieronder samengevat:

I. Aanwezigheid van anorganische as, in het bijzonder silica.

II. Lagere structuur vergeleken met conventionele carbon back.

III. Aanwezigheid van vluchtige stoffen, die het rCB oppervlak bedekken.

IV. Vorming van koolstof-residuen, die de microstructuur van het oppervlak beïnvloeden.

Een geschikte nabehandeling is nodig om de rCB kwaliteit verder te verbeteren. In Hoofdstuk 2 worden nabehandelingen voor de verwijdering van as besproken, die voornamelijk op oplossen ervan gebaseerd zijn. Problemen bij deze behandelingen zijn de hoge kosten en het ontstaan van een nieuwe afvalstroom in de vorm van zuur/base oplossingen. Er worden verschillende pogingen ondernomen om de aggregaatstructuur te verbeteren door malen van rCB; dit blijt echter nog steeds een beperkende factor vanwege een sterke chemische binding tussen de deeltjes. In Hoofdstuk 8 wordt gekozen voor etsen in een lagedruk-plasma met argon, om het $\mathrm{rCB}$-oppervlak te reactiveren. In deze studie wordt aangetoond, dat deze techniek vluchtige stoffen uit $\mathrm{rCB}$ kan verwijderen. Omdat daarbij een schoner oppervlak van silica door het etsen bereikt wordt, wordt ook het vulkanisatiegedrag van rubber beïnvloed. Desondanks blijven de eigenschappen van het rubber grotendeels gelijk. Het hier toegepaste plasma was niet sterk genoeg om koolstofresten te verwijderen omwille van hun sterke binding aan het rCB oppervlak.

Ten slotte word de beste kwaliteit $\mathrm{rCB}$, gepyrolyseerd bij $700^{\circ} \mathrm{C}$ met een minimale verblijftijd, gebruikt om het hoog-versterkende N330 carbon black gedeeltelijk te vervangen; dit wordt beschreven in Hoofdstuk 9. Hier wordt aangetoond, dat rCB tot $33 \%$ van N330 kan vervangen zonder noemenswaardige gevolgen voor het 
vulkanisatiegedrag en de trek-rek eigenschappen. De toevoeging van rCB leidt zelfs tot verbeterde dynamische eigenschappen, een aanwijzing voor een betere grip op ijs en nat wegdek, en een lagere rolweerstand van banden-loopvlakken daarop gebaseerd. 


\section{Appendix I}

\section{Development of a lab scale pelletizing unit}

In order to find a suitable method for pelletizing small quantities of $\mathrm{rCB}$, the following methods were compared:

- Magnetic stirring

- Manual shaking

- Rotary evaporator

- Rotating disc pelletizer

- Ball mill

In industry, pelletizing of carbon black is done by using a pin mixer, into which the material is injected by a moving screw. Once the material is injected, several pins rotate in the drum and make the particles free flowing. During the free flowing state of the particles, a binder is sprayed which leads to agglomeration of the particles into small pellets at sub-millimeter length scale. Since pin mixers are only available for large scales in the range of kilograms or tons, different methods were tested in the university lab to make pellets out of fluffy carbon blacks.

Binder selection - In initial trials, sugar solution and water were used as two binders. Similar ability of pelletizing was observed for both binders at lab scale was observed. However, sugar solution needs higher evaporation temperature $\left(150^{\circ} \mathrm{C}-\right.$ $200{ }^{\circ} \mathrm{C}$ ) to remove it after pelletization which coincides with the volatile temperature range. of rCB. Therefore, in order not to change the $\mathrm{rCB}$ composition, water was selected as binder.

\section{Magnetic stirring and manual shaking}

The fluffy carbon black was placed in a beaker with a magnetic stirrer. The material was stirred and water was added in the form of droplets as a binder. A very small quantity, i.e. $\sim 5 \mathrm{~g}$, was possible to be pelletized, but for quantities larger than $10 \mathrm{~g}$, only half of the material would pelletize due to inhomogeneous stirring. Since $300 \mathrm{~g}$ per sample was needed, this technique was insufficient for handling the required amount.

Manual shaking of a fluffy sample with water in a round bottom flask also resulted in forming pellets; however, the quantity which could effectively be pelletized is again very small. 


\section{Rotary evaporator}

A rotary evaporator (see Figure 1) was also utilized to rotate the sample in a round bottom flask with water. Water as binder was injected using two methods:

(i) droplets, and

(ii) spray

Since the rotation of the beaker was uni-directional, a part of the carbon black clustered together and formed one big round pellet of size $\sim 3 \mathrm{~cm}$ with very low strength of binding. Both droplets and spray methods of binder injection gave same results. and formed a loosely bonded ball of size $\sim 3 \mathrm{~cm}$.

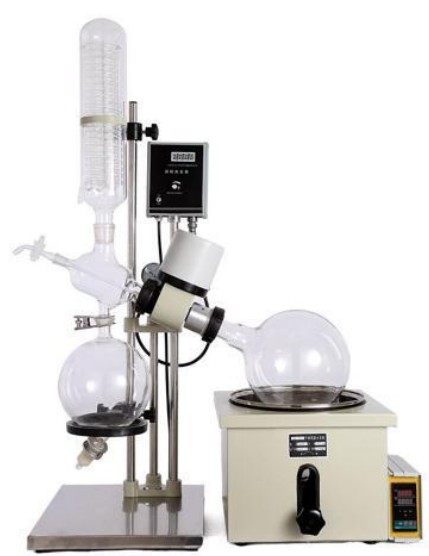

Figure 1 Rotary evaporator.

\section{Rotating disc pelletizer}

Rotary disc pelletizers (Figure 2) are commonly used in the cement industry. A rotary disc pelletizer was available at TU Eindhoven. Unlike cement or fly ash, carbon black has a very low bulk density and is hydrophobic of nature. Trials of pelletizing fluffy carbon black were performed at different disc rotation speeds and inclining angles. At high inclining angles of the rotary disc, the sample was difficult to handle at higher speeds. Additionally, the hydrophobic nature of carbon black lead to poor water adsorption and resulted in sliding of carbon black on the disc without getting pelletized. 


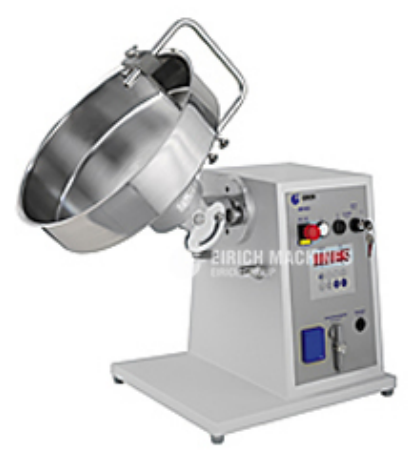

Figure 2 Rotary disc pelletizer.

\section{Ball mill}

A planetary ball mill (Figure 3 ) was initially used for grinding the carbon black. In a ball mill, jars are rotated in a planetary motion. In this mill, high rotating speeds upto $400 \mathrm{rpm}$ can be reached. For grinding of carbon black, the jars were filled with the rCB samples and the milling balls, and rotated at a speed of $250 \mathrm{rpm}$ for 10 minutes.

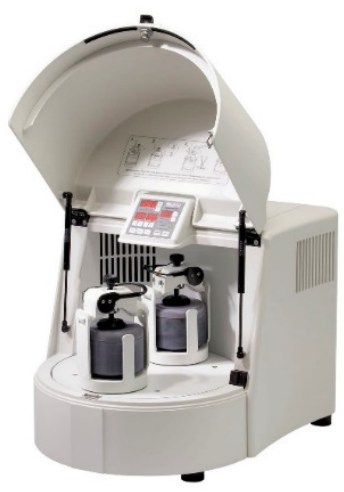

Figure 3 Planetary ball mill used for grinding and pelletizing. Model: Pulverisette $5 / 2$ by Fritsch.

After grinding, the balls were removed and water was added as a binder for pelletizing. Pelletizing was initially performed for $4 \mathrm{~g}$ at $200 \mathrm{rpm}$ for 5 minutes. As agglomeration was evident but with loose binding at these conditions. Further in 
Table 1, various conditions screening were used for optimization of pelletizing process. The pellets formed on these conditions are illustrated in Figure 4.

Table 1 Ball mill conditions used for pelletizing.

\begin{tabular}{|l|c|c|c|c|c|}
\hline $\begin{array}{l}\text { Trials } \\
\text { Conditions } \\
\text { - }\end{array}$ & $\mathbf{1}$ & $\mathbf{2}$ & $\mathbf{3}$ & $\mathbf{4}$ & $\mathbf{5}$ \\
\hline $\begin{array}{l}\text { Sample } \\
\text { (gm) }\end{array}$ & 4 & 4 & 10 & 20 & 20 \\
\hline Binder (ml) & 4 & 4 & 10 & 20 & 20 \\
\hline Binder & Spray & Drops & Drops & Drops & Drops \\
\hline $\begin{array}{l}\text { Speed } \\
\text { (rpm) }\end{array}$ & 200 & 200 & 200 & 200 & 300 \\
\hline Time (min) & 5 & 5 & 5 & 5 & 5 \\
\hline
\end{tabular}

(1) Loose pellets

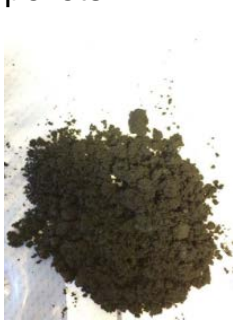

(2) Strong pellets

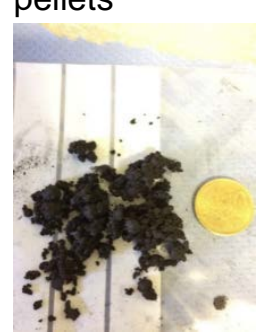

(3) Small pellets
(4) No pellet

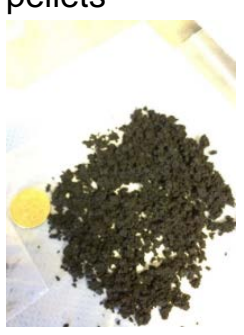

(5) small pellets

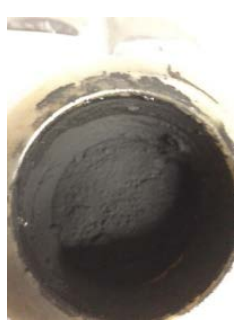

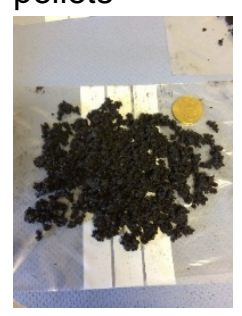

Figure 4 Pellets formation on different trial conditions

In the initial two trials, the method of binder application was varied as spray and drops. In Condition 1, carbon black was not pelletized; in Condition 2, pelletizing of carbon black was evident. From the first two conditions, it was known that water droplets work better in case of ball mill pelletizing. In Condition 3, the amount of carbon black was increased to $10 \mathrm{~g}$. The amount of binder was also increased in a ratio of $1: 1$, while speed and time were kept similar to condition 2. Pellet formation was evident in the case of Condition 3. For Condition 4, the sample and binder amount was increased to $20 \mathrm{~g}$ and $20 \mathrm{ml}$, respectively. No pellets were formed under 
these conditions. A similar amount of carbon black was used in Condition 5, but at a higher speed of $300 \mathrm{rpm}$, and pellets formation was evident here.

After comparing the above mentioned different techniques for pelletizing, the ball mill was selected for pelletizing as it gives the best results without any material loss. Pelletizing was finally done in a ball mill containing two jars, which means that it can handle 40 grams of sample in one run $(20 \mathrm{~g}$ in each jar). The quality of the ball mill pellets was evaluated by in-rubber tests, comparing industrially pelletized carbon black N660 and ball mill pelletized carbon black of the same type. $120 \mathrm{~g}$ of carbon black N660 was pelletized in 3 runs using Condition 5 .
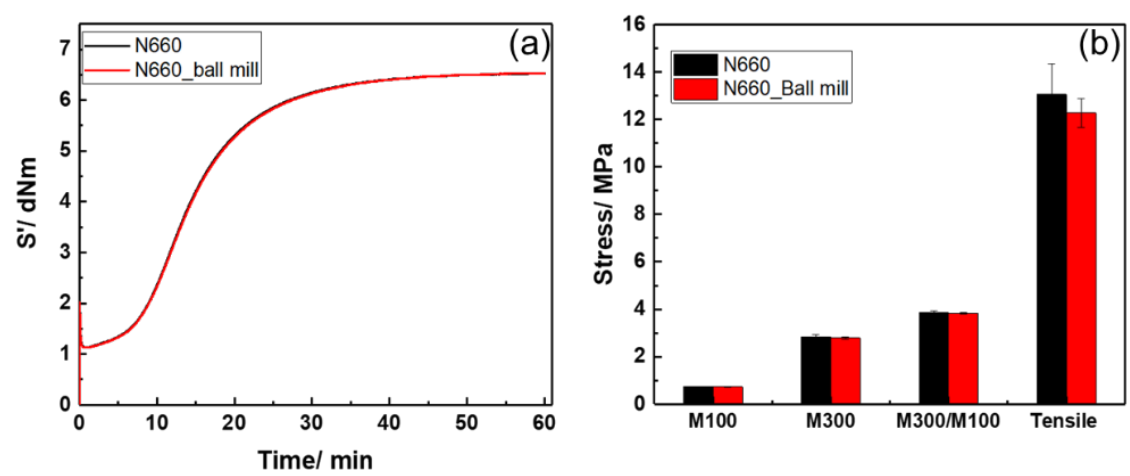

Figure 5 (a) Cure characteristics and (b) tensile properties of rubber compounds containing industrially pelletized carbon black (black) and ball mill pelletized carbon black (red).

In Figure 5, the cure characteristics and tensile properties are compared. Similar cure characteristics are evident. In terms of tensile properties, modulus at $100 \%$ (M100), modulus at 300\% (M300) and reinforcement index (M300/M100) were similar for both samples. Slight differences were found in the case of tensile strength: Industrially pelletized carbon black has a slightly higher tensile strength than the ball mill pelletized one. However, this difference between the samples was within the standard deviation.

The finalized process rCB's lab pelletizing is summarized here:

- For pelletizing, ball mill equipement was used for high speed rotations without grinding balls.

- 20 grams of grinded carbon black was added in $500 \mathrm{ml}$ jar of ball mill. 
- Water drops were added in 1:1 ratio; 20 grams CB: $20 \mathrm{ml}$ water.

- Jar containing both $C B$ and water was then placed in Ball mill for pelletizing.

- Ball mill was operated at room temperature conditions for 5 minutes at $300 \mathrm{rpm}$.

- After this, the pelletized sample was taken out by using a scraper or spoon. 


\section{Bibliography}

\section{Patent}

EU patent filing 21159 726: "Verfahren zur Herstellung von Ruß aus Abfällen, Ruß hergestellt nach dem Verfahren, Verfahren zur Herstellung einer Kautschukmischung, sowie Kautschukmischung enthaltend den Ruß sowie Fahrzeugreifen".

Inventors: B. Ramani, A. Anjum, E. Bramer, G. Brem, W. Dierkes; to Continental AG.

\section{Conference article}

A. Anjum, B. Ramani, E. Bramer, W. Dierkes, G. Brem, A. Blume, Role of Recovered Carbon Black Ash Content Composition on In-rubber Performance, International Rubber Conference, IRC 2019, London.

\section{Conference presentations}

A. Anjum, B. Ramani, E. Bramer, W. Dierkes, G. Brem, A. Blume, Pyrolytic Char Production and Quality, A review, European Tyre Recycling Association, ETRA 2018, Brussels.

A. Anjum, B. Ramani, E. Bramer, W. Dierkes, G. Brem, Advanced Recycling for Sustainable Tires, PhD Seminar, 2018, Łódź

A. Anjum, B. Ramani, E. Bramer, W. Dierkes, G. Brem, A. Blume, Pyrolytic Char Production and Quality, A review, Deutsche Kautschuk-Gesellschaft West, DKGWest 2019,.Bad Neuenahr.

A. Anjum, B. Ramani, E. Bramer, W. Dierkes, G. Brem, A. Blume, Evidences of Free Sulfur Presence in Recovered Carbon Black, A Feedstock Comparison Study, European Carbon Black Summit, 2019, London.

A. Anjum, B. Ramani, E. Bramer, W. Dierkes, G. Brem, A. Blume, Role of Recovered Carbon Black Ash Content Composition on In-rubber Performance, International Rubber Conference, IRC 2019, London.

A. Anjum, B. Ramani, E. Bramer, W. Dierkes, G. Brem, A. Blume, Impact of Recovered Carbon Black Inorganic Impurities on Crosslinking and In-Rubber Performance, Vereniging van Kunststof en Rubber Technologen, VKRT 2020, Utrecht. 
A. Anjum, B. Ramani, E. Bramer, W. Dierkes, G. Brem, A. Blume, Influence of Pyrolysis Temperature on Recovered Carbon Black Characteritics and In-Rubber Performance, Tire Technology Virtual Live, TireTech 2021.

\section{Posters}

A. Anjum, W. Dierkes, A. Blume, Advanced Recycling for Sustainable Tires, M2i Conference, 2017, Noordwijkerhout.

A. Anjum, H. Gojzewski, W. Dierkes, A. Blume, Recovered Carbon Black; Material Characteristics and In-Rubber Performance, M2i Conference, 2018, Noordwijkerhout.

A. Anjum, W. Dierkes, A. Blume, Recovered Carbon Black Inorganic Impurities Impact on its In-Rubber Properties, M2i Conference, 2019, Noordwijkerhout.

\section{Award}

International Rubber Conference Student prize "Sustainable Innovation", 2019, London.

\section{Journal articles (to be published)}

A. Anjum, B. Ramani, E. Bramer, W. Dierkes, G. Brem, J.W.M Noordermeer, A. Blume, Influence of pyrolysis temperature on the characteristics of recovered carbon black.

A. Anjum, B. Ramani, E. Bramer, W. Dierkes, G. Brem, J.W.M Noordermeer, A. Blume, Influence of pyrolysis parameters on the in-rubber performance of recovered carbon black.

A. Anjum, B. Ramani, E. Bramer, W. Dierkes, G. Brem, J.W.M Noordermeer, A. Blume, Argon Plasma treatment of recovered carbon black. 


\section{Acknowledgements}

Foremost, I am grateful to the Almighty who gave me a blessed life to spend with such great people.

It is without a doubt that many people, in one way or other, have contributed to this four years journey. For me, this began a year earlier in 2016 when I wrote my first email to Prof. Anke Blume in search of a Ph.D. position. During our year-long email conversations, she was always kind to me and respond quickly to all sorts of queries. Dear Anke, Thank you very much for believing in me and giving me this opportunity in your group. After exactly 365 days from my first email, I received a welcome email from our group secretary, and the real journey finally started on my $26^{\text {th }}$ birthday, April $1^{\text {st }}, 2017$. It was a sweet start with a decorated desk.

I will always remain grateful to have a supervisor like Dr. Wilma Dierkes who not only mentored me in conducting research but also offered a listening ear when it came to personal matters. Her diligent efforts and professional work ethic have greatly shaped my professional personality. Dear Wilma, without your trainings and courageous efforts, it would not be possible to reach this page of the thesis. Your commitment to work is apparent to all of your students which motivates them to give their $100 \%$. I have never been so efficient in utilizing time before, I specifically remembered our early return from Ph.D. seminar for M2i meeting, on the way we prepared for an upcoming conference.

I would like to thank Prof. Jacques Noordermeer who spent a great deal of his time in reviewing my thesis and improving it with his experienced recommendations. Although he initially had some troubles with my name as I was called Amir, Anmol, and Ayush on different occasions, however, discussions with him were always spot on. Dear Jacques, I feel honored that my thesis has been scanned through one of the most well-known professors in the field of rubber.

I would like to acknowledge Prof. Gerrit Brem and Eddy Bramer from the Thermal Engineering group for collaborating with us on this project. Special thanks to Balan Ramani, the fellow Ph.D. student on this project. Dear Balan, we did it! your immense work from the process side is indispensable in this project, and I am looking forward to joining your defense soon.

I want to express my gratitude to Continental Tires, AG and M2i Materials Institute for their financial support of this research project. I sincerely thank my industrial supervisor, Dr. Alexander Burkhart, who steered this project to a conclusion and immensely helped us in arranging measurements and industrial visit at Conti. I would like to extend my gratitude to all of the committee members: Prof. Mario Beiner, Prof Danka Katrokova-Krüger, Prof. Sascha Kersten, Dr. Chris Norris, and Dr. Michael Warskulat. Thank you all for taking the time and providing me with your constructive feedback. 
I sincerely thank Dr. Rafal Piotr Anyszka for arranging plasma experiments in Poland at Politechnika Łódzka. I met the nicest people there, plus it was also a good chance to reconnect with some of our former Polish colleagues: Anna and Karolina.

Dear ETE staff, thank you for your continuous help in these four years. Ceciel and Dries are special mentions here, as I would like to call them the "glue of the group", or sticky rubber of the group $(: p)$. Dear super-secretary, from day one you helped me in all administrative work with great flexibility. Your inclusiveness in festive arrangements is always incredible. Sir Dries, the man with the herculean task of lab management, even though you had a lot to maintain in the labs, you were always available for technical support even outside our lab.

My ETEians, you all became a prominent part of this journey. I shared the office with some incredible colleagues, Xiaozhen who mostly sits with her back towards her table, Amir who is apparently me but from Iran, and our food supply Sun. They all made our office a welcoming place to everyone, even Eddie the snack table felt that and was always parked there. I will surely miss our coffee breaks along with Ayush's cold jokes, Marzieh's high pitch screaming, Wilma's reporter Jin, Neven who was always there at seven, Dorota's donuts tradition, Rafal's polish sweets, and of course some good coffee from ZuzaBucks and CarmeLavazza. My Indian neighbors, the social guy Anmol and the chef Rounak, were always kind to help me even after work. I know I won't be able to converge here all the memories, but thank you very much you all for everything!

Along this journey, some friends have become part of family. I would like to especially thank Akansha, Amir, and Sun, who were always there for me and my family in difficult times. Akansha, I will always remember your indispensable support at some of the most toughest and memorable moments of our family. Amir, you always landed your support no matter how many times I decided to shift from one place to another. Sun, You helped me in many ways, from professional matters to personal matters, everything was possible to be discussed with you.

Last but for sure not least, I would like to thank my family. I am indebted to my parent's support, who provided everything to see their children succeed. Ammi, Abbu, whatever I have achieved is based on the sound early education you have taught me at home. This one is for you, see your son is now a Doctor!

Dear my little astronaut Zidane, since you have arrived in our lives, you always reminded me about life outside work and became a healthy distraction. At this little age of three, you have a craze of planets. I am excitingly looking forward to seeing you and your dreams grow.

Dear my Komal, our married journey started with this work. Without you, I would not be able to create a balanced life. During these years, you came out of your comfort zone and took charge of many responsibilities, just to help me keep going. I love you! You are a true companion and I am very lucky to have you!

Arqam Anjum 

This research is a collaborative project of the University of Twente, Continental Tires AG, and M2i Materials Innovation Institute. The objective of the present research is to re-use the carbon black in rubber compounds, which is recovered by pyrolysis of post-consumer passenger car tires. The thesis is focused on understanding the influence of pyrolysis parameters on recovered carbon black characteristics and their consequent effect on its in-rubber performance. A suitable after-treatment is also developed to further enhance its characteristics. Finally, the recovered carbon is used to partially substitute the fossil-based carbon black in rubber compounds.

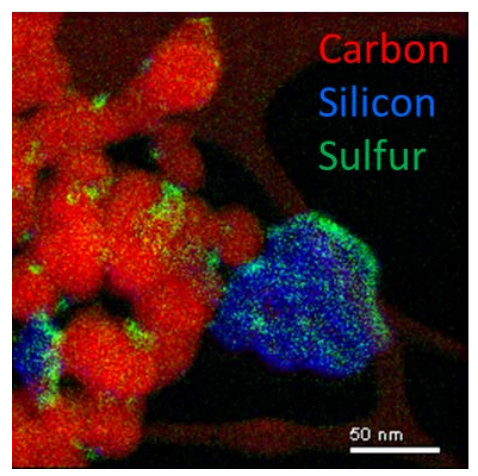

